EDUCATIONAL LEADERS' VIEWS ABOUT SCHOOL CULTURE, CLIMATE, LEADERSHIP, AND SUCCESS: A COMPARATIVE STUDY OF NEW ZEALAND, FINLAND, AND GHANA BY

\title{
DARKO BAAFI
}

A thesis submitted to the Victoria University of Wellington in fulfilment of the requirements for the degree of Doctor of Philosophy

Victoria University of Wellington

2021 


\begin{abstract}
This comparative project explored educational leaders' views, practices, and experiences in relation to school culture, climate, leadership, and student success in three international contexts: New Zealand, Finland, and Ghana. Taking an interpretive methodological stance, the study used policy documents, observations, artefacts, and interviews as data sources. A total of twenty-seven participants (school leaders, university experts, and Ministry officials) took part; nine from each of the three countries.
\end{abstract}

Key insights from the study include identifying positive aspects from each of the three countries. Generally, each of the cases showed positive relationships between students' success and teacher-teacher, teacher-students, teacher-principal, shared leadership, teamwork, school-based guidance and counselling, and more. Specifically, for New Zealand, positive impetus for students' success included, respect for teaching, use of local curriculum, a clear and relevant Education Act, and free tuition. For Finland, the positive variables included respect for teaching, local-based curriculum, school-based psychologists, and free tuition and school meals. For Ghana, these included school-based Christian Chaplains and Imams, a free boarding system which included tuition and meals, and a relevant quota system to encourage minority inclusion in education.

While partially confirming the relevant literature on effective school leadership and students' success, the study argues for a deeper understanding of the subject to include issues of global socio-cultural, socio-political, and socio-economic undercurrents and trends; symbolic capital; and hierarchical decision-making models'.

It is these sociological variables, forms and relationships, and dimensions of a complex education subsystem which act as catalysts for the daily practices of school leadership that influence students' success.

The study offers (a) a theoretical framework for analysing school leadership and students' success and (b) key recommendations for Ministries of Education and school administration and leaders. 


\section{Acknowledgements}

Throughout this $\mathrm{PhD}$ journey, I have received considerable encouragement, assistance, inspiration and support from a number of sources, such as:

The welcoming gesture of the New Zealand Government for opening her doors (Tangata Whenuatanga) to us, international students, to study in New Zealand. I must say that I have really enjoyed the multicultural learning environment in this country.

The support from my two supervisors, Associate Professor Kabini Sanga and Associate Professor Jenny Ritchie, two deputy heads of the school at the Faculty of Education, Victoria University of Wellington, whose valuable expertise (Wānanga) have brought this research to completion. I salute these great scholars and acknowledge their support to me.

The positive contributions from my former director, Lea Kuusilehto Awale of the School of Education, University of Jyvaskyla, who bestowed on me some of her love, trust, sincerity, and integrity. Your support is much appreciated.

The generosity of my tutors, Dr Deborah Laurs and Dr Fuapepe Rimoni for their excellent expressions of community (Whanaungatanga) and cooperation (Ako), and for all opportunities given me during my studies.

The excellent contributions from Laura, van Peer, who structured the thesis by doing the editing, the formatting and finally the proofreading.

The wonderful and consistent expressions of love from my parents, especially, Beatrice Nuamah-Kutin and Phylix Adobea, my wife, Philomena Okyere, and sisters, Ohenewaa Gyasi and Theresah Owusu Ampofo who had offered wise counsel and sympathetic gestures to me before, during, and after this dissertation.

Finally, there are many friends who showed considerable support to me during my studies, especially, Dr Kwabena Minta of RMIT, Melbourne, Australia who supported me financially, Dr Eric Boamah, Theresah Owusu Ampofo, Ohenewaa Gyasi, Phyllis Adobea, and the great Ghanaian community, Wellington, New Zealand for their numerous forms of help. 


\section{Table of Contents}

ABSTRACT ....................................................................................................................................

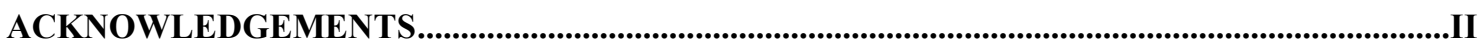

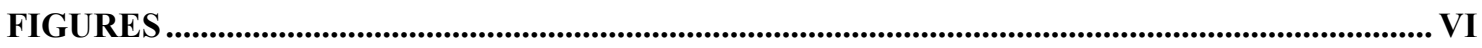

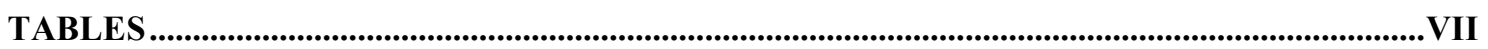

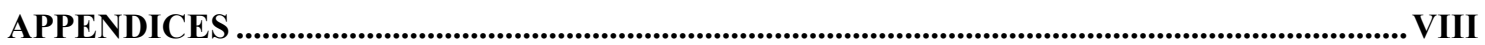

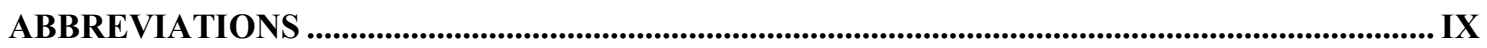

MĀORI VALUES IN TRANSLATION.................................................................................................X

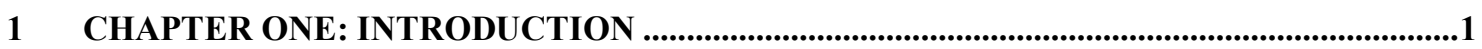

1.1 THE RESEARCH PROBLEM ........................................................................................................................2

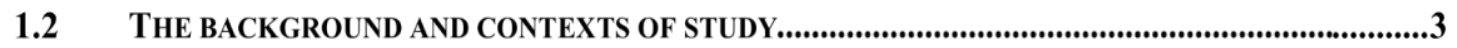

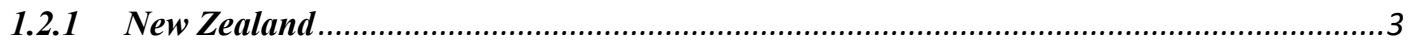

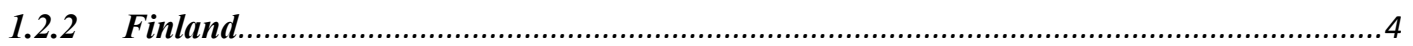

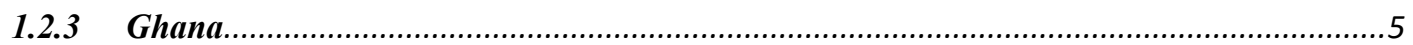

1.2.4 Commonalities and differences of histories in the three contexts of study ........................ 6

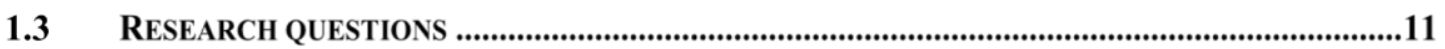

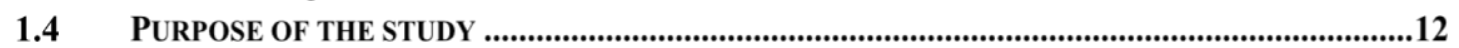

1.5 SIGNIFICANCE OF THE STUDY ................................................................................12

1.6 LIMITATIONS OF THE STUDY …….................................................................................13

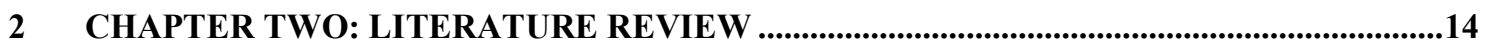

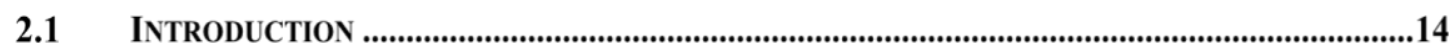

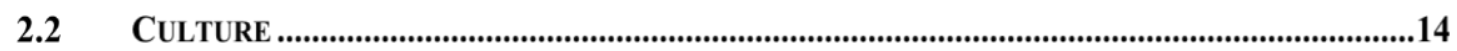

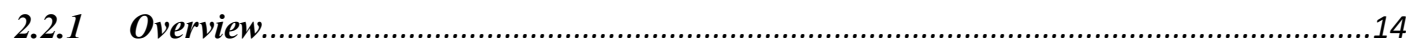

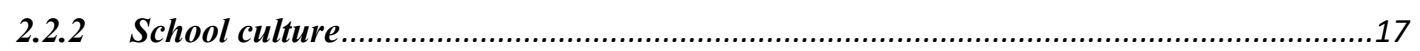

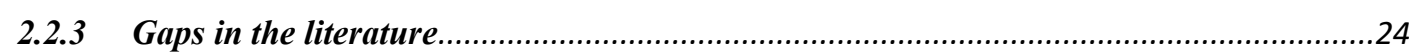

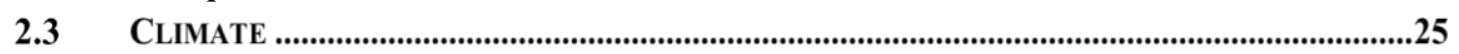

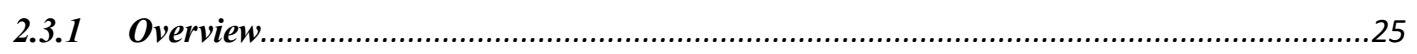

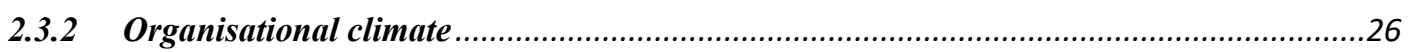

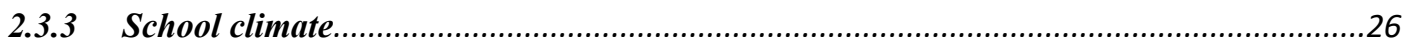

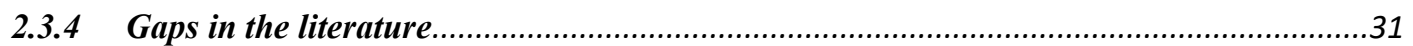

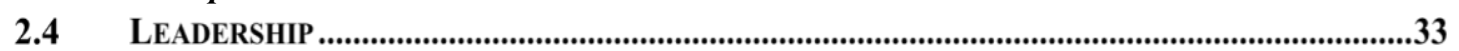

2.4.1 Overview

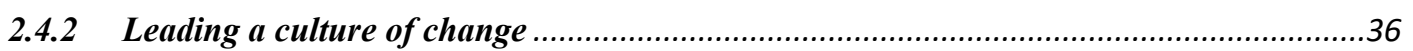

2.4.3 Why do some leaders fail and others succeed in leading a culture of change?..................41

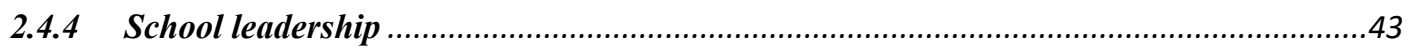

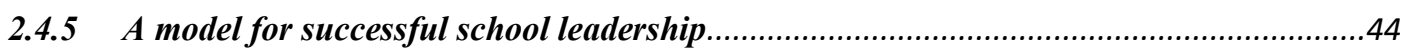

2.4.6 A model of how successful school leaders impact students' success ..............................52

2.5 PROFESSIONAL LEARNING COMMUNITIES ....................................................................59

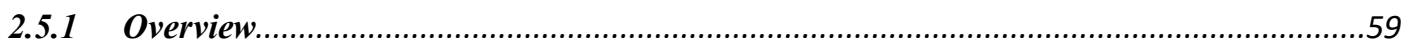

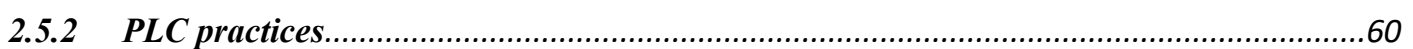

2.6 STUDENTS' NEEDS, MOTIVATION, AND SUCCESS ...............................................................63 


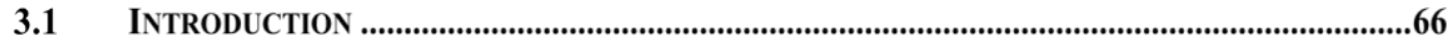

3.2 RESEARCH PARADIGM AND INTERPRETIVE METHODOLOGICAL STANCE ..............................66

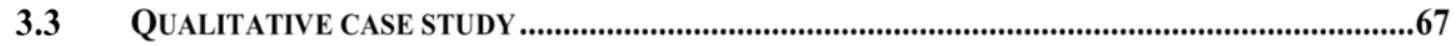

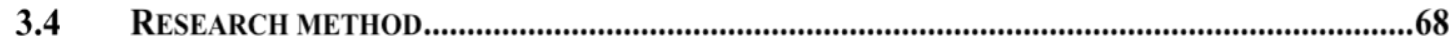

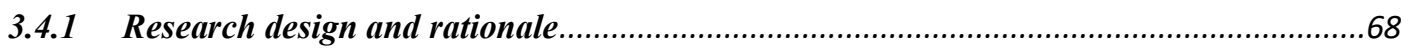

3.4.2 Selection process and criteria of the schools............................................................69

3.4.3 Selection process and criteria of the universities and ministries ...................................70

3.4.4 Selection process and criteria of the participants ..........................................................70

3.4.5 Human Ethics' Committee, Victoria University of Wellington ........................................71

3.4.6 Piloting of the data instruments..................................................................................... 73

3.4.7 Data collection techniques (observation, artefacts collection, and interviews) ................73

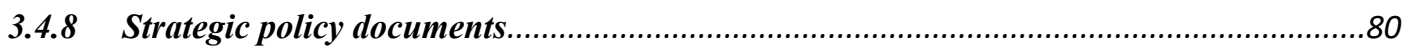

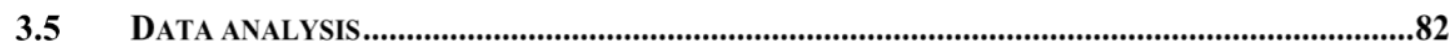

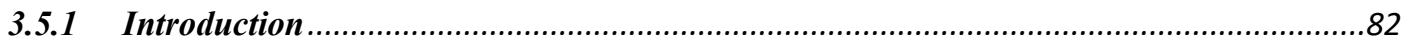

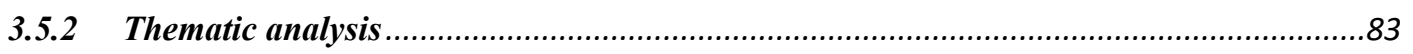

3.5.3 Data analysis process for strategic policy documents......................................................84

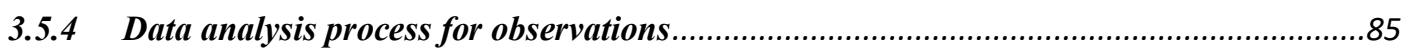

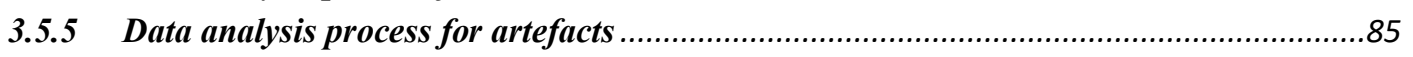

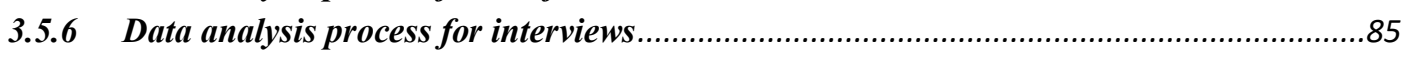

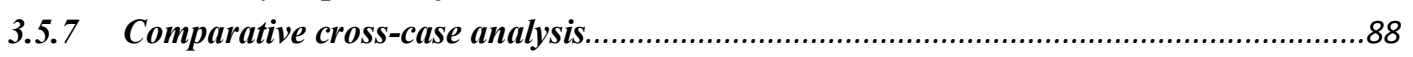

3.6 TRUSTWORTHINESS AND CREDIBILITY OF THE DATA INTERPRETATION ................................88

4 CHAPTER FOUR: RESEARCH FINDINGS AND DISCUSSIONS ....................................92

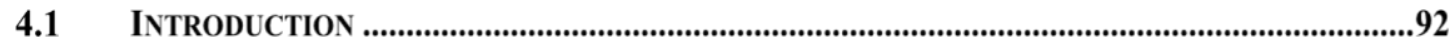

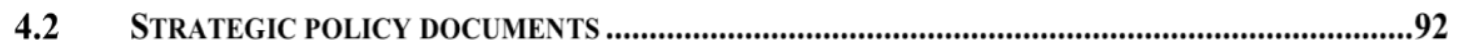

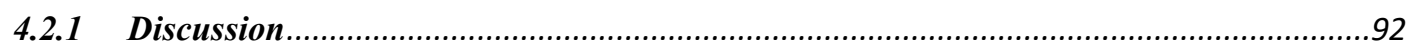

4.2.2 School culture and climate .......................................................................................92

4.2.3 School leadership and professional networking communities .....................................102

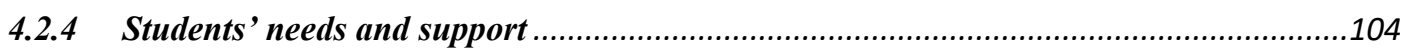

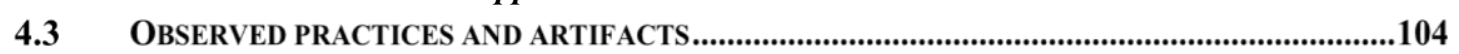

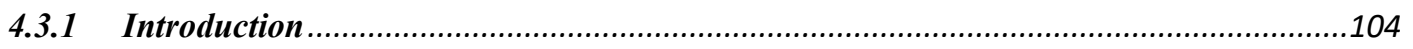

4.3.2 Brief background of the three selected schools.............................................................105

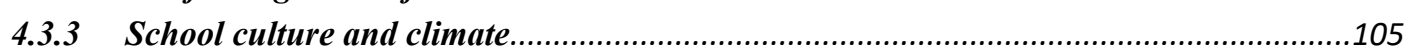

4.3.4 School leadership and professional networking communities .....................................122

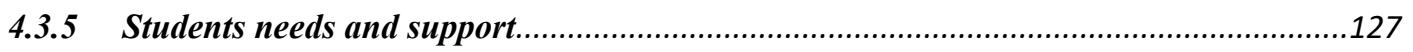

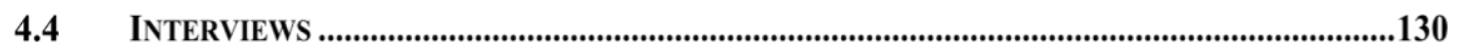

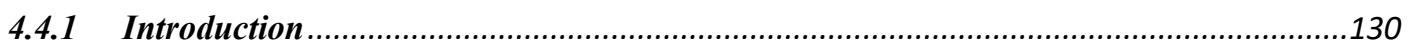

4.4.2 New Zealand case: school culture and climate ..............................................................131

4.4.3 New Zealand case: school leadership and professional networking communities...........136

4.4 .4 New Zealand case: students' needs and support..........................................................144

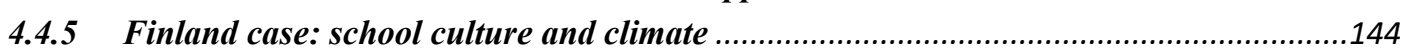

4.4.6 Finland case: school leadership and professional networking communities .................149

4.4.7 Finland case: students' needs and support ...............................................................155

4.4.8 Ghana case: school culture and climate .................................................................157

4.4.9 Ghana case: school leadership and professional networking communities ...................168

4.4.10 Ghana case: students' needs and support..............................................................172

5 CHAPTER FIVE: COMPARISON OF FINDINGS...........................................................174

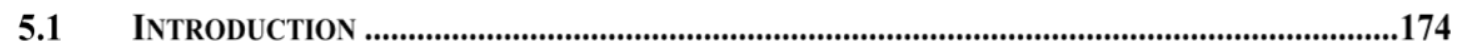


5.2 SUMMARY OF FINDINGS: NEW ZEALAND ...............................................................................174

5.3 SUMMARY OF FINDINGS: FINLAND ..........................................................................................178

5.4 SUMMARY OF FINDINGS: GHANA ..........................................................................................181

5.5 SIMILARITIES AND DISSIMILARITIES OF THE THREE MULTIPLE CASES...................................186

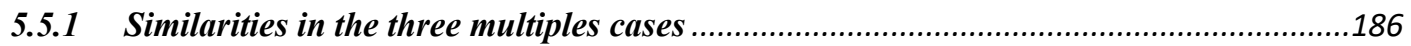

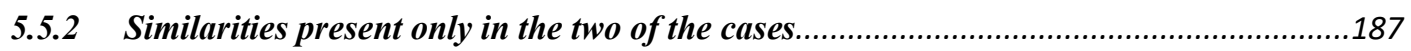

5.5.3 Dissimilarities present in the three multiple cases ........................................................188

6 CHAPTER SIX: RETHEORIZING SCHOOL CULTURE, CLIMATE, LEADERSHIP, AND

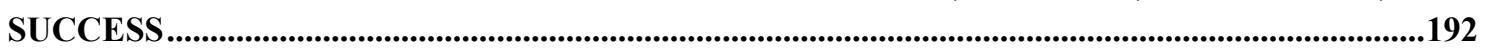

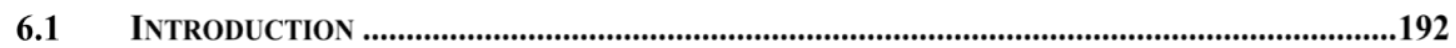

6.2 DESCRIPTIVE ANALYSIS FROM THE THREE MULTIPLE CASES.............................................192

6.3 FIVE LEVELS TO GIVE DEEP MEANING TO SCHOOL CULTURE, CLIMATE, LEADERSHIP AND

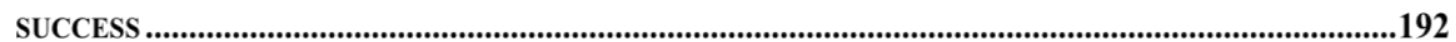

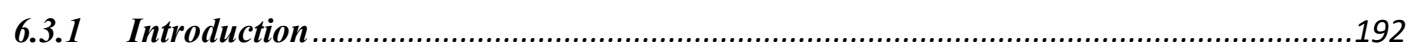

6.3.2 Level (A): Organisational levels of culture, climate, leadership, and success..................193

6.3.3 Level (B): Emergent organisational levels of culture, climate leadership and success ..196

6.3.4 Level (C): Contemporary educative, social, cultural, and political contexts ...................198

6.3.5 Level (D): Historical educative, social, cultural, and political contexts ..........................201

6.3.6 Level (E): Globalised educative, social, cultural, and political contexts ........................203

6.4 SOCIOLOGICAL DESCRIPTIONS FOR SCHOOL CULTURE, CLIMATE, LEADERSHIP, AND

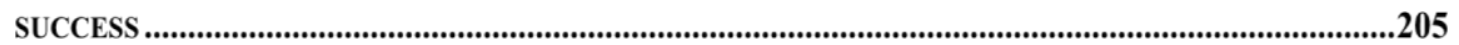

7 CHAPTER SEVEN: CONCLUSION AND RECOMMENDATIONS ....................................208

7.1 CONCLUSION ...........................................................................................................................208

7.2 RECOMMENDATIONS AND IMPLICATIONS.......................................................................209

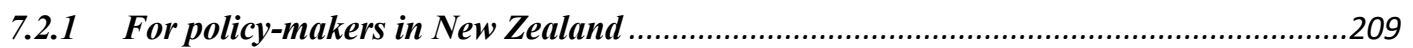

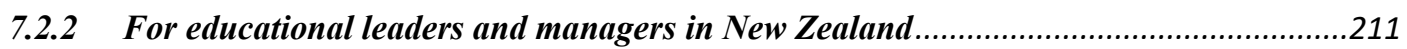

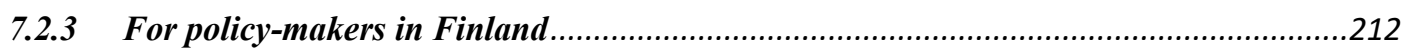

7.2.4 For educational leadership and managers in Finland ................................................213

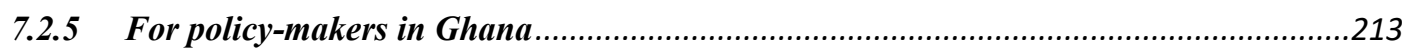

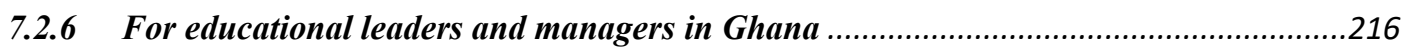

7.3 OVERALL CONCLUSION ..................................................................................................217

7.4 EPILOGUE........................................................................................................................219

REFERENCES .........................................................................................................................................221

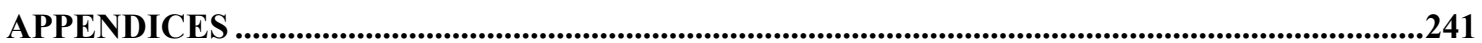




\section{Figures}

Figure 1: The Map of New Zealand............................................ 4

Figure 2: Geographical Location of Finland...................................... 5

Figure 3: Geographical Location of Ghana...................................... 6

Figure 4: Representation of Levels of Culture ............................... 16

Figure 5: The Model for Successful School Leadership........................... 45

Figure 6: The Fourth Paths of School Leaders' Impact on Students' Learning........... 54

Figure 7: The Eight Main Characteristics of the PLCs............................ 61

Figure 8: Strategic Policy Documents Examined............................... 82

Figure 9: Diagrammatic Representation for Thematic Analyses Steps Used............ 84

Figure 10: Query and Visualisation Sample for the School Z in Ghana................. 87

Figure 11: Similarities and Differences of Cultural Practices from Policy Documents.. 93

Figure 12: Strategic Documentary Findings on School Culture................... 100

Figure 13: Observed Practices of School Culture............................... 106

Figure 14: First Level of Analytical Framework................................... 194

Figure 15: The First and the Second Levels of the Analytical Framework............ 196

Figure 16: The Third Level of Analytical Framework............................... 199

Figure 17: The Fourth Level of Analytical Framework............................ 203

Figure 18: The Combine Effect of the Fifth Level of the Framework.................. 205 


\section{Tables}

Table 1: Below Outlines the Relationship between Culture and Climate............... 32

Table 2: The Selection Criteria of the Three Schools................................ 69

Table 3: The Number of Participants Selected from the Three Contexts............... 71

Table 4: Sources of Data for Addressing the Research Questions.................... 74

Table 5: Things Observed and Analysed from the Three Sites........................ 75

Table 6: Steps I Adopted and Used to Ensure the Trustworthiness.................. 89 


\section{Appendices}

Appendix 1: The Sample Copy: The Ethics Approval Letter........................ 241

Appendix 2: The Sample Copy: The Letter of Invitation........................... 242

Appendix 3: The Sample Copy: The Consent Form............................. 245

Appendix 4: The Sample Copy: The Interview Guide for Principals ............... 247

Appendix 5: The Sample Copy: The Interview Guide for Teachers................. 248

Appendix 6: The Sample Copy: The Interview Guide for University's Officials........ 249

Appendix 7: The Sample Copy: The Interview Guide for Ministry's Officials........ 250

Appendix 8: The Sample Copy: The Field Notes............................... 251

Appendix 9: The Sample Copy: The Information Sheet for Observed Practices..... 252

Appendix 10: The Sample Copy: The Coding Process......................... 253

Appendix 11: The Sample Copy: The Word Frequency........................ 254

Appendix 12: The Sample Copy: The Coding Themes.......................... 255 


\begin{abstract}
Abbreviations
EC Educational Council, New Zealand

FNBE Finnish National Board of Education

FNME Finnish National Maturation Examination

IMF International Monetary Fund

MOE Ministry of Education, Ghana

MOEC Ministry of Education and Culture, Finland

NCEA National Certificate Educational Achievement

NZQA New Zealand Qualifications Authority

OECD Organisation for Economic Co-operation and Development

PLC Professional Learning Community

SAP Structural Adjustment Programme

UN United Nations

UNIESCO United Nations Educational, Scientific and Cultural Organisation

STATS 1 New Zealand Statistical Service

STATS 2 Ghana Statistical Service
\end{abstract}




\section{Māori values in translation}

\begin{tabular}{|c|c|}
\hline Ako & Practices in the classroom and beyond \\
\hline Akoranga & $\begin{array}{l}\text { Reciprocal nature of learning and teaching; the } \\
\text { learner can also be the teacher }\end{array}$ \\
\hline Ka-Hikitia & Success \\
\hline Manaakitanga & Integrity, trust, sincerity, and equity \\
\hline Pono & $\begin{array}{l}\text { Showing integrity by acting in ways that are fair, } \\
\text { honest, ethical and just }\end{array}$ \\
\hline Rangatiratanga & Leadership and self-management \\
\hline Tangata-whenuatanga & $\begin{array}{l}\text { Place-based socio-cultural awareness and } \\
\text { knowledge }\end{array}$ \\
\hline Wānanga & Communication, problem-solving and innovation \\
\hline Whakamana & $\begin{array}{l}\text { Empowering learners to reach their highest } \\
\text { potentials by providing high quality education }\end{array}$ \\
\hline Whanaungatanga & Kinship ties, collaboration, and collectiveness \\
\hline
\end{tabular}

Adapted from (Education Council, 2017) 


\section{CHAPTER ONE: Introduction}

Education for liberation comes to the minds of many scholars and has included critical pedagogics about the prominence of school culture, climate, leadership, and other factors as means to improve students' learning outcomes over the years (Hoy, 1990; Liston \& Zeichner, 1996; Shor \& Freire, 1987). Policy-makers and educational leaders and managers, including principals and teachers who are interested in students' transformation, tend to raise these pertinent issues regarding how to improve education (Shor \& Freire, 1987). Questions include, how do teachers transform themselves into facilitators of liberator of student learning? How do teachers begin the transformation of their students? What are the consequences, including fear, risks, and rewards, of the transformation? Does a liberating process include authority, and structures? And many others (McLaren, 1994; Shor \& Freire, 1987). These questions seem to have appeared very often in teachers' daily discourses within schools in Brazil (Shor \& Freire, 1987), New Zealand (Stoll \& Louis, 2007), and Finland (Sahlberg, 2013).

These discourses sometimes take for granted the efficacy of the global socio-cultural, socio-political, and socio-economic web nets/undercurrents which play a great part in day-to-day practices and activities of the school (Giroux \& McLaren, 1989). This study argues for the partial rejection of school-based culture, climate, leadership, and other factors such as students' motivational needs and support and professional learning practices as the only means to enhance students' learning outcomes.

This partial rejection is based on the critiquing of school culture, climate, leadership, and success in two schools. As an alternative, these above concepts are deeply explained to cover wider global trends including the socio-cultural, socio-political, and socioeconomic dynamics and complexities of the society rather than just the superficial daily happenings within education sub-systems of which a school is just a part. The new theory provides a better understanding of how these concepts - school culture, climate, leadership, and many more - operate in a broader sense within the education wider web. From here let us move on to consider the discourse pertaining to the research issue that is central to this study. 


\subsection{The research problem}

The socio-cultural complexities of the society, the school, and its environment play a crucial role in organisational effectiveness and development (Gutek, 2014). Such complexities include the family, the culture, physical environment, emotional development, competencies, experiences, politics, historical antecedents, power, pedagogy, and 'organisational structure' (Giroux \& McLaren, 1989; Shor \& Freire, 1987). These complexities are embedded in all aspects of organisational daily lives and stories and act as the moving forces for the effectiveness of the organisation (McLaren, 1994; Northouse, 2004). For this reason, these complexities need to be addressed daily in organisations (Dowson, Mclnerney, \& Van Etten, 2006; DuFour \& Fullan, 2013; Fullan, 2004).

Furthermore, international literature attests to the fact that school culture, climate, and leadership, which are part of these socio-cultural complexities in an organisation especially the school - also have a strong influence on student outcomes (Hoy, 1990). These factors are gradually gaining much attention from governments, educational leaders and managers, researchers, and individuals in their quest to improve students' learning, performance, and success (Hargreaves, 1995).

In the same vein, the global literature has indicated that professional learning communities and students' needs - including safety and wellbeing, scholarships, guidance and counselling, health needs, food, security, and many others - have a strong influence on students (Brennan \& McGilloway, 2014; Brophy, 2004; Stoll \& Louis, 2007). This leads to the aim of this research which was to learn from educational leaders' views about school's culture, climate, leadership, and other contributing factors that promote students' learning, performance, and success in the three international contexts: New Zealand, Finland, and Ghana.

The underpinnings for this research project include firstly, my background as a teacher who has taught in basic and secondary schools in Ghana. These experiences stimulated my interest for this research project. Secondly, my leadership philosophy as a transformational teacher is a key motivation for this study. As a transformational teacher, I always wanted to see how best my students could succeed in life. This passion drives 
my interest for the project. A third key factor is derived from my experiences in studying and working in New Zealand and Finland.

Based on these experiences, especially in education, socio-cultural dynamics, policies, and programs in the three contexts, I wanted to learn from global educational leaders so as to possibly make a difference to education outcomes in my country, Ghana. Furthermore, I wanted to understand the social and welfare educational systems as in the hybrid systems of Finland, as well as the capitalist and less welfare focussed approaches in New Zealand and Ghana. Finally, I have an interest in this research phenomenon because it seems useful to learn from applying the discipline of comparative and international education to these three national contexts and exploring what is happening on the ground from educational leaders. Through utilising this approach, it was hoped that the three countries might learn from each other to improve their educational outcomes.

\subsection{The background and contexts of study}

This section provides an overview of the geographical locations of New Zealand, Finland, and Ghana. It details the estimated land size, population, and ethnicities, and concludes by briefly identifying the similarities and dissimilarities present in the histories of the three countries.

\subsubsection{New Zealand}

New Zealand is a country located in the South Pacific Ocean with an estimated land area of about 263,310 square kilometres. The country has an estimated population as at December, 2019, of about 4, 942, 500 and a growth rate of 2.1 percent. (Stats, 2019). The ethnic distribution of the population for the 2014 population census was as follows: People of European origin constitute 74 percent of the population; Māori represent 14.9 percent; Asian ethnic groups represent 11. 8 percent; those of Pacific descent, 7.4 percent; and Middle Eastern, Africans, and Latin American tribes represent 1.2 percent of the entire population in New Zealand as in 2014 (Stats, 2014). Please see below the map of New Zealand. 
Figure 1: The Map of New Zealand

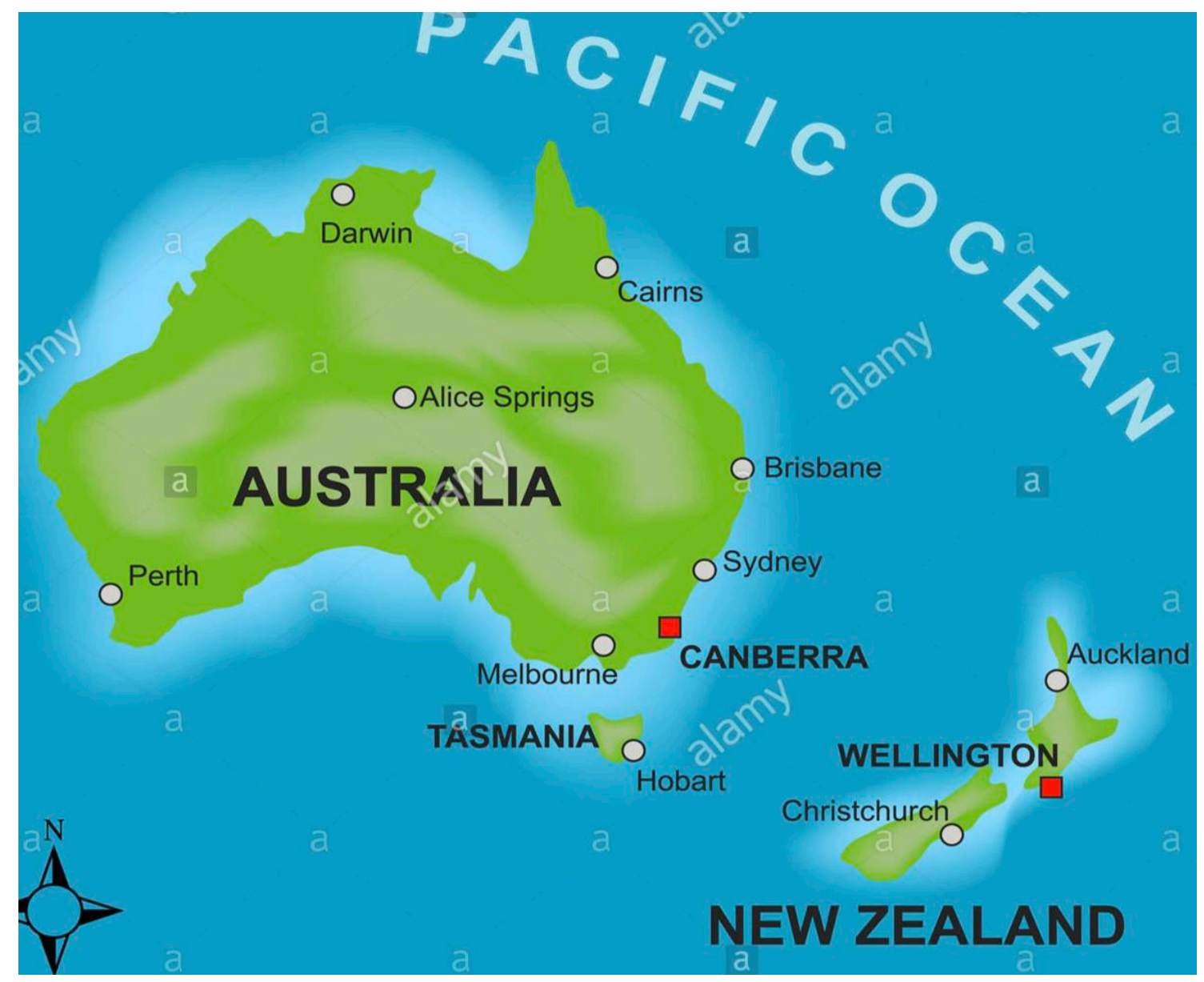

Adapted from the Stylized Map Showing the Countries, Australia and New Zealand (https://www.alamy.com/stock-photo-a-stylized-map-showing-the-countries-ofaustralia-and-new-zealand-27437023.html?pv=1\&stamp=2\&imageid=D7F830ADEE2D-4D2A-B997-). In the public domain.

Date created: March, 2021

\subsubsection{Finland}

Finland is a country in the Northern hemisphere of Europe with a total land size of about 338,000 square kilometres. The country borders Sweden to the west, Norway to the north, and Russia to the east. Finland has a total population at December 2019 of about 5,53 million distributed as follows: The 4,848,761 Finns represent 87.9 percent; 289,052 Swedes represent 5.2 percent; and 1,992 Saami represent 0.03 percent. The remaining 6.9 percent represent other foreign nationals in the country. The country has two official 
languages which are Finnish and Swedish. About 92 percent of the people speak Finnish, 6 percent speak Swedish, and 0.03 percent speak Saami (FNBE, 2016). See the map below for the geographical location of Finland in Europe.

Figure 2: Geographical Location of Finland

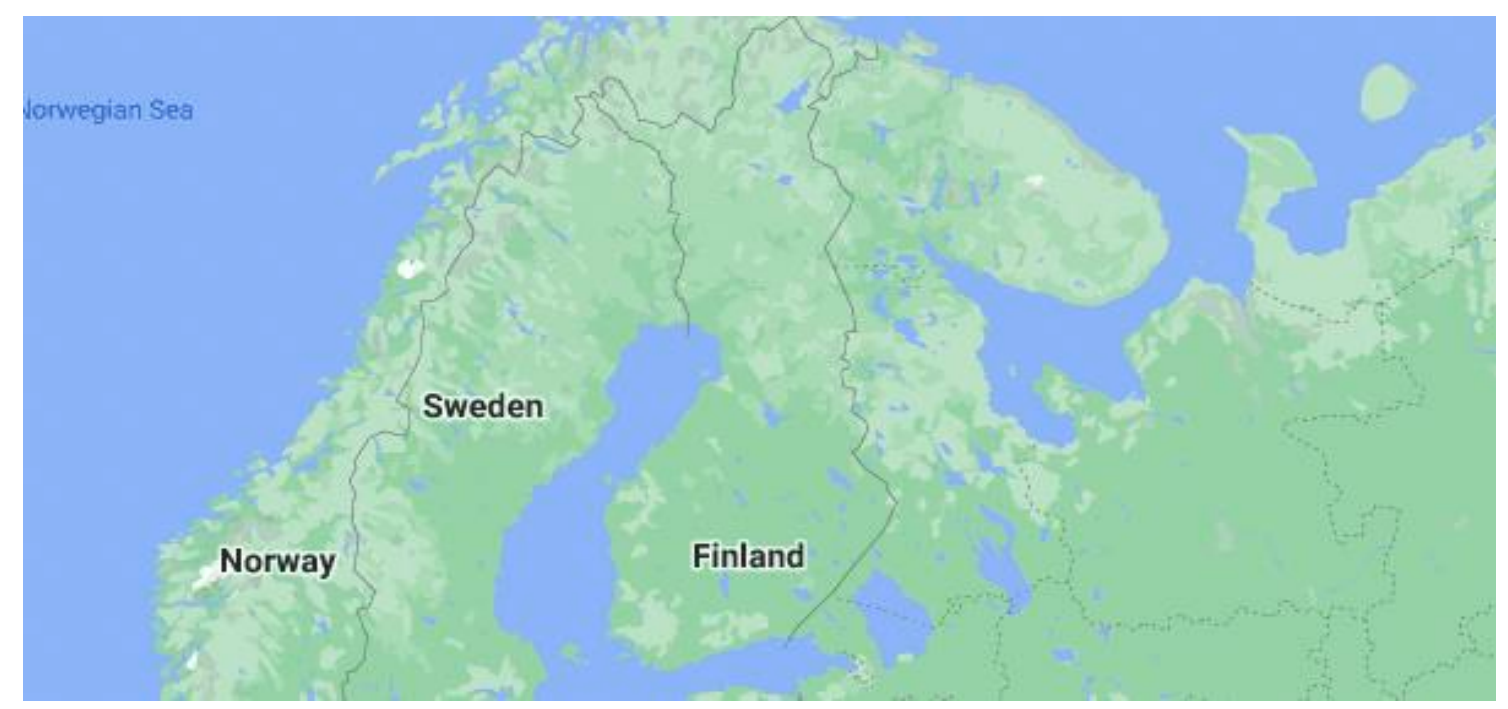

Adapted from Google Maps: Finland

(https://www.google.com/maps/place/Finland/@64.6233799,17.0907948,5z/data=!3m1 !4b1!4m5!3m4!1s0x4681 cadf4b32f6dd:0x146d63c75a810!8m2!3d61.92411!4d25.7481 511). In the public domain.

Date created: March, 2021

\subsubsection{Ghana}

Ghana is in the western part of Africa and has a total land area of about 238,533 square kilometres. It shares borders with Togo to the east, Ivory Coast to the west, Burkina Faso to the north, and the Gulf of Guinea to the south. According to the 2010 Population and Housing Census conducted by Ghana Statistical Service, Ghana's population was projected to reach 28,308,301 in 2016 (Stats, 2016). It was composed of 93.7 percent Ghanaians by birth and 6.3 percent of people of foreign origin. The ethnic distribution of the native born Ghanaians is as follows: The Akan represent 47.5 percent of the population, the Ewe 13.9 percent, Ga-Dangme 7.4 percent, Mole Dagbani 16.6 percent, 
Mande 1.1 percent, Grusi 2.1 percent, and Gurma 3.7 percent (Stats, 2010, 2016) Following the figure below of the map of Ghana is a discussion of the commonalities and differences of the histories of the three comparative and international contexts of this study.

Figure 3: Geographical Location of Ghana

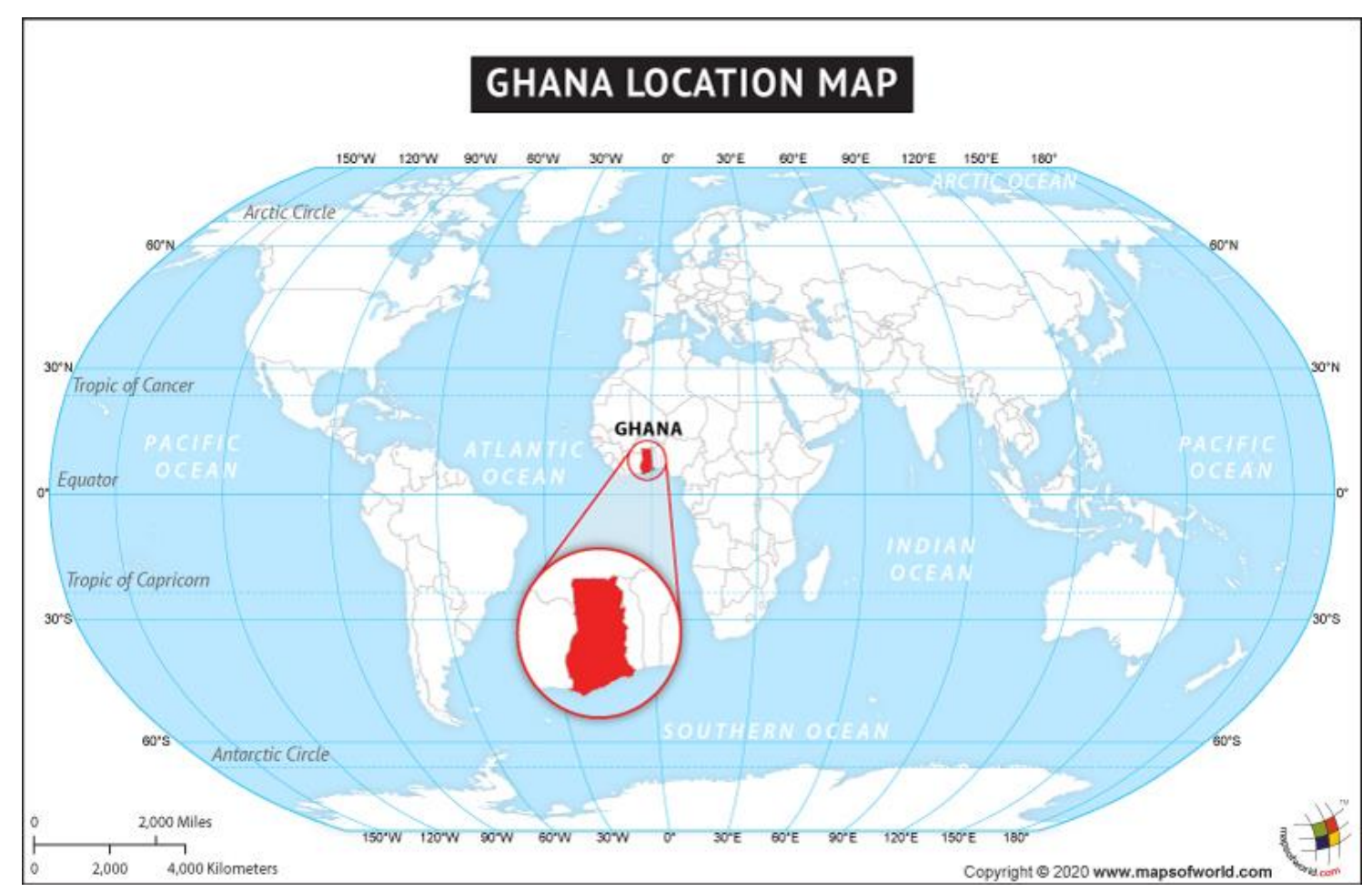

Adapted from Maps of World (https:/www.mapsofworld.com/ghana/ghana-locationmap.html). In the public domain.

Date created: March, 2021

\subsubsection{Commonalities and differences of histories in the three contexts of study}

This section discusses the similarities and dissimilarities present in the histories of the three contexts of study under the following themes. These include: indigenous peoples and institutions; Christianity and formal education; welfare education and neoliberalism; and diversity, benchmarking, and ideological differences. 


\section{Indigenous people and institutions}

The literature shows that all the three comparative countries had indigenous peoples and associated indigenous knowledge, including institutions, before the arrival of the cultural outsiders. For example, in New Zealand, before the arrival of James Cook, the British navigator in 1769, the indigenous Māori had their own way of life (Salmond, 2017). Similarly, in Finland, the Finns and Saami people were the indigenous inhabitants of the territory before the invasion of the Swedes and Russians in the $12^{\text {th }}$ and the $13^{\text {th }}$ centuries respectively (Kirby, 2006). Comparatively, in Ghana, the Akan, Ewes, Bono, Ga, MoleDagbani, and many others were the indigenous people before the coming of the early Europeans, the Portuguese, the Dutch, and the British in the $14^{\text {th }}$ century (Graham, 1971).

Again, the three comparative and international contexts had their indigenous socioeconomic, socio-cultural and political institutions. Socio-economic institutions included various art industries, trading activities, farming, fishing, hunting, and canoe industries (Chazan, 1982; Graham, 1971; Kirby, 2006; Salmond, 2017). Sociocultural institutions included marriage ceremonies, education, funeral rites, and acceptable traditional values and norms (Graham, 1971; Kirby, 2006; Salmond, 2017). Indigenous education was conducted through learning by perception under which children learned the professions of their parents or grandparents from their youth as they followed them to farming, fishing, weaving, and many other everyday activities (Graham, 1971; Sanga \& Chu, 2009). The political institutions structured so that each group or community was headed by the family heads, clan heads, council of elders, as well as chiefs. These indigenous leaders adjudicated justice and maintained law and order before the annexations of these countries by foreign powers. (Graham, 1971; Kirby, 2006; Salmond, 2017)

\section{Introduction of Christianity and formal education}

It is evident in the literature that the Christian faith and formal education were introduced to the three comparative and international contexts by cultural outsiders during their encounters. For example, in New Zealand, the Christian faith was first introduced to the indigenous Māori in 1814. Samuel Marsden from the Church Mission of England set up the first mission station in New Zealand to convert Māori to Christianity (Walker, 1990).

On the educational front in New Zealand, in 1816, the Reverend Thomas Kendall opened the first early Christian Missionary learning facility to teach Māori to read and write 
(Salmond, 2017). Kendell's aim was to train Māori children to understand the scriptures and to learn the British way of life (Salmond, 2017; Walker, 1990). Elaborating on this, in 1835, William Colenso translated and printed five thousand copies of the New Testament in the Māori language (Salmond, 2017).

In Finland, between 1510-1557, the Bishop of Turku, Mikael Agricola, took Christianity in the form of the Lutheran Faith to the Finns (Zetterberg, 2017). Also, he created the Finnish written language and helped with the translation of the Bible into Finnish (Kirby, 2006). As a result of this, in the 1660s, education became widespread in Finnish societies due to the activities of the early Lutheran Missionaries (Kirby, 2006). More importantly, literacy became a requirement for a person to get married (Zetterberg, 2017).

Comparatively, in the Gold Coast of Africa, now Ghana, Christianity was introduced to the indigenous groups by the early Christian Missionaries including the Roman Catholic Mission from Portugal in 1471, the Basel Mission from Switzerland in 1804, and the Wesleyan Mission from the United Kingdom (UK) in 1826 (Graham, 1971). These religious denominations established schools throughout the country to train people to read and write (Graham, 1971). Between 1853-1868, Rev. J. G. Christaller, a Christian Missionary from the Basel Mission, Switzerland translated a section of the Bible, religious songs, and prayers into the local languages in Gold Coast, now Ghana (Akrofi, 2018).

The introduction of Christianity lead to policies in education in the $19^{\text {th }}$ Century in all three contexts, New Zealand, Finland, and Ghana.

\section{Welfare education and Neoliberal global influence}

It is evident in the literature that educational policy in the early and the middle of the 18 th century in the three comparative and international contexts was predominantly focused on welfare (Cassell \& Nelson, 2013; Graham, 1971; Lavery, 2006; McMaster, 2013). In this welfare mind-set the state has to support the provision of education by making sure that the citizenry enjoy a free and compulsory education throughout the country (Gutek, 2014). The period of the early and middle $20^{\text {th }}$ century saw many countries fully regain their autonomy from their colonisers to run their own affairs; New Zealand, Finland, and Ghana were not exceptions (Graham, 1971; Salmond, 2017; Zetterberg, 2017). 
In New Zealand, the Department of Education was established in 1877 to provide free and compulsory education to every citizen of school age (McMaster, 2013; Sutherland, 2018). Similarly, in Finland, in 1866, a national school system was established to make education accessible and free to all children of school age throughout the country (Zetterberg, 2017). In the same vein, after independence in 1957 from the British, under the leadership of Kwame Nkrumah, the first prime minister and the president of the country, Gold Coast of Africa, now Ghana, set up the Ministry of Education to provide free and compulsory education to all Ghanaian children of school age throughout the country (Graham, 1971).

More recently, education and its development in the three national contexts were affected by the neoliberal global doctrine which began in the 1980s (Hakala, Uusikylä, \& Järvinen, 2015; IMF, 1999; McMaster, 2013; Sutherland, 2018). Neoliberal thinkers believed that the state, which in early and middle of the $20^{\text {th }}$ century had been the sole provider of socio-economic amenities in many countries, had to withdraw the support it provided to the citizenry (Gutek, 2014; IMF, 1999; McMaster, 2013; Sutherland, 2018). That is to say, the economy of the state must be run using market principles such as deregulation, privatisation, competition, standardisation, and marketisation (Gutek, 2014).

In the three contexts under study, key sectors of the economy of such as health care, communication, and essential services like electricity and water and education have been affected by the dictates of these market principles (Gutek, 2014; IMF, 1999). For example, in New Zealand, the doctrine was embraced by the Labour Government in 1984 (Court \& O'Neill, 2011; Sutherland, 2018). Similarly, in Finland, despite an attempt by the Labour Unions to prevent the influence of the doctrine, especially the application of market principles to education, they failed (Hakala et al., 2015) and the ideology made its way into education (Cassell \& Nelson, 2013). Furthermore, Ghana also saw the impact of the neoliberal policies which swept across the globe (IMF, 1999; Kraus, 1991). This global policy affected commerce, health, communication, and education due to the Structural Adjustment Programme (SAP) introduced by the IMF (Kraus, 1991) as a way to improve developmental challenges in Africa (IMF, 1999).

In conclusion, education in all three countries has been impacted as this widespread philosophy ushered deregulation, standardisation, competition, marketisation, and 
privatisation - the principles of the business environment - into education (Sutherland, 2018).

\section{Diversity, international benchmarking, and ideological differences}

In recent times, New Zealand can be considered to be one of the most multicultural and super diverse societies in the world with more than fifteen percent of students coming from abroad (Scott \& Norgrove, 2017). It is the home of about a one hundred and sixty foreign and international languages (Behrens, 2013; Spoonley, 2015) and has been classified as "superdiverse" (Royal Society of New Zealand, 2013). Finnish society is similarly diverse, and the country's education has also attracted many students from abroad (OECD, 2018c). Furthermore, Ghanaian society whilst tribally diverse, has also attracted students from abroad especially from the West Africa sub-region (MOE, 2017a). It is evident from the literature that the country has approximately fifty major tribal groupings and languages (Lentz \& Nugent, 2000). However, New Zealand's diversity supersedes that of both Finland and Ghana (MOE, 2017a; OECD, 2018c; Spoonley, 2015).

Furthermore, New Zealand and Finland enjoy some of the highest levels of economic wellbeing in the world (OECD, 2018c; Scott \& Norgrove, 2017). The two countries are top performers globally in terms of education, environmental safety, personal security, job security, and gender equalities (OECD, 2018c; Scott \& Norgrove, 2017). Ghana, on the other hand, is a middle-income country with some degree of both institutional corruption and gender inequality (Cooke, Hague, \& Mckay, 2016).

In relation to secondary education, Finland ranks highly in literacy and numeracy rates, with a high secondary school completion rate among students aged between 15-19 representing ninety nine percent of the population (OECD, 2015). This high achievement is evident in the OECD's PISA-surveys in mathematics, reading, and science for students aged fifteen to eighteen years olds since 2000 (OECD, 2015). New Zealand has also consistently performed well in reading, mathematics, and science in all PISA-surveys since 2000 (OECD, 2013) and has a high proportion of skilled adults ready for the job market, which is above the OECD's average (Scott \& Norgrove, 2017). Lastly, Ghana is doing well on all indicators within the African context, especially in West Africa. However, in the year 2015 when Ghana's education data was run alongside that of other 
OECD countries for the first time, it was ranked last of the seventy countries (OECD, 2016).

Critical theorists consider that ideology in education may have direct consequences for educational leaders and managers as it creates 'the standard to which...' activities including behaviours and organisational functions are to be performed (McLaren, 1994). Whilst the neoliberal system may be praised for efficiency, accountability, and individual autonomy, postmodern and critical theorists have critiqued the philosophy as corporate capitalism and market-driven, thus breeding inequalities, especially in education (Sutherland, 2018). It can be seen that New Zealand's education is partly driven by neoliberal ideological principles such as accountability, standardisation, and competition with some form of social interventions (OECD, 2013).

International literature has reported that New Zealand faces a high school dropout rate, and high levels of poverty, hunger, and suicide rates among youth, especially the indigenous Māori and Pacifica (Court \& O'Neill, 2011; UNICEF, 2017).

Finland is a welfare state (OECD, 2018c). This policy mind-set has generated a strong incentive for students and vulnerable people including the weak, the sick, and the poor in the society to enjoy their part of the national cake, especially the free education (Adamson, 2012). On the other hand, Ghana has a hybrid educational philosophy; that is the combination of the welfare and the capitalist ideological mind set (MOE, 2017a). Despite many benefits of this hybrid system, the country is faced with massive institutional corruption and inequalities (Cooke et al., 2016; MOE, 2017a).

In conclusion, these similarities and differences present in education and the larger society in the three nations have impact on people's lives, especially students, their culture, and schools. This research project has explored educational leaders' views about school culture, climate, leadership, and other contributing factors that promote students' learning, performance, and success in the three contexts. The following research questions were developed to relate to these key concepts of school culture, climate, leadership, professional learning community, student needs, and success. These concepts are discussed in detail in Chapter Two.

\subsection{Research questions}

There are three key research questions for the study: 
- What is the relationship between school culture, climate, leadership, and students' success in New Zealand, Finland, and Ghana?

- What is the relationship between the use of Professional Learning Communities (PLCs), students' needs, motivation, and success in New Zealand, Finland, and Ghana?

- How can school culture, climate, leadership and success be retheorized?

\subsection{Purpose of the study}

The purposes of this study were threefold. The intention was to:

- Gather and interpret the meaning of educational leaders' views, experiences, and practices about school culture, climate, and leadership that support students' learning, performance, and ultimately success in New Zealand, Finland, and Ghana.

- Explore the relationship between professional learning communities and students' success in New Zealand, Finland, and Ghana.

- Describe the relationship between students' needs and academic success in New Zealand, Finland, and Ghana.

\subsection{Significance of the study}

The study is important for its contributions to knowledge in the field of education and training. In particular, this research:

- Enhances understanding of the nature of school culture, climate, leadership, and other benchmarks that are related to students' success in the three international contexts (New Zealand, Finland, and Ghana).

- Provides scope for new issues about school practices to arise from schools' leaders within their current place of work and their career journey.

- Offers potential policy benefits to the three comparatives in relation to other national contexts understanding of school culture, climate, leadership, and other factors that might foster students' learning, performance, and ultimately success. 


\subsection{Limitations of the study}

The study included only one school from each of the three contexts. As such, readers are advised to note the following: First, the findings will not necessarily reflect or transfer to all schools throughout the countries studied. Second, the study only focused on school culture, climate, leadership, and success and what educational leaders do to impact these in supporting students' learning. On this note, two of the principals were new and had spent less than a year in their schools. This may not have impacted the answers they provided to the research questions because the basic roles of principals are similar across different school contexts. Third, some indigenous languages such as Māori and Finnish were blended with English during individual interviews. Several means were used to crosscheck their meanings and understandings including, Google scholar, Māori, and Finnish documents translated or written side-by-side with English. These may not have influenced the meanings of words or sentences formations. Fourth, due to the qualitative nature of this research, the thesis' findings cannot be claimed to be generalisable. Finally, the data collection does not cover the entire schools throughout the three countries, New Zealand, Finland, and Ghana; thus the study cannot be generalised. 


\section{CHAPTER TWO: Literature review}

\subsection{Introduction}

This comparative and international study of school culture, climate, leadership, and students' success in education investigates the existing body of knowledge with a focus on six thematic areas of research. These thematic areas of research are connected and interrelated to the aim of the study and the research questions. They are: school culture, school climate, school leadership, professional learning community, students' needs, and success expressions. The chapter is divided into six parts. The first section addresses culture in general and school culture. The second part highlights climate in general, and school climate. Leadership in general and school leadership is the focus on the third section. The fourth part discusses the notion of Professional Learning Communities and its application. The fifth and the sixth sections throw more light on students' needs and aspirations with regard to educational success.

\subsection{Culture}

This section provides an overview of the concepts of culture, then a detailed examination of school culture, and concludes by identifying gaps in the literature.

\subsubsection{Overview}

Many attempts have been made to define the term "culture". These attempts have come from various academic disciplines (Dimitrov, 2013; Hoy, 1990; Schein, 2010) ranging from anthropology, sociology, psychology, and sociocultural stances (Dimitrov, 2013; Mann, 2010). According to Johnson and Christensen (2008, p. 400), the term culture is a "system of shared beliefs, values, practices, perspectives, folk knowledge, languages, norms, rituals, and material objects and artefacts that members of a group use in understanding their world and in relating to others". Culture has been explained as an integral and inalienable part of what we are today and become tomorrow for a particular group of people in the society (Macdonald, 1991) and involves the belief systems, symbols, communication, rituals, shared perception and consciousness, as well as the values that bundle a group together (Dimitrov, 2013; Macdonald, 1991; Mann, 2010). Schein defines culture in the following way, as the: 
pattern of basic assumptions that a given group has invented, discovered, or developed in learning to cope with its problems of externaladaptation and internal integration, and that have worked well enough to be considered valid, and, therefore, to be taught to new members as the correct way to perceive, think in relation to their problems. (Schein, 2010, p. 12)

Culture reflects deep-rooted norms and traditions, beliefs about how things are done, and the work conducted by individuals, groups and organisations in a given society (Dimitrov, 2013; Schneider, Ehrhart, \& Macey, 2013). From a critical pedagogy perspective, culture can be defined as the particular ways in which a social group lives out and makes sense of its given circumstances and conditions of life and environment around them (Giroux \& McLaren, 1989). In addition to this, the term is defined as a "set of practices, ideologies, and values from which different groups draw to make sense of the world" (McLaren, 1994, p. 180).Questioning and interrogation help us to get answers and understand who possesses power and how it is metamorphosed in the social organisations that link up schooling to the wider social and political order (McLaren, 1994).

According to Schein (2010, p. 18), the construct of culture in a broad sense can be classified into three levels: cultural artifacts, values, and basic underlying assumptions. The visible aspects of culture are what we term as artefacts or the exposed beliefs that can be seen and felt (Schein, 2010; Schneider et al., 2013); for example, the dress code and art symbols of an organisation (Dimitrov, 2013; Macdonald, 1991; Perlin, 1990). Cultural values include ideals, goals, aspirations, ideologies, and rationalisations that drive members to act (Schein, 2010). The underlying assumptions are basic unconscious invisible underpinnings which are taken for granted (Schein, 2010) and may affect the success or the failure of people in the society (Ott, 2004). They may influence emotions and feelings of the members in a community as they perform their duties (Schein, 2010; Schneider et al., 2013).

It is evident in the literature that the visible and invisible aspects of culture are both product and process (Bolman \& Deal, 2013). As a product, culture includes knowledge and wisdom accumulated from the organisational members, especially their experiences, myths, practices, and opinions that are beneficial for organisational improvement (Bolman \& Deal, 2013). Furthermore, culture as a process evolves, renews and recreates 
practices, experiences, and norms as new members learn from the status quo and become masters themselves in the organisation (Ott, 2004). Therefore, knowledge of the organisational cultural values, norms, procedure, rituals, assumptions, and traditions are essential for organisational leaders as they help promote growth and development within organisations and the larger society (Dimitrov, 2013; Mann, 2010; Schneider et al., 2013). See the figure below for levels of culture as identified in the broader spectrum in the international literature.

Figure 4: Representation of Levels of Culture

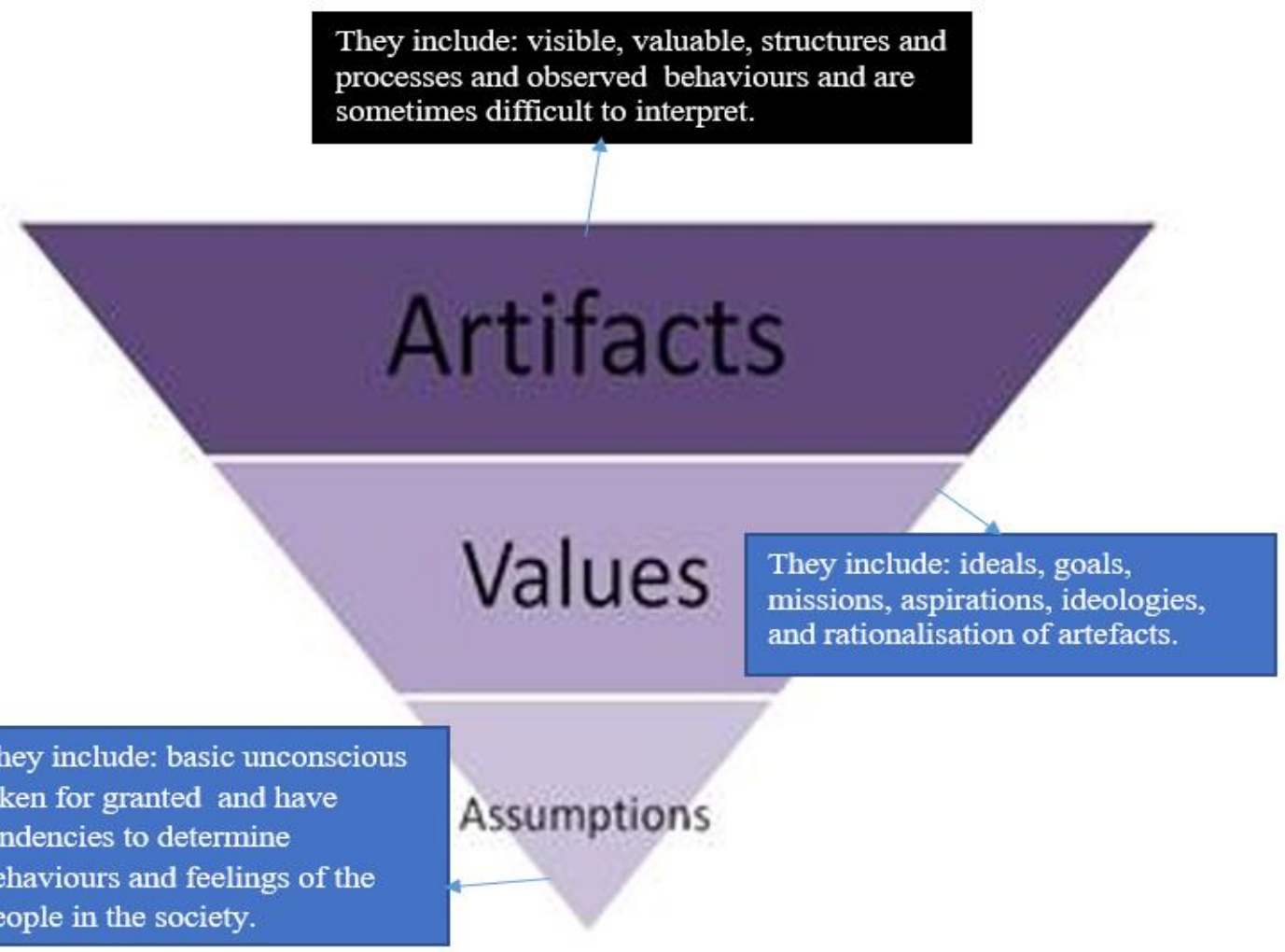

Adapted from (Schein, 2010)

This general classification is shared by anthropologists, sociologists, and psychologists (Schein, 2010). However, critical pedagogy has expanded the scope to cover cultural power relations that exist among and between societal actors (Giroux \& McLaren, 1989) and categorises the metaphor into three central groupings. These include the dominant culture, subordinate cultures, and subcultures (McLaren, 1994). The dominant culture signifies "social practices and representations that affirm the central values, interest, and concerns of the social class in control of the material and symbolic wealth of society" 
(McLaren, 1994, p. 180). Groups who are a part of the dominant culture may also belong to a subordinate culture (Giroux \& McLaren, 1989). People or individuals who are members of subcultures often use some practices and symbols to help define their identity separately from the main dominant culture (McLaren, 1994). These categorisations of cultures by critical pedagogy are manifest in our institutions, including schools, daily lives and have an impact on leadership, what we teach, and what students' learn (Giroux \& McLaren, 1989).

\subsubsection{School culture}

The term "school culture" is broad, and many attempts have been made by academic scholars to define this phrase (Brown, 2015; Hargreaves, 1995; Hoy, 1990; Maxwell \& Ross Thomas, 1991; Schein, 2010; Zhu, Devos, \& Tondeur, 2013). Hargreaves (1995, p. $25)$, defines the term from an anthropological point of view. To him, the term "school culture" encompasses the "knowledge, beliefs, values, customs, morals, rituals, symbols and language of a group: some way of life" (Hargreaves, 1995). It includes the power and knowledge to understand daily happenings of schools and may enhance students' learning and development (Hargreaves, 1995).

The concept culture is the spirit that drives the duties and functions of the school for the betterment of the society (Schneider et al., 2013). School culture is a holistic entity that influences every actor in the school settings including the students, teachers, parents, administrators, and management in carrying out their duties (Prosser, 1999). In simple terms school culture has been described as: "the way we do things around here" (Prosser, 1999, p. 14).

The phrase school culture has several features and perspectives (Maxwell \& Ross Thomas, 1991; Peterson \& Deal, 2002; Schein, 2010; Zhu et al., 2013). A significant feature includes the shared values, beliefs, and norms (Peterson \& Deal, 2002, p. 14). A shared value is a thing held in high esteem which is considered essential by the school's actors (Power \& Whitty, 1999). It has some form of influence on behaviour patterns, standards, and norms (Maxwell \& Ross Thomas, 1991) on the growth and development of the school (Maxwell \& Ross Thomas, 1991; Schein, 2010; Zhu et al., 2013). The values manifest in the school serve as norms which deal with the 'dos and don'ts' as well as standards which are concerned with the rewards and sanctions regarding behaviours of 
individuals in the school (Maxwell \& Ross Thomas, 1991; Zhu et al., 2013). For example, respect for other members may be considered as an core value in a particular school, or the school may value collaboration as a driving force for its development (Zhu et al., 2013).

The belief systems of members of the school community, according to Peterson and Deal (2002), reflect the "beliefs and understandings about the world around us" (p. 14). Whilst they may be "consciously held, cognitive views about truth and reality" (Ott, 2004, p. 489) they include tacit assumptions which are upheld by members (Goldring, 2002; Hoy, 1990; Zhu et al., 2013). These intangible belief systems influence values systems (Goldring, 2002; Hoy, 1990; Sapher \& King, 1985). They dictate values, norms, standards, and behaviours held by the teachers, principals, and students.

Those beliefs or cultural norms in schools may include both written and unwritten rules and prescriptions that schools' personnel and students are expected to follow (Goldring, 2002; Hargreaves, 1995; Peterson \& Deal, 2002; Prosser, 1999). Examples of such cultural norms include shared vision and innovations, decision-making processes, communication, collaboration, and traditions held by members to perform their duties (Goldring, 2002; Maxwell \& Ross Thomas, 1991; Sapher \& King, 1985).

The school culture includes a shared vision and purpose. Many schools across the globe have specific visons and purposes that are firmly anchored in various working relationships and activities aimed at notions of progress and development (Peterson \& Deal, 2002). The vision and the purpose may be deeply rooted in the school's activities (Hoy, 1990; Maxwell \& Ross Thomas, 1991; Zhu, Devos, \& Li, 2011). Such a purpose may drive the short, medium, and long term planning, the daily tasks, and resource allocation of the school (Peterson \& Deal, 2002). The purpose can be seen in the school's written statements that highlight what the school stands for and how they intend to improve learning outcomes. (Maxwell \& Ross Thomas, 1991; Schein, 2010; Zhu et al., 2013).

The mission statement of a school can be seen as representing the cultural foundation of the school (Roby, 2011; Schein, 2010). As well, it may aim to inspire and rekindle energy in members of the school to perform their duties effectively for societal development (Schein, 2010). It can provide motivation to teachers to give their best to support students' 
learning (Angelides \& Ainscow, 2000) as well as energise them to move forward from their comfort zones to support all aspects of the school's life (Schneider et al., 2013). This in turn may enhance students' advancement (Hargreaves, 1995). The shared vision and purpose may encourage students' parents, community members, and the larger society to get involved and support the school's activities so as to enhance both teaching and learning (Deal \& Peterson, 2016).

The culture of a school may further include collegiality, experimentation, high expectations, trust and confidence, tangible support, reaching out to knowledge bases, appreciation and recognition, caring, celebration and honour, involvement in decisionmaking, protection of what is important, traditions, as well as honest and open communication. All of these aspects are considered to be important to the development of the school especially with regard to students' learning (Peterson \& Deal, 2002; Sapher \& King, 1985).

These above norms may regulate behaviours that can been viewed in the classroom and outside the classroom (Peterson \& Deal, 2002). The norms evolve within various activities and actions of the people in the school (Prosser, 1999) and guide members' conduct and working operations. They set the rules of the game that new members are expected to follow and to learn (Angelides \& Ainscow, 2000).

Another feature of the normative function of a shared vision is that is may serve in building relationships among and between principals, teachers, non-teaching staff and stakeholders (Hoy, 1990). These forms of relationships have tremendous impact on the school's effectiveness (Angelides \& Ainscow, 2000; Hoy, 1990). These impacts include: showing the direction and picture for the future of the organisation (Goldring, 2002); giving the school members clear-cut guidelines as to how to carry their duties in relation to the future direction of the organisation (Sapher \& King, 1985); and reflecting the vision statement or the mission statement of the school (Sapher \& King, 1985).

The vision statement or mission statement is concerned about the values of the school (Goldring, 2002). For example, it highlights what the organisation considers as vital in its operations and the knowledge and skills that members have to learn for growth and development (Goldring, 2002). Practically, this shared school vision works well in schools where all the actors know this stated vision and regularly discuss it in the staff 
and departmental meetings and coffee breaks (Sapher \& King, 1985). Secondly, it is effective when the principal reminds the teachers and the students of the vision statement on a regular basis (Angelides \& Ainscow, 2000) and when it is clearly displayed on walls for teachers, students, and stakeholders to read (Angelides \& Ainscow, 2000; Sapher \& King, 1985). These actions help the school's personnel to reflect from time to time as to whether their activities are in line with the vision statement and if not, to consider what can be done to align them (Hoy, 1990; Sapher \& King, 1985).

Innovation, relationships, and support norms are also vital for a school's effectiveness (Brown, 2015). This is because they form the foundation of school improvement (Maxwell \& Ross Thomas, 1991). Innovation norms involve creative thinking which brings out new ideas, strategies, methods, and theories and products to benefit the school's members (Easton, 2011). These norms encompass collective learning for the school's members towards a defined goal (Maxwell \& Ross Thomas, 1991) and deal with organisational changes which sometimes challenge the established cultural beliefs, norms, values, and assumptions (Goldring, 2002). Outcomes of such changes sometimes are unknown or unpredictable (Sapher \& King, 1985) and rely deeply on the capabilities and understandings of the leaders (Easton, 2011).

Relationships of all forms have a tremendous impact on the school's learning outcomes (Sapher \& King, 1985). Basic relationships including interactions between members within and outside the school can also contribute to improvement and development (Sapher \& King, 1985). In particular, relationships among peers, teachers, and between teachers and principals may have a positive impact on students' learning, performance and ultimately success (Lance, 2010; Sapher \& King, 1985). It is evident in the literature that positive relationships and interactions help the vision of the school to be carried out and achieved (Brown, 2015). Positive relationships also build confidence in members of the school to communicate their ideas freely to benefit the school's ultimate goal; that is, students' wellbeing, growth and learning (Lance, 2010). More so, trust is developed as a result of relationship-building amongst the principal, teachers, students, and students' parents to enhance students' learning (Brown, 2015; Lance, 2010). Finally, good relationships and trust helps members to address their concerns in the shortest possible time, especially where there is a proper mechanism for them to channel their grievances (Brown, 2015; Goldring, 2002). 
On the other hand, a school with poor relationships amongst the principals, teachers, nonteaching staff, parents, and students is likely to be negatively impacted (Brown, 2015; Goldring, 2002; Sapher \& King, 1985). As evident in literature, ineffective interactions amongst a school's actors can lead to tensions and antagonism which may affect students' learning outcomes due to the lack of teamwork and coordination (Brown, 2015; Goldring, 2002; Sapher \& King, 1985).

For this reason,a school norm which values the practice of support is important for effectiveness (Hargreaves, 1995). This support involves the ability of members to seek help from colleagues at the work place, and a willingness of colleagues to provide assistance (Sapher \& King, 1985). Such support may include mentoring, guidance and counselling, learning support, clinics, and high expectations as well as conducive avenues for members to assist one another. The availability of these systems help the vision of the school to be accomplished (Brown, 2015) through teamwork that cements cordial relations (Hoy, 1990; Lance, 2010).

School support processes bring the expertise of various school actors to light (Hargreaves, 1995). It encourages innovation and learning (Hargreaves, 1995) and, through innovation and teamwork, new discoveries such as a new methods of teaching, a new theory, or a new leadership skill. These may then be developed which will be of great benefit to all members and for the school's development (Schneider et al., 2013). Lastly, support systems help build the confidence of new members including new teachers, principals, and students (Goldring, 2002; Lance, 2010; Sapher \& King, 1985).

The norm of shared decision-making is considered to be one of the cardinal principles for schools' development and, as such, school administrators, leaders, and managers must take it seriously when they want to effect changes (Macneil, Prater, \& Busch, 2009; Maxwell \& Ross Thomas, 1991; Sapher \& King, 1985; Zhu et al., 2011). Achieving and applying shared norms requirescollective planning by the school members for achieving a common goal or objective (Sapher \& King, 1985; Zhu et al., 2011) and can be achieved via discussion, debates, and presentations resulting in a common idea for the betterment of the school (Maxwell \& Ross Thomas, 1991; Zhu et al., 2011). Shared decision-making works practically in schools where personnel contribute to staff meetings, social gathering debates, subject discussions, tutorials, coffee breaks, workshops, conferences, and during a school's general assembly meetings (Sapher \& King, 1985). It has 
significant benefits as it enables actors of the school including the principal, teachers, non-teaching staff, students and their families to speak with a common voice (Knox, 2002). This common voice contributes to a sense of unity within the school and to improving students' achievements (Knox, 2002; Lance, 2010; Sapher \& King, 1985). Shared decision-making in schools helps school leaders to develop aschool culture that focuses on learning rather than teaching (Stoll \& Louis, 2007) and involves tolerance, and the ethics of care, trust, love, community building, early intervention, and researchedbased learning to improve students' outputs (Easton, 2011).

Furthermore, shared decision-making bridges the relationship between the school' members and students' parents (Schneider et al., 2013). This relationship encourages a high level of engagement through collaboration (Gaziel, 1997) which helps both the school's members and parents to find possible ways to address challenges faced by the school (Schneider et al., 2013). In effect, it helps the school to become a more professional learning community (Cowie \& Crawford, 2007).

Honest and open communication are important norms for a school's effectiveness (Gaziel, 1997). Honest and open communication are needed for school leaders, students, and parents as they help build relationships and trust among these actors. Where there is no open communication, there is a stronger likelihood of no trust among those leaders, and students' learning outcomes may suffer (Lance, 2010; Sapher \& King, 1985). On the other hand, honest communication builds the spirit of accountability and trust among the school' members (Belcher, 2017); open communication and trust manifest in the school where members see criticism as an avenue for self-improvement without feeling ashamed or rejected (Lance, 2010; Sapher \& King, 1985). Honest communication brings about caring and empathy within and among school's actors (Lance, 2010). This occurs when the principal sees the school as a family and also recognises individual abilities and strengths (Cowie \& Crawford, 2007). Furthermore, open and honest communication encourages respect, trust and commitment among the school's personnel.. For example, teachers who are honest will take care of school property, are accountable and responsible for their actions, and act ethically in service of the school's effectiveness (Cowie \& Crawford, 2007; Lance, 2010).

The school's traditions also support school wellbeing and effectiveness (Belcher, 2017; Cowie \& Crawford, 2007; Sapher \& King, 1985). School traditions involve special events 
such as anniversaries, independence celebrations, religious holidays, school clubs and societies' events, and award and graduation ceremonies (Sapher \& King, 1985). These traditions may be deeply rooted in school activities and become recurring events in the school's life (Sapher \& King, 1985). They help the school members to remember their past. For example, a school event such as the graduation ceremony and teachers' award's night, where distinguished students and teachers who have excelled in various disciplines are honoured, may be motivating and inspire others to follow suit (Gaziel, 1997; Sapher \& King, 1985).

A further norm is that of valuing the competency of the school's leadership to deliver positive outcomes (Lance, 2010). This happens where the school's leadership, including the teachers, have the ability and capacity to do challenging tasks and they are recognised by the school for initiating and executing these as well (Gaziel, 1997). Valuing the competencies of both teachers and students may include when the school's principal involves the teachers, students, and parents in the decision making process and trusts that their competencies will contribute to the school's improvement (Lance, 2010). For this, the principal brings teachers, students, and parents together for policy planning as well as showing appreciation for their contributions (Cowie \& Crawford, 2007; Lance, 2010). The school stands to benefit when the work of teachers, principal, and non-teaching staff is valued and appreciated by the community in which they operate (Knox, 2002). Such appreciation energises them to do more for students in raising the bar in relation to students' learning outcomes (Knox, 2002; Sapher \& King, 1985). It also encourages team work, openness, and trust, as well as leading to mutual respect between the school's actors within and outside the school. In turn, this contributes to effectiveness, improvement, and enhancement of the school's developmental outcomes (Cowie \& Crawford, 2007; Gaziel, 1997; Knox, 2002).

It is evident in the literature that researched-based learning works well in the school where the leaders are wanting to improve students' outcomes (Lance, 2010; Sapher \& King, 1985). In applying a model of research-based learning, teachers and principals may analyse students' data and use this analysis as the basis from which to develop new ideas, concepts, and methods to enhance the teaching and learning processes. This makes a difference to the school's personnel as it helps them to learn new ways of teaching which 
may lead to a new discovery and solutions to some problems in the school (Lance, 2010; Sapher \& King, 1985).

In conclusion, substantial evidence suggests that school culture is nurtured or built and in turn influences the growth and development of the organisation (Cowie \& Crawford, 2007; Gaziel, 1997; Hoy, 1990; Knox, 2002; Sapher \& King, 1985). The school culture provides direction and shapes the norms of the school. It gives the school's leaders direction to articulate the spirit of shared decision making. The leaders deploy collegiality, experimentation, high expectation, trust and confidence, tangible support to achieve the set goals. The school culture also provides direction for reaching out to utilise knowledge-bases, and to show appreciation and recognition, caring, celebration and honour. The leaders involve personnels in decision making process, value traditions and use ethics of care, trust, and collaboration to lead the learning (Brown, 2015; Cowie \& Crawford, 2007; Gaziel, 1997; Hoy, 1990; Knox, 2002; Lance, 2010; Sapher \& King, 1985). For this research, these concepts guided the determination of the research questions and informed the data analysis to explore educational leaders' views about school culture, climate, leadership, and success in the three sites inNew Zealand, Finland, and Ghana.

It is evident in the literature that in a positive school culture, there is a strong sense of community, empathy, we-feeling, trust, and collaboration held by personnel and that this is enacted in ways that reach well beyond the symbolic mission statement hanging on the walls (Deal \& Peterson, 2016; Hargreaves, 1995; Schneider et al., 2013). However, in a toxic school culture, the purpose may instead be self-serving and focused on individual achievements rather than the collective interests (Peterson \& Deal, 2002; Prosser, 1999).

\subsubsection{Gaps in the literature}

It is noteworthy that there were several gaps identified in the reviewed literature. First, there has been little research on school culture from African perspectives. Most of the reviewed literature was from Western counties such as Canada, the UK, United States of America, Australia, New Zealand, and Finland. Finally, there were little leadership interventions identified for African contexts as compared with Western countries in the reviewed literature. It is anticipated that this research will begin to address some of these gaps. 


\subsection{Climate}

This section provides an overview of the concept of social "climate" and a detailed examination of organisational climate in relation to job satisfaction. This is followed by consideration of school climate, and the section concludes by identifying gaps in the literature.

\subsubsection{Overview}

It is evident in the literature that the term "climate" has become of much concern for businesses, governments, non-governmental agencies, educational leaders, managers, and administrators as well as students (Dessel, 2010; Hoy, 1990). It has bearing on their search for the best possible ways to improve working relationships and the environment in which they operate (Angelides \& Ainscow, 2000; Cornell, Shukla, \& Konold, 2015; Kim \& Hopkins, 2017; Macneil et al., 2009; Schneider et al., 2013).

There are various explanations of the term "climate" (Hoy, 1990; Schaufeli, 2016; Schneider et al., 2013; Shanker, Bhanugopan, van der Heijden, \& Farrell, 2017). For example, it has been explained as the procedures, policies, and practices that support the wellbeing of members in a community or the society (Schaufeli, 2016). The term "climate" can be explained as a shared and enduring perception and feeling of the aspects of the work environment (Asif, 2011). In a similar vein, "climate" is described as the feelings of individuals or a group socially, emotionally, intellectually, and physically of the environment in which they work (Cobb, 2014). Again, the term deals with the conditions of the environment as perceived by the members within it (Poghosyan, Nannini, Stone, \& Smaldone, 2013; Schneider et al., 2013) and includes the body and soul of the behaviour of the people in a community (Macneil et al., 2009).

On this note, the term "climate" has several characteristics depending on the arena in which it is located (Maxwell \& Ross Thomas, 1991; Schneider et al., 2013). Firstly, climate is developed in a particular environment over a period of time (Maxwell \& Ross Thomas, 1991) and involves the traditions of that particular community (Hoy, 1990; Maxwell \& Ross Thomas, 1991). Secondly, "climate" is also psychosocial construct in which members use their senses to perceive things around them (Maxwell \& Ross Thomas, 1991). This includes the behaviour of the people and how these behaviours are expressed in the society (Cornell et al., 2015). It also relates to some extent to the affective 
aspect of the people (Maxwell \& Ross Thomas, 1991), particularly relationship-building within the community (Asif, 2011; Cornell et al., 2015).

Another important feature of climate is that it can be observed, especially in the behaviour effects of the people in the society (Dessel, 2010; Maxwell \& Ross Thomas, 1991; Schneider et al., 2013). Such observables include: job satisfaction, bullying, victimisation, relationships, support systems, behaviour patterns, and many more (Cobb, 2014; Dessel, 2010; Joseph, 2015; Maxwell \& Ross Thomas, 1991; Schneider et al., 2013). These observables are present in all organisations including schools (Hoy, 1990; Maxwell \& Ross Thomas, 1991).

\subsubsection{Organisational climate}

Organisational climate has been described by early researchers as "the enduring quality of organisational life" (Hoy,1990, p. 151). It includes the meanings individuals or a group attach to their feelings in the work environment in the society, either positive or negative (Schneider et al., 2013). It includes emotional needs and aspirations of the organisational members towards innovation and development (Ghavifekr \& Pillai, 2016).

Organisational climate is viewed as the shared perception of members' experience as they carry out their duties in the society (Schneider et al., 2013). Aspects of organisational climate include work procedures, ethics, policies, practices, rewards and punishments, leadership styles, support systems, and networks (Ahmad, Jasimuddin, \& Kee, 2018) which may contribute to job satisfaction in an organisation including a school (Ghavifekr \& Pillai, 2016).

\subsubsection{School climate}

School climate has been described as the "teachers' perceptions of their general work environment" (Hoy, 1990, p. 151). It includes their positive or negative feelings relating to their working environment as perceived by school's principals, teachers, non-teaching staff and students as they work (Poghosyan et al., 2013). Similarly, the school climate can be explained as the shared perceptions held by members and the meanings they draw from policies, practices, and procedures in the school's environment (Schneider et al., 2013). Voight (2014, p. 310) notes that the school climate is "the social, emotional, and physical aspects of the school environment" and, more importantly, it exists where there is engagement and general acceptance (Ghavifekr \& Pillai, 2016; Joseph, 2015) and 
members are strengthened to share their experiences, innovations, and creativity in the work place (Joseph, 2015).

It is evident in the literature that the climate of the school can be understood and explained with reference to four thematic areas: environmental safety, relationship-building, researched-based learning and support services (Education Review Office, New Zealand, 2015).

A safe school is one that cares for physical emotions, psychological wellbeing, and intellectual safety of the students (Cobb, 2014). The environmental, physical and emotional safety measures of the school must be a priority of the school's leaders and managers maysince they can be a source of innovations to improve students' learning outcomes (Cobb, 2014). Furthermore, caring for the students' safety and wellbeing helps to reduce abuses such as bullying, teasing, name-calling, sexual exploitation, racial victimisation, and many more which impede students' academic progress (Cobb, 2014; Cornell et al., 2015). On this note, a school with a positive school climate develops early interventions to address such abuses (Hopson \& Lawson, 2011; Koopman, Patton, Ubbes, \& Zullig, 2010).

Such early interventional measures may include disciplinary measures within the structures of the school in relation to the rules and how they are enforced (Voight, 2015). Rules in the school, especially behavioural expectations, must be clear and fair to all the students (Hopson \& Lawson, 2011; Voight, 2015). This will deter students from violating the school rules (Hopson \& Lawson, 2011). Again, clear disciplinary expectations may help to deter future abuses such as bullying, stealing, in-fighting, and gossiping among students in the school environment (Koopman et al., 2010).

Furthermore, lessons which foster an an ethic of care should be included in students' curriculum (Hopson \& Lawson, 2011). The focus of such teaching will include care for fellow students and teachers, care for the school's property such as computers, stores, projectors, books; and care for the school's environment such as trees, animals, vegetation.. Also, care for personal hygiene may be included in students' lessons (Ahmad et al., 2018; Cobb, 2014; Hopson \& Lawson, 2011). These lessons may significantly mayreduce tension, abuse, and violent conflicts within schools and the wider community (Ahmad et al., 2018; Cobb, 2014; Voight, 2015). 
The second feature of the school climate is relationship-building within schools and beyond school boundaries (Ahmad et al., 2018; Cornell et al., 2015; Koopman et al., 2010; Voight, 2015). Social relationships here mean interactions between and amongst the school's actors in executing their functions (Hopson \& Lawson, 2011). These interactions occur between students and school personnel, amongst students, and between personnel and students' parents (Koopman et al., 2010). They are particularly important in that they determine the quality of the school's life (Cobb, 2014; Hopson \& Lawson, 2011). A healthy school is one with a positive climate, established relationships, collaboration, and team work to enhance learning outcomes of students (Bear, Yang, Mantz, \& Harris, 2017; Hopson \& Lawson, 2011). This relationship-building may help improve interactions and communications that exist between students, teachers, principals, and non-teaching staff and have several advantages (Bear et al., 2017; Hopson \& Lawson, 2011; Voight, 2015).

Relationship-building provides a platform for school members such as students, teachers, principals, non-teaching staff, and parents to help each other to promote learning objectives (Cobb, 2014; Hopson \& Lawson, 2011; Sapher \& King, 1985). Secondly, these relationships provide personnel with an avenue to identify problems faced by students and to develop interventions to solve them (Voight, 2015). Lastly, trust is built as a result of intervention measures developed to address students' challenges (Bear et al., 2017; Gilstad-Hayden et al., 2014; Soto \& Deemer, 2018). These communications and interactions may encourage students to open up and articulate their voices freely to improve their learning outcomes and development (Voight, 2015).

Schools that develop positive peer-relationships appear to succeed better than those with poor or no relationships (Hopson \& Lawson, 2011; Koopman et al., 2010; Voight, 2015). These relationships and interactions may be fostered through team-work (Dessel, 2010) and such include, group assignments, debates, drama, and group presentations (Hopson \& Lawson, 2011). These relationships, through interactions, may lead to exchange of ideas (Voight, 2015) and leadership qualities may also be learnt or emerge among or between students (Cowie \& Crawford, 2007; Koopman et al., 2010). Furthermore, such interactions serve as avenue for socialisation (Dessel, 2010; Voight, 2015). For example, through socialisation, friendship, trust, and many other aspects may be fostered and 
enhance learning in situations where the school's vision is clear to all members (Dessel, 2010; Hopson \& Lawson, 2011; Voight, 2015).

Good relationships between school personnel and their students' parents and caregivers are crucial for school leaders, administrators, and managers who want to introduce innovations or changes (Cobb, 2014; Dawson \& Wymbs, 2016; Sheridan et al., 2017; Voight, 2015). Such relationships bridge the gap between teachers, principals, nonteaching staff, and students' parents (Dawson \& Wymbs, 2016; Hopson \& Lawson, 2011; Whitaker \& Hoover-Dempsey, 2013). Bridging the gap between parents and teachers helps both to know what is going on in the school and outside to enhance learning (Cobb, 2014; Cornell et al., 2015; Sheridan et al., 2017). For example, through parent-teacher interactions, the school's leaders and parents may get information from each other on students' daily activities (Hopson \& Lawson, 2011; Koopman et al., 2010; Whitaker \& Hoover-Dempsey, 2013). These positive interactions may help build trust between the leaders and parents, and thus, contribute to the school's effectiveness (Hopson \& Lawson, 2011; Hoy, 1990; Koopman et al., 2010). Moreover, parents' experience pertaining to previous engagements can be brought to bear during interactions (Whitaker \& HooverDempsey, 2013). These experiences may foster addressing a particular behaviour in schools such as bullying, name-calling, theft, and others (Sheridan et al., 2017; Whitaker \& Hoover-Dempsey, 2013).

It is further evident that positive interactions among schools' personnel promote job satisfaction (Ghavifekr \& Pillai, 2016; Halawah, 2005; Lee \& Nie, 2014). For example, a positive personnel relationship serves as a catalyst for school effectiveness (Dou, Devos, \& Valcke, 2016). These relationships are fostered when the school's principal, the teachers, the non-teaching staff, and other stakeholders exchange communications (Goldring, 2002; Koopman et al., 2010; Voight, 2015). Exchanges can easily occur through email and text messaging, verbal exchanges, and telephone calls (Dou et al., 2016; Ghavifekr \& Pillai, 2016; Lee \& Nie, 2014; Sapher \& King, 1985; Voight, 2015).

Many scholars have established that what the students learn and how they learn plays a key role in their advancement and development (Dessel, 2010; Hopson \& Lawson, 2011; Thapa, Cohen, Guffey, \& Higgins-D'Alessandro, 2013). This is because schools act as socialising places for students' advancement (Dou et al., 2016; Thapa et al., 2013), and through teaching and learning, they are able to discover their talents and develop useful 
dispositions (Dessel, 2010; Thapa et al., 2013). These talents and dispositions may include intercultural competencies, conflict resolution, good working and studying habits, and strategies for peaceful coexistence (Dessel, 2010; Hopson \& Lawson, 2011). Therefore,school leaders wanting to improve students' learning outcomes must thoughtfully prioritise what the students' learn at school (Ahmad et al., 2018; Cowie \& Crawford, 2007; Dou et al., 2016; Hopson \& Lawson, 2011).

A healthy school climate can be engendered via a research-based teaching and learning approach (Hopson \& Lawson, 2011; Zullig, Huebner, \& Patton, 2011) This can be avhieved viathe willingness and ability of the school's personnel to reach out to knowledge such as sharing learnings from academic journals, attending seminars and workshops that in effect, can improve students' learning performance and success (Hopson \& Lawson, 2011; Sapher \& King, 1985).

It is also possible for schools to develop an experimental teaching and learning approach (Cobb, 2014; Dou et al., 2016; Hopson \& Lawson, 2011; Sapher \& King, 1985). This can be seen in, for example, fostering the ability of the teachers and students to come up with new techniques or ideas to support teaching and learning (Cobb, 2014; Sapher \& King, 1985). Those innovations and ideas maymay expand the knowledge capacity of the students and teachers to improve the quality of teaching and learning (Cobb, 2014; Sapher \& King, 1985; Thapa et al., 2013).

Finally, a healthy school builds a healthy support climate in the classroom and beyond (Ahmad et al., 2018; Cobb, 2014; Dou et al., 2016; Hopson \& Lawson, 2011; Thapa et al., 2013). The school's support here involves the way in which students, teachers, principals, and non-teaching staff receive assistance from each other for the betterment of the school (Hopson \& Lawson, 2011). For example, material support may comprise such things as computers, syllabus, textbooks, projectors, exercise books, and libraries (Hopson \& Lawson, 2011). Therefore, a good principal will endeavour to make these readily available for the teachers and students in order to enhance both lesson delivery and learning outcomes (Cobb, 2014; Hopson \& Lawson, 2011).

Emotional support, social support, psychological support, welfare support, health support, technical support, and physical support are all needed in the school (Chen \& Wei, 2013; Cobb, 2014; Collie, Shapka, \& Perry, 2012; Hopson \& Lawson, 2011; 
Kearney, Murakami, Bunch, Viamontes, \& Campbell, 2018). These services may enhance the school's personnel and students' wellbeing for societal growth and development (Earnest \& Brady, 2014).

Furthermore, students need to feel safe at all levels of the school's environment, from drug use, bullying, harassment, racial and tribal discrimination, name-calling, stereotyping, shootings and other violence, aggressive behaviour, and alcoholism, any or all of which have negative repercussions for students' learning (Borish, King, \& Dewey, 2017; Cobb, 2014; King, Dewey, \& Borish, 2015; Koopman et al., 2010; Voight, 2015). Therefore, the principal and teachers can develop early interventions and support centres to address these social cankers that may affect students' learning outcomes (Cobb, 2014).

In conclusion, it is evident from the literature that a safe and a supportive school climate includes aspects such as relationships building, respect for diversity and identities (Bear et al., 2017; Cobb, 2014; Macneil et al., 2009), emotional and safety development, as well as physical and psychological safety from dangers such as substance usage(Ahmad et al., 2018; Bottiani, Bradshaw, \& Mendelson, 2014; Cobb, 2014).

\subsubsection{Gaps in the literature}

There were several gaps identified in the reviewed literature. Firstly, there has been little research on school climate from Africa's perspectives. Most of the reviewed literature was from Western counties such as Canada, the UK, United States of America, Australia, and New Zealand as well as some Asiatic countries..

Next, there were little leadership interventions identified that would operate best in an African context as compared with the Western countries. Finally, it appears that most of the reviewed literature uses the two constructs, school climate and culture, interchangeably. 
Table 1: Below Outlines the Relationship between Culture and Climate

\begin{tabular}{|l|l|}
\hline \multicolumn{1}{|c|}{ Culture } & \multicolumn{1}{|c|}{ Climate } \\
\hline $\begin{array}{l}\text { School culture deals with systems, rituals } \\
\text { and myth held by a group of people and } \\
\text { is abstract. }\end{array}$ & $\begin{array}{l}\text { School climate deals with the perception } \\
\text { held by school's personnel for enduring } \\
\text { the quality of the environment that they } \\
\text { live in either positive or a negative one } \\
\text { and is concert. }\end{array}$ \\
\hline $\begin{array}{l}\text { It concerns with customs, values and } \\
\text { believe systems. Such includes the } \\
\text { school's mission statement. }\end{array}$ & $\begin{array}{l}\text { It concerns how the school personnel see } \\
\text { and feel their working environment. }\end{array}$ \\
$\begin{array}{l}\text { Researchers within the field of education } \\
\text { prefer to use the qualitative and } \\
\text { ethnographic methods to study school } \\
\text { cultural norms and their impacts. }\end{array}$ & $\begin{array}{l}\text { Researchers within the field of education } \\
\text { climate to establish the perceived } \\
\text { behavior of students, teachers, parents, } \\
\text { principals in school's environment. }\end{array}$ \\
\hline $\begin{array}{l}\text { It is deep rooted in the school's norms. } \\
\text { it is perceived in the activities and } \\
\text { behaviors of school's members. }\end{array}$ \\
\hline
\end{tabular}

Adapted from (Hargreaves, 1995; Hoy, 1990)

In conclusion, the concepts school culture and climate - including the positive belief systems, customs, values and norms as well as a good working environment - have the potential to support students' learning and wellbeing (Hargreaves, 1995; Hoy, 1990). It is clear that implementing the key elements outlined above will require the dynamic influence of effective leadership to inspire the shared vision of the organisation (Hargreaves, 1995). In the following section, aspects of such leadership are explored 


\subsection{Leadership}

Evidence from multiple studies has shown importance of leadership, especially school leadership on student learning, performance, and achievement (Day, \& Sammons, 2013; Fullan, 2007; Leithwood, Harris \& Hopkins, 2008). This together with other factors can impact the ability and capacity of students to learn. This section on leadership has been divided into five parts. The first part provides an overview of the concept of leadership, especially a detailed examination of leadership and management. In the second part, the focus is on processes that foster a culture of change. The third part addresses why some leaders fail and others succeed in leading a culture of change. This is followed by a model of successful school leadership, and the concluding section examines a model of how successful leaders impact their students' success.

\subsubsection{Overview}

There is enough evidence in the literature to confirm that leadership and management roles in organisation are vital because successes or failures of the organisation depend on the know-how of the leaders and managers (Day, \& Sammons, 2013; Fullan, 2007). For this reason, over the years, organisational improvement researchers have developed keen interest in identifying leadership and management practices that foster innovations and efficiency in the work-place (Day, \& Sammons, 2013; Fullan, 2007; Leithwood, Harris \& Hopkins, 2008).

It has been suggested that a good leader changes an organisation while a great leader changes people (Hoerr, 2005). Since people are at the centre of every organisation, the role of the leader is significant in both nurturing and challenging them through creating conducive culture and climate within the organisation and beyond that may help them grow and develop (Fullan, 2007).

Due to the crucial nature of these two concepts, leadership and management, academicians, leaders, and managers in trying to define these concepts tend to have used them interchangeably (Day, \& Sammons, 2013). However, some international leadership and management literature has established a distinction between these two constructs, leadership and management (Day, \& Sammons, 2013; Fullan, 2007; Hoerr, 2005). One of the distinctions between leadership and management in an organisation is that leadership creates the vision, deals with people outside the organisation, and inspires 
others, whilst management executes the vision, deals with the people directly or indirectly, and maintains organisational standards (Hoerr, 2005).

Furthermore, Day and Sammons (2013) consider that leadership concerns the organisational vision, sets up strategies to accomplish the vision, including formulating plans to achieve the set goals, is responsive to numerous diverse needs and situations, links up resources to outcomes, and forecasts the long and short-term development of the organisation. Management, on the other hand, is concerned with the practices in an organisation in order to ensure that these are true reflections of the expectations of the leadership (Fullan, 2007).

Management carries out restructuring processes and strategic plans for organisational effectiveness as well as markets and promotes the organisation (Day, \& Sammons, 2013; Fullan, 2007). Lastly, the role of management is to ensure that the organisation is smoothly run (Day, \& Sammons, 2013). These hallmarks are some features of a good leader and a good manager.

There are many different definitions and explanations with regard to the concept of leadership within the educational context. Micheal Fullan, who has written extensively on organisational leadership and management, has noted that:

Nuanced leadership has curiosity about what is possible, openness to other people, sensitivity to context, and a loyalty for a better future. They see beneath the surface, enabling them to detect patterns and their consequences for the system. They connect people to their own and each other's humanity. They don't lead, they teach. They have an instinct for orchestration. They are humble in the face of challenges for the group to be successful and proud to celebrate success. Above all, they are courageously and relentlessly committed to changing the system for the betterment of humanity. (Fullan, 2018, p. 112)

To throw more light on the above statement, a good leader is open, fair, and always sensitive to the environment under which he or she operates. He or she sees ahead of time, respects the dignity of his or her followers, and inspires them. Challenges are confronted with humility and boldness and also openness for criticism. Such a leader must be willing to bring a transformational change and innovation for the betterment of the whole organisation. (Northouse, 2004) 
Leadership is not a matter of solely organising people to tackle challenging situations we already know how to address, but involves supporting people to address confronting issues that have never yet been successfully solved (Fullan, 2007). This includes settng up strategies to tackle those challenging situations, motivating people, creating a mission, and building a culture of organisational improvement (Goleman, Boyatzis, \& McKee, 2002).

The following central themes run through these attempts to define leadership. They are: influence, personality perspective, goal attainment, power relationship, and processes (Northouse, 2004; Sanga \& Chu, 2009; Starratt, 2004; Yukl, 2010).

Northouse (2004) describes the role of leadership as one of being an "influencer" (Northouse, 2004, p. 3). Leadership as influence involves how leaders impact those they are leading. This "influence is the sine qua non." That is to say, without the influence of a leader, leadership does not exit (Sanga \& Chu, 2009). From a personality point of view leadership is a combination of "special traits or characteristics that individuals possess that enable them to induce others to accomplish tasks" (Northouse, 2004, p. 2). This type of leadership sometimes occurs in groups as seen in the ability of an individual to influence a group of individuals who have a common vision (Bolman \& Deal, 2013; Yukl, 2010).

Leadership can be seen as goal driven. It involves the leader helping a group of people to achieve their goals and meet their needs and aspirations (Northouse, 2004; Sanga \& Chu, 2009). Such leaders advance the productivity of a group by encouraging every single member in that group to be more effective in order to achieve the common goals (Hoerr, 2005). They communicate clearly and frequently, as well as listen to others (Northouse, 2004). To listen does not necessarily mean the leader is sdeviating from the set goals or his or her roles, nor abdicating from the responsibility accorded to her or him within the organisation (Hoerr, 2005). Rather, listening involves incorporating ideas and talents from others to help shape the collectively shared vision of the organisation (Hoerr, 2005; Yukl, 2010).

Similarly, recognising leadership as reflecting power relations involves acknowledgement of the power relationships that exist between the rulers and the followers (Yukl, 2010). Finally, leadership as a process involves a transactional event 
that happens between the followers and the leader as they come into contact in an organisation (Yukl, 2010). Under this form of leadership, any member of the organisation can become a leader (Northouse, 2004). Leadership is not restricted to a certain group of people or certain members in the society (Northouse, 2004; Yukl, 2010). .

A difficulty faced by leaders is the demands placed upon them to solve numerous interconnected problems in the society, many of which seem not to have clear-cut solutions (Day, \& Sammons, 2013; Fullan, 2007; Hoerr, 2005). This points to the need for leaders to facilitate a culture of change within their organisation that will enable such solutions to be sought and enacted on a collective basis.

\subsubsection{Leading a culture of change}

Leadership and change are two key constructs within any organisation (Fullan, 2007). As such, leading a culture of change requires of the leadership an applicable knowledge base, visionary ideas, and effective strategies in order to confront the complex challenges faced by the organisation (Northouse, 2004). In this context, Fullan (2007) has identified a framework for effective leaders with a transformational agenda with regard to implementing a culture of change within their organisation. The five components of this framework are: moral purpose; understanding change; relationship building; knowledge creation and sharing; and finally coherence making.

With regard to moral purpose or acting as moral agents, leaders must have a mind-set focussed on making a positive difference in the lives of the organisation, including the workers, the work culture, and the climate (Fullan, 2007). To be effective as a leader, he or she must have or work to improve his or her moral purpose because a leader is a visionary as well as a role model to the people he or she leads (Northouse, 2004). "Moral purpose" relates to both aims and the processes to realise these. Leaders with such qualities are authentic in upholding and modelling these moral qualities. It cannot merely be stated in a mission statement, but should be supported by a strategic plan for its full realisation (Fullan, 2007).

Leadership, if it is to be more effective in an organisation, has to be explicit in making a positive difference in the lives of the people, and also adopting measures that energise the people to resolve obstacles confronting them (Yukl, 2010). Such a leader must "walk the talk" by modelling an ethic of care, trust, love, fairness, honesty, and sincerity as 
cardinal principles to guide his or her conduct and actions in the organisation and beyond (Day, \& Sammons, 2013). Additionally, such a leader must be held accountable and ultimately be measured by the level to which he or she awakens both intrinsic and extrinsic commitments of his or her people (Northouse, 2004). Such a leader must forge good interactions, mutual trust, and common purpose among the group (Fullan, 2007).

It is important that the leader must understand the change process. Furthermore, this objective of generating positive change must be understood by all persons involved, especially those people whom this change may impact the most (Northouse, 2004). This may reduce potential fear and panic associated through a change process (Fullan, 2007). Employees fear of losing their jobs during this process may lead to resistance to the change (Bolman \& Deal, 2013). However, assurance that the change is coming will be of benefit to them and support with the process may reduce this resistance (Bolman \& Deal, 2013; Fullan, 2007). As Fullan noted, moral purpose without understanding of change may lead to "moral martyrdom" (Fullan, 2007, p. 5). Not withstanding, leaders who are willing and able to facilitate a shared commitment to a particular moral purpose may see greater successful outcomes including discovering deeper moral purpose in promoting efficiency of the organisation (Fullan, 2007; Northouse, 2004).

The third factor associated with successful culture of change initiatives is how various relationships within and beyond organisations are improved (Fullan, 2007). Organisational improvement is likely to occur when various relationships are strengthened and may become worse when there are loose relationships (Fullan, 2007; Goleman, Boyatzis, \& McKee, 2002). For this reason, a great leader with a transformational agenda must serve as a bridge that fosters relationship-building, especially in an environment where members are different than their own (Bolman \& Deal, 2013). The leader can employ purposeful interaction and problem solving to achieve the organisational goals (Fullan, 2007).

Fourthly, knowledge creation and sharing both work in tandem with the three themes discussed above (Fuda, 2013). In a successful organisation, leaders and members are committed to generating and sharing information both within the organisation and beyond (Fullan, 2007). These practices serve to improve communication, build trust, and promote organisational efficiency (Bolman \& Deal, 2013). People are unlikely to voluntarily share knowledge unless they feel some moral commitment to share it freely and also may not 
share their understandings unless there is a culture of sharing at the work-place (Northouse, 2004). Therefore, it is incumbent on a leader who wants organisational improvement to promote a culture of sharing amongst and between organisational members (Yukl, 2010). Turning this information to knowledge requires relationshipbuilding between the leader and organisational members (Fullan, 2007).

Finally, an effective leader may be able to advance the cause of the organisaion if there is coherence in persuing the moral purpose, understanding the change, developing relationships, and encouraging knowledge sharing within the organisation (Fullan, 2007). These factors may work effectively where there is coherence in the leader's execution backed by tireless energy, enthusiasm, a "can do" spirit, as well as knowledge and skill to use various leadership styles in a given situation (Fuda, 2013). From here leads to the discussion of these styles, and their merits and weaknesses in promoting organisation effeciency.

Evidence in the literature appears to indicate that variability in leadership styles is a consideration with regard to the implementation of effective change towards organisational improvement (Fullan, 2007; Goleman, Boyatzis, \& McKee, 2002; Northouse, 2004). It has been suggested that leaders who exhibit expertise in the following leadership styles may generate the best climate to improve organisational outcomes: authoritative, democratic, coaching, and affiliative (Goleman, Boyatzis, \& McKee, 2002).

An authoritative leadership style is reliably concerned with motivating a group to reach the ultimate set goals of the organisation (Peltz, 2020). This style works well when the members in an organisation are energised toward the goals at the work environment and beyond (Fullan, 2007). Such a leader inspires and drives organisational members towards realisation of the vision because he or she is considered to have expertise to contribute to that particular field (Northouse, 2004). The authoritative leader leads the people by making sure that each member within the group understands the desired organisational outcomes (Yukl, 2010). The standards to achieve the vision are made clear to organisational members, including rewards and sanctions (Reid, 2020). This leader exhibits an ethic of care, trust, and empathy for others and knows best how to deal with the emotions of the people he or she leads (Northouse, 2004). This type of leadership 
style is suitable for many situations, especially when an organisation is changing its old ways to embrace innovations over a period of time (Goleman, Boyatzis, \& McKee, 2002).

Despite the above advantantages of the authoritative leadership, there are several disadvantages of using this leadership style. Firstly, this leadership style fails to function well and becomes ineffective when the leader is working with a team who are more expert and knowledgeable than he or she (Peltz, 2020). Under this situation, the authority of the leader becomes questionable and out of touch (Northouse, 2004). A second limitation is that when the authority of the leader becomes overbearing due to his or her ineptitude, it may also diminish the collective spirit of the team that he or she leads, thereby affecting the organisation in a negative way (Goleman, Boyatzis, \& McKee, 2001).

There is considerable evidence in the literature that a democratic leadership style builds consensus, via the leader making sure that individuals or groups share their views or thoughts freely in decision-making in the organisation (Goleman, Boyatzis, \& McKee, 2001). In this mode, members are encouraged by leadership to have their say in decisions, and thereby affect the way they do their work (Yukl, 2010). In this democratic paradigm, individuals are given freedom to operate and are also accountable and responsible for their actions and inactions (Northouse, 2004). The leader keeps the spirit of the organisational morale high and listens to all concerns from members, addressing these accordingly (Reid, 2020). Lastly, because setting the organisational goals is always done in collaboration with members, a democratic leadership style appears to be more effective and realistic because members can reflectively evaluate what they have been keen to achieve in terms of which goals have been achieved, and why some may not yet have been realised (Goleman, Boyatzis, \& McKee, 2002).

A democratic leadership style has several advantages and disadvantages in an organisation. Advantages are, firstly, that democratic leadership provides an avenue for consensus building where various views from organisational members are articulated freely in the decision-making process (Goleman, Boyatzis, \& McKee, 2002). Secondly, it makes organisational members accountable and responsible for their own actions and inactions (Oginde, 2020). Finally, the democratic approach is ideal in a situation where a leader is uncertain about the best direction to take and needs some form of ideas and guidance from the organisational members, recognising the individual sets of knowledge and expertise that each can bring to the decision-making process (Northouse, 2004). 
The disadvantages include, firstly, that a democratic leadership style may lead to needless debate in an organisation during a decision-making process (Yukl, 2010). This may spark conflict when ideas are contested during meetings (Oginde, 2020). Lastly, some people may not be in a position to offer well-informed contributions, which can interfere with effective decision-making (Goleman, Boyatzis, \& McKee, 2002).

A coaching style of leadership can be effective for leading a culture of change in an organisation (Yukl, 2010). Under this process, leaders assist people to identify their unique strengths and needs, thereby aligning the organisational change process with their dreams and career aspirations (Emory, \& Peltz, 2020). A coaching leadership style has several advantages and disadvantages when used in an organisation. Such advantages include, first, it has a long term effect on improving organisational efficiency because it focuses basically on the personal development of people (Goleman, Boyatzis, \& McKee, 2001). Second, the process works well when organisational members are already aware of their shortcomings or weaknesses and are willing to improve upon them (Northouse, 2004). However, this style is considered to be time consuming. This is true because, evidence from the literature suggests that, due to their numerous tasks in modern day organisations, many leaders do not have enough time to slow down to teach people and help them to develop. (Goleman, Boyatzis, \& McKee, 2002)

Lastly, through a motivational form of leadership style, organisational members are able to establish their long term goals as well as conceptualising a roadmap to achieving them (Fuda, 2013). In this process, an agreement is reached between the leader and organisational members as to how various roles and responsibilies could help the organisational members attain these goals (Northouse, 2004). Also, adequate instructions and feedback are provided by the leaders to guide members for attaining the set goals. (Goleman, Boyatzis, \& McKee, 2001). This links up with affiliative leadership styles.

This style of leadership is a people-centered one (Goleman, Boyatzis, \& McKee, 2002). Its proponents cherish organisational members and their emotions more than the work they do or the tasks assigned to the them and the set goals (Northouse, 2004). This process is more suitable and valuable when it intends to improve harmony, morale, communication, wellbeing, and build trust among members for successful outcomes (Goleman, Boyatzis, \& McKee, 2002). 
One advantage of an affiliative leadership process is that the leader has the ability to build a culture of harmony through an effective communication (Emory, \& Peltz, 2020). This is likely to support team members to be more successful and stronger (Northouse, 2004). In spite of this, it is possible that this style can erroneously communicate the message that mediocre contributions by people within organisational teams will be tolerated (Boyd, 2020). Furthermore, this may discourage some committed team members, thereby leading to low productivity in an organisation (Goleman, Boyatzis, \& McKee, 2002).

Evidence in the literature suggests that it is preferable to have a variety in styles of leadership within in an organisation (Fullan, 2007; Goleman, Boyatzis, \& McKee, 2002; Northouse, 2004). Such styles may be applicable depending on the situation and desirable outcomes the leader intends to achieve (Northouse, 2004). It is also likely that the most effective leaders switch from one style to another in order to acheive desirable outcomes (Goleman, Boyatzis, \& McKee, 2002).

Notwithstanding this overview of leadership styles and strategies, with these information and techniques available to our contemporary leaders, one may ask why some of our leaders fail and others succeed. The next section presents available evidence from the literature in relation to this question.

\subsubsection{Why do some leaders fail and others succeed in leading a culture of change?}

Literature in the areas of leadership and management addressing the above question has been arranged within four thematic areas. They are, firstly, the ability of the leader to see the current reality in the organisation. Secondly, there is a need to identify opportunities present and beyond. Thirdly, the leader needs the capacity to explain his or her ideas to attract or convince followers, and finally, to implement changes in the organisation (Fullan, 2007; Fuda, 2013; Goleman, Boyatzis, \& McKee, 2002; Thornton, 2011).

Thornton (2011) posits that a successful leader always see the big picture of the organisation. That means getting a broader perspective and understanding of the current situation of organisation. Challenges arising for the organisation are squarely addressed immediately they arise and the leader desists from offering superficial praise (Fuda, 2013). A realistic view of the organisation is presented, supported with facts so as to find the best possible solution (Goleman, Boyatzis, \& McKee, 2002). On the contrary, leaders 
who are not able to point out organisational realities and solve them because of fear, personal ego, and bias and who listen selectively are likely to be less successful (Thornton, 2011).

It has been suggested that great leaders see opportunities while others merely recognise and follow the status quo (Day, \& Sammons, 2013). Successful leaders have to the skills to connect organisational "dots"; to brainstorm and scan for new ideas that will move the organisation forward (Thornton, 2011). In applying their cognitive abilities to brainstorming these possibilities, they utilise their creative thinking from which may arise new possibilities that will improve the organisational work efficiency, thereby satisfying human needs and wants (Fuda, 2013; Thornton, 2011). On the other hand, their unsuccessful counterparts lack the motivation to create or to look for new opportunities and always stick to their old ways of doing things (Fullan, 2007). This happens because they may be afraid to take any risk, fearing that they will not succeed (Goleman, Boyatzis, \& McKee, 2002).

Whilst having ideas is one thing, the ability to communicate those ideas to members in an organisation is another (Northouse, 2004). Therefore, effective leaders communicate their vision and ideas in simple and clear terms (Thornton, 2011). It is important that those ideas are reasonable and convincing so that members may be able to act upon them to improve work efficiency (Fuda, 2013). Such leaders explain the importance of their actions thereby using motivation to drive members along (Goleman, Boyatzis, \& McKee, 2002). On the other hand, a lack of clarity in terms of convincing organisational members or conveying messages to members about how the work must be done may cause some leaders to be unsuccessful (Thornton, 2011). The inability of the leader to identify actionable plans and steps for organisational members to take may also cause some leaders to fail (Gurr, 2017).

Literature also suggests that some leaders are efficient and effective in communicating their vision and ideas, yet fail during their execution process (Goleman, Boyatzis, \& McKee, 2002; Thornton, 2011). Implementing change requires selfless efforts and commitment from leaders (Fuda, 2013). Also, external factors and commitments such as politics, state institutions, and pressure form the wider society also have direct and indirect impacts on the success of the organisation (Fuda, 2013; Fullan, 2007; Northouse, 
2004). These factors may undermine a leader's ability to effectively initiate any meaningful change in the organisation (Fuda, 2013; Fullan, 2007).

The following section considers the school as an organisation in which principals, heads of departments, and teachers, all serve as leaders within their own domains.

\subsubsection{School leadership}

The notion that schools can impact the wellbeing of students is of interest for researchers, academicians, parents, and many others (Day, \& Sammons, 2013). Educational leaders and managers, including principals and teachers, are under considerable pressure from society to show their commitment and contributions to the success of the learning outcomes of their students (Day, \& Sammons, 2013; Leithwood, Harris, \& Hopkins 2008).

For this reason, the roles of these leaders have become vital because without effective leadership, the goal of the school cannot be achieved to the fullest (Cowie \& Crawford, 2007; Hollander \& Won, 1978; Kimball, 2011; Smith \& Peterson, 1988). Also, without these leaders in our schools, the vision, directing, staffing, evaluation, and many other aspects which require leadership, will fall short in schools (Gurr, 2015).

The International Successful School Principalship Project (ISSPP), has been researching various aspects of successful school leadership since 2001. This body describes a successful school as one which focuses on educating students, including promoting good values, such as fairness, compassion, love, and integrating life-long learning (Moral, Martín-Romera, Martínez-Valdivia, \& Olmo-Extremera, 2018). Factors identified include fostering citizenship; patriotism; and personal, spiritual, and emotional growth and competencies, as well as enhancing academic progress and development for students (Day, \& Sammons, 2013; Gurr, 2015; Leithwood, Harris \& Hopkins, 2008).

Research indicates that schools' success depends on a high level of competence and vision of the leaders in carrying out their duties, especially the role of the principal (Dou et al., 2016). This is because the principal guides the school's actors - teachers, nonteaching staff, students, and parents - towards the agreed vision and how it can be achieved (Kimball, 2011; Supovitz, Sirinides, \& May, 2009). 
Due to the crucial role of the school leaders, the ISSPP, has developed a model which synthesises aspects regarding the nature of successful school and principal leadership across the globe (Day, \& Sammons, 2013; Gurr, 2015; Leithwood, Harris \& Hopkins, 2008). The model was deveoped by soliciting various views, ideas, experiences, and opinions from educational leaders from thirteen countries (Moral, Martín-Romera, Martínez-Valdivia, \& Olmo-Extremera, 2018). These countries include, for example Australia, New Zealand, Canada, China, Norway, and Sweden (Gurr, 2015).

A number of factors were identified by the ISSPP project as traits of successful school leadership (Gurr, 2015). They include, high expectations, a pragmatic approach, leadership distribution, core leadership practices, heroic leadership, trust and respect, continuous learning, context sensitivity, personal resources, and capacity development (Gurr, 2015; Leithwood, Harris, \& Hopkins, 2008).

\subsubsection{A model for successful school leadership}

It has been suggested that the model (See Figure 5) is suitable to all leadership and management functions of schools throughout the globe, for school leders who want to enhance their student' learning, performance, and success (Day \& Sammons, 2013; Gurr, 2015; Leithwood, Harris, \& Hopkins, 2008). 
Figure 5: The Model for Successful School Leadership

See the diagrammatic representation below for this effect:

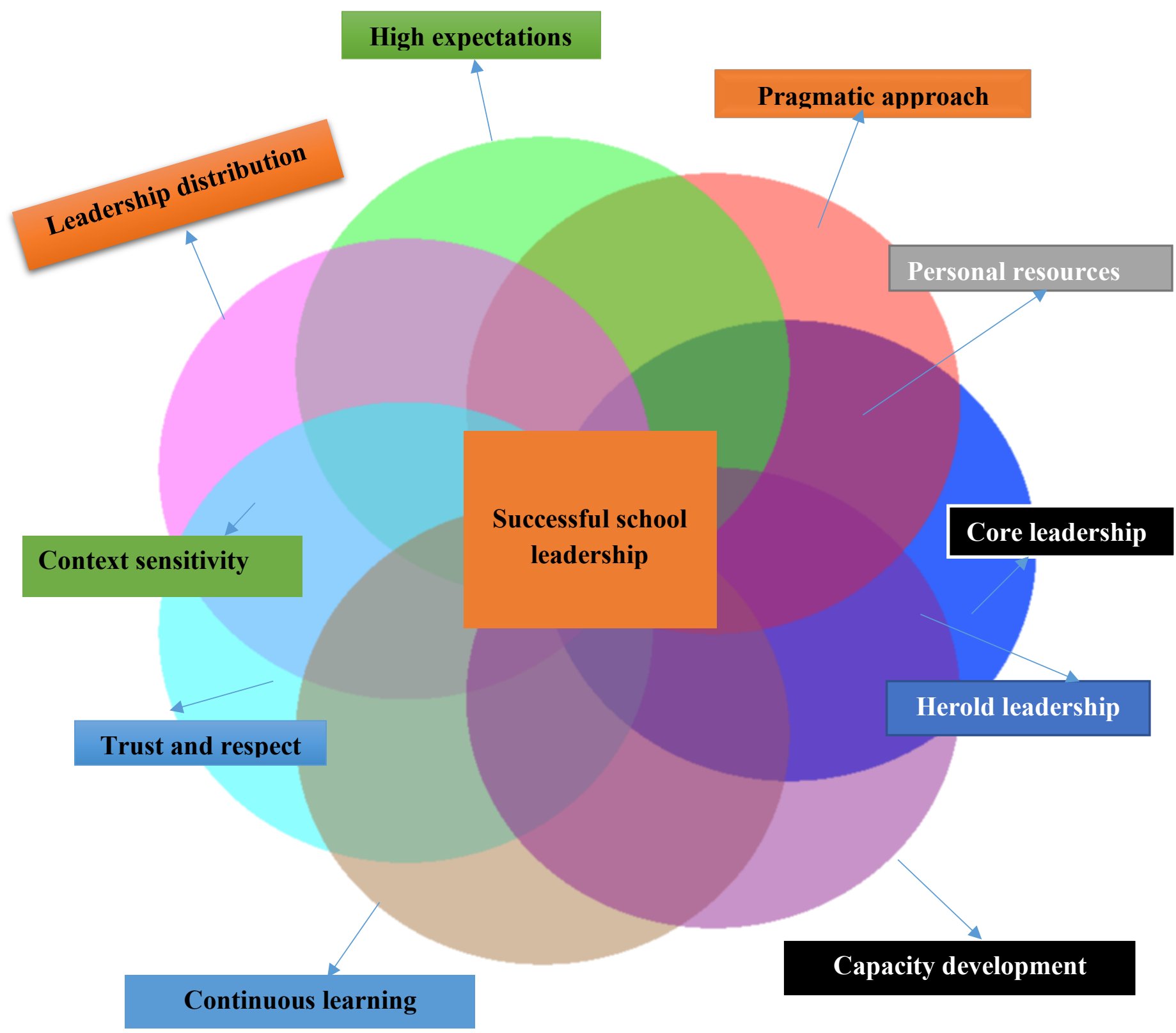

Adapted from (Gurr, 2015) 
In the diagram above it is important to understand that the high expectations are evident at both collective and individualised levels within the school (Gurr, 2015). This commitment is consistently reinforced and exhibited in the organisational level of the principal (Leithwood, Harris, \& Hopkins, 2008). As the expectations within the school rise, accountability demands increase, and collegiality becomes necessary as an integral tool for developing teachers' capacity (Hoerr, 2005). At the individualised level, the principal demonstrates helping individuals to do their best within the school to enhance the learning process (Day \& Sammons, 2013),

On the issue of pragmatism, a successful principal uses no single leadership approach in satisfying every situation at the school level. What he or she does is to look at the context of the situation and employ a particular leadership style that he or she deems fit (Hoerr, 2005). This is so because leadership acts a catalyst to various networks within the organisation and, without it, many good things are unlikely to function effectively (Leithwood, Harris, \& Hopkins, 2008). Therefore, a successful principal combines various leadership styles depending on the situation and is not dogmaticabout employing only one style (Moral, Martín-Romera, Martínez-Valdivia, \& Olmo-Extremera, 2018).

There is enough evidence in the international literature that the dominant leadership styles often used at school by principals are transformational and instructional depending on the situation (Day \& Sammons, 2013; Hoerr, 2005). To this effect, the principal's aim here is to improve students' learning outcomes, so he or she develops an approach to leadership to lead the community successfully (Hoerr, 2005). Under this transformational style, the principal uses motivational tools, supports, and many others to develop the staff to enhance students, learning, performance, and success (Moral, Martín-Romera, Martínez-Valdivia, \& Olmo-Extremera, 2018). Also, a successful principal uses these approaches to ensure that the curriculum, pedagogy, and assessment are improved to be student-centered rather than teacher-centered (Day, \& Sammons, 2013), and to evelop networks with others schools, stakeholders, and the community under which the school operates, thus enhancing teaching and learning practices for students (Hoerr, 2005).

ISSPP reports that successful leaders openly say that their success is due to a shared leadership style they use at school level (Day, \& Sammons, 2013) and has a tremendous impact on learning outcomes of their students (Hoerr, 2005). This style of leadership enhances academic improvement by ensuring accountability and responsibility to other 
subunits within the school level (Leithwood, Harris, \& Hopkins, 2008). It promotes democratic education to enhance learning which is the prime focus of a school (Moral, Martín-Romera, Martínez-Valdivia, \& Olmo-Extremera, 2018). For example, at the departmental levels of schools, teachers have the right to appoint or elect their Heads of Department (HODs), to facilitate the smooth running of their duties (Day \& Sammons, 2013). More so, at the teachers' level, they have the privilege to appoint or elect their team leaders and many other positions (Hoerr, 2005). This aspect of decentralisation within various units of the school gives a say to every individual to contribute to students' learning processes. Again, it encourages division of labor and specialisation to improve students' learning outcomes (Gurr, 2017).

Evidence in the literature affirms that personal qualities, beliefs, and values exhibited by leaders may contribute to organisational success (Gurr, 2015; Hoerr, 2005). These qualities, beliefs, and values include optimistism, persistence, trust, tolerance, empathy, honesty, openness, and respectfulness and many others (Gurr, 2015). Successful principals always have these traits because they have strong tenacity to improve working relations (Gurr, 2015).

Successful principals display a high level of ethics of care and empathy for others in the work environment (Northouse, 2004). They value and appreciate the opinions of others (Leithwood, Harris, \& Hopkins, 2008), and they also exhibit democratic values such as freedom of speech and expression, responsibility and accountability, and collective care in order to build trust among members (Gurr, 2015). They view organisational hinderances as challenges to be overcome (Day \& Sammons, 2013) and use a transformational leadership style as a tool to develop others (Thornton, 2011). In short, they are motivated to improve the learning environment at all times in the school (Moral, Martín-Romera, Martínez-Valdivia, \& Olmo-Extremera, 2018). More so, they walk the talk and have the courage to do what is right to enhance their students' total wellbeing and development (Day \& Sammons, 2013).

Apart from being a highly moral upright leader, a successful principal is culturally sensitive to the context within which he or she works (Leithwood, Harris, \& Hopkins, 2008). For example, issues concerning history, culture, customs, traditions, and norms must be given attention in order to improve the learning environment (Fullan, 2007). To make this a reality, the principal must demonstrate a high level of cultural competence in 
leading the school (Day \& Sammons, 2013). This has becomes necessary due to the complex nature of the society (Gurr, 2015).

By demonstrating understanding of the context within which he or she operates optimises the principal's chances of success (Day \& Sammons, 2013). This understanding includes improving working relations with different members and cultures within the school (Hoy, 1990), and also resorting to mediation and moderation as tools to address mixed feelings among and between organisational members to enhance the working climate (Fullan, 2007; Leithwood, Harris, \& Hopkins, 2008).

There is enough evidence to the effect that the core practices of a school leader include setting the vision and direction, developing others, leading a culture of change, and improving teaching and learning (Day \& Sammons, 2013; Gurr, 2015; Leithwood, Harris $\&$ Hopkins, 2008). These will work effectively if the leader understands and appreciates the cultural context and the working climate within which he or she works (Day \& Sammons, 2013). By appreciating this, the principal adopts varieties leadership styles to discharge their duties and is not labelled or seen as always using one particular style (Gurr, 2015).

In addition, ISSPP has gone further to identify extra roles of a successful principals (Day $\&$ Sammons, 2013). These include articulating ethical values and standards of the school, developing trust among members and beyond, developing a safe and secure environment conducive for learning, promoting equity and justice, and many others (Gurr, 2017).

In another development, these core practices above will work effectively where there is evidence of heroic leadership (Gurr, 2015; Leithwood, Harris \& Hopkins, 2008). Under this, a successful principal questions and challenges the status quo and provides alternatives to look at, thereby empowering others to see what he or she has seen to enhance teaching and learning outcomes (Hoerr, 2005). Such a leader always seeks opportunities and best practices that will improve learning outcomes for students (Day \& Sammons, 2013). The leader uses collaborative tools to align all efforts of members to a shared vision of the school (Gurr, 2015). Ensuring this shared vision, heroic principalship acts as a custodian to the vision and champions it to its fullest (Day \& Sammons, 2013).

Leithwood, Harris, and Hopkins, (2008) affirm that championing this shared vision at school will lead to a high level of trust and respect among members. International 
leadership and management literature reports that one of the characteristics of a successful principal is the degree to which he or she is respected and trusted by the community of learning he or she leads (Day \& Sammons, 2013; Gurr, 2015; Leithwood, Harris, and Hopkins, 2008).

Working with integrity as a leader includes walking the talk, being firm and fair, transparent, accountable and responsible, involving as many people as possible in decision-making processes, serving and modelling good values and practices, and more (Day \& Sammons, 2013; Leithwood, Harris and Hopkins, 2008). A principal acting with these values may win the hearts of the followers (Hoerr, 2005) and will receive the needed respect and trust to carry out changes (Fullan, 2007). The trust and respect accorded to the principal may improve working relations in the school (Townsend, 2009). Evidence in the international literature suggests that, with the establishment of such trust and respect, any top down decision-making may receive less resistance and will enhance teaching and learning processes in the school (Day, \& Sammons, 2013).

Successful school leaders focus on developing people and are people-centred. They try to bring the best out in them (Gurr, 2015; Leithwood, Harris, \& Hopkins, 2008). Their ultimate satisfaction is to see how best their students improve and develop to fit into the wider society (Gurr, 2015). Also, they are concerned with how to develop personnel to improve learning, especially, teaching and non-teaching staff (Day \& Sammons, 2013). This is achieved through motivating and equiping personnel with adequate knowledge, skills, and resources needed to enhance their teaching and learning to improve students' learning outcomes (Leithwood, Harris, \& Hopkins). Equipping personnel includes organising capacity building workshops, motivating their commitment levels, and developing their resilience to apply their skills and knowledge in any given situation (Day \& Sammons, 2013). Also, individual or group support has to be given to personnel to foster their intellectual stimulation to carry out their duties to enhance learning outcomes of their students (Hoerr, 2005). This support includes modelling appropriate values and behaviours that fit deeply to foster this intellectual stimulation (Fullan, 2007).

Successful school leaders focus on lifelong learning among their students and personnel (Day \& Sammons, 2013; Gurr, 2015; Leithwood, Harris, \& Hopkins, 2008;). Such leaders are restless and always in search of new ideas, inluding new ways of doing things and opportunities to enhance personnel development as well as students' learning outputs 
(Gurr, 2015). This is so because knowledge is socially contructed; therefore the ability of leaders to learn from each other through interacting among themselves, and sharing experiences, ideas, and opinions may impact learning outcomes of their students (Day \& Sammons, 2013). This lifelong learning is always carried out through both formal and informal professional developments (Gurr, 2015). These processes include continuous mentoring programmes, conferences, workshops, in-service programmes, and seminars that provide opportunities for personnel to update their knowledge and skills (Hoerr, 2005).

The purpose of such ongoing professional learning is to benefit all members of the school, including, principals, teachers, non-teaching staff, and students (Day \& Sammons, 2013). Many factors come into play including building positive relationships among the school personnel and the wider society to enhance learning (Hoerr, 2005).

This again places the onus on the principal's ability to balance academic work with high expectations, combined with ethics of care, responsibility, accountability, and social justice in order to foster students' learning (Fullan, 2007). It may also require constant engagement of stakeholders to arrive at consensus in relation to things beneficial and the pathway the school should take to improve learning outcomes (Hoerr, 2005).

The principal has oversight of organising such professional development programmes for personnel, and combining instructional and transformational practices in order to make changes in schools which are all a means to sustain this success (Gurr, 2015; Hoerr, 2005; Leithwood, Harris, \& Hopkins, 2008).

In conclusion, it is evident in the literature that successful school leaders need to perform some basic functions at school. First, the school's leaders install in the staff the vision that all students could learn with appropriate learning support. Similarly, teachers who are mostly close to the students in the classroom help in promoting the vision when guiding the learning processes (Aitken \& Higgs, 2010). Also, to create a hospitable climate is the duty of the school's personnel, especially the principal and the teachers (Kearney et al., 2018; Wallace, 2011). This includes building good relationships and providing emotional, physical, psychological, and environmental safety for students within and outside the school to enhance learning (Cobb, 2014). The leaders, especially 
the teachers, motivate the students to learn, respect one another, and to care for the school property and environment (Sebastian, Allensworth, \& Huang, 2016; Wallace, 2011).

Cultivation of leadership in others within the school setup is also another cardinal feature of the school's leaders (Hollander \& Won, 1978). The leader's role as a transformational agent is to influence and transform individuals within the school (Leithwood \& Jantzi, 2005). Such leaders are very much concerned with values, morals, standards, ethics of care, justice, trust, and critique, in order to drive the school community to accomplish the school's vision which is ultimately focussed on improving students' growth, wellbeing and learning (Sebastian et al., 2016; Starratt, 2004). It is important that transformational leaders distribute leadership within the wider teaching collective (Sebastian et al., 2016).

Transformational leaders make leadership in the school a shared enterprise by assigning various roles to the departmental heads, teachers, students, and, if possible, parents (Heck \& Hallinger, 2009; Wallace, 2011). They encourage and grant teachers self-autonomy to carry out their duties as well as to learn from one another (Dou et al., 2016). In order for the leadership to improve learning in the school, teachers must also demonstrate leadership in guiding students to be accountable, responsible, and develop learning autonomy (Belcher, 2017; Dou et al., 2016). Leaders must be the source of light to the students by living an exemplary life in the classroom and beyond (Belcher, 2017). Teachers must be fair and firm in guiding the learning process as well as supporting students of all abilities and backgrounds to learn (Sebastian et al., 2016).

To this end it is important that there is professional development for teachers, research funding, and resources such as projectors, computers, labs, studios, and well-equipped libraries to facilitate students' learning (Dou et al., 2016; Wallace, 2011) as a lack of such may affect the learning process (Leithwood, Harris, \& Hopkins, 2008).

In shaping the vision for the school, a school's leaders and administrators must manage students' feedback, achievement data, and other processes so as to give timely guidance and counselling (Gurr, 2015). This is because students' data are vital sources of information to assess in order to keep track the progress of every student (Sebastian et al., 2016). Data may include students' assessment reports, examination records, project reports, and portfolios (Day \& Sammons, 2013). Analysis of these documents and resources enables school leaders to plan early interventional measures to support 
students' learning (Sebastian et al., 2016; Wallace, 2011). The following section considers what successful school leaders can do to improve success for all students.

\subsubsection{A model of how successful school leaders impact students' success}

In positive school cultures, there is a strong sense of community, empathy, "we-feeling", trust, and collaboration held by personnel that is enacted beyond the symbolic mission statement hanging on the walls (Deal \& Peterson, 2016; Hargreaves, 1995; Schneider et al., 2013). However, in a toxic school culture, the purpose may instead be self-serving and focused on individual achievements rather than the collective interests (Peterson \& Deal, 2002; Prosser, 1999).

Research has identified that a successful school focuses on educating students by inculcating values such as fairness, integrity, love, compassion, and life-long learning. It also includes promoting citizenship education, and social, economic, and personal competencies as well as improving the academic progress of its students as a contribution to the wider society (Day \& Sammons, 2013; Fullan \& Langworthy, 2014; Gurr, 2015; Hoerr, 2005; Leithwood, Harris, \& Hopkins, 2008)

Many questions have been raised regarding what factors contribute to student success and this has been consistently a feature in international research projects, including that of the ISSPP (Day \& Sammons, 2013; Fullan, \& Langworthy, 2014; Gurr, 2015; Leithwood, Sun, \& Pollock, 2017; Townsend, \& Bayetto, 2020). Fullan and Langworthy (2014) consider that students' success can only be achieved when students are able to transfer what they have learned to different situations that they may encounter.

To achieve this, the school leaders have a critical role to play (Day \& Sammons, 2013). They must demonstrate their understanding of what has been termed as the " $6 \mathrm{Cs}$ ". These are the Character of education, Citizenship, Collaboration, Communication, Creativity and Critical thinking (Fullan, Hill, \& Rincón-Gallardo 2017). Character of education involves leadership understanding the basic purpose and fuctions of education, including academic content and matters arising within the contemporary world which have direct impact on students' learning and success. Citizenship refers to the ability of school leaders to immerse themselves fully in addressing issues, often cross-cultural nature, in the school and to enhance learning. Collaboration involves integrating academic, social, 
and personal capabilities of all actors within the school, giving priority to those that enhance students' learning and development. This includes active involvement of students in all decision-making processes of the school and ensuring that learning is student-centred (Day \& Sammons, 2013). Communication revolves around generating a friendly atmosphere that encourages students to speak out in the school to enhance their learning (Fullan, \& Langworthy, 2014). Under Creativity, the learning design must impact and connect to the development of our local communities, societies, and the wider world. Finally, Critical thinking involves fostering the ability of students to critically apply their learning across different situations as well as incorporating their knowledge of the use of digital technologies and its connectivities (Fullan, \& Langworthy, 2014).

Many surveys of principals and teachers reported in international journals focussing on leadership and management have used three main benchmarks to measure learning outcomes and success of students (Day \& Sammons, 2013; Fullan, \& Langworthy, 2014; Gurr, 2015; Hoerr, 2005; Leithwood, Sun, \& Pollock, 2017; Oduro, Dachi, Fertig, \& Rarieya, 2007). These include students' academic achievement, student social development skills, and student empowerment.

On the issue of students' academic achievement as a determinant of success, EduQual, a UK-based research consortium focussed on implementing education quality in low income countries, has conducted a research project in three developing countries, Ghana, Tanzania, and Pakistan. The study concluded that one of the indicators of quality and students' learning achievements and success is students' test scores on nationally standardised comparable tests of skills, behaviour, knowledge, and atitude. The study considered that standardised tests of cognitive success are predictors of students' future advancements and earnings (Oduro, Dachi, Fertig, \& Rarieya, 2007).

In contrast to this focus on standardised indicators, other research has emphasised the ability of students to use their social, economic, and personal skills in variable situations in service of societal development to be a determinant factor for success (Leithwood, Sun, \& Pollock, 2017). Similarly, the ISSPP extended the scope of student success to include the ability of students to be creative and to think critically in any given situation in order to improve their societal conditions (Day \& Sammons, 2013; Gurr, 2015). Fullan and Langworthy (2014) describe student success as including students' strength and capacity to balance competing cultural values and needs with their academic work. These 
factors are important in considering how school leaders influence their students' learning outcomes and success.

Various models have been proposed to explain ways in which school leaders can impact students' learning outcomes and success (Day, \& Sammons, 2013; Gurr, 2015; Hoerr, 2005; Leithwood, Sun, \& Pollock, 2017).

I have selected the model by Leithwood and colleagues to consider how school leaders impact students' learning outcomes and success as it contains a more in-depth explanation. Furthermore, their research involves thirteen or so countries of study in which New Zealand and Finland featured.

The four levels of this model are the Rational Path, the Emotional Path, the Organisational Path and, finally, the Family Path (Leithwood, Sun, \& Pollock, 2017). See the diagram below for these representation and explanations.

Figure 6: The Fourth Paths of School Leaders' Impact on Students' Learning

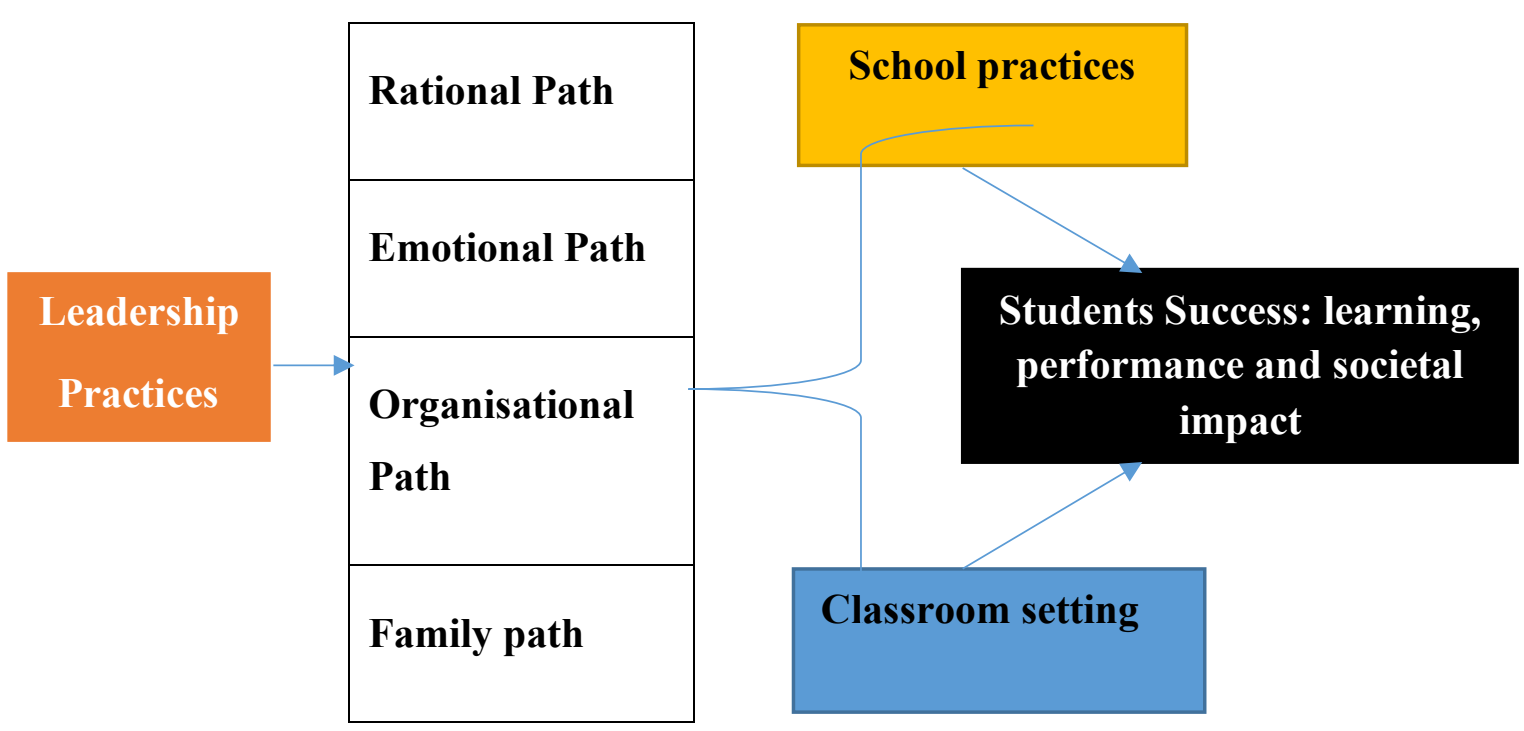

Adopted from (Leithwood, Sun, \& Pollock, 2017)

The Rational Path of this model is associated with teaching and learning practices, and how teaching and learning are organised from the leadership perspective and context (Leithwood, Sun, \& Pollock, 2017). It is rooted in the working knowledge and skills of staff members, including understanding of the curriculum and teaching and learning 
(Gurr, 2015). It consists of technology useage, the environment for conducting learning and teaching, pedagogy used and students' participation in learning, including, assessment and feedback (Shankar, 2019). It also focuses on the basic duties of teachers in the classroom and outside which enhance the learning outcomes of students (Day \& Sammons, 2013).

These aspects may require interventionary measures from school leaders for directing students learning (Fullan \& Langworthy, 2014). Such measures may include ensuring that there is a workable process for developing and monitoring the quality of teaching and learning, the assessment of students, and learning autonomy (Gurr, 2015). Furthermore, considerations include the participation of students to develop their own learning, adequate know-how of the use of modern classroom technology to enhance learning by the school staff, and a conducive climate which is adequately inviting and attractive for learning (Day \& Sammons, 2013).

New Pedagogies for Deep Learning has redefined the current roles of school and students in the following ways (Fullan \& Langworthy, 2014). Teachers must:

- Build trusting relationships with students and peer teachers and seek good mentors.

- Help students to find and build their interests and aspirations through deep learning tasks.

- Require changing learning goals, tasks, and success criteria for self and students that require creativity and the use of new knowledge.

- Develop repertoires of teaching strategies and apply a variety of different strategies to activate learning.

- Provide high quality feedback and encouragement, especially when students face challenges in learning.

- Collaborate with other teachers and leaders in researching the impact of different learning strategies on students.

- Model a proactive disposition towards learning and taking action with the new learning, and finally,

- Engage in continuous discovery and creation of digital learning tools and resource to enhance teaching and learning. (Fullan \& Langworthy, 2014, p. 13). 
The students' roles under Deep Learning to enhance their learning outcomes and success are similar to those above and include:

- Building trusting relationships with teachers and peers and seeking good mentors.

- Exploring own interests and aspirations in learning goals and tasks.

- Developing the capacity to define learning goals, tasks, and success criteria and partnering in learning process.

- Engaging in reciprocal teaching and learning from and with peers and teachers.

- Developing capacity for reflection along with perseverance to face challenges, and also providing high level feedback and encouragement to others.

- Providing feedback to peers and teachers on what is working in one's own learning and one's own progress.

- Developing intellectual attitudes and attitudinal dispositions toward creating new learning and doing things with it in the world.

- Continuously discovering and developing digital learning tools and resources to explore new content, concepts, information. and ideas (Fullan \& Langworthy, 2014, p. 13).

These, in effect, will enable students to become more efficient and independent and be in charge of their own learning process (Fullan \& Langworthy, 2014, p. 13). They may also build their confidence levels through purposeful tasks, which has the potential to enable them to make a strong difference in the world (Day \& Sammons. 2013).

The Emotional Path emphasises dispositions including passions, feelings, and the affective nature of personnel in shaping their work to enhance the ultimate aim of the school, which is learning (Leithwood, Sun, \& Pollock, 2017). Included here are the teachers' and students' commitment to learning, that teachers and students trust one another, and organisational practices that encourage a sense of belonging (Fullan \& Langworthy, 2014).

In addition, optimism, self efficacy, and resilience are vital qualities and values for school leadership to model and foster in order to initiate changes to enhance students' learning and development (Gurr, 2015). These psychological and affective resources make significant contributions to school leadership (Leithwood, Sun, \& Pollock, 2017). This optimism includes habitual expectations in confronting challenging situations as well as 
a positive mind set that can invite success (Fullan \& Langworthy, 2014). Self-efficacy here deals with the leaders' ability and capacity to perform their duties to achieve success (Tschannen-Moran, \& Gareis, 2017). They must have the confidence to feel that they can solve whatever challenges come on their way (Sun \& Leithwood, 2017).

Finally, resilience refers to the school leaders' ability to adjust or recover quickly in response to organisational misfortunes through initiating processes or leading changes in the organisation for betterment of students (Spillane, 2017). Such leaders have the zeal to bounce back from failures in the process of initiating changes and may even go beyond their previous goals set for organisational members in order to extend success in the long term (Malloy \& Leithwood, 2017).

Research indicates that a transformational approach of leadership is likely to reflect most of these values and practices (Gurr, 2015; Leithwood, Sun, \& Pollock, 2017). These values and practices help the transformational leader to be more competent, transparent, benevolent, and reliable, thereby building trust amongst and within personnel (Sun \& Leithwood, 2017). They also create a climate which may inspire others to higher levels of effort and achievement in order to enhance the learning outcomes of students (Malloy \& Leithwood, 2017).

The Organisational Path involves school structure, including the various relationships and interactions among organisational members (Leithwood, Sun, \& Pollock, 2017). It includes consideration of operational standards and procedures, development of personnel, policies, norms, cultures, and organisational values (Gurr, 2015). Also, under this level, emphasis is laid on the role of the school leaders in helping to build capacity for organisational personnel and other adults in facilitating students learning outcomes (Leithwood, Sun, \& Pollock, 2017).

Under the Organisational Path, school leaders focus much of their energies and efforts in shaping the expertise and knowledge of others to enhance students' learning outcomes (Pollock, Wang, \& Hauseman, 2017). Shaping the expertise and knowledge of personnel includes capacity building in relation to professional competence (Murphy, 2017). The emphasis here is to develop and update the professional competencies of both the teachers and non-teaching staff in order to enhance students' learning outcomes (Gurr, 2015). 
The professional development provided should ideally be inclusive of senior leaders, middle leaders, and teacher leaders, as well as student leaders if available and appropriate (Leithwood, Sun, \& Pollock, 2017). This requires adequate expertise and effort from the school principal to help develop the competencies and expertise of the participants (Day \& Sammons. 2013). The middle leadership roles here, for example, involve the heads of departments working as mentors or coaches with teachers to plan curriculum (Gurr, 2015). Reviewing each action plan and supporting other teachers, especially the newcomers to familiarise themselves in the school to enhance learning, is also important in this process (Murphy, 2017). These levels, the Rational Path, Emotional Path, and Organisational Path, may not be complete without the Family Path which links up the school and the wider society.

The Family Path deals with the external forces which have direct or indirect relationships with schools (Leithwood, Sun, \& Pollock, 2017). It includes the conditions and expectations from the students' families, the community, and wider society (Day \& Sammons. 2013).

School leaders need to respond to the direct and indirect influence of external factors in the teaching and learning processes (Fullan \& Langworthy, 2014), and to consider ways in which family factors and resources may impact learning outcomes of students (Leithwood, Sun, \& Pollock, 2017). For example, the Tasman school survey has demonstrated that school leadership can impact the home contexts of students which, in turn, can enhance the teaching and learning processes of students (Townsend, \& Bayetto, 2020).

The Family Path may have the largest amount of influence in determining the academic success of students (Day \& Sammons. 2013; Leithwood, Sun, \& Pollock, 2017; Townsend, \& Bayetto, 2020). For this reason, a successful school leader taps the expertise of parents to address particular challenges faced by students (Day \& Sammons. 2013). However, this can also become a challenge to students' learning. This may occur when the income of a student's parents is insufficient, when parents have low levels education, or are facing other challenges in their lives (Townsend, \& Bayetto, 2020) which may have negative impacts on students learning, performance and success (Leithwood, Sun, \& Pollock, 2017). 
Under the category of Deep Learning, Fullan and colleagues extend this scope to cover the wider society and macro level of change. This encompasses the formal governmental structures and systems, official agencies, business, groups, foundations, and advocacy groups as well as international bodies such as the United Nations (Fullan, Hill, \& RincónGallardo, 2017). These "pull and push" factors from outside the school have direct links to the day-to-day activities of the schools and any adverse effects may affect students' learning, performance, and success.

In conclusion, successful school leaders are able to effectively manage the various paths discussed above, which may contribute to strengthening the school's professional learning community in order to improve student outcomes. This leads to discussion of the notion of professional learning communities.

\subsection{Professional Learning Communities}

\subsubsection{Overview}

This section provides an overview of the concept of Professional Learning Communities (PLCs), followed by a detailed examination of PLC practices, and concludes by identifying eight main features that demonstrate a school's commitment to professional learning as a community.

Transformation in schools is undeniably difficult, but it is achievable in a school that tries to be more learning-driven (DuFour \& Fullan, 2013). Whilst some schools can meet the needs of their students who come from diverse socio-cultural and economic backgrounds, others struggle to do so (Easton, 2011). Despite these disparities, the demand of the society that each student learns well remains unchanged (Caine \& Caine, 2010). This requires leaders in education to adopt a range of strategies with the intention of making schools accountable, dynamic, and committed to more professional learning (DuFour, 2004).

The phrase "learning professionals" deals with the school's personnel, those certified, responsible, and accountable for leading the learning for all students (Easton, 2011). The term "learning community" also involves a group of individuals who share the same vision and convene regularly to focus on learning. In a school setting, a Professional Learning Community (PLC) involves a group of educators performing their duties with 
the aim to improve learning through a shared mission (Darling-Hammond, Wei, Andree, Richardson, \& Orphanos, 2009). These educators place students at the centre of learning (Olivier \& Huffman, 2016; Salleh, 2016).

\subsubsection{PLC practices}

Many countries have experienced gains by adopting the practices and processes of PLCs (Olivier \& Huffman, 2016; Salleh, 2016; Sun-Keung Pang et al., 2016). For example, in Singapore, a study found that PLC practices have been significant in relation to enhancing students' learning (Salleh, 2016). Similarly, in Hong Kong, it emerged that schools with strong emphasis on PLC practices have stronger student outcomes than those without (Sun-Keung Pang et al., 2016). In a district in the United States of America, PLC practices have a strong level of impact on students' learning within the district (Olivier \& Huffman, 2016). Students' learning has become the foremost priority of educational leaders working in PLCs (Stoll \& Louis, 2007). A large body of literature has characterised PLCs with many qualities (D'Ardenne et al., 2013; DuFour \& Fullan, 2013; Easton, 2011; Penner-Williams, Díaz, \& Gonzales Worthen, 2017; Vanblaere \& Devos, 2016; Wennergren \& Blossing, 2015). Stoll and Louis (2007, p. 18) report that for a school to demonstrate commitment to professional learning as a community, it must exhibit eight key traits as the means to improve students' learning and staff effectiveness. See the figure below for these key characteristics. 


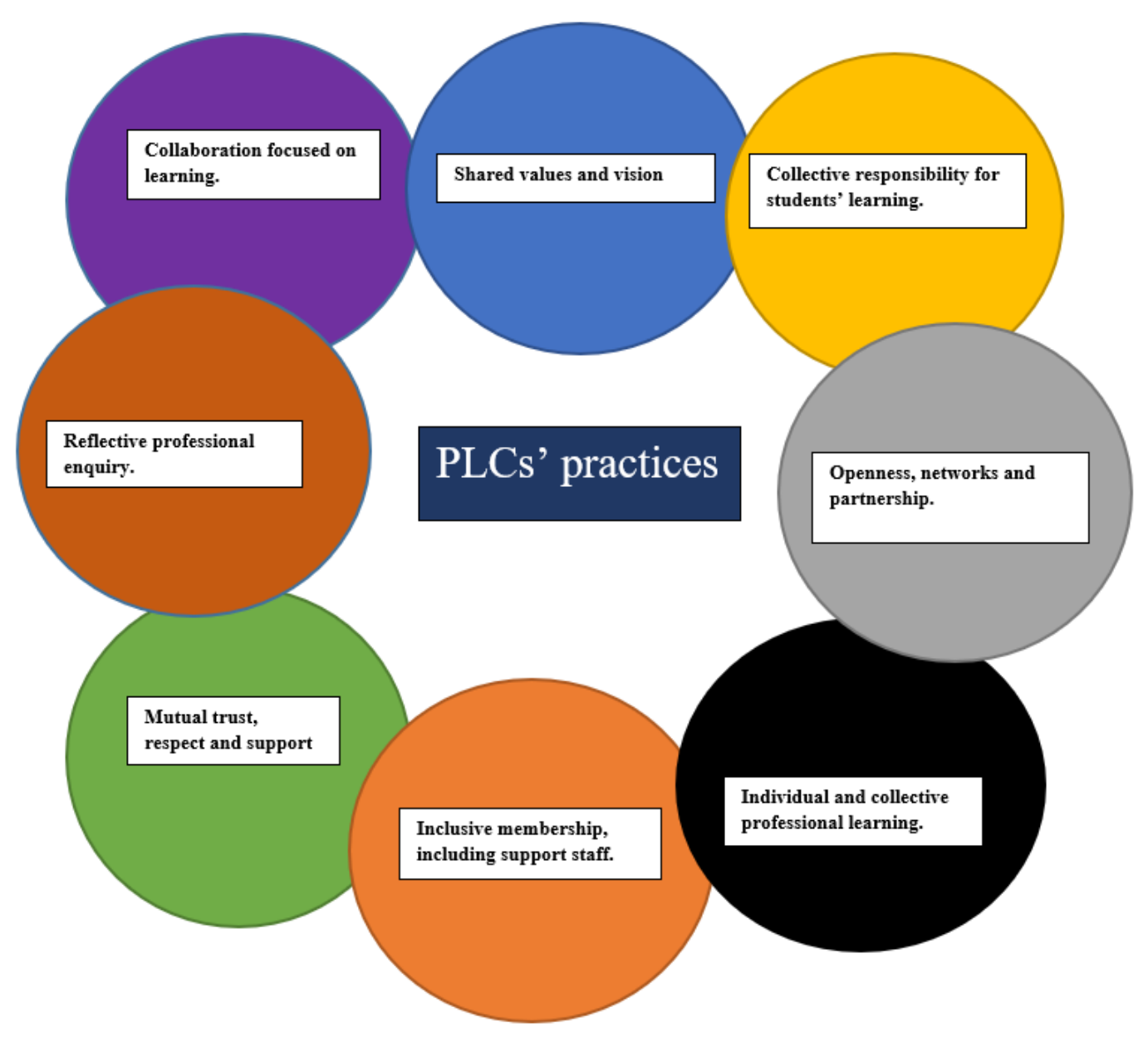

Adapted from (Stoll \& Louis, 2007)

Elaborating on the diagram above, the shared values and vision in a school will have a central focus on students' learning (DuFour \& Fullan, 2013). These shared values and vision may include a mission statement of the school, distributive leadership, and shared resources such as teaching strategies (Easton, 2011). Shared decisions on instruction and curriculum agreed during staff meetings or departmental meetings provide a clear basis for the pedagogical purpose for students' learning (Lin, Zhang, Chen, \& Lee, 2016). This helps members to be aware of and committed to the school's mission (D'Ardenne et al., 2013).

Figure 6 also indicates the importance of a collaborative culture focussed on students' learning (DuFour \& Fullan, 2013; Easton, 2011). To achieve this, school members 
constantly share teaching materials and reflect on teaching methods and practices to enhance learning (DuFour, 2004). Furthmore students' data information is shared with students' parents (Sun-Keung Pang, Wang, \& Lai-Mei Leung, 2016). This includes sharing information about students' academic success and challenges and health history in order to support his or her learning outcomes and wellbeing (Stoll \& Louis, 2007). Furthermore, collaborations including allowing students to learn among peers, and between school personnel, various relationships, and networks must be encouraged in schools with the collaborative focus on students' learning (Salleh, 2016). These learning avenues may help students to develop strong networks needed for their future career prospects (Stoll \& Louis, 2007).

A further characteristic is reflective professional enquiry (Stoll \& Louis, 2007). A joint inquiry into contemporary issues and best practices are a hallmark of a school wanting to be expand its professional learning community (Easton, 2011). This includes the ability of the school to use current data information to plan and evaluate students' learning in a more global manner (DuFour \& Fullan, 2013).

Individual and collective professional learning which is action-driven is necessary in order to identify and achieve goals (DuFour \& Fullan, 2013; Easton, 2011). Educators should encourage practical learning including activity-based learning (Sun-Keung Pang et al., 2016) which may lead to students' increased learning autonomy (Vanblaere \& Devos, 2016). This collective professional learning must involve teamwork among students and can enable them to address societal challenges (Parsons, 2016).

Openness, networking, and partnership are further characteristics that enhance collective responsibility to achieve results and lifelong learning (DuFour, 2004). School leaders must systematically come together as a team to monitor the progress of each student in terms of learning (Penner-Williams et al., 2017). These teams must work with open minds as well as network with other schools locally, nationally or abroad, in order to share the latest teaching and learning technology and theories (Stoll \& Louis, 2007). As such, students' learning is progressed (Linder, Post, \& Calabrese, 2012) whilst school leaders receive both the collective reward of their students' performance along with critical feedback (Stoll \& Louis, 2007).

A PLC is nurtured via a building process which requires mutual trust, respect, and support from each member of the community including principals, teachers, students, nonteaching staff, parents, and care-givers (Stoll \& Louis, 2007). These values of mutual respect, trust, and support provide a school's personnel with a foundation from which to 
develop interventional measures to support students' particular learning challenges (Olivier \& Huffman, 2016). This mutual trust and respect may encourage teachers and students to openly and freely articulate their voices on issues affecting their learning (Stoll \& Louis, 2007).

Finally, inclusive membership of support staff fosters both individual and collective professional learning (Stoll \& Louis, 2007). Inclusive membership must involve all stakeholders within the learning community for the school's effectiveness and development (Olivier \& Huffman, 2016). Tasks are shared or distributed to encourage specialisation and efficiency within the work environment (Hargreaves, 1995). Also, individual and collectively relevant professional learning and development programmes should be encouraged in the school such as mentoring programmes (Stoll \& Louis, 2007). These seem to have a positive influence on students' learning, performance, and success in schools (Easton, 2011; Stoll \& Louis, 2007).

\subsection{Students' needs, motivation, and success}

Strategies that support the learning needs of students and help improve their performance and ultimately success in schools include academic support, social workers, religious groups, clubs and societies, technical support, access to a nurse, a guidance and counselling unit, a school psychologist, and free meals (Brion-Meisels, 2014; Essuman \& Bosumtwi-Sam, 2013; Goldman, Goodboy, \& Weber, 2016; Tian, Han, \& Huebner, 2014; Witt \& Barnett, 2012).

In some contexts, a school nurse helps to provide health services to students within the educational fraternity (Denny, Grant, \& Galbreath, 2014). These services may include support with wellbeing issues such as sex education, pregnancy, alcoholism, drug use, nutrition, sleeping habits, and stress management as well as attending to sick students (Brophy, 2004).

Similarly, a school counsellor's role includes working collaboratively with school personnel, students, and parents in identifying and addressing the needs of students (Rowley, Stroh, \& Sink, 2005). A counsellor may also provide advice regarding the career path the students may take with support of the students' parents and teachers.

Furthermore, if a school has a psychologist this person can also provide emotional, physical, and behavioural mentoring as well as guidance to those studentswho are 
experiencing learning challenges (Goldman et al., 2016). Furthermore, he or she may assist with the development, planning, and evaluation of programmes in the school in order to meet the wider identified learning needs of students (Tian et al., 2014).

Finally, the provision of free school meals is regarded as an integral component contributing to students' learning, health promotion, and nutritional needs (SarlioLähteenkorva \& Manninen, 2010). The provision of meals is recognised as having a tremendous impact on students' enrolment, attendance, and retention throughout the world and also reduces absenteeism (Lucas, Patterson, Sacks, Billich, \& Evans, 2017; McEwan, 2013). These above needs and supports contribute to students' motivation to enhance their learning outcomes (Brophy, 2004).

In addition to these support services and needs, there is sufficient evidence in the literature that other motivators play an important role in students' learning outcomes and success (Kaplan, Karabenick, \& Groot, 2009). To discover this, one must understand the term "motivation". This term has been explained as the process of initiating, giving guidance, intensifying behaviour, and for an individual or a group to be goal-oriented towards a mission (Brophy, 2004).

There are two main forms of motivation: intrinsic and extrinsic (Brophy, 2004; Goldman et al., 2016). Intrinsic motivation involves an individual or group self-regulating actions and behaviours (Brophy, 2004). The affective aspect of motivation includes entertainment, happiness, tranquillity, pleasurable sensations, and physical wellbeing (Kaplan et al., 2009). Cognitive goals include curiosity in exploring and attaining an understanding, positive self-evaluation, and self-creativity (Anderman \& Weber, 2009). On the other hand, extrinsic motivation relies on tangible things such as rewards, including cash and items in kind, positive feedback such as "good" or "excellent", and the desire for better and positive relationships within an organisation (Anderman \& Weber, 2009; Brophy, 2004). Motivation to learn involves both intrinsic and extrinsic reinforcements to arouse students toward a particular vision (Brophy, 2004; Kaplan et al., 2009).

There is a key distinction to be made between extrinsic reinforcement-driven motivations and intrinsic enjoyment-driven motivation (Brophy, 2004, p. 15). These two forms may work in tandem in supporting a specific students' learning objectives (Brophy, 2004). A 
stronger focus on arousing and stimulating students' intrinsic motivation to learn involves supporting and encouraging them to be thoughtful in relation to skills acquisitions, strategies, and information processing through learning in the classroom and beyond for societal development (Anderman \& Weber, 2009; Brophy, 2004). This goes beyond offering them a mere incentive for good performance in the classroom (Anderman \& Weber, 2009).

Overall conclusion: based on the findings from the literature presented in this chapter, consideration of school cultural values, such as a positive belief system, rituals, and norms; a positive school climate, such as a conducive learning environment; and successful school leadership practices including high expectation, distributive leadership, context sensitivity, trust and respect, capacity development and more were used to guide data collection and analysis of this study. Furthermore, PLC practices including collaboration, networking, and motivational practices - both intrinsic and extrinsic identified in the literature were applied in order to interrogate the data from the three focus schools to engender understanding of the practices educational leaders put in place to support their students' learning, to improve performance, and to achieve success in the three sites in New Zealand, Finland, and Ghana. 


\section{CHAPTER THREE: Methodology}

\subsection{Introduction}

This study is a comparative and international education research project and focuses on education in three comparative settings. This chapter is divided into six main sections and sub-sections. Following this introduction, the second section discusses the research paradigm for this project and its philosophical underpinnings. The third section throws more light on qualitative case study, the type of case study employed for this research and the justification for its selection. The fourth part of this chapter addresses the research design and explains the rationale for adopting these methods for this comparative and international education research and the selection criteria for the schools, the universities, the ministries, and the participants. Furthermore, it discusses the data collection tools used for data gathering, such as observation, artefacts collection, and face-to-face interviews, and the procedure used for selecting the levels of organisational policy documents. The fifth part presents the procedures of data analysis. and finally, the sixth part provides an overview of the trustworthiness and credibility of this research project.

\subsection{Research paradigm and interpretive methodological stance}

It is evident in the international literature that research paradigm plays an important role in research study (Denzin \& Lincoln, 2008; Johnson \& Christensen, 2008). According to Johnson and Christensen (2008), the research paradigm is the "perspective held by a community of researchers that is based on a set of shared assumptions, concepts, values and practice" (p. 33). Similarly, the research paradigm guides the basic beliefs held by a group or by a researcher and the actions that direct those beliefs (Denzin \& Lincoln, 2008; Krauss, 2005).

Based on this, this research adopted and used an interpretative-descriptive methodological stance to explore educational leaders' views about school culture, climate, leadership, and students' success. Justifying the choice of this paradigm philosophically: ontologically, this worldview assumes that reality is multiple, subjective in nature, external, intangible, value-laden, culturally and experientially based, locally specific, and often shared among individuals, groups, and cultures (Krauss, 2005). Epistemologically, knowledge exists in peoples' experiences, practices, opinions, and discourses (Yin, 2010). It can be learned and understood through interactions from people 
holding such knowledge in order to ascertain their social reality (Bunniss \& Kelly, 2010; Krauss, 2005; Yin, 2010).

An interpretative-descriptive paradigm provides understanding of a phenomenon within its natural setting (Krauss, 2005) by providing a clear picture of an event, situation, or a phenomenon in its natural setting (Creswell, 2009; Johnson \& Christensen, 2008). More so, it describes the relationships that are present in a phenomenon (Yin, 2010). Lastly, it employs qualitative tools to mirror people's opinions, beliefs, behaviours, and attitudes in a given community at a particular period of time (Johnson \& Christensen, 2008). This leads to the choice of a qualitative case study.

\subsection{Qualitative case study}

A qualitative case study approach is commonly used in qualitative research (Gerring, 2007; Johnson \& Christensen, 2008; Robson, 1993; Yin, 2010). A qualitative case study in educational research is a systematic empirical investigation - conducted within a specific environment, space, and time - into an event, an activity, a programme, a practice, a belief system, or an institution in order to uncover social realities (Bassey, 2012).

This qualitative case study relied on multiple cases which focused on the three comparative and international bound units or contexts under study (Johnson \& Christensen, 2008; Robson, 1993; Yin, 2010). A single case study by definition focuses on a single related unit while mulitiple case focuses on multiple related units (Yin, 2010). Multiple case was adopted for this study of educational leaders' views about school culture, climate, leadership, and success in the three comparative and international contexts, New Zealand, Finland and Ghana.

Qualitative case study methodology has several features which warranted its selection for this study. First, it is used as an empirical inquiry to explore contemporary situations, ideas, opinions, beliefs, experiences, and practices in depth within their natural environment (Johnson \& Christensen, 2008; Yin, 2010). Secondly, it gathers evidence from a real-life context (Bassey, 2012; Gerring, 2007; Yin, 2010). Next, it employs multiple sources of evidence to explore the real-life situation in its natural environment at a particular period (Gerring, 2007; Johnson \& Christensen, 2008; Yin, 2010). Furthermore, its robust nature, compelling approach (Yin, 2010) and descriptive means 
of ascertaining social realities added weight to the selection of this approach for this research (Bassey, 2012).

In conclusion, the nature of my research problem and questions, as well as the nature of the environment or the community, which was mostly within the educational fraternity, paved the way for employing this approach (Johnson \& Christensen, 2008).

\subsection{Research method}

\subsubsection{Research design and rationale}

Research design in a qualitative case research presents the procedures or techniques adopted and used to collect and analyse research data in a particular location at a particular period of time (Creswell, 2009; Horrocks \& King, 2010). It gives the researcher more opportunity for assessing research design within each method of inquiry and the context in which it occurs (Creswell, 2013; Johnson \& Christensen, 2008). This was a multiple case and explored educational leaders' views in the three international contexts.

Comparative and international educational research examines education and its development (Phillips, 2011) drawing data from one country or more in relation to practices, ideas, situations, and philosophies, then comparing this with similar data from other countries in order to understand and appreciate what is going in education in those countries in a more global perspective (Bray, 2015).

For this reason, several publications in comparative and international education have reported that comparative and international education research is a useful means to acquire knowledge and skills in education (Bray, 2015; Kubow \& Blosser, 2014; Thomas, 2017). Elaborating on this, the knowledge and skills acquired through comparative and international education research may assist in the development of the institutions and practices in education (Bray, 2015). Moreover, it may highlight the relationship between culture, society, and education among countries (Thomas, 2017). Highlighting these relationships in education may establish useful practices, philosophies, and ideas that are valid in more than a single country and that may be applied in other countries to improve education and its development (Phillips, 2011). 


\subsubsection{Selection process and criteria of the schools}

This study selected one secondary school in New Zealand, one upper secondary school in Finland, and one senior high school in Ghana. See the table below for the selection criteria for the schools.

Table 2: The Selection Criteria of the Three Schools

\begin{tabular}{|c|c|c|c|c|c|}
\hline Schools & Type & Funding & $\begin{array}{l}\text { National } \\
\text { assessment }\end{array}$ & $\begin{array}{l}\text { Years for } \\
\text { completion }\end{array}$ & $\begin{array}{l}\text { Willingness of } \\
\text { participants }\end{array}$ \\
\hline $\begin{array}{l}\text { New } \\
\text { Zealand } \\
\text { (X) }\end{array}$ & $\begin{array}{l}\text { Secondary } \\
\text { level school }\end{array}$ & $\begin{array}{l}\text { Public } \\
\text { funded }\end{array}$ & $\begin{array}{l}\text { National } \\
\text { Certificate of } \\
\text { Educational } \\
\text { Achievement } \\
\text { (NZQA, 2018) }\end{array}$ & 3 years & Free will \\
\hline $\begin{array}{l}\text { Finland } \\
(\mathbf{Y})\end{array}$ & $\begin{array}{l}\text { Secondary } \\
\text { level school }\end{array}$ & $\begin{array}{l}\text { Public } \\
\text { funded }\end{array}$ & $\begin{array}{l}\text { Finnish } \\
\text { National } \\
\text { Maturation } \\
\text { Examination } \\
\text { (MOEC, } \\
2017)\end{array}$ & 3 years & Free will \\
\hline $\begin{array}{l}\text { Ghana } \\
\text { (Z) }\end{array}$ & $\begin{array}{l}\text { Secondary } \\
\text { level school }\end{array}$ & $\begin{array}{l}\text { Public } \\
\text { funded }\end{array}$ & $\begin{array}{l}\text { West Africa } \\
\text { Secondary } \\
\text { School } \\
\text { Certificate } \\
\text { Examination } \\
\text { (UNESCO, } \\
\text { 2019a) }\end{array}$ & 3 years & Free will \\
\hline
\end{tabular}

Elaborating on the table, the students in the three comparative schools undertook the achievement measures listed above as requirements for tertiary education entrance (Berisha \& Seppänen, 2017; NZQA, 2018; UNESCO, 2019c). I gathered data from a high school in New Zealand which offers the NCEA qualifications, a matriculation examination school in Finland, and a West Africa Secondary School Certificate Examination in Ghana. 


\subsubsection{Selection process and criteria of the universities and ministries}

One university in each of the three countries was selected for the study. The three institutions selected for this study each had a faculty of education. They were also in the world's university ranking list of two thousand (Times Higher Education, 2021). The Ministry of Education in each of the three countries was selected to participate in this research. The reason for this was that the ministries are responsible for education and its development in the three international contexts for the study. Through the connections and networks of my supervisors, access was gained to a university other than the one in which I was studying, and the Ministry of Education of New Zealand. Similarly, in Finland, through my former head of school, access was gained to that university and the Ministry of Education and Culture, Finland. On the other hand, in Ghana, I passed through the normal bureaucratic structures of the two institutions. I wrote official letters addressed to the sector minister in charge of education and the dean, Faculty of Education and waited for their approval before access was gained to those two institutions.

\subsubsection{Selection process and criteria of the participants}

\section{Principals and teachers}

The participants for this study were chosen from the three schools identified in Table 2 above. The principals and the teachers had the following qualities: they were secondary school personnel, had led and directed the learning process for more than a year, had experience in the secondary school curriculum, and held professional certificates or degrees in education. Lastly, they were willing and available to be part of the study. In summing up, one principal and six teachers in each of the three contexts accepted and took part in the study.

\section{Ministry officials}

One Ministry of Education official in each of the three international contexts who was experienced in both domestic and international education was selected. Through my former head of school in Finland and her networking at the Ministry of Education, I was able to contact an official who was the ministry's representative to the European Union and invite her to participate in an interview. In Ghana, after passing through the 
bureaucratic process for nearly two months, I was assigned to speak to the Ministry's expert who represented the Ministry at the international level. In New Zealand, I went through the bureaucratic process and was assigned with an expert who was knowledgeable in both domestic and international education.

\section{University experts}

Lastly, one educational expert who was knowledgeable in both domestic and international education was selected from the universities. Through my personal network and contacts and my supervisors' networks, those experts were selected from the institutions. The table below summarises the number of participants selected from the three comparative countries.

Table 3: The Number of Participants Selected from the Three Contexts

\begin{tabular}{|lcccc|}
\hline Participants & New Zealand & Finland & Ghana & Total \\
Teachers & 6 & 6 & 6 & 18 \\
Principals & 1 & 1 & 1 & 3 \\
Uni. experts & 1 & 1 & 1 & 3 \\
Min. officials & 1 & 1 & 1 & 3 \\
Total & 9 & 9 & 9 & 27 \\
\hline
\end{tabular}

\subsubsection{Human Ethics' Committee, Victoria University of Wellington}

Gaining access to the research sites and participants is one of the ethical considerations in qualitative comparative case research (Yin, 2010). In order to ensure ethical protection for all concerned, the sponsoring institution has to take into account many factors before granting approval or permission for a particular research to be carried out (Creswell, 2013; Yin, 2010). For this study, the sponsoring institution for this comparative and international case research was Victoria University of Wellington, New Zealand.

Many scholars have explained the process of gaining access to participants in a qualitative comparative case research as the act of seeking permission from the human subjects in order to carry out a research project in a particular geographical setting at a particular 
period of time (Creswell, 2013; Johnson \& Christensen, 2008). Informed consent needs to be sought from the the university ethics committee, schools' boards, and heads of institutions and organisations as well as private individuals for a particular research project over a given period of time (Johnson \& Christensen, 2008).

For these reasons, then, I sought approval from the Human Ethics' Committee, Victoria University of Wellington before an Ethics Approval Letter was gained with the registration number $\mathbf{2 5 6 5 4}$. This committee was a campus committee at the university set up to review research study and consider any potential harmful threats of my research project to the participants as well as the sites under which the investigations were to be carried out. The following steps were followed before gaining the permission.

First, I submitted a detailed procedure for carrying out this research project through an online application portal of Victoria University called "Research Master". On this portal, several questions were asked including, did the study involve minors or was the study involving a high-risk population? Secondly, the board requested the selection criteria of the research participants and how I intended to gain access to the three research sites. Furthermore, I attached the interview protocols and the observation guides on the portal for the committee's consideration and advice. Finally, when the board was satisfied with my explanations and the documentation attached above, they issued me with an Ethics Approval letter with the registration number above.

In conclusion, I showed this Approval Letter from the Human Research Ethics Committee, Victoria University of Wellington and other documents such as the consent forms, letter of invitation, and participant information sheet to the institutional management and research participants in the various institutions and organisations where I gathered the data. See the appendices for the following attachments:

Appendix 1: in page 241. The ethics Approval Letter, Victoria University of Wellington. Appendix 2: in page 242. The Letter of invitation to the institutions in the three sites and, Appendix 3: in page 245. The consent form issued to all the participants

In the following section I outline how I piloted the research instruments before setting off to the three sites for the data collection. 


\subsubsection{Piloting of the data instruments}

Before the observations and subsequent interviews were gathered from the educational leaders in the three institutions in the three different countries, I piloted the interview guides and protocols adopted. I also tested my data collection devices to check their functionalities and durability. The devices included: an audio voice recorder, an iPhone voice recorder, and an Apple Laptop with a voice recorder.

I piloted the interviews with a fellow doctoral student at the Victoria University of Wellington. The literature explains that piloting research instruments and devices is worthwhile in helping the development of the lines in which various questions could be asked (Creswell, 2009). Also, it establishes any strengths and weaknesses of the recording devices that may affect their use in an effective and reliable data gathering process (Yin, 2010). This piloting test helped me to refine the data gathering plans. The theoretical plans were refined when I learned some practical tips in data gathering from a colleague, a doctoral student who had just returned from the field in Vietnam. For example, she shared her experience in a practical way about how to develop confidence, rapport, and trust, how to ask questions, and to follow the initial questions with probing ones.

\subsubsection{Data collection techniques (observation, artefacts collection, and interviews)}

The study made use of the three main research questions to explore educational leaders' views about school culture, climate, and leadership, and other contributing factors that promote students' learning, performance, and success in the three contexts under study. Table 4, below, summarises the sources of data for addressing the three main research questions. 
Table 4: Sources of Data for Addressing the Research Questions

See the table below for these effect.

\begin{tabular}{|l|ll|}
\hline \multicolumn{1}{|c|}{ Questions } & \multicolumn{1}{c|}{ Data sources } \\
\hline 1. What is the relationship between & - Observations \\
school culture, climate, leadership & - Artifacts collection \\
and success in New Zealand, & - Face to face interviews \\
Finland and Ghana? & - Strategic policy documents \\
\hline 2. What is the relationship between, & - Observations \\
PLCs, students needs and success & - Artifacts collection \\
in New Zealand, Finland and & - Face to face interviews \\
Ghana? & - Strategic policy documents \\
\hline H. How can school culture, climate, & - Data analyses \\
leadership and success be deeply & - Data findings \\
understood?
\end{tabular}

\section{Observations}

Observation was adopted as a tool and used to mirror the processes of the institutions, behaviours of the participants, and cultural symbols and artefacts of the schools, the ministries, and the universities in each of the contexts. According to Creswell (2013, p. 166), an observation is the "act of noting a phenomenon in the field setting through the five senses of the observer, often with an instrument and recording it for a scientific purpose". See the table below, it summarises things I observed in the institutions in the three sites. 
Table 5: Things Observed and Analysed from the Three Sites

$\begin{array}{cccc}\text { Observed Support } & \text { Symbols } & \text { Bhysical } \\ \text { environment }\end{array}$

Practices: services

\begin{tabular}{|llll} 
Clinics & $\begin{array}{l}\text { Flags and } \\
\text { uniforms }\end{array}$ & $\begin{array}{l}\text { School's } \\
\text { relationships }\end{array}$ & $\begin{array}{l}\text { School's security } \\
\text { and }\end{array}$ \\
\hline School nurses & $\begin{array}{l}\text { School's } \\
\text { motto and } \\
\text { trophies }\end{array}$ & $\begin{array}{l}\text { Structures and } \\
\text { communication }\end{array}$ & $\begin{array}{l}\text { Compound, } \\
\text { classrooms and }\end{array}$ \\
$\begin{array}{l}\text { Counselling } \\
\text { services }\end{array}$ & $\begin{array}{l}\text { Wall designs } \\
\text { and paintings }\end{array}$ & $\begin{array}{l}\text { Teamwork and } \\
\text { networking }\end{array}$ & $\begin{array}{l}\text { Seating } \\
\text { arrangement }\end{array}$ \\
$\begin{array}{l}\text { School } \\
\text { feeding }\end{array}$ & $\begin{array}{l}\text { Mission } \\
\text { statements }\end{array}$ & Collaborations & $\begin{array}{l}\text { Service delivery } \\
\text { and }\end{array}$ \\
$\begin{array}{l}\text { Libraries and } \\
\text { studios. }\end{array}$ & $\begin{array}{l}\text { Bust portraits } \\
\text { and photos. }\end{array}$ & Other practices & Buildings \\
\hline
\end{tabular}

The observations in the three schools took place in Finland on the $24^{\text {th }}$ day of April 2018; in Ghana, the $06^{\text {th }}$ day of July 2018; and in New Zealand, it on the $15^{\text {th }}$ day of December 2018 .

The three principals, one from each of the schools, assigned one teacher in each one of the schools to guide me for the observations. During the observational processes in each of the institutions, I asked probing questions for clarification from the assigned liaison teachers, especially regarding the meanings of the symbols and signs I saw in the schools. I recorded the observables in a field notebook and with photographs. Lastly, the observations in each of the contexts lasted for one to one-and-a-half hours.

\section{Artefacts collections}

According to the literature, cultural artefacts are good sources of data in qualitative study (Creswell, 2009; Johnson \& Christensen, 2008; Yin, 2010). Cultural artefacts, which are a form of documentary evidence according to Johnson and Christensen, (2008) are data "collected, recorded, or left behind at earlier time, usually by a different person and often for an entirely different purpose than the current research purpose at hand" (p. 217). Such data include: personal documents including anything recorded, photographed, or written 
for a private motive or for a personal purpose (Creswell, 2009); official records including anything written down, recorded, or photographed by an organisation; and physical and archived data (Creswell, 2009; Johnson \& Christensen, 2008). These are sources of data information that provide specific information within a particular context over a period of time (Johnson \& Christensen, 2008).

Studies have shown the importance of cultural artefacts to research development. First, cultural artefacts provide the researcher with data information at little cost over a period of time at a given location or a site (Creswell, 2009). Second, cultural artefacts give data information which can be accessed at any time at the site (Johnson \& Christensen, 2008) and are also available and convenient to the observer or the researcher (Creswell, 2009). Finally, the researcher's time and energy are saved (Creswell, 2009, 2013) because she or he does not need to transcribe this form of data information (Johnson \& Christensen, 2008).

On the other hand, despite these advantages of the cultural artefacts, they have some disadvantages. The disadvantages include: First, in some instance, access to the data information may be restricted and not available to the researcher. For example, data information from organisations such as government agencies may be difficult to access due to its sensitivity and access will be blocked (Creswell, 2009). Second, some of the materials may be incomplete and this makes the documents difficult to analyse and may affect the authenticity of the study (Creswell, 2009; Yin, 2010).

In conclusion, the following artefacts were gathered for analysis from the three sites: photographs of the schools' mottos and logos, the vision and the mission statements, trophies, the classrooms settings, flags, uniforms, crests, and other related symbols that are related to the research's questions. These artefacts were photographed with an Iphone camera, and stored for analysis during the observations in the three comparative sites.

\section{Face-to-face interviews}

Several studies have found that a qualitative interview is a good data collection tool and comes in many types and forms (Creswell, 2013; Horrocks \& King, 2010; Johnson \& Christensen, 2008; Ribbins, 2007; Silverman, 2004). 
Face-to-face interviews with unstructured and generally open-ended questions were adopted and used to gather the data from the research participants (the teachers, the principals, the ministries' officials, and the universities' experts) from the three sites.

Qualitative interviews involve interaction between two or more persons, one of whom is a stranger (an interviewer) who asks questions on a particular topic and the other gives answers to questions (Seale, Gobo, Gubrium, \& Silverman, 2004). Similarly, qualitative interviews involve a verbal exchange between an interviewer and an interviewee (Thorpe, 2011), whereby the interviewer seeks to find out some explanations for some actions, behaviour, experience, opinion, practices, and beliefs of an individual or a group.

There are many forms of qualitative interview in a case study research. These include: Face-to-face interviews, telephone interviews, email or internet interviews, and focus groups (Johnson \& Christensen, p. 203). These forms of interviews have several advantages and disadvantages

The advantages of face-to-face interview include the following aspects. First, it is useful when the research participants cannot be observed directly (Johnson \& Christensen, 2008). Second, a face-to-face setting is useful when the researcher wants to learn and understand an event in its natural settings or environment (Creswell, 2009). Furthermore, it gives the researcher the opportunity to control or regulate the line of questioning; to tailor the research questions (Creswell, 2009; Johnson \& Christensen, 2008). Lastly, it provides an avenue for the participants to reiterate their information (Creswell, 2009) and gives the researcher an opportunity to ask probing questions to clarify issues (Creswell, 2009; Johnson \& Christensen, 2008).

On the other hand, the disadvantages include the following aspects. Firstly, the information is "filtered through the views of the interviewees" (Creswell, 2009, p. 179), and secondly, the researcher's biases could affect the authenticity of the data (Johnson \& Christensen, 2008).

There were several steps I took during the face-to-face interviews with the school participants in the three sites. During the observations in the three schools, I visited the staff common room of the schools with the liaison teacher who introduced me to some of their teacher colleagues. Through these friendly introductions and interactions, I took the opportunity to explain my research project to some of them and through this process, I 
was able to get some teachers to willingly volunteer to support the project. On my first day of the schools' visit, especially in New Zealand and Ghana, many participants including the principals accepted my invitation to take part in the project. These participants gave me their free days and times for the interviews. I recorded the participants' data and time provided in the field note book to serve me a reminder.

Furthermore, the information sheet and consent forms were issued to each of the participants who accepted the invitation to take part in this research project. An information sheet and consent form, as the name suggests, is a document which establishes the ethical guidelines of a research project including the purpose of the study, the procedure for data collection, risks and benefits to the participants, as well as the steps that will be taken to maintain confidentiality (Johnson \& Christensen, 2008). I gave each one of the participants an information sheet and consent form to read, and if they were willing to participate, to sign. I informed the participants that if there were any unforeseen circumstances which could affect our meetings for the interviews in the subsequent days, they should let me know and we exchanged our contact details. When I got home, I sent messages through email to acknowledge the participants for their interest in this research project. More so, through the notice about the unforeseen circumstances on the part of the participants, a couple of them sent through email messages to change the agreed dates and some to change the agreed times. We arranged different days and times through the same medium and I made sure that the new days fixed were convenient to the participants.

I arrived at each of the three sites for the interviews very early in order to be ready and available to the participant. In New Zealand, I waited at the security post for each of the participants. In Finland, I was given a seat at the principal's office to wait for the participants, and in Ghana, I was offered a seat in the staff common room to wait for the participants. Furthermore, all the participants' arrived according to their scheduled time and ushered me into their own chosen sites or locations for the interviews.

Before the interviews, I requested the consent forms from each one of the participants as he or she took me to his or her preferred site for the interviews. Interestingly, some of the participants failed to bring their information sheet and consent forms before the start of the interviews. I was anticipating this, so I carried a set of additional forms as backups. I gave those participants without consent forms new forms to read, and if willing to continue, to sign. Furthermore, with each one of the participants I went over the purpose 
of the study, participants' rights, and confidentiality. I also explained the amount of time that would be needed for the interviews, as well as plans for using the data results for publications and conference presentations. I must state here that none of the participants failed to sign the consent forms. Finally, I collected all the signed consent forms from each one of the participants and started the interviews.

During the face-to-face interviews with each of the participants I wanted to learn and understand the educational leaders' views about the school culture, climate, leadership, and other contributing factors that promote students' learning, performance, and ultimately success in the three comparative and international contexts. I therefore asked each one of the participants an initial question or questions from the interview guide. For example, one of the questions asked was: Could you please tell me a little bit about the history of this institution? After the question and the subsequent questions, I paused for some minutes for the participants to finish before moving to the next questions. This helped the participants to express their thoughts freely without obstructions. Creswell notes that a good interviewer is the one who listens rather than the one who frequently speaks during a face-to-face interview (Creswell, 2009). In addition, for the purpose of clarification I asked participants some follow-up probing questions during the interviews. I also asked some of the participants to explain to me the meanings of some of the artefacts gathered during the observations in the institutions.

The interviews lasted between fifty and ninety minutes for each of the participants. During the interviews I took notes on the interview protocol. The literature explains that an interview protocol is a form or a sheet designed purposely for taking notes during interviews (Creswell, 2009; Johnson \& Christensen, 2008), and has an advantage that it serves as a data backup in the event the audio recording failing to function during an interview (Creswell, 2009). I took notes from all the participants for this study. I audio recorded all the individual interviews and saved them on iCloud in a MacBook Air and iPhone as well as on the secure OneDrive platform at Victoria University of Wellington, New Zealand.

In conclusion, I thanked each of the participants for participating in this project. I reminded them that, if requested, their transcripts would be returned after I finished transcribing the data. On this note, in Finland, four out of nine of the participants requested their transcripts. They were sent to them and two of the four were returned to 
me with minor corrections and additions. Similarly, in Ghana, three out of the nine participants requested their transcript. They were sent, and one of the three scripts was returned with minor corrections. In the same vein, in New Zealand, three were sent to participants although none of these were returned to me with corrections. Finally, I sent all the participants email messages to acknowledge their various roles before and during the data gathering in the school. See the appendix for the interview protocols for the teachers, principals, university experts, and ministry officials.

\section{Important note}

Focus group interviews were approved by the Human Ethics Committee, Victoria University of Wellington as a data gathering tool in the three comparative and international contexts. However, this data collection strategy was not used because I could not get all the focus group participants (the teachers and the principals) in each of the three schools to gather as a group for the interviews for a range of reasons such as that they were about to go on vacations and the teachers were busily conducting examinations and invigilation.

In addition to the observation and interview data gathered from the three comparative and international fields, strategic documents were also examined. How the documentary evidence was gathered and used is discussed next.

\subsubsection{Strategic policy documents}

As the literature explains, educational policy is a set of guidelines that guide the actions, beliefs, and the ideological positions of the people in a particular country or location over a given period of time (Cardno, 1999, 2018; Fitzgerald, 2007). This research project used documentary evidence on policy initiatives in education from global, national, and organisational perspectives in the three different national contexts.

On this note, strategic international policy documents from the Organisation for Economic Co-operation and Development (OECD) were utilised. The key concepts analysed were: the amount of money the governments invest in education; enrolment rates for students between 15 and 19 years of age; teacher-student ratios; class size; and PISA rankings. In addition, national curricula for the three countries were analysed for visions, principles, values, key competencies, official languages, purpose, and scope. 
Similarly, organisational policy documents from each of the three sites were analysed with a focus on leadership standards, professional knowledge, and professional practice..

In conclusion, the purpose of the document analysis was to understand how the institutions in the three comparative contexts aligned with the global, national, and organisational policies as well as how those policies were manifested in educational leaders' practices in promoting students' learning, performance, and success. See Figure 8 , below, for a list of the strategic documents in education that were examined for this research. 
Figure 8: Strategic Policy Documents Examined

\section{International policy strategic documents:}

- Education at a Glance 2018: OECD Indicators for New Zealand (OECD, 2018a)

- Education at a Glance 2018, Country Note, Finland (OECD, 2018b).

- Global educational rankings, PISA (OECD, 2016).

- Education Expenditures: Sustainable Development Goals (UNESCO, 2019b).

- International Labor Organization (ILO, 2019)

\section{National policy strategic documents}

- The New Zealand Curriculum, Ministry of Education (MOE, 2007).

- Curriculum in Finland, Finnish National Board of Education (FNBE, 2016).

- National Pre-Tertiary Education Curriculum Framework. Ministry of Education, Ghana (MOE, 2018).

\section{Organisational level documents}

- The Code of Professional Responsibilities: Examples in Practice. Education Council, New Zealand (Education Council, 2017).

- Ethics, Transparency and Integrity in Education. Codes of Conduct for teachers in Europe, Finland. A background study. (Kaniņš \& Golubeva, 2017)

- National Teachers' Standards for Ghana, Guidelines (MOE, 2017b).

\subsection{Data analysis}

\subsubsection{Introduction}

This research adopted and used thematic and comparative cross-case methods to analyse the strategic documents collected, observations, the artefacts, and data gathered from the face-to-face interviews. Furthermore, NIVO software for qualitative data analysis was used to code the face-to-face interviews. Although data from the observations, artefact collection, face-to-face interviews, and strategic policy documents were gathered and conducted in that order, the data analysis began with the documents. This is because I wanted to learn and understand how these strategic, international, national, and 
organisational policies were reflected in the practices of the educational leaders in the three sites. These analyses aimed to explore the three research questions. (Refer to table 4, in p. 75) for these questions.

\subsubsection{Thematic analysis}

Thematic analysis in qualitative research often requires an in-depth participation and explanations from the researcher (Guest, MacQueen, \& Namey, 2014a). This is because analysis goes beyond counting explicit phrases, words, or symbols that emerged from the textual data (Guest, MacQueen, \& Namey, 2012). For this reason, the researcher focuses on navigating and describing emerging ideas present in the data set thematically (Guest, MacQueen, \& Namey, 2014b). The processes leading to identification of the themes include: developing codes, comparing code frequencies, building patterns of the codes or relationships or categorisations and sub-categorisations, and finally arriving at themes (Creswell, 2009; Johnson \& Christensen, 2008).

Furthermore, this analysis method was guided by the general inductive approach (Creswell, 2009). In this approach in qualitative research the researcher organises the data set from the bottom-up and this has several advantages (Creswell, 2009).

To begin with, the inductive approach offers very clear steps for both novices and highly pragmatic researchers for identifying meaningful themes in relation to the research questions (Olson, Young, \& Schultz, 2015). In addition, findings that emerge via this approach are derived from the underlying structure of experiences that are evident in the raw data (Rau, 2015), whereby, they begin from the respondents' experiences, stories, thinking, and practices as condensed from the textual data (Johnson \& Christensen, 2008). Lastly, inductive analysis enables the researcher to triangulate the study through different methods and lenses to determine the information accuracy, thereby promoting research validity (Creswell, 2009; Johnson \& Christensen, 2008; Robson, 1993). See Figure 9, below, for thematic steps adopted from Johnson and Christensen. 


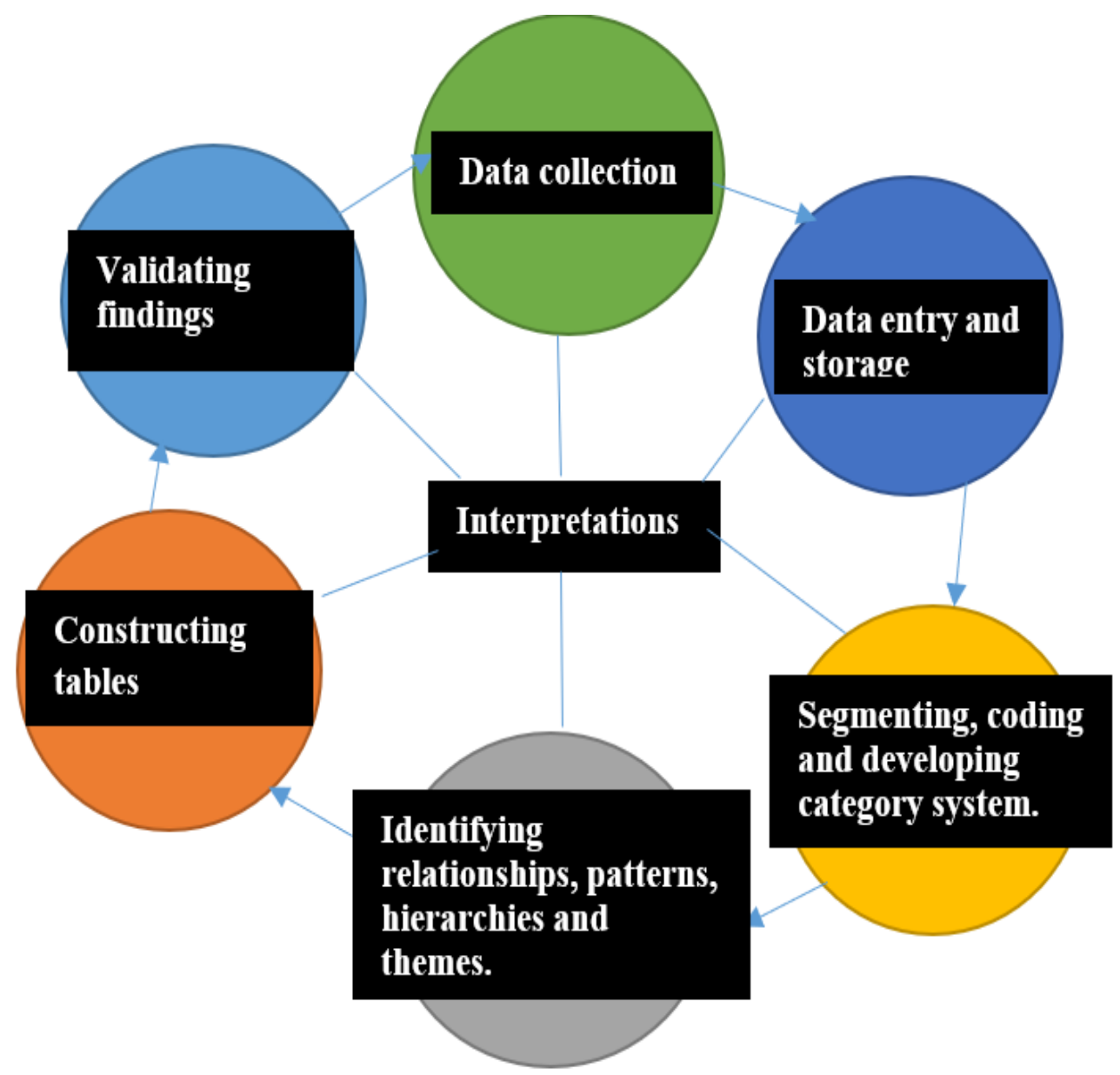

Adapted from (Johnson \& Christensen, 2008)

These above steps were applied to analyse the information gathered from the strategic policy documents, observations, artefacts, and face-to-face interviews.

\subsubsection{Data analysis process for strategic policy documents}

I first selected documents related to my research questions. See (Figure 8, in p. 82). Secondly, I developed a protocol to search for particular concepts, ideas, and situations which were relevant to my two research questions, and coding was applied across the documents from the three sites. This coding was informed by the reviewed literature and my own experiences from in the field. I assigned numeral vales to the frequency of all the codes identified. They were 0, which reads (Unavailable), 1. (Available), 2. (More available) and 3. (Most available). Also, I grouped together concepts, constructs, and words that were similar or connected to another or repeated. I grouped any unusual and unexpected concepts, constructs, or words which were surprising, compelling, and 
interesting and stood out as well. Furthermore, the initial themes were derived in relation to the frequencies of the words' appearances. Through this process, some themes overlapped, and I rearranged them to align with the most relevant themes. Finally, I constructed tables to show the identified themes.

See appendix 9, (in page, 252) for these practical steps.

\subsubsection{Data analysis process for observations}

Observation notes taken from the three sites were developed and analysed using the same steps as in Table 5, in (p. 76) above. I applied coding across notes taken from the three sites to navigate the availability of the concepts, ideas, and symbols. See: Table 5 in (p. 76) for this observational guide. In addition, numerical values were assigned to the frequency of all codes identified, such as 0 (Unavailable), 1. (Available) and so on. Through this process, similar codes were sorted together, and not similar ones were made to stand alone. After this categorisation, sub-themes and the main themes came out.

See appendix 9, (in p, 252) for these practical steps.

\subsubsection{Data analysis process for artefacts}

The meanings of the artefacts were learned and understood from the participants in the three sites. This was so because explanations were sought about each of the photographed artefacts. Decoded meanings were developed in the form of a transcript. After this coding, numerical values, relationships, and categorisation were applied to the entire transcript and, finally, sub-themes and main themes emerged. These identified themes for each case in the three contexts were then compared under the heading "comparative cross case".

See Appendix 9, (in p. 252) for sample artifacts observed with their meanings.

\subsubsection{Data analysis process for interviews}

The following were the steps adopted to analyse the face-to-face interviews from the three sites. Firstly, the data from the three sites were transcribed verbatim using Microsoft word. The data was arranged based on my interview questions, followed by participants' answers to the questions asked. I coded the questions by "heading one" and "participants' answers" as normal using Microsoft word coding scheme.After this, the transcripts were 
read slowly, carefully, and repeatedly over several months in order to familiarise myself with the data.

From here, I opened an NVivo 12 account from Victoria University of Wellington, New Zealand's Software Information Technology Service. I then imported the transcripts, one after the other, to projects titled "New Zealand's case", "Finland's case", and "Ghana's case". Within the cases, I created files for all the participants, including the principals, the teachers, the university experts, and the ministry officials.

Next, I highlighted each file created to apply auto-coding. I must note here that the teachers' files from each of the three sites were highlighted together. I right-clicked the highlighted files one after the other and selected auto-code to code the entire files. This process automatically organised the data according to the interview questions followed by participants' answers provided respectively. I then opened each of the auto-coded data segments in turn. I read each item thoroughly and after due consideration gave it a new code. These generated new codes were informed by the literature reviews and lessons learned from the fields of this study. Furthermore, using this inductive approach opened up unexpected and new emerging ideas throughout the data.

I used the Word visualising function of the programme which acts on the word frequency of all the codes by right-clicking the codes and selecting "visualize". After this, I clicked on the word clouds to display and understand the word frequency of the selected code. I furthered utilised the function "tilted summary" to understand the word frequency, especially, the words' length and count of the codes. Similarly, I queried the codes by right clicking each of the codes and selecting "query". After this, I clicked "word frequency" to understand the respective words' counts. See Figure 10, below, for the query and visualization sample for school's Z leadership's structure. 
Figure 10: Query and Visualisation Sample for the School Z in Ghana

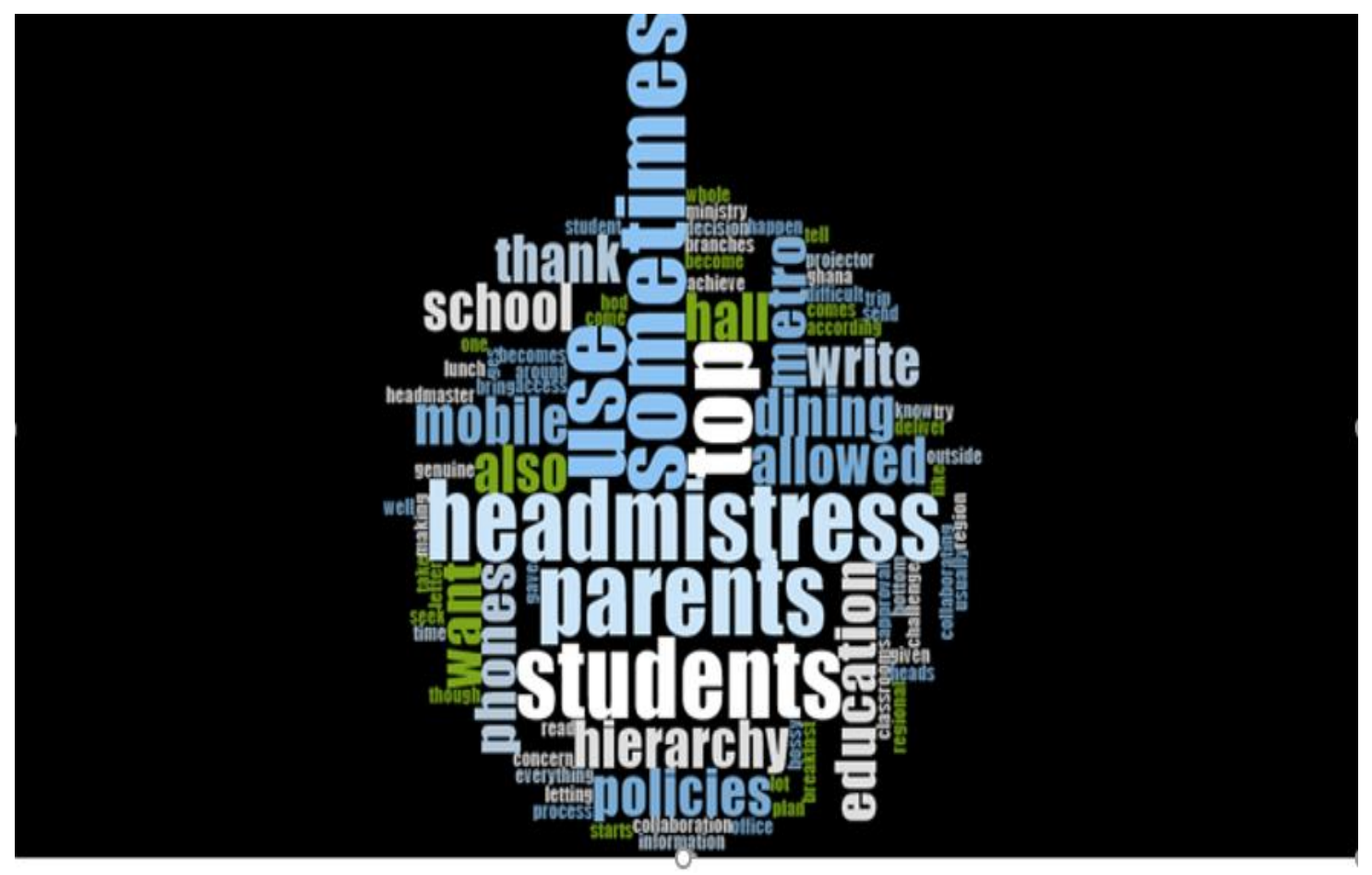

On this note, similar codes were sorted together as well as unalike or dissimilar ones. I right-clicked codes that were similar to others by holding the mouse tightly to drag the codes to drop to the similar codes. Furthermore, unalike codes were made to stand alone and through these processes of sorting, categorisation, and relationships, the sub-themes and the main themes emerged.

In conclusion, the themes that emerged from this analytical process were: school culture, school climate, school leadership, professional learning community, students' needs and support, students' motivation, and, finally, teaching and learning constraints. Again, the emergent themes from the three countries were compared to each other. See below how this analysis was carried out and refer to appendix 12, (in pp. 255) for further details. 


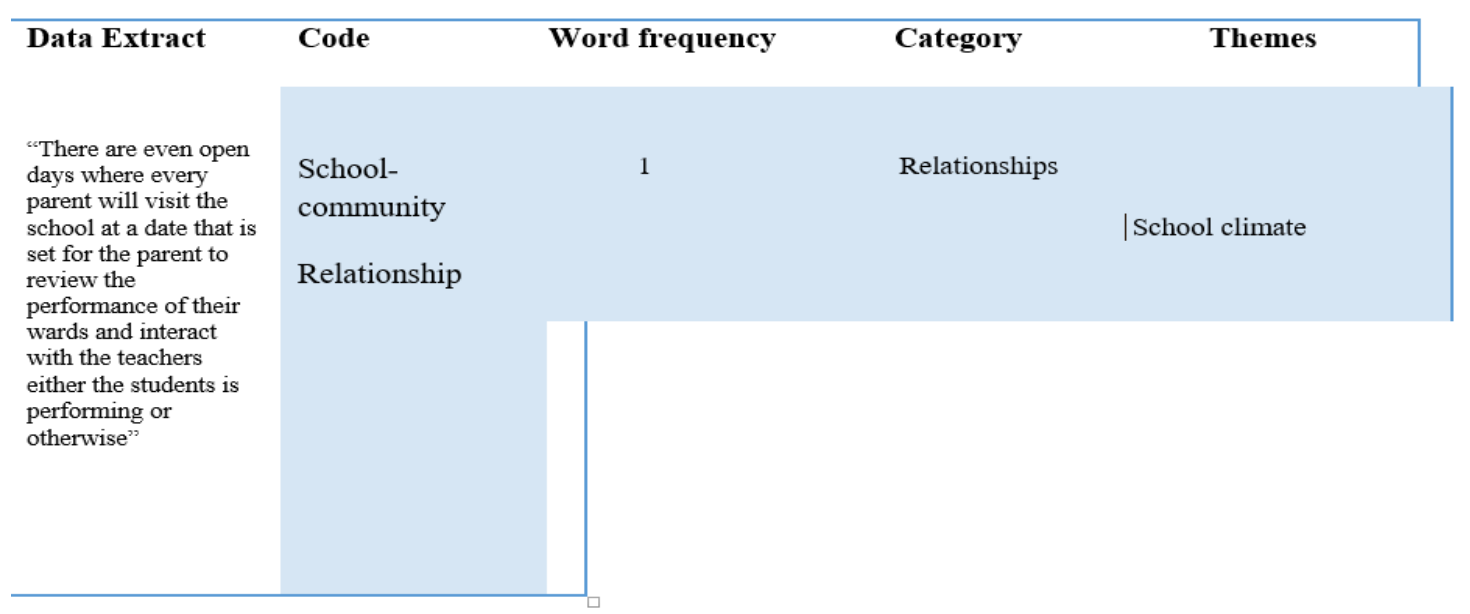

\subsubsection{Comparative cross-case analysis}

Comparative cross-case analysis is one of the methods of analysis in a qualitative study; it requires searching for similarities and differences across multiple cases in order to determine participants' realities from their natural settings (Guest et al., 2012; Johnson \& Christensen, 2008). I used this approach because it is applicable to comparative and international education research.

\subsection{Trustworthiness and credibility of the data interpretation}

It is evident in the literature that some qualitative research projects are stronger than others in terms of issues of validity or trustworthiness and credibility (Johnson \& Christensen, 2008; Yin, 2010). According to Yin (2010), the validity or trustworthiness of qualitative study is the stronger when the researcher has "properly collected and interpreted its data, so that the conclusions accurately reflect and represent the real world or laboratory that was studied" (p. 78). In the same vein, the term refers to "qualitative research that is plausible, credible, trustworthy and therefore defensible" (Johnson \& Christensen, p. 275).

Based on these assertions, the following forms of trustworthiness were employed for this piece of research project: descriptive validity, interpretive validity, theoretical validity, and internal validity. These were applied in this study in order to lessen the influence of my personal biases as I had lived, studied, and worked in all the three countries which were the focus of the study. Descriptive validity refers to the "factual accuracy of the account as reported by the researcher" (Johnson \& Christensen, p. 277). In other words, 
this, in qualitative case research, involves accuracy in reporting events, behaviours of the people, opinions, experience, and perspectives from their natural states (Yin, 2010).

Interpretative validity involves attaching meaning to the participants' viewpoints (Johnson \& Christensen, 2008; Yin, 2010). Specifically, it "refers to the degree to which the research participants' viewpoints, thoughts, feelings, intentions, experiences are accurately understood by the qualitative researcher and portrayed in the research report" (Johnson \& Christensen, 2008, p. 277). Theoretical validity refers to the state of the act in which the various theories adopted and used fit the data and therefore can be defended because of their credibility (Johnson \& Christensen, 2008). Finally, internal validity deals with establishing and adding meanings to the participants' perspectives from their natural sites or settings at a particular period of time (Johnson \& Christensen, 2008; Yin, 2010). See Table 6, below, for strategies adopted and used to ensure these processes.

Table 6: Steps I Adopted and Used to Ensure the Trustworthiness

\begin{tabular}{|l|l|}
\hline \multicolumn{1}{|c|}{ Descriptions } \\
Method triangulation (Johnson \& & $\begin{array}{l}\text { I adopted and used observations, artefacts collection, } \\
\text { and face-to-face interviews for data collection. }\end{array}$ \\
Christensen, 2008). & $\begin{array}{l}\text { I used data information from the observations, } \\
\text { artefacts collection, face-to-face interviews, and } \\
\text { policy documents in education from the three sites to } \\
\text { help understand this research phenomenon. }\end{array}$ \\
\hline Theory triangulation (Yin, 2010). & $\begin{array}{l}\text { I adopted and used several theories such as } \\
\text { theory to help interpret, understand, and explain the }\end{array}$ \\
\hline
\end{tabular}


Supervisors' checks (Yin, 2010).

External audit (Yin, 2010)

Reflexibility (Johnson \& Christensen, 2008).

Participants' feedback (Johnson \& Christensen, 2008). data. These were used as lenses to interrogate the research data.

The primary and the secondary supervisors were constantly checking the data collections, the analysis, and the interpreting of the data.

The work in progress was sent once every two weeks to the academic support center at Victoria University of Wellington, New Zealand for expert advice.

My two supervisors constantly reminded me of my potential biases and predisposition as I have lived, studied, and worked in the three comparative and international contexts of this study. To avoid this risk, I made available to them some of the participants' transcripts from the sites to familiarize themselves with the data set, especially the secondary supervisor.

Furthermore, they were constantly involved in the selection of the policy documents to be used for this project, especially the secondary supervisor.

Using the Google search engine and through participation in the Ako partnership programme of Victoria University of Wellington, I learned the meaning of some indigenous Māori words that emerged in the New Zealand transcript; for example, Manaakitanga (meaning sharing, caring, generosity and others), Rangatiratanga, (meaning leadership supporting others) and Akoranga (meaning learning and teaching) that came up in the course of the faceto-face interviews. 


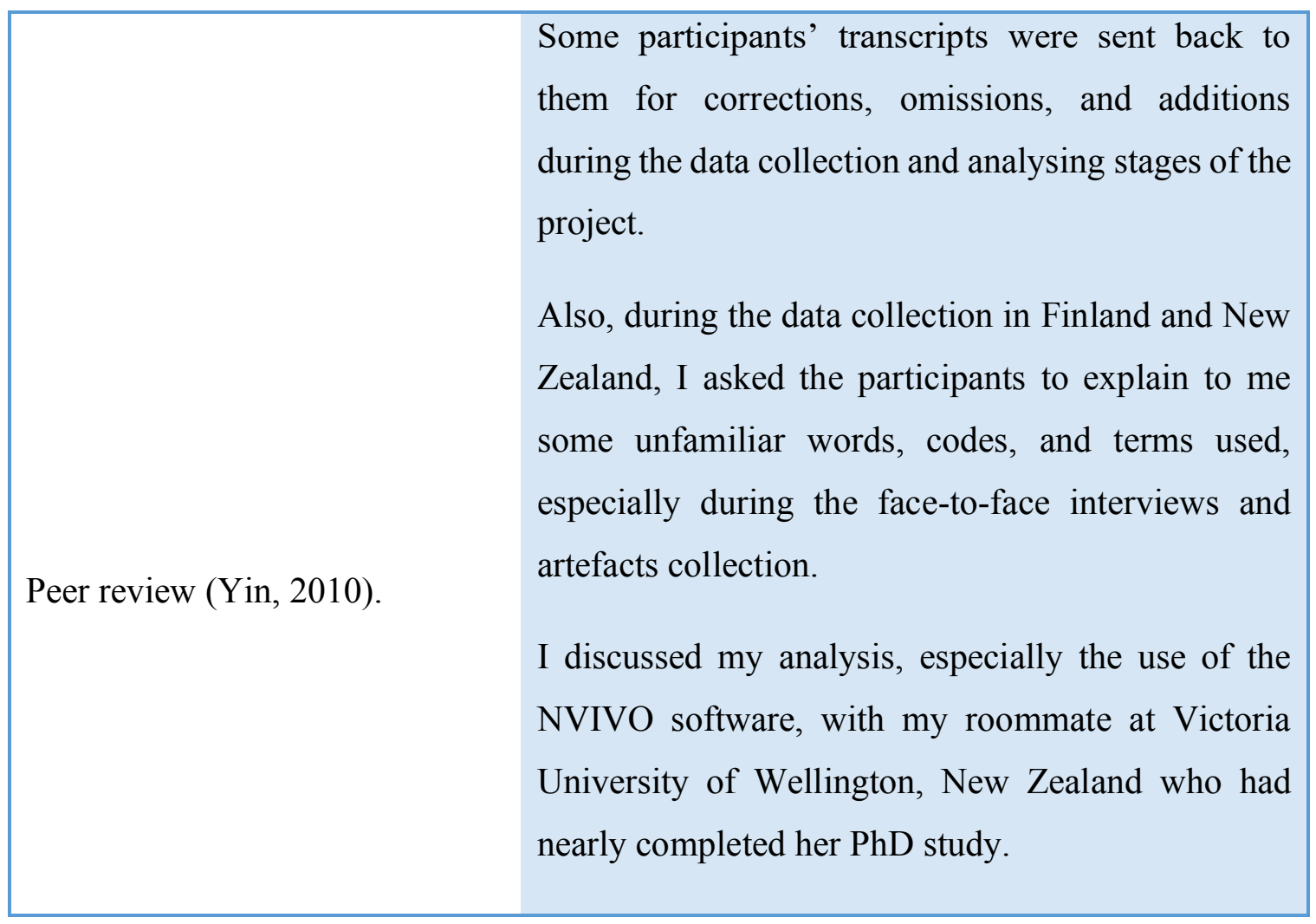




\section{CHAPTER FOUR: Research findings and discussions}

\subsection{Introduction}

This study focuses on the relationships between school culture, climate, leadership, and other contributing factors that foster students' learning, performance, and success in the three sites, New Zealand, Finland, and Ghana. In analysing the strategic policy documents, observations, artefact data, and the face-to-face interviews, three overarching categories were utilised, related to my research questions. They were school culture and climate, school leadership and professional networking communities, and students' needs and support. This analysis has identified the commonalities and dissimilarities of practices across the settings in the three different countries, that impact students' learning outcomes.

This chapter has been divided into three sections. The first part provides an overview of the findings and discussions unique to the strategic policy documents selected and analysed. The second part provides detailed examination, findings, and discussions of the observed practices and artefacts. The chapter concludes by identifying emergent findings and discussion of these related to data from the face-to-face interviews from the three contexts.

\subsection{Strategic policy documents}

After rigorous examination of the selected strategic documents, the following findings were selected from the three sites to report to readers. These have been represented in the Venn diagrams below to showcase the similarities and dissimilarities of these findings across the countries studied.

\subsubsection{Discussion}

These findings under strategic policy documents have been given further interpretations as per each of the diagrams below about what strategic documents are saying in promoting learning and students' development in the countries under study.

\subsubsection{School culture and climate}

Figure 11, below, reports some selected cultural practices that are similar across all the study sites, as well as those that are unique to one country or two. 
Figure 11: Similarities and Differences of Cultural Practices from Policy Documents

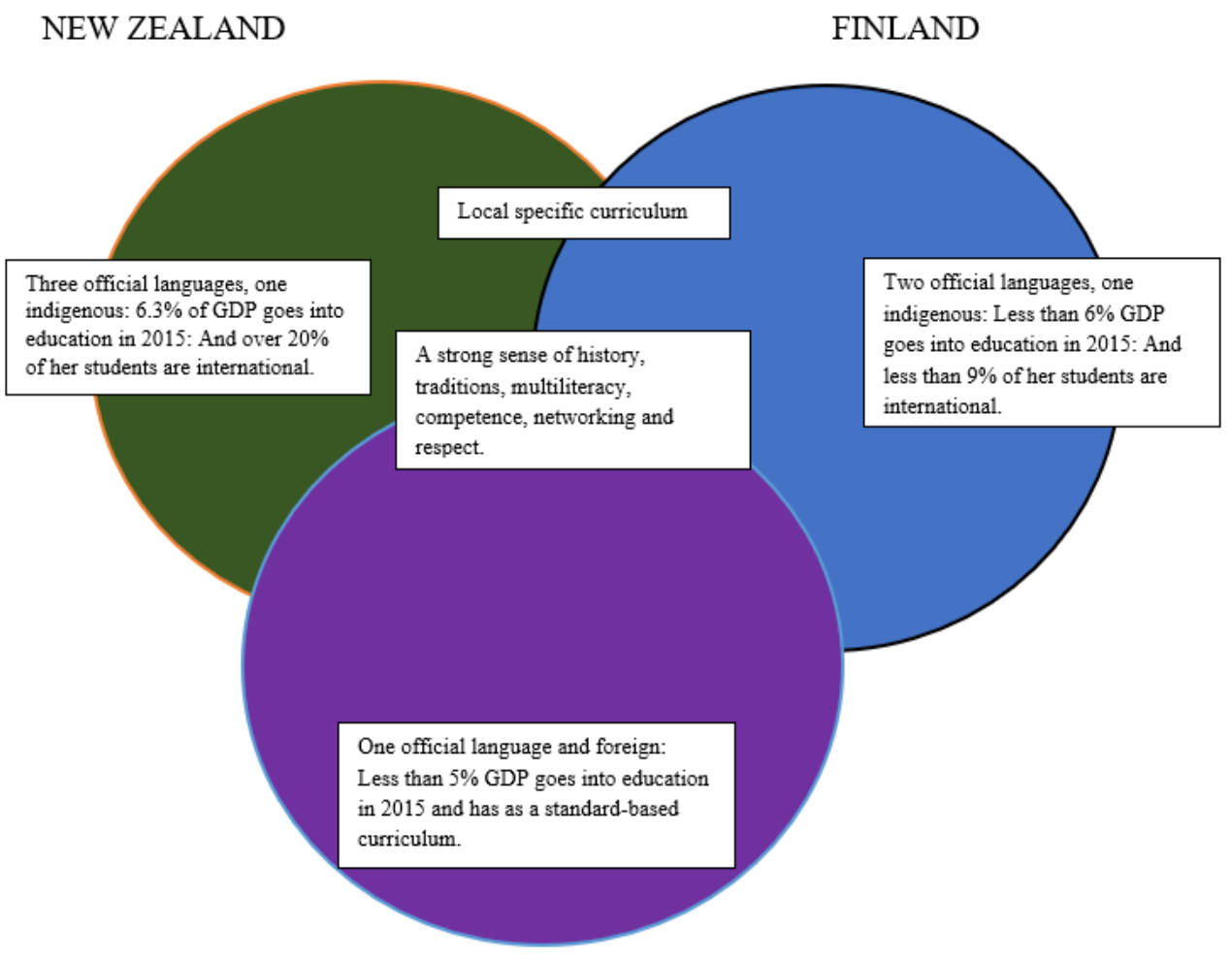

GHANA

\section{Key note}

The word foreign' in the Ghana segment means, the country has one official language, that is English and it is foreign in orgin.

\section{History, traditions, multiliteracy, competence, networks, and respect}

Each country's history, traditions, values, and norms affect the way the citizens behave as well as how they go about their duties over a given period of time (Schein, 2010). These behaviours, or rituals, sometimes become internalised in an organisation as they guide behaviour patterns including what new members have to learn (Deal \& Peterson, 2016).

This statement is supported by New Zealand's school curriculum, which in the preamble states: 
The New Zealand Curriculum is a clear statement of what we deem important in education. It takes as its starting point a vision of our young people as lifelong learners who are confident and creative, connected, and actively involved. It includes a clear set of principles on which to base curriculum decision making. It sets out values that are to be encouraged, modelled, and explored. It defines five key competencies that are critical to sustained learning and effective participation in society and that underline the emphasis on lifelong learning. (MOE, 2007, p. 4)

This curriculum spells out what the country values in as being important in education; what young people ought to know for their growth and development. It also determines the direction by which these values and principles can be achieved (MOE, 2007).

For this reason, history, traditions, and norms are valued as important, especially those of the indigenous people:

Te reo Māori is indigenous to Aotearoa New Zealand. It is a taonga recognised under the Treaty of Waitangi, a primary source of our nation's self-knowledge and identity, and an official language. By understanding and using te reo Māori, New Zealanders become more aware of the role played by the indigenous language and culture in defining and asserting our point of difference in the wider world. (MOE, 2007, p. 14)

This statement is at the heart of the school curriculum and explains the importance of Māori to the history of the country, especially the contributions of the indigenous groups, partnership, mutual understanding, and peaceful coexistence. The statement seems to provide directions in which the state institutions and organisation should be run, especially schools, to improve students' learning, performance and ultimately success, Ka Hikitia, meaning success.

Similarly, in Finland, the national school curriculum specifies that the development of education:

Draws up National Core Curriculum for early childhood education and core, pre-primary education, basic education, general upper secondary education and upper secondary vocational qualifications and the Requirements of Competence-based Qualifications. These documents determine the core objectives, contents and guidelines for teaching. Education providers prepare their own local curricula based on these national documents. (FNBE, 2016, p. 4) 
The national Core curriculum of Finland directs policy directions on education, and especially what the country values as important. For example, the country, which gained independence from Russia in 1917, places much value on their history and traditions and places much emphasis on indigenous Finnish and Saami languages (FNBE, 2016).

Elaborating on this, the independence history is told through schools in the country, especially in the upper secondary school. This enables the students to know where they come from, where they are now, and the direction they are heading (Kangaslahti, 2018). On the other hand, the country takes pride in her indigenous languages and has made them the official languages for medium of instruction as well as transacting government business throughout the country as stated in the national curriculum (FNBE, 2016).

In the same vein, Ghana's National Pre-Tertiary Education Curriculum Framework has this to share in its preamble:

The National Pre-Tertiary Education Curriculum sets out the conception of standards and the learning outcomes to be captured in the subject curricula that are to be achieved by all learners. There is a focus on performance standards rather than objectives. (MOE, 2018, p. iii)

This quote demonstrates how the Finnish national school curriculum gives policy direction in reference to education and its related development throughout the country. For example, the curriculum document indicates that the country values her history, traditions, and culture, stating that Ghana has:

[a] rich, proud history which underpins the people's way of life. Ghanaian traditions include values such as honesty, respect and tolerance that are cherished by the society at large and must be expressed within the educational context. There is therefore, the need to preserve and pass on these values to the younger generation in order to prepare them to participate in and contribute meaningfully to the culture, society, and economy of the country. (MOE, 2018)

Ghana recognises her diverse ethnic nature, history, and traditions. These traditional accepted values are the backbone of the peoples' way of life and must be preserved for the future generations (MOE, 2018). Through educational institutions, these values can be preserved to promote national unity, peaceful coexistence, stability, and national development (GES, 2008). 
All three curricula enshrine multiliteracy, competence, and emphasise that respect of the students and learning must be centred on certain core values (FNBE, 2016; MOE, 2007, 2018). These enable students to think critically for themselves, and to develop cognitive and aesthetic aspects of learning. They also equip students with the needed knowledge and skills to help solve societal challenges and to be competitive globally (FNBE, 2016; MOE, 2007, 2018). Realisation of these values requires a clear instructional language, direction of learning, an adequate budget, human resources, people, and leadership (Bray, 2015; Pepperberg, 2006).

\section{Languages, curriculum, education spending (GDP), and internationalisation}

In a socio-cultural learning context, language plays an important role (Rogoff, 1990). It reflects cultural beliefs and values of people or a community (Wang, Bruce, \& Hughes, 2011). Further to this, language supports various forms of communications among individuals and groups and strengthens relationships between and among people as well as transmitting ideas (Wang et al., 2011) This includes learning and development in all situations (Rogoff, 1990). In New Zealand's curriculum:

\section{Te reo Māori and New Zealand Sign Languages are official languages of New Zealand. English, the medium for teaching and learning in most schools, is a de facto official language by virtue of its widespread use. For this reason, these three languages have special mention in the New Zealand Curriculum. (Newman, 2007, p. 14)}

The country recognises Māori and New Zealand Sign Language and their usage in the school, classroom, and beyond. This is noteworthy in that despite the colonial dominance of the country in the years gone by (Walker, 1990), the country now recognises the indigenous language, Te Reo Māori, as well as English brought by the colonisers, and New Zealand Sign Language as official languages.

For example, the curriculum emphatically states that by learning Māori, students are able to "participate with understanding and confidence in situations where te reo and tikanga Māori predominate and integrate language and cultural understandings into their lives" (Newman, 2007, p. 14).

The New Zealand curriculum reinforces that all the three national languages (Māori, English, and New Zealand sign language) may be used as first or additional languages of 
instruction for guiding teaching and learning process throughout the country. For this reason, the writings hanging on walls of classrooms and outside of school $\mathrm{X}$ were all in English and Māori. See the photo below for an example:

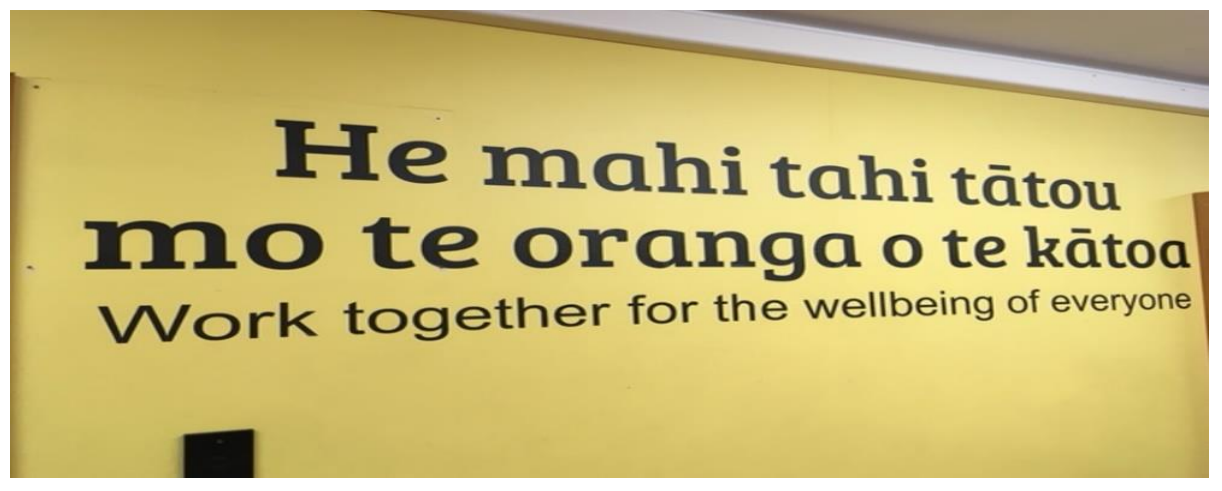

Source: from school X, on $13^{\text {th }}$ of December 2018.

In Finland, the curriculum also prescribes two official languages as the means to guide the teaching and learning process. The two languages are Finnish, which is spoken by about 92 percent of the population, and Swedish, which is spoken by about six percent of the population. Furthermore, the country recognises other languages such as Saami, the indigenous people of northern Finland, which is spoken by 0.03 percent of the population (FNBE, 2016).

Despite Finland's long colonial history with the Swedish and Russians, they recognise their indigenous language as the medium for teaching and learning as well as the mode of conducting government business. One coloniser's language, Swedish, is used as well. It is evident from the documentary analysis that schooling in the areas dominated by Finnish speakers is mostly conducted in Finnish (FNBE, 2016).

In Ghana, the documents revealed that the country recognises English as an official language for teaching and learning and the medium of conducting government business throughout the country. In addition, indigenous languages are recognised in the early stages of teaching and learning. Teachers must speak at least one of the forty nine or more Ghanaian languages used as a medium of instruction (MOE, 2018).

English is the medium used for teaching and learning from class or grade four up to the university levels of education throughout the country. None of the indigenous languages are official but can be used for teaching and learning from the early stages of the pupils' 
learning up to class or grade of four. This development of Ghana's association with English is partly because of her long-standing colonial history with the British despite her numerous ethnic and tribal languages.

Furthermore, a national curriculum spells out the direction for teaching and learning through the vision statement, purpose, values, principles, competence, and many others of a given society or country over a given period of time (FNBE, 2016).

New Zealand and Finland have national curricula with local specifics (FNBE, 2016; MOE, 2007). That is to say the schools have to look at these national curricula to design their school-based ones. The national curricula of these two countries give municipalities, districts schools, principals, and teachers the autonomy to prepare their own specific curricula to guide the learning process based on the national standards. This implies that the curriculum of the two countries allow schools much flexibility and autonomy.

On the other hand, Ghana's curriculum places much emphasis on national standards with less local autonomy and flexibility given to the municipalities, districts, and schools. This is depicted in the curriculum as:

The role of this framework is to emphasis the construction, application and use of knowledge in our schools by setting national standards. These national standards in turn can provide opportunities for directing learning and instruction. Furthermore, it allows for the appropriate management, assessment, since learning outcomes can be measured against comparable standards. As such, learning outcomes can be appropriately measured as indicator of the quality of the educational system. (MOE, 2018, p. 18)

Elaborating on this quote, Ghana's curriculum places much premium on national standards as the way to direct teaching and learning. Its emphasis is on measurement of individual learning outcomes through a national testing system used as means to compare and determine educational quality and learning. Ghana's strong emphasis on these concepts has a long neoliberal history, dating from the 1980s. This was partly because of the Structural Adjustment Program SAP introduced by the IMF and the World Bank (IMF, 1999) with the requirement that the state had to deregulate, standardise, and market education as well as allow schools to be accountable and compete (Huff, 2013). These principles are still felt in the education system of the country today as seen in the curriculum focus on measurement of outcomes. 
Countries' performances in education can be compared by international indexes or indicators, especially those who are the OECD's members (Rust \& Verran, 2018). Paying attention to these indicators on the global stage provides a country with an indication of comparative positions (OECD, 2018b).

The OECD's documents indicate that New Zealand's government spent $6.3 \%$ of her GDP on education in the year 2015. This was the second highest among all the OECD countries after Norway (Rust \& Verran, 2018). While the government of Finland in the same year spent less than $6 \%$ of her GDP on education, this was still above the OECD average of $5 \%$, and took the $13^{\text {th }}$ position on the ranking list (OECD, 2018b; Rust \& Verran, 2018). On the same score, in 2015, the Government of Ghana spent $4.51 \%$ of her total GDP on education (UNESCO, 2019b). These outlays seem to suggest that the respective governments of the three countries see education as an important asset and investment for socio-economic development.

Internationalisation has become a part of the world globalised system as people try to seek knowledge, skills, marriage, and other opportunities from different countries (Rust \& Verran, 2018). In 2016, “20\% of New Zealand's tertiary students were international students, the second highest share in the OECD and well above the average of $6 \%$ " (Rust \& Verran, 2018, p. 8). In contrast, Finland has less than 10\% of her students coming from outside (OECD, 2018b). Between 2010 and 2017, the country attracted 6 percent to 8 percent international students, especially from Asia, the other Nordic countries, the rest of Europe, and the Russia Federation, and still above the OECD average of six percent (OECD, 2019).

New Zealand seems to attract overseas students by offering quality education. This may be because the country enjoys quality education, peace and security, stability, scholarship, and many other opportunities. Comparatively, Finland seems to appear far less attractive than New Zealand in terms of overseas students.

Furthermore, the following data in relation to school climate were identified from the strategic documents from three sites and their meanings have been discussed under the preceding sections. See the Venn diagram below for these findings followed by the discussions. 
Figure 12: Strategic Documentary Findings on School Culture

New Zealand

Finland

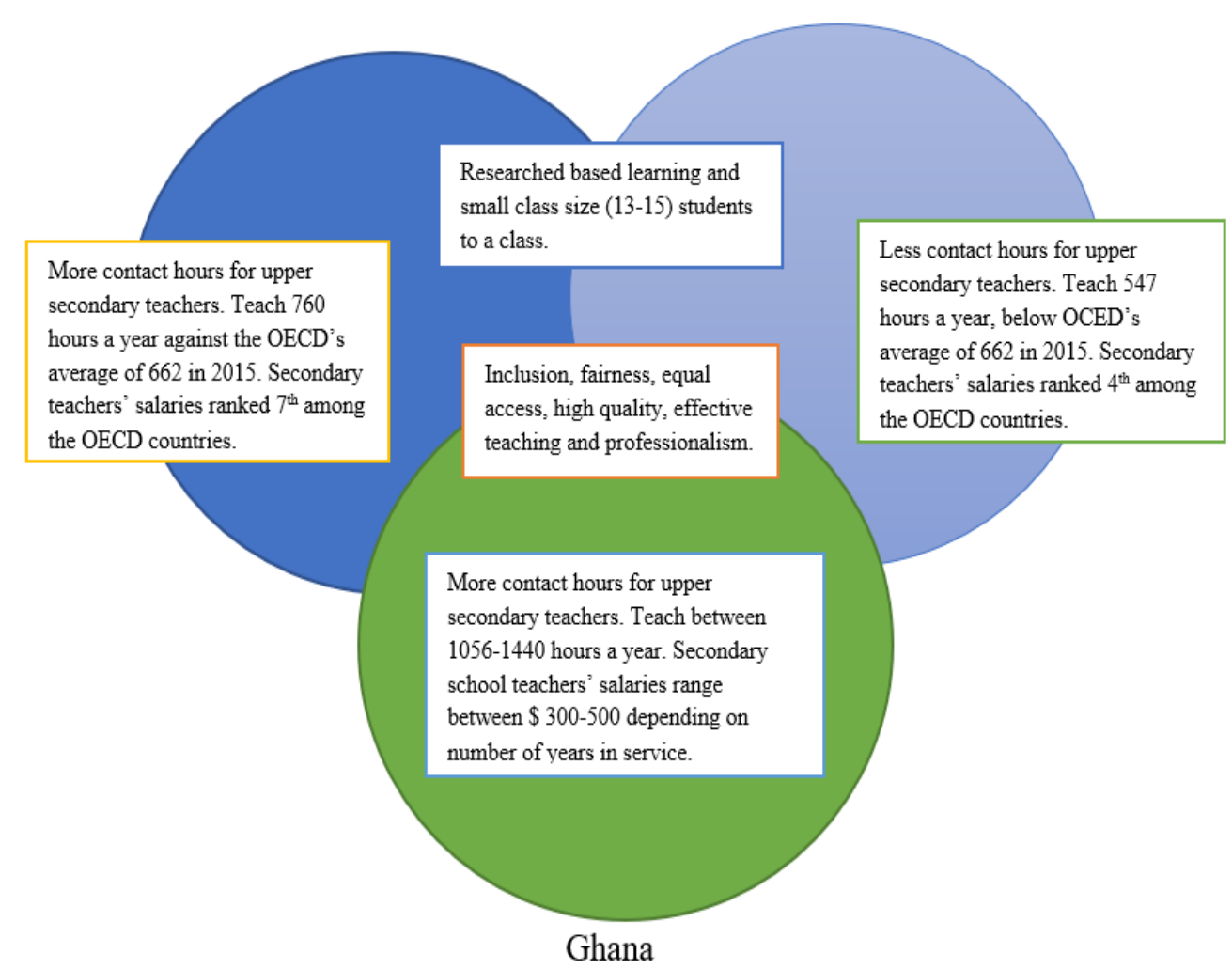

\section{Teachers' contact hours and salaries}

Teachers working conditions including statutory salaries, working hours, and class size have influence on teaching and learning (OECD, 2018a). Teachers in the upper secondary school in New Zealand have more contact hours of teaching than most of their OECD counterparts. They teach 760 hours in a year matching the OECD's average of 760 in 2015 (Scott \& Norgrove, 2017). In Finland, teachers teach 547 hours a year which is below the same average of the OECD (OECD, 2019). In Ghana, teachers on the same score have more contact hours of teaching. They teach 24-30 hours a week which is between 1056-1440 hours a year (ILO, 2019).

In terms of salaries, New Zealand teachers' salaries ranked $7^{\text {th }}$ in 2015 (Scott \& Norgrove, 2017) while Finland was ranked $4^{\text {th }}$ on the OECD's salary indicator for the year in 2015 (OECD, 2018a). In the same vein, in Ghana the secondary teachers' salaries 
range between 300-500 US dollars depending on the person's scale and rank of the educational ladder (ILO, 2019).

\section{ICT and class size}

Most curricula of countries make provision for the kinds of knowledge and skills needed for their citizens to strive, including information communication technology (FNBE, 2016; MOE, 2007). Interestingly, research-based learning was identified in the curricula of New Zealand and Finland as a means to improve quality learning, students' performance, and success (FNBE, 2016; MOE, 2007). In a similar vein, Ghana's accelerated development policy framework on ICT has this to say, "The main mission [is] to transform Ghana into an information-rich, knowledge-based and technologydriven high-income economy and society" (MOE, 2018, p. 11).

It was evident from the reviewed documents that New Zealand and Finland have relatively small class sizes of between 13 and 15 students to a class; this was within the OECD's average of 15 in the year 2015 (Scott \& Norgrove, 2017). Comparatively, in Ghana, student-teacher ratio range on average is 27-28 per a class (UNESCO, 2019a).

\section{Inclusion, equity, equal access, high quality, and effective teaching}

The curricula and the professional code of ethics of the countries under study highlight a number of principles (EC, 2017; FNBE, 2016; MOE, 2017b). They identify inclusion equity, fairness and equal access, high quality teaching, and professionalism as effective ways to promote students' learning, and to improve their performance and success. It is argued that these values and principles must be applied to all students in the country irrespective of their tribes, colour, gender, ethnicity, sex, and religion (EC, 2017; Kaniņš $\&$ Golubeva, 2017). For example, the code of professional responsibilities and standards for teachers in New Zealand established the following care values for guiding teaching and learning:

WHAKAMANA: empowering all learners to reach their highest potentials by providing high quality education. MANAAKITANGA: creating a welcoming, caring and creative learning environment that treats everyone with respect and dignity. PONO: showing integrity by acting in ways that are fair, honest, ethical and just and WHANAUNGANGA: engaging in positive and collaborative 
relationship with our learners, their families and whanau, our colleagues and the wider community. (EC, 2017, p. 2)

In Finland, the ethical principles are reflected in the teachers' professional code. They include trust, accountability, personal and system improvement, quality education, democratic governance, fairness, integrity, and many others as means to ensure equality and equity among students of all ages (FNBE, 2016). These principles are backed by the United Nations Universal Declaration of Human Rights (Kaniṇš \& Golubeva, 2017).

In the same vein, the inclusive education policy of Ghana established that:

every child has the right and can learn. Hence, the Universal Design for learning model is the super structure upon which the policy is expected to deliver quality equitable education to all. (MOE, 2013, p. 4)

The national documents of these countries have highlighted these provisions as a means to create equal opportunities and an enabling environment for every student to identify his or her inalienable rights. These principles include fairness in relation to resource allocation, teachers' feedback, marking, sense of judgement, and many others which are within the framework of the United Nations Universal Declaration of Human Rights created shortly after the Second World War, 1939-1945 (UN, 2019).

\subsubsection{School leadership and professional networking communities}

The role of leadership in an organisation must be underestimated because leaders act as the pivot for the effectiveness of an organisation (Yukl, 2010). For this reason, within the professional code for teachers and the curricula for the three countries, values and expectations for leaders are outlined.

\section{Local specific standards and autonomy}

The curriculum and code of conduct of every nation act as tools to help teachers and education stakeholders to understand the standards of conduct that are expected and also underpin their decision-making processes (MOE, 2007). These documents specify integrity measures expected from organisational members within the profession (EC, 2017; MOE, 2013). 
The professional codes for schools and teachers of New Zealand and Finland advocate local specific standards for schools and teachers in relation to the issue of autonomy (EC, 2017; Kaniņš \& Golubeva, 2017). For example, the Code for Professional Responsibility and Standards for Teaching Profession of New Zealand affirms this in this manner: "The standards are purposely designed at a high level, so every practitioner can apply them to suit the context they are working in" (EC, 2017, p. 14).

On the other hand, their counterparts in Ghana have national specific standards (MOE, 2017b). This is demonstrated in the national teachers' standards as:

\begin{abstract}
These standards are designed to improve the quality of teachers' delivery and students' performance and should therefore be used as a reference tool for students, teachers, teacher educators, practising teachers, head teachers, mentors, school, inspectors and all who are working at training students. The standards will also enable teacher educators and others to direct their efforts opportunely to the area student teachers need most support. (MOE, 2017b, p. 4)
\end{abstract}

Local autonomy in New Zealand and Finland schools give teachers freedom to decide on assessment, and to choose learning materials and pedagogy to facilitate the teaching and learning process. Conversely, the national specific standards in Ghana assess teaching and learning as well as teachers' conduct against national standards.

\title{
Ethical leadership, high quality teaching, and professionalism
}

The national teachers' codes and standards for the three countries recognise school leaders who are of high moral standard and who exhibit high-quality teaching practice and professionalism at school and beyond at all times (EC, 2017; Kaniņš \& Golubeva, 2017; MOE, 2017b).

In the latest PISA results in 2018, New Zealand continues to slide downwards. The country has had nine years of prescribed national standards in literacy and numeracy, which were recently removed by the current government. Nevertheless, the standards are likely to have engendered the decline (McGregor \& Medina, 2019).

Finland's reading literacy results in PISA shares second place with Canada, and in natural sciences the country ranked third among all the OECD countries in 2018. Nevertheless, 
the country gathered fewer points than it did in previous PISA surveys since 2000 (MOFA, 2019).

Ghana is still not a member of the OECD although, as reiterated by the ministry's official during the interviews, plans were underway to join the organisation in the year 2020 (Interview data, 22/08/2018). This international benchmarking especially the one from the OECD seems useful to countries as intended to point out lapses in their educational systems as well as offering indications intended to improve teachers' professional competencies and students' learning outcomes (OECD, 2018a).

The notion of professional learning communities has featured in the quest to improve school effectiveness. Organisations aspiring to be more professional need a shared purpose and vision, and to use collaboration, research-based inquiry and learning, contemporary data information, and best practices to improve students' learning outcomes (Easton, 2011). The code of professional responsibility and curricula of the two countries, New Zealand and Finland, explicitly state an expectation of commitment to the teaching profession, learners, families, and the larger community including, trust, care, love, and accountability (EC, 2017; Kaniņš \& Golubeva, 2017). Ghana's document explicitly states the dos and don'ts of teachers including community engagement, collaboration, and participation (GES, 2008).

\subsubsection{Students' needs and support}

Finally, reference to the following student needs and support were discovered in the strategic documents from each of the three sites. They include information technology, human rights, and safety and wellbeing as means to support and improve the teaching and learning process in all of the contexts (FNBE, 2016; MOE, 2007, 2018). These findings from the strategic policy documents were aligned with the observations, artefacts, and interview data in order to understand the actual happenings on the ground in the three research sites.

\subsection{Observed practices and artifacts}

\subsubsection{Introduction}

After several months of interrogation of the research data, specifically the observed practices and artefacts, the findings presented in this chapter emerged. These have been 
given interpretations under the three themes identified earlier on. However, before that brief backgrounds of the three selected schools are presented.

\subsubsection{Brief background of the three selected schools}

School X in New Zealand is a government funded school with more than one thousand five hundred students and requires the wearing of a school uniform. There are a little over one hundred and fifty staff, including teachers, principals, and non-teaching staff (Field data, 15/12/2018).

School $\mathrm{Y}$ in Finland is a university school funded by the central government through the municipality. It has almost two thousand students and a little over one hundred teaching and non-teaching staff. It does not have a school uniform and is a bit different from the typical Finnish traditional school where the Finnish mode of instruction is entirely used. It uses the International Baccalaureate IB syllabus to guide the learning process (Field data, 14/04/2018).

Comparatively, school $\mathrm{Z}$ in Ghana is a government approved one. It has almost three thousand students who wear a school uniform. It has a little over one hundred and fifty staff including teaching and non-teaching staff (Field data, 16/07/2018).

\subsubsection{School culture and climate}

The following cultural characteristics were observed in the three schools within the three sites. See the Venn diagram below for a brief summary followed by discussions. 
Figure 13: Observed Practices of School Culture

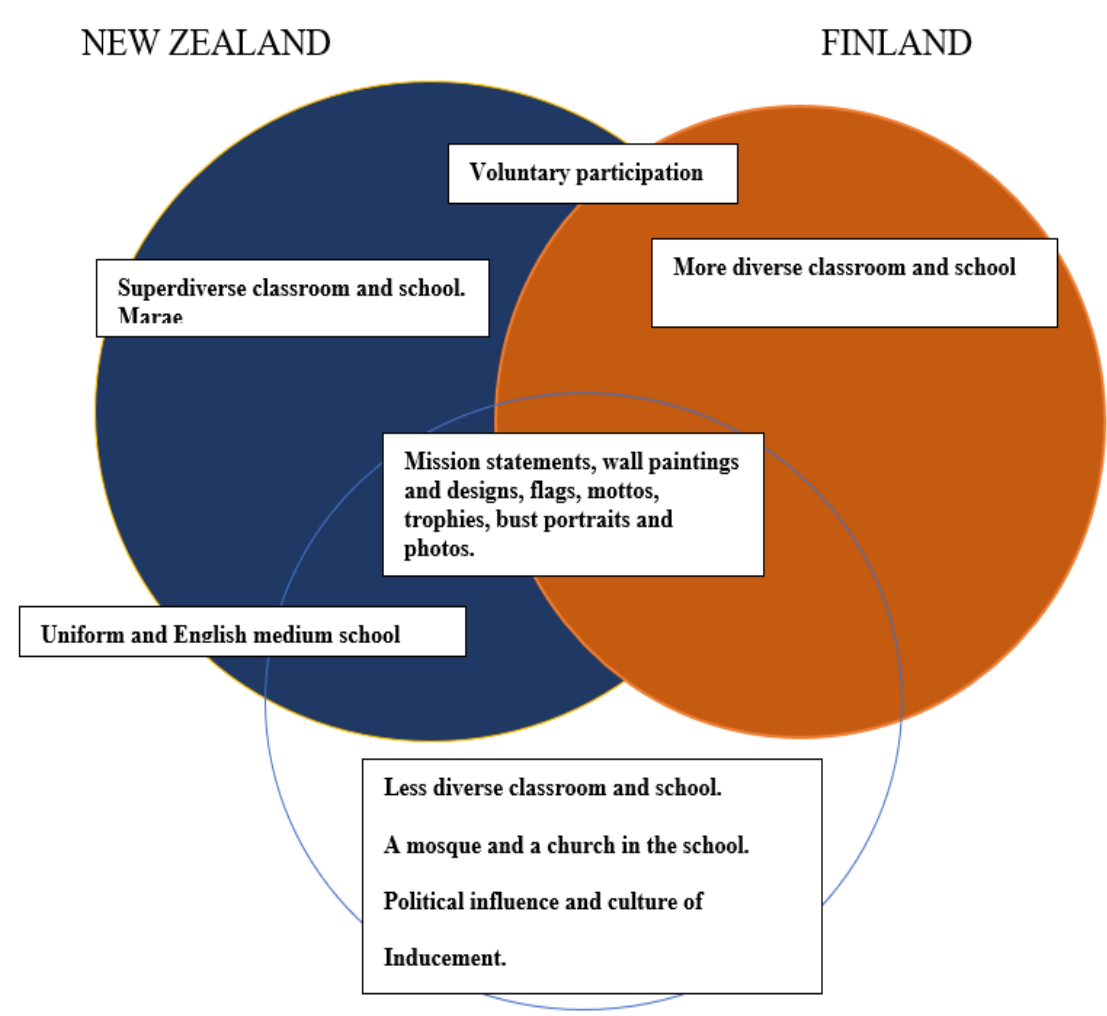

GHANA

The use of the words "more" and "less" in the Figure 13 above is explained in the discussions below.

\section{Culture of nepotism and tribalism}

Nepotism, tribalism, and ethnicity sometime takes centre stage in African politics and institutions (Lentz \& Nugent, 2000). Ghana is an African nation with over sixty indigenous tribal languages (Bemile, 2000; Lentz \& Nugent, 2000). However, this beautiful multicultural and multilingual environment sometimes can spark tensions, antagonism, and the worst form is violent conflict (Lentz \& Nugent, 2000).

In view of this, my general observation in one of the institutions studied in Ghana indicated that the issue of tribalism and nepotism may play a role in service delivery, especially within educational settings. Observational reflections from the fieldnotes indicate a strong nepotism in service delivery within an observed institution. To buttress this with a fact, I was required to pass through a series of bureaucratic structures before 
access could be gained for my research participants. The two persons in charge that I was directed to and spoke with were of the view that they had been transferred from their previous roles (Interview data, 28/08/2018).

In Ghana, the university expert commented that:

Yes, one could for instance (indicate) where one comes from and individuals from different tribes or ethnic groups don't want to mix with others. This is a very diverse society so these (are) some of the challenges... but we try as much as possible to educate students to know why there is the need for them to work collaboratively. (University expert, 14/08/2018)

Later, when answering a question in connection with teacher shortages and recruitment processes, the expert remarked that:

At times, it is not that we don't have the trained teachers but because of nepotism and favouritism. Some mighty ones at the top, or those in power of affairs, will put their people, tribesmen or women, in the classrooms (University's expert, 14/08/2018).

Furthermore, other participants identified the same challenge; for example, in the following:

Especially the political leaders and those people at the Ministry of Education do this. There are equally good people who qualify to teach and are denied the opportunity to be in the classrooms. (Interview data, $15 / 07 / 2018)$

Expanding on the quotes above, ethnicity and tribalism have been seen and felt in all aspects of the Ghanaian society especially in politics and education (Chazan, 1982). This finding was interesting because, as expressed by the expert, this tribalism has gained much root in the moral fibre of institutions including the universities in the country. In effect, as remarked by the expert, this has created a big challenge for educators in trying to initiate a collaborative learning environment between students from different backgrounds. Manifestation of this social disorder also takes place in teacher recruitment processes and the posting system in the country as reiterated above. Consequently, the situation breeds unqualified teachers in the teaching profession while other, better qualified teachers are not employed.

\section{History, traditions, and symbols}


The following symbols and cultural practices were visible in the three schools studied. They included mission statements, wall paintings, flags, mottos, trophies, bust portraits, and photos. They serve as symbolic reminders to help school actors, including students, to remember where they have come from, where they are now, and where they are heading to.

The history of New Zealand was affirmed by all the participants, including the teachers, the principals, headmasters or headmistress, ministry officials and the university experts as something of significance to students' learning (Interview data, 09/11/2019).

New Zealand was colonised by the British as a result of Māori agreeing to an 1840 Treaty of Waitangi, and whilst the commitments to Māori in the treaty were ignored for 135 years, since 1975 the government has begun to address these obligations, including in education (Walker, 1990). For example, one of the interviewees in New Zealand expressed his opinion on this as:

I think the Treaty has been around mainly about a hundred or so years and within those years we have ups and downs about how to implement them in daily practices. So, we tend to have a discussion in every classroom about the Treaty and its implication for all of us. Because every time we do so, someone is going to tell you "I come from here or there", so we try to have some sort of very long discussions for people to understand that it relates to all of us. For me, what people call the [Treaty] principles of protection, participation, and partnership are quite important for me and our students, particularly in our education. And, it relates to the idea that the Treaty is very relational and a very vivid document about the injustice which happened during colonialization and continuing in a way; and we are all sort of victims in one way or the other. So those are the things that don't have necessary answers to repeat them, but they are something that we discuss, something that we all struggle with and the struggle continues. So, it is an ongoing practice. That will be my take on it. (Interview data, $14 / 11 / 2019)$

In Finland, everyone interviewed emphasised the importance of history, traditions, and rituals on their daily task. One of them shared his or her experience as:

Here in the University of Helsinki, we have two teacher training schools: Helsinki Normal Lyceum and Vikki teacher training school. And then both schools have quite a history. Normal Lyceum is now 151 years and Vikki is 149 years old. So, our teacher training schools are very old and very traditional schools. They are here in Finland we have only one older Finnish school. Until early 1970s, this Normal 
Lyceum was a boys' school and Vikki teacher training was a girls' school, and then after the early 70s, when we changed our educational system to basic education system, both schools started taking in boys and girls. Our teachers here in Finland, they have practiced in our teacher training schools a long time and it is part of our long history. (University's expert, 24/04/ 2018)

Comparatively, in Ghana, all the participants expressed that history is important to them in their work, and that it impacts the way they carry out their duties in supporting students' learning. One of the teachers shared his experience to this effect as:

Yes, there is also stool, a stool is a traditional as it was, let me use a "chair" over here, we called it a stool, or a traditional chair. It symbolises kinship per se and because the school is named after a royal and then the stool has a linkage with the person that the school has been named after, so is relevant and if you could see the main gate of the school the structure is even carved in relation to the stool that we have in the logo. (Interview data, 16/07/2018)

These comments seemed to provide evidence of the importance of history to the schools in relation to students' learning. Findings in relation to the artefacts observed in the three sites also demonstrate the significance of history, traditions, and other rituals to students' learning outcomes. For example, in school X, New Zealand, the leaders shared that building positive culture and climate through haka (Māori war dance) and sports plays a key role in students' learning and development (Fieldnote, 16/12/2019).

Again, the importance of the haka and sports are emphasised by some interviewees in the school $\mathrm{X}$ as ceremonial rituals. As one of thoses interviewees opined, the significance of sports and haka are to develop physical, emotional, and psychological wellbeing of the students (Fieldnote, 14/11/2019).

In the same vein, another interviewee emphasised that haka is:

an indigenous art forms. It is the way we are expressing identity, language, and culture quite practically. I quite enjoy it. It is like any learner defines the thing they like doing and let them do it. It gives them a way of being Māori and being with other people who are like them in the school setting. The boy's schools have adopted the haka as part of their Rugby programme and the whole school learns the haka. It is so close and associated with their national sports. So, you can see six hundred school boys doing the school haka and then that is about being part of the school. (Interview data, 26/10.2019) 
Elaborating on the quotation above, it appeared that the indigenous dance helped the group, especially Māori students, to identify their identity as well as their unique culture. Also, it served as a source of entrainment for boys and was associated in schools and national sports. The quotation produces evidence of how the haka challenge and sports played a crucial role for students' development in the school.

Comparatively, in Finland, some artefacts that I observed in the school expressed the importance of culture and climate, especially history and sports, to students' development (Fieldnote, 24, 03/2018). The pictures hanging on the walls of the school that I observed show that the school values history, especially the role of the Veterans in the Second World War (1939-1945), and sports as means to improve students' wellbeing and development (Fieldnote, 26/04/2018).

Valuing one's history especially the national anthem and the Independence Day celebration plays a significant role in students' learning outcomes. This was expressed in the interview data from Finland as:

We sing the Finnish national anthem once a year when we have our Independence Day celebration. We have that every year in December and the national anthem is sung there with the students; and in Finland, we have days where we have the flag on the flagpole. We have some days where we hoist such flags on the poles. We do that. Every school has one flagpole. That is the way we keep the tradition going in Finland (Interview data, 24/04/2018)

Again, on the issue of sports, another teacher shared his opinion as: "Yeah, we play indoor hockey twice a week. There are about 10-15 players who play that for fun" (Teacher E, 24/06/2018).

These artefacts and comments seem to provide evidence of the role history and sports play in students' development in two schools in New Zealand and Finland. These influence the teachers' approach to their daily teaching.

In Ghana, the teachers also recounted the importance of traditions and sports to their daily activities (Fieldnote, 16/07/2018). This is also expressed on the school's walls and compound. For example, I observed the culture whereby students wore uniforms in school Z, and in the school compound was a bust portrait. The portrait has royal 
connotation as the school was established by a king of Kumasi Ghana (Fieldnote, 16/07/2018).

Photos showing the importance of athletics and sports hanging on the walls of the classrooms and in the office of the principal of school $\mathrm{Z}$ were of significance. For example, one of the interviewees noted that athletics and sports build the affective, cognitive, and psychomotor development of students for their learning (Fieldnote, 16/07/2018).

The significance of these artefacts was also expressed in the interview data. One of the interviewees explained:

The school started as Ashanti Collegiate in the former location called Asafo, a suburb of Kumasi. The school aim I am told was to educate the royals. That is Otumfour, royal family, Osei Tutu, the king and his family and those related to him and the Crown. When the school grew up, it then moved from Asafo to Dicheamso. That is also a suburb of Kumasi. As time went by, the government absorbed it and it became a government assisted senior secondary school. The school is now 70 or so years old. (Interview data, 16/07/2018)

Furthermore, all the teachers in the school emphasised that building the culture of sports has a relationship to students' development. A teacher shared this opinion:

Apart from academic work, the school was noted for sports, so far as sporting activities are concerned. Within the country now, the school is among the best schools noted for sporting activities. Sporting activities cuts across many areas, particularly field with football and many others. When it comes to athletics, we are there; when it comes to table tennis, volleyball, we are there. Every aspect concerning sports we are available. (Interview date, 16/07/2018)

According to (Bolman \& Deal, 2013), organisational rituals and symbols help unique identification of members within a given society. For this reason, the two schools, New Zealand and Ghana have unique uniforms to distinguish themselves from other schools and students (Field note).

The importance of the uniform in school $\mathrm{Z}$ in Ghana was expressed by one of the teachers as:

When you look at our students' outfit dress code, the particular colours of the school (are) green and yellow. So, at the initial stage, the students were wearing the green outfit, especially the girls, as a school uniform. 
But later on, it was changed to become the yellowish, and then green combined the green. We are still maintaining it so that is our colour. So, when you look at the buildings, the structures around, all of them have been painted yellow and then green colours. (Interview data, 17/07/2018)

This dress code can be viewed as providing a shared sense of belonging, and of community for common purpose, identification, and uniformity. This can be interpreted as subjugating the personality and individuality of students. However; it can also be interpreted as an attempt to even out socio-economic inequalities, so can be seen as an equity measure.

The Ghanaian Education Ministry expert explained that the Government of Ghana provides the students with free uniforms, especially public schools, with the intention being to reduce socio-economic complexities that affect students' learning, performance, and ultimately success.

On the other hand, school Y, Finland, does not have a uniform and students remove their shoes and jackets before going into their classrooms. One of the teachers explained that:

The kids hang their clothes outside the classroom and take their shoes off at all times. ... when you go to any Finnish home, the first thing is to take off your shoes. It's not like America or where you came from where you will be walking, and you bring the shoes into the room. But in Finnish homes, you must take off your shoes. (Interview data, 24/04/2018)

Also, a teacher explained that the removal of shoes was recommended but optional. This was how she expressed this:

Yeah, it is normal to take off jacket and shoes in Finland. The shoes, in the new school, we have a carpet, and to keep the carpet clean and nice, we have recommended that they should have shoes that are meant for indoors and if they want to take their shoes off, they can do so. They can decide which one they want. (Interview data, 24/04/2018)

In conclusion, almost all the participants remarked that the school's culture including history, traditions, rituals, symbols such as songs, dress code, and trophies seemed to have some importance on the development of a school.

These findings emphasised the importance of the impact of the macro factors within the organisational units. These macro factors consist of various roles of cultural values, such 
as history, traditions and symbols, students' parents, community, ministries, networks, and partnerships (Fullan \& Langworthy, 2014). They have strong influence on the dayto-day activities of the school..

Successful leaders who want to influence learning outcomes of their students must first understand the traditions and history of the context in which they are working, and from here build connections through influencing political, class, cultural, and community leaders and others stakeholders in order to enhance learning and teaching (Leithwood, Sun, \& Pollock, 2017).

\section{Diversity}

New Zealand has recently been recognised as demonstrating a situation of superdiversity, due to the influx of diverse immigrants in recent year (Royal Society of New Zealand, 2013). Artefacts were displayed on walls of classrooms to exhibit how diversity is important and expressed in school X in New Zealand. For example, as explained by an interviewee, flags of the various nationalities of students were displayed on walls of the classroom to signify unity and common purpose (Interview data, 17/12/2018).

Comparatively, I did not observe a similar display in the few classrooms I visited in Finland and Ghana.

The teacher $\mathrm{D}$ in school $\mathrm{X}$ reaffirmed this recognition of ethnic diversity with the following remarks from the interview data:

New Zealand is different because we have a lot of various people from various different groups. We wanted to create a shared value and it really hard. I think our education system has really done well because our education is internationally and locally respected. (Interview data, $17 / 12 / 2018)$

Similarly, his counterpart from Finland had this to share:

Since I came from the high school sector, I am mainly giving you some examples from that sector. I don't know if somebody has told you, we have 50 nationalities under the same roof here. So international colours show that we are multicultural. We do not even recognise even somebody is an original Finnish or whatever or where she or he is from. That is what I will mention for now. Because, this is the most international school in Finland. I think the last number I heard was 47 nationalities, of course. (Interview data, 24/04/2018) 
In the same vein, school $\mathrm{Z}$ in Ghana taught students from different tribal groups. This was explaines by the university's expert in the following:

In this country, I will say we have depending on where the school is located. For instance, if the school is in the capital region, the indigenous people are the Gas, if you go to maybe the central region, the indigenous people are the Fantis. Where the school is situated or located, the indigenous people in that area dominate the schools. (University's expert, 27/07/2018)

The principal of the school $\mathrm{X}$ in New Zealand reiterated that his school has one hundred or more international students, of which 20 percent have just come to study, and the remaining were those who have already acquired New Zealand's residence (Fieldnote, 17/12/2018). New Zealand has more of her students coming from outside than Finland and Ghana. These findings on internationalisation are consistent with previous findings (Scott \& Norgrove, 2017; Spoonley, 2015).

These findings support the recent study of improving schools and leadership to enhance students learning outcomes and success (Fullan, Hill, \& Rincón-Gallardo, 2017). The study noted that deep seated changes are needed at the macro and micro levels of schools. to especially, leaders' interpersonal and cultural competencies.

Further research affirms that successful school leaders must be culturally sensitive to the context under which they work (Leithwood, Harris, \& Hopkins, 2008). Issues including history, cultures, customs, traditions, and local norms must be given attention in order to improve the learning environment (Fullan, 2007). To make this a reality, the principal must demonstrate a high level of cultural competence in leading the school (Day \& Sammons, 2013) and this has become necessary due to the increasingly complex makeup of today's societies (Gurr, 2015).

School leaders demonstrating understanding of the context under which they operate may optimise their chances of success (Day \& Sammons, 2013). Strategies include: improving working relations with different members and cultures within the school (Hoy, 1990); utilising mediation and moderation as tools to address mixed feelings among and between organisational members to enhance the working climate (Fullan, 2007; Leithwood, Harris, \& Hopkins, 2008); and demonstrating understanding of various spiritual beliefs and practices of personnel and students in order to improve teaching and learning (Gurr, 2015). 


\section{Spiritual beliefs and practices}

Practices in a particular community or society play a part in the socio-cultural complexity web (Rosa \& Montero, 1990). In my observation in school X in New Zealand on $17^{\text {th }}$ December 2018, I saw the Māori culture of the marae - a traditional Māori community meeting place - used in support of students' learning, especially the Māori students. The woman in attendance at the marae remarked that the facility offered religious and education purposes When probed further for explanation, she was hesitant to speak further. It is possible that there was some form of sacred knowledge she did not want me to hear or know about, or that it was not her role to convey such, because she was not comfortable explaining every detail to me and I therefore assumed that perhaps some history of the marae is not meant for public consumption and must be kept sacred (Fieldnote, 15/12/2018).

This school was a former Christian school and therefore has a Christian chaplain who is in charge of students' religious growth and development. She supports the guidance and counselling especially, spiritual growth and wellbeing matters (Fieldnote, 15/12.2018)

Comparatively, school $\mathrm{Z}$ in Ghana has a church and a mosque built to support spiritual wellbeing and development of its students (Fieldnote, 16/07/2018).

Most of the teachers in school Z stated that these facilities support the physical, psychological, and spiritual growth of the students (Fieldnote, 16/07/2018). This is what a teacher stated in relation to religion within the school culture:

Yes, every Sunday the children, you know, they have got their religious denominations. Therefore, some are Catholics, some are Presbyterians, some are the Adventist, so when it is [the] is weekend the classroom is empty. They don't go to school, they don't attend class. Therefore, the children have got the right to go and worship. Let's say this is also culture, so when they worship they are worshipping their God, so each religious denomination has a place where they meet to worship God. (Interview data, 18/07/2018)

Another teacher in school Z, in Ghana, supported the importance of religion pertaining students' growth and development in this way:

So, during the morning assemblies before we start everything, we have a preacher who comes around to preach to the students so that they have the spiritual growth apart from the academic work. We have to 
make sure that we get spiritual growth, so the preacher comes around. Either we get the preacher from outside or a teacher preacher or a student preacher before we start the morning assembly. (Interview data, $18 / 07 / 2018$ )

On the other hand, in Finland, the school has no chaplain or Imam. However, the teacher of Religion, Psychology, and Philosophy teaches all forms of religions. He or she does not see himself as a Christian chaplain or an Iman or anything else, but supports students in relation to their individual spiritual and religious growth and development. (Fieldnote, 24/04/2018).

This finding is similar to that of previous research which indicates that cultural values including religious beliefs and practices can act as a catalyst for school improvement to enhance students' learning outcomes (Day \& Sammons, 2013; Leithwood, Sun, \& Pollock, 2017; Townsend, \& Bayetto, 2020).

As such, school leaders need to respond to diverse religious and cultural backgrounds in their daily teaching and learning process (Fullan \& Langworthy, 2014). For example, they may tap into religious knowledge and beliefs of their students in order to address particular challenges they are facing (Day \& Sammons. 2013).

\section{Language of instruction (English and Finnish)}

Vygotsky's theory of socio-cultural learning considers language as an aspect or a tool for cognitive development (Cole, 1990; Tharp \& Gallimore, 1990). Examples of languages include: signs, cultural artefacts and symbols (Cole, 1990). These language forms coordinate human beings with the "physical world and each other" (Cole, 1990, p. 91). That is to say, language facilitates the interaction and communication of all forms of values of knowledge (Moll, 1990).

New Zealand and Ghana have English as the medium of instruction. Finland has Finnish and Swedish as its mediums of instruction, but the teaching process also uses the English language because of the many international students in the school don't speak Finnish.

Participation: voluntary vs. inducement, monetary, and political influence 
Socio-cultural complexities play a crucial role in organisational effectiveness (Jenkins, 2002). Therefore, critical attention was paid to the organisational structure and processes including bureaucracy, networking, and relationships in the three observed sites.

Interestingly, all the participants in New Zealand and Finland were readily willing to support the study. None of the participants demanded anything from me. This development seemed to be related to the culture of the people in those countries (Fieldnote, 24/04/2018-26/10/2019).

On the contrary, five out nine of my participants from Ghana demanded cash in kind to support my study. When I probed further, I was told that they had made the incorrect assumption that I had been sponsored by international donors to do this research and therefore, I must show some appreciation. Upon explaining to them the inaccuracy and ethical implications of this action, they agreed to take part without being given cash in kind to do so. I provided most of my interviewees, especially the teachers from Ghana, with some soft drinks and food for lunch after each interview.

Comparatively, the positive response to the invitation to participate in the study indicated that almost all the participants from New Zealand and Finland valued this research.. Their colleagues from Ghana were different and I felt that they considered that they were doing me a favour (Fieldnotes, 24/04/2018-26/10/2019).

With regard to political influence, many nations across the globe have specific commitments and were emphasised during the face-to-face interview with the ministry of education officials in the three comparative countries in the following ways.

For New Zealand, the interviewee remarked that:

The educational workforce is a critical part of the system. They are the human beings that actually deliver and through various policy setting, through the life circle and program settings, the life circle of a teacher in their profession, so I will go through the technical staff and will go through the human side a little bit as well. So, between the teaching council and New Zealand qualification Authority, here are qualifications require by teachers before they are enrolled in schools. As part of the initial teacher qualification standards, and then setting the standards, is what essentially teacher education providers used in training colleges. They set the standards of what they expect to teach. So, over the last decade, the teaching council has reviewed and updated this requirement of this initial teacher qualification and what we expect 
people graduating and going into the classrooms to know and teach. They have a section about what skills graduating teachers are expected to demonstrate in terms of the Treaty of Waitangi and multi learning culture. By setting these standards, the expectation is that is what truly the young people must be taught within the teacher education. That is number one. Also, the Teacher Council requires people to update their qualification in every five years or so. So, through the up-dating process, there is a requirement to reflect on either the current practices meeting the requirements. And the system at the moment makes the school principals play important roles. We again provide a professional learning environment to the education workforce and we have a set of focus areas for that. Just last year, the current government decided that cultural competence will be one of the key focus areas for professional learning and development. (Ministry official, 26/10/2019)

This comment indicates that the New Zealand Qualification Authority and Teacher Council set standards and qualifications for educational providers, teachers, and teacher trainees to follow in the country and that national politics has a strong influence on education.

Similarly, a strong influence of politics was felt in the field notes from Ghana. For example, in one of institutions studied, there were two experts who were directors that I spoke to during the process to gain access. I first contacted one of them who told me that my documents must be sent through the system. He or she could talk to me without approval from the top (Field note, 16/08/2018).

This development was reaffirmed by the Ghana university expert during the face-to-face interview in this manner:

Exactly; everything under education is dictated by the politics of the day because we do things based on our own political interest and if it will favour us. We don't look at whether it has positive and negative implications for the students' learning outcomes.

He further explained this development as:

Politicians in this country try to abandon expert advice in most of the decision-making in the country. For instance, when the previous government was in power there was curtailment of allowance as I said. We used to bond the training college trainees so that once they finished, there is an automatic posting for them to schools. Over the years, that has helped the system because we were always assured that we will get teachers in classrooms. The previous government came and pointed out that there will be no more allowance. The allowance was curtailed, and they directed the teacher trainees to go for loans. Then after the 
elections 2016, there was even a campaign promise from the opposition saying that when they come back, they are going to restore the allowance.

Further, he remarked that:

The allowance restoration indeed helped them to win the election in 2016. In 2017, they restored the allowance because it was in their manifesto. Certainly, they must restore the allowance. And this same party now, as a matter of a year, instead of the training colleges being three years, has become four years. So, you wonder what the justification is for it. If you go to the secondary school, free senior high school was a promise, immediately they came, they have implemented it. Wholesale free, it means that now boarders are eating for free. Either it will impact positively or not. It's not the issue because we are implementing something that we promise to do to increase enrolment and now classrooms are crowded, and now the government is saying they are going to do a double shift system where we will group the students into two, one group will go as other students will be on vacations? (University's expert, 14/08/2018)

Expanding on the quotations above, it appears that, in Ghana, there is strong political interference in the decision-making process, especially in education. Politicians tend to satisfy their party parochial interests, especially what is in their manifestos, rather than the general feelings of the masses. Also, there is a missing link between the ministry of education and academicians in the country.

These findings are consistent with earlier evidence which shows that a change of macro factors can act as catalyst for students learning, performance, and success. Such factors include, cultural values and norms, formal governmental structures and systems, official agencies, business, groups, foundations and advocacy groups, and international bodies (Fullan, Hill, \& Rincón-Gallardo, 2017). These "pull and push" factors from outside the school have significant impact on the day-to-day activities of the schools and any adverse effect may affect students' learning, performance, and success as evident in Ghana case above.

The following characteristics of school climates emerged from the observations and artefacts data from the three sites. See below brief findings, establishing the similarities and dissimilarities of the cases under study as well as their meanings and interpretations.

\section{Security and class size}


It is evident in the literature that the term climate has to do with organisational behaviour and environment, including the feelings of the workers, emotions, physical buildings, and many other factors as perceived by its members in executing their day-to-day duties (Cobb, 2014).

The field data from New Zealand, Finland, and Ghana show that all three schools have electronic security gates and security personnel at the entrances to check who comes in, what the person's mission is, and the time for visitors to leave. At each visit, I was made to pass through these security checks in New Zealand and Finland. However, while school Z in Ghana has similar features including security gate and personnel to mind it, it is interesting to note that on the second day and subsequent days I visited the school, there was no person at the entrance, and I walked through without any security checks. While it is possible that there are other explanations for this circumstance that I might not be aware of, this appears to show that the schools $\mathrm{X}$ and $\mathrm{Y}$, in New Zealand and Finland respectively, have a stronger commitment to security than does the school $\mathrm{Z}$ in Ghana.

This finding supports the recent studies of improving school leadership to enhance students' learning, performance, and success (Day \& Sammons, 2013; Fullan, Hill, \& Rincón-Gallardo, 2017). The study noted that a healthy school environment such as good security protection for students and personnel has a positive impact on students' learning, performance, and success (Day \& Sammons, 2013).

Fullan termed a healthy school environment, the micro level of change (Fullan, Hill, \& Rincón-Gallardo, 2017). This requires intervention measures from school leaders for directing students' learning (Fullan \& Langworthy, 2014). Such measures include: ensuring that there is workable and guaranteed security and processes for developing quality teaching and learning; assessment for students; and learning autonomy (Gurr, 2015). For example, there must be adequate participation for students to develop their learning, use modern classroom technology, and leaders and teachers need to foster a climate which is adequately inviting and attractive for learning (Day \& Sammons, 2013).

A feature of a school with a healthy climate is that it has small class sizes in which teachers can respond to the individual needs of the students (Hopson \& Lawson, 2011). This study observed a small class size in schools $\mathrm{X}$ in New Zealand and $\mathrm{Y}$ in Finland (Interview data, 20/03/2018 and 15/12/2019). I counted about 14-15 students in two 
classes and 19 in one other class, and the school principal confirmed the class size to be an average of 15 .

On the same score, I observed and counted about 70 or so students to a class in school Z in Ghana. This was confirmed by the participants during the face-to-face interviews. One of the teachers expressed his experience on this as:

As I said, the class size is also very big, but we are trying to manage it. It doesn't support learning at all because one teacher taking care of about 90 students, you can imagine the work load, how to deliver lessons to all. Other thing just like we were also discussing the use of mobile phones. (Interview data, 15/07/2018)

A colleague teacher supported this and shared:

When the students came to Form 1, they were 131. Some stopped. Some went to other class as I speak to you. The Form 2 literature students are 114 and I feel that that is not good because large class doesn't help. I have been to the school administration on several occasion and anytime I went, I am told there is nothing they could do. Because they don't have enough classrooms and so for me collaborating with the administration to ensure that there is effective teaching and learning and I realized that class size can affect teaching and learning. (Interview data, 15/07/2018)

With regard to the above observations and comments, one could see clearly that the two schools in Finland and New Zealand have a smaller class size than the one in Ghana. This finding is consistent with what the OECD explored in 2015 of the two countries (Scott \& Norgrove, 2017).

In school $\mathrm{Z}$ in Ghana, it appeared that the two teachers interviewed handled between 90 to a little over 100 students to a class which may affect teaching and learning. These findings are consistent with previous evidence which indicates that the abolition of user fees in low-income countries, especially in the Sub Saharan African countries which include Ghana, has led to large class sizes. Furthermore, these mushrooming class sizes have had a negative effect on quality teaching and learning within those countries (Barrett, Sajid, Clegg, Hinostroza, Lowe, Nikel, Novelli, Oduro, Pillay, Tikly, \& Guoxing, 2007). 
In conclusion, these artefacts from the three sites produce evidence of the nature of class size and reaffirmed what I observed; a small class size for schools $\mathrm{X}$ and $\mathrm{Y}$ in New Zealand and Finland respectively, as well as a large class size for school $\mathrm{Z}$ of Ghana.

\section{Strong Networks}

I observed that networks and trust play a very vital role within the three contexts and the institutions studied. Prior to the data gathering process, emails were sent through the channels through which communication must be done. None of those institutions initially responded to my emails requesting to use their schools for my data gathering process. However, with the assistance of my two supervisors and my former director of education, University of Jyvaskyla, who have strong networks in New Zealand and Finland, I was able to have access to the schools and the institutions of the two countries. In Ghana, after I showed up personally and passed through the due process, I was able to get access to my research participants.

\subsubsection{School leadership and professional networking communities}

Leading and managing an organisation such as a school requires committed leadership to guide the vision and direction for development (Yukl, 2010). For this reason, the three schools from the three sites value leadership that is shared, responsive, deliberative, and creates an enabling environment which is fair, friendly, free, and fatherly in promoting student learning outcomes (Fieldnote, 24/04/2018-26/10/2019).

Distributive leadership emerged in the field data as it was observed in the principal's offices, departmental levels, and classrooms of all three sites (Field data, 24/04/2018$25 / 10 / 2019)$. This form of leadership was evident in a description by an interviewee from the school $\mathrm{Z}$ during the face-to-face interview:

anything that we find to be bullying of any sort, first, goes to the deans. We have teachers who are really in charge of these and they deal with all behaviour issues that may crop up and decide what is the best way to resolve it and we also have a deputy principal; he oversees all these events. So, any disciplinary issues of the day go to him. He oversees the disciplinary issues. We have various ways to find information about what the students are doing or how things are happening. (Interview data, 15/12/2018) 

thus:

I think it comes through my head of department. So, my head of department will walk to the principal and tell him what I am doing and what is working for me.... Also, part of the appraisal process is reflecting on our teaching and writing about that. And we have a teacher who reads through how the appraisal is done and we get feedback from it (Interview data, 15/12/2018)

Their counterparts in Finland expressed their opinions on the same subject:

Our principals, they are models of shared leadership. We have our chief principal; he is the head of our university and, of course, in our school. We have an international school, a comprehensive school principal, and a primary school principal. All these principals have their deputies. Also, the power is shared in the working teams. My quality development team has some sort of autonomy to organise things, so it is individual teacher level. Our team levels. The chief principal sees this as the model of shared leadership and, of course, I will not deny that we have shared responsibilities but of course, we have a shared responsibility to the students as well. (Interview data, 24/04/2018).

Similarly, in Ghana, all the school leaders attested that there is a relationship between distributive leadership and students' success as seen in this quote:

Yes. Here before you can go to the administration or before there can be a link between you and the administration, it should pass through the Head of Department, (HOD). You cannot ignore the HOD or you cannot bypass the HOD and do anything in the administration or outside; so over here we use the HOD. We consult the HOD so much in terms of problems or in terms of delivering information, in terms of him sending information, in terms of him linking us to the administration so we are being informed about what to do. (Interview data, 15/07/2018)

Another colleague from school $\mathrm{Z}$ also responded to the same question:

The students, too, sometimes if they have problem with other students but before the problem gets to the headmaster, it must pass through the housemistress's office. Also, they have appointed some duties to the fellow teachers so that it must go to the house masters, house mistress. They must solve this problem, but if the problem is too cumbersome for the house masters or the mistress, we then forward it to the headmaster because he is the person who can decide what to do. (Interview data, 16/07/2018) 
The quotations above provide evidence that distributive leadership has some impact in running school activities, especially teaching and learning. Almost all school leaders interviewed shared similar views about this.

In spite of this, it is evident in the literature that an effective professional learning community has the ultimate aim to promote and sustain students' learning (Stoll \& Louis, 2007). This common goal is driven by clear action, motivation, and support for its realisation (Parsons, 2016).

The data from the two sites in New Zealand and Finland reveals these common practices as established as professional learning practices by many researchers and academicians. From the observation fieldnotes, it appears that teachers in New Zealand and Finland have more autonomy, care, and trust to carry out their duties than their counterparts from Ghana (Fieldnote, 24/04/2018-25/10/2019).

These observations were supported by participants' responses during the face-to-face interviews when the question in relation to autonomy was asked. All the participants in New Zealand agreed that they have autonomy to carry out their duties in accordance with the law, the curriculum, and the professional code without fear or favour. This was expressed by one of the New Zealand teachers as:

So, when people are given autonomy, is not just the autonomy that you have been given but how to use the autonomy you have been given. So, something that people do within their autonomy reflects their own cultural background too strongly and excludes other people. So, on the one hand, you got somebody must tell me what to do and I believe what I am doing. (Interview data, 15/12/2018)

Similarly, their counterparts in Finland reaffirmed this; for example:

My autonomy basically, of course I need to respect the curriculum, but nobody tells me how I need to teach my subject, even if I decided to give lectures. The supervisor will just say "okay, that is what you really want". So, I can arrange my teaching as I wish. We are very heavily using computers and even everything almost electronic form. Nobody tells me which learning environment should I use more, or should I use whatever. I can decide what I am using. Nobody tells me how I need to assess my students or our students, what is the assessment method I need to use. What I do is, I need to give feedback after each course, but it is totally up to me to ... develop my assessment method and that is about the autonomy. One responsibility I did not mention is that I develop my subject group as well. My subjects' group is a group of

School culture, climate, leadership and success 
Chemistry, Physics, and Mathematics. We get money (assigned) to the subject group annually. The principal gives some money to the subject groups. We may decide how to spend that money ourselves. If we have some problems, we do not do that much because the university provides us. (Interview data, 24/04/2018)

On the other hand, their counterparts from Ghana in school $\mathrm{Z}$ shared this information in relation to the issue of autonomy:

When the headmaster is passing by and he finds out that you are even using your mobile phone to teach, the conclusion is that you are not teaching. It has happened to me. I was teaching literacy devices and I realised that things change over time. So, we also must adjust our teaching and learning. So, I just googled, and I was told by the principal "Don't do that, don't use mobile phones in class". I wasn't even given a chance to explain myself, so I must go to him. No, you don't have to be doing that, so the disconnection is too wired here. I have my tablet that I have downloaded notes even my teaching notes, but we have been told not to use these. (Interview data, 14/07/2018)

Another teacher from school $\mathrm{Z}$ in Ghana also shared his opinion on this same matter as:

This is what we are told at a point in time, you can even become a threat if you do so. It will not go anywhere, and you can leave the school. It has happened to a colleague friend. You see some of the classes, we have elective subjects. French is paired with the other subjects, so the students in class, some of them pursue French, others pursue Ghanaian language. What happens is that sometimes the French teacher will not have classrooms for his French students. He always has to go around looking for an unoccupied classroom for his students. Sometimes, when you go to the school administration with this request, they tell you they don't have any classroom. And if you insist, you may become like a threat to administration, so the teacher is recommended to be transferred (Interview data, 14/07/2018)

It appears, then, that the teachers in school $\mathrm{Z}$ in Ghana have less autonomy to initiate and change things within their own circles. They have less voice and must always follow the status quo; the chain of command. The evidence suggests that a teacher can even be transferred from his or her current position to somewhere else as a punishment if they dare to challenge the system.

These findings are consistent with the micro level factors of change and challenges related to the organisational path (Fullan, Hill, \& Rincón-Gallardo, 2017; Pollock,Wang, \& Hauseman, 2017). These involve school structure and various relationships and interactions among organisational members (Leithwood, Sun, \& Pollock, 2017). Other 
factors identified in the literature include operational standards and procedures, and the development of personnel, policies, norms, cultures, and organisational values (Gurr, 2015). Also, under this level, emphasis is laid on the role of the school leaders in helping building capacity for organisational personnel and other adults in facilitating students learning outcomes (Leithwood, Sun, \& Pollock, 2017).

International research has shown that school leaders focus much of their energies and efforts in shaping the expertise and knowledge of others to enhance students learning outcomes (Pollock, Wang, \& Hauseman, 2017). Shaping the expertise and knowledge of personnel includes capacity building in relation to professional competence (Murphy, 2017). The emphasis here is to develop and update professional competencies of the teachers and non-teaching staff in order to enhance students learning outcomes (Gurr, 2015).

This professional development must include the senior leaders, middle leaders, and teacher leaders as well as student leaders as appropriate (Leithwood, Sun, \& Pollock, 2017). This requires adequate expertise and effort from the school principal to help develop the competencies and expertise of the adults in the school to facilitate the ultimate goal of the school which is students' learning (Day \& Sammons. 2013). For example, the roles of senior leaders, including principals, include improving school instructions, budgeting, school maintenance, and occupational health and safety compliance which are all aspects that in turn foster students' learning outcomes (Pollock, Wang, \& Hauseman, 2017). The middle leaders' roles involve the heads of departments working closely with teachers as mentors or coaches to plan curriculum (Gurr, 2015). Also important is reviewing action plans and supporting other teachers, especially the new-comers to familiarise themselves in the school to enhance learning (Murphy, 2017). Again, there must be a leadership model in the school that fosters the autonomy of teachers, so being empowering to those teachers which will in turn foster a sense of learning empowerment in the students (Day \& Sammons. 2013). Any negative impact on these developments may also have a negative impact on the quality of teaching and learning (Pollock,Wang, \& Hauseman, 2017) as evident in the Ghana case above.

In conclusion, connecting the professional learning community's practices within the three schools in order to understand and appreciate what is happening, it appears that the local specific standards of New Zealand and Finland provide room for teachers' and 
students' creativity, innovation, and voice, and encourage initiative. Ultimately, this encourages trust between students, personnel, and other actors within the larger community to enhance development. On the contrary, within Ghana, the national standards give less room for the above-mentioned professional learning practices and may produce students and teachers who always do what they are told, thereby missing the opportunity for critical collaboration for creative improvements.

\subsubsection{Students needs and support}

There is ample evidence in the literature that when students' needs are recognised and supported, it intensifies and sustains their interest towards the school's mission, which is learning (Brophy, 2004). In the observational fieldnotes and interviews from the three sites of the study, a range of issues was identified in relation to students' support needs.

A range of academic and support services such as school-based nurses, IT, guidance and counselling unit, language centres. and cafeteria were observed at the three sites as means to augment students' learning and to motivate school personnel to discharge duties to accomplish the set vision (Fieldnotes, 24-04-2018/26-10-2019).

Issues related to students' needs were not only prominent in the observed data but also in the interviews. In an account of this, all the participants agreed that the school-based IT systems supports their teaching and learning in various ways (Interview data, 24/04/201825/10/2019). For example, one of the interviewees from school X in New Zealand shared her experiences:

Basically, all my teaching today is going through an IT. We have what we call a school's website and all our resources and all our assessments are put in this electronic database. All the teachers put their resources there for the students. And the resources are online for the students at home as well. We have what we call a transporter; the students see where we are, what we are doing and the materials we are teaching as well as the assessments. They know when the students are absent or present at school. We have a system called Kanohi, if their children are not at school, they can access it immediately. The receptionist downstairs will record all the information about the students. There is a sign-in portal for all the students in the morning at the reception. Always, at the beginning of the lesson we have a roll check to see if the all the students are in or not. Put all the result for any task there for the students and parents to see. So, parents know what level their child is at. Apart from that, all the assessment is online. (Interview data, $15 / 12 / 2018)$ 
Consistent to what their colleagues from New Zealand said, one of the Finnish interviewees expressed that:

I do a lot of group work and, for example, in psychology I tell them I have given them a google drive platform where they can start filling in this kind like. We call it case study sheet. So, it is like a black sheet where each student should fill in information about some studies, so they could do it individually at home but then it is better for them when they do it in groups, but I am not suggesting who does which study; it is up to them and it is their responsibility. Even though I just give them the platform. Then, it is up to them how they are going to use the platform I have given to them. (Interview data, 24/04/2018)

Similarly, the interviewees from Ghana agreed and affirmed the importance of those needs and support to students' learning. One of the interviewees explained that:

It is supposed to be a high level of IT, but in our part of the world, especially in the classroom that we are going, most of computers are not connected to electricity so when you send your laptop there it will be useless, especially when our laptops don't have durable batteries to sustain the duration of the lessons, so we try to avoid it. (Interview data, $15 / 07 / 2017)$

Expanding on the quotations above, all three schools have these support services above. However, New Zealand and Finland have ultra-modern versions of those services compared with Ghana. This may be because the two Western schools had been recently renovated. On the other hand, while school $\mathrm{Z}$ also has all those facilities and resources, there are not enough of them and they are not ultra-modern. The school has almost three thousand students, but less than one hundred functional computers and other equipment. Surprisingly, most connections of electricity to classrooms had been disconnected. According to the principal, this was because of the students has been using it to charge their phones.

This finding supports the concept of deep learning in which schools must develop intellectual attitudes and attitudinal dispositions toward creating new learnings and ways of doing things in the world. As such there must be continuous discovery and development of digital learning tools and resources to explore new content, concepts, information, and ideas to enhance students learning outcomes (Fullan, Hill, \& RincónGallardo, 2017).

Library, music studio, art studio, and school-based technical officers 
Ultra-modern support services including library, art, and music studios were observed in schools X and Y in New Zealand and Finland respectively. On the other hand, there were less ultra-modern versions of these in school $\mathrm{Z}$ in Ghana. Furthermore, a comparison of the findings revealed that New Zealand and Finland have technical support officers to support students' learning and teachers' professional development. Conversely, Ghana has no technical support service officers in school Z.

\section{School-based psychologist, social workers, special education teachers, and free meals}

Comparing the findings across the three sites, school Y in Finland has a psychologist, social workers, and special education teachers in the school. However, the counterpart schools in New Zealand and Ghana do not.

This was noted by one of the interviewees in school Y:

We have special needs education teachers and practice in our school. They practice at the same time with the subject teachers. Sometimes, we put both special needs teachers and subject teachers together and plan together. However, we must remember only one lesson out of the nine lessons, but we have structure that support that. (Interview data, 24/04/2018)

Also, talking about this same issue, another interviewee from the same school, Y said:

We have the great support system and a lot of staff for the students. We have a school nurse, we have the psychologist here that you can go and talk to. We have... I don't know the English term. It's like the kind of social worker also here, then we have special education teacher, If I have worry about a student, the first thing I do is to talk to the student. I ask if they agree with me about my worry, how do they feel about, and then after that they continue to talk if the student can go to the nurse or the psychologist. (Interview data, 24/04/2018)

On the other hand, the following explanations were made by the interviewees from the two schools from New Zealand and Ghana in relation to resources such as a psychologist and many others. One of the interviewees from New Zealand said: "Yeah, we have no school psychologist" (Interview data, 15/12/2018). Similarly, an interviewee from Ghana put it as: "We do not have a school psychologist and all those works are being performed by the school counsellor" (Interview data, 15/07/2018).

Whilst the schools in Ghana and Finland provide free school meals, the New Zealand school does not. In Finland, one interviewee stated that: 
Yes, they eat for free. Every student in Finland eats for free at school ...till the child is grown up to 18 years. The teachers' pay some but not much. It is less than half of the amount, but the pupils and the students in the high school eat for free. (Interview data, 24/04/2018)

Their counterpart from Ghana had this to share:

Yes, according to the headmistress of the school and the PTA they have heard a lot, so the teachers also enjoy the meals - breakfast, lunch, and then the resident tutors also enjoy the supper as well. The reason is that sometimes when the students feel that the food is not good, the teachers also have to taste it to enable us to know the problem concerning the food. If they are complaining, then we get to know how we will solve the problem. That is the reason why teachers also enjoy the meals. (Interview data, 15/07/2018)

Students' support needs such as guidance and counselling, school nurses, psychologists, free meals, ultra-modern libraries, and many other resources have a strong relationship with students' learning, performance, and ultimately success. These resources support intrinsic and extrinsic aspects of motivation among school personnel and students to achieve the goal; that is, learning.

These findings from the three multiple cases are consistent with earlier evidence which establish that motivation of all forms within schools and beyond may act as catalysts for teaching and learning. These psychological and affective resources make significant contributions to school leadership for special initiatives involving risk taking to make schools successful to enhance students learning outcomes (Leithwood, Sun, \& Pollock, 2017). This leads to the findings from the interviews.

\subsection{Interviews}

\subsubsection{Introduction}

After rigorous examination and interrogation of the interview data from the three sites, these findings are discussed under the themes of school culture and climate, school leadership and professional networking communities, and students' needs and support. Below findings emerging from the three schools are discussed. However, readers are reminded that the case study included only one school from each of the three contexts. Therefore, readers must bear in mind that these findings will not necessarily reflect on, or transfer to, other schools throughout the comparative countries, New Zealand, Finland, and Ghana. 


\subsubsection{New Zealand case: school culture and climate}

\section{Respect, care, and community (Manaakitanga)}

The literature claims that academic and professional freedoms; fundamental human rights including the right to life, to education, the right to vote and be voted for; and many others must be a backbone of any country aspiring to be a democratic one (Stewart, Benade, \& Devine, 2019). In relation to this, the teachers in school $\mathrm{X}$ in New Zealand emphasised that the culture of respect and care had a positive impact on the way they approached their teaching and learning in the classroom and beyond. These have a trickle-down effect on students' learning and development. (Interview data, 15/12/2018). An interviewee expressed this as:

We are respected, you are supported more than any other place around the world. I have been around the world. That I can tell you, New Zealanders care about, there is a sense of community, there is a sense of belongingness, there is a sense of dignity to people. I think this is a reason why the people perform better. (Interview data, 15/12/2018)

Comments such as this provide evidence that the teaching profession is respected and cared for in the country. This sense of dignity has a positive impact on students' learning, performance, and success. However, it also emerged that some respondents felt the teaching profession has received less recognition and respect from successive governments of New Zealand. This was what an interviewee in school X had to say about this:

I think it is three sources. I think the same thing is happening in the UK. The first source is that which is the most serious - the erosion of the status, respect, and trust for the teachers. This is a very sad thing both in New Zealand and in England and a lot of these come from the central government. (Interview data, 16/12/2018)

Comments such as this provide evidence to the effect that teachers perceive their status, including recognition, respect, and trust has declined in recent times in New Zealand due to actions and inactions of successive governments.

This development has become a disincentive to teaching and learning and may affect students' outputs. This finding is consistent with a 2006 report in New Zealand that found that the teaching profession was not regarded to be of as high a status as politicians, business owners, pilots, lawyers, diplomats, and many others (Langton \& Hall, 2006). 
Evidence in the international literature on leadership that promotes learning outcomes of students supports these findings. Leithwood, Sun and Pollock (2017) described the family path as dealing with external forces which have direct or indirect relationships with the schools. Further forces include expectations from the students' families, community, and the wider society from schools (Day \& Sammons. 2013). There is a complex interaction between governmental policy and society's orientation towards schools and education in general (Leithwood, Sun, \& Pollock, 2017).

Therefore, school leaders need to respond to these external factors that influence the teaching and learning process (Fullan \& Langworthy, 2014). School leadership can directly influence both family factors and resources in order to impact students' learning outcomes (Leithwood, Sun, \& Pollock, 2017).

\section{Education Act and Review Board}

Contemporary education and its environment must be viewed as an arena for contestation, conflicts, and negotiation. These competing needs must be addressed daily in education (Giroux \& McLaren, 1989). It emerged from the educational leaders in New Zealand that the Educational Act 1989 gives a clear direction in education matters such academic freedoms, teaching and learning responsibilities, and Treaty of Waitangi obligations. These directions enshrined in the Act make a big difference to the manner in which educational leaders and managers approached their teaching and learning each day. (Interview data, 25/10/2019)

This claim was supported by the New Zealand ministry official who explained that:

Parliament is sovereign and The Education Act in 1989 is the thing that drives education in this country. The government can change the Education Act, but for the most part, the Education Act is the thing that sets the policy settings and we must work within them. We've got a free system where we set schools as crown entities and they are governed by their boards of trustees and managed by principals and the national curriculum sets the standards. So, there are some foundation stones by multiparty agreement .... So, the Education Act has been amended but it's still got the core principles and the schools can operate within these standards. So, yes, the Ministry is associated, plays a critical role and we give them free and frank advice and they make decisions and directions. The content of the core foundations is very well set. (Interview data, 25/10/2019) 
These comments explain a number of things. First, the New Zealand Education Act 1989 allows schools a great degree of autonomy, where they are governed by their local board of trustees. Secondly, it sets policy directions, especially the standards that schools must operate within. Finally, the Act identifies some core values in education which have stood over time despite several amendments. Stewart and friends affirm this by adding that the Act sets boundaries upon which education and its related matters must be regulated as evident in the quotation above (Stewart et al., 2019).

A number of researchers have reported that what goes on in education is more than what we see within the school building. Therefore the external politics, curriculum, pedagogy, and many other factors play an important role in schools' development (Giroux \& McLaren, 1989; Liston \& Zeichner, 1996).

During interviews, teachers in school $\mathrm{X}$ in New Zealand remarked on how they were supported by the national review board. A teacher expressed his experience as:

We have the review officials and it's very good. But in England, we have the opposite and I am very happy with what we've got here. What we've got here is they look at what you are saying, and what you are doing, and they look at the level to which you are self-monitoring. In theory, this is a self-monitoring school where you are doing what you say you are doing. If it not good, then is it going in the wrong direction. The school is neither good or bad but getting better or getting worse. Schools are not static because the roles keep changing over time. If you stay static, then you are getting worse. So, what they do is to come and visit a few classrooms. Last time that they came here, they pulled me out of the five people that they talked to. (Interview data, 15/12/2018)

This comment suggests that the teachers in school $\mathrm{X}$ are satisfied with the work that the Education Review Office does to improve the quality of teaching and learning. The school has its own self-monitoring and evaluation mechanisms and the presence of review officials aims to see things in a more practical sense and to discuss with teachers what they were doing or have done for an administrative and policy purposes.

\section{Impact of the decile system}

Intended to improve the quality of education, New Zealand has a decile system where schools are ranked from one to ten. Under this system, low-ranking schools are provided with more assistance and support to catch up with the highly-ranked ones. However, this good intention of the Education Ministry has been misconstrued. As such, parents prefer 
to send their children to a highly-ranked decile school rather than the lower-ranked ones because of the prestige associated with high decile schools (Interview data, 25/10/2019).

The Ministry's official explained shared his experience on this as:

A large part of the community has associated the decile ranking with quality. That was never what the decile system intended to do. Not how the ministry operated, but I think it is fair to say that the large part of the New Zealand society relates decile ranking, which is associated with economic mission but not a quality mission. But they use it as a quality mission. So, some schools are more popular than others because they think their children will gain better education. The higher the decile, the higher they think might be a good or a better school and want their juniors to go there. (Interview data, 25/10/2019)

The quotation clarifies that the decile system, which was intended to improve schools in terms of resource allocation, has widely been perceived to be about the quality of the school. This development has led parents to think that a school with a highly-ranked decile might be better than a lower decile once. This finding supports research carried out in the University of Auckland in recent years. The study showed that students from high decile backgrounds were much more likely to study for an LLB at the University of Auckland than those from lower decile schools (Stagwood, 2018). This might explain the reason why parents prefer decile nine and ten secondary schools.

\section{Collaboration, teamwork, and relationships (Whanaungatanga)}

Recent evidence suggests that collaboration, teamwork, and various relationships among personnel and between students have a big role to play so far as a school's effectiveness and development are concerned (Hoy, 1990). Therefore, to improve students' learning in New Zealand, especially Māori education success, the Education Council of New Zealand has tasked teachers to demonstrate a high level of Whanaungatanga. That is; building relationships among and between the school's personnel, students, and the wider community to foster students' learning outcomes, and development (Education Council Aotearoa New Zealand, 2011).

Findings from the interview data indicate that good relations between and among students' parents, principals, teachers, students, and the wider community may contribute to successful students' learning outcomes (Interview data, 16/12/2018). 
The following quotes from the New Zealand school teachers and leaders elaborate on this focus on relationships:

Through emails, phones, and many more we collaborate. It usually depends because sometimes the parents will say, "I want to get in touch with you because my son needs a psychologist". This usually comes to me and others through the dean. It might be a parent saying, "My son is feeling interested about your grading assessment which is coming up. What can we do to support him?" It might be, I have gotten a parent to ring me directly, but I usually contact them directly. Even if it is behaviour issues of some kind - "My son is not engaging and what you are doing?" And sometimes, it is minor trouble and we invite the dean and book an appointment with the parent. And sometimes I phone the parents if the student is not concentrating on my lessons and I try all means to bring him on board and it fails. So, I have conversation with them all the time. (Interview data, 15/12/2018)

Another teacher reaffirmed this and shared her opinion as:

It is probably building good relationships with the students and getting to know them and what they are interested in and support them with a task. I must ask them about the music they have listened to and something that they like to do outside the classroom. I tell them, why not write a story about that? For example, I will ask them, "Why not write a story about serving people?" I concentrate on what they are interested in and I think that is my strategy.

Furthermore, another teacher shared how she teams up with students' parents, saying:

I think we really invite students' parents to the school which is quite lovely. Again, it comes down to the effect that many parents are very lucky to have their sons to come to the school and they always want to be supportive and the school's environment is fine. This happens most often in primary schools and is all about community. But when they come to secondary schools, maybe they say goodbye. Maybe they are teenagers, that is why. They don't want their parents around. Sometimes, where there is going to be an occasion and I say, "Your son is delivering a speech"; they really love to come, and they say to me, "Thank you very much". (Interview data, 15/12/2018)

Other teachers also considered that positive teamwork with support from their colleagues makes a big impact on the way they carry out their day-to-day duties to improve students' learning outcomes. The HOD's comments support this:

Yeah, I've got fifteen teachers in my department. I try to keep it informal and casual. We have a regular meeting in the department. Over there we talk seriously about what we are doing, but I like to keep 
it very casual, like just sip a cup of coffee and tea and we just talk about how things are going, and if you have concerns you bring it out. I want to make an environment if they feel things are not going on the right way, they can talk about it. That is very important, yeah. (Interview data, 16/12/2018)

These comments indicate a number of things. First, technology usage including emails, phone calls, and others fosters collaboration among and between students, school personnel, and the wider community. Again, it appears that through collaboration, especially between school and community, students' challenges can be addressed. Also, it is likely that a good relationship between teachers and students enables teachers to know their students very well in order to design learning to meet their needs and interests. Finally, it suggests that casual teamwork among personnel with a good listening atmosphere where everyone can share his or her opinion freely helps shape the learning discourse and support students' outcomes.

In conclusion, collaboration, teamwork, and various relationships - Whanaungatanga in schools and outside seems likely to be a contributing factor in improving students' learning, performance, and success as evident in the quotations above. These provide evidence that a heathy school with a positive climate among students, and between personnel and the larger community may be linked to a successful school outcome. This finding is quite similar to Dawson and colleagues' finding that collaboration and relationships of all kinds in the school have the potency to improve the learning outcomes of students (Dawson \& Wymbs, 2016). This, then, directly leads to the styles of leadership that coordinates most of these relationships.

Successful leaders build trusting relationships with teaching colleagues, students and families. Leaders develop a repertoire of relationship-building strategies. They also collaborate with other teachers and leaders in researching the impact of different learning strategies on students, and model a proactive disposition towards learning and taking action with the new learning (Fullan \& Langworthy, 2014).

\subsubsection{New Zealand case: school leadership and professional networking communities}

Distributive and shared leadership (Rangatiratanga) 
Rangatiratanga refers to leadership. School leaders in New Zealand are expected to demonstrate certain values, including Manaakitanga, which involves integrity, trust, sincerity, and equity (Education Council Aotearoa New Zealand, 2017). Active demonstration of such awareness and knowledge has a significance impact on students' learning and development (Dou et al., 2016). In school X in New Zealand, almost all the teachers emphasised that distributive or shared leadership, showing integrity, trust, sincerity, and equity as ethical principles, has importance for the ways in which they, as teachers, do their work.

A beginning teacher discussed her experiences of being supported by her HoD:

So, we have a departmental meeting. At the departmental meetings, we have goals to address any learning difficulties or a situation of students. We have an assessment meeting within the department with all the staff. We look at the marking and progress of individual students. For example, I had a student's parents for year twelve who wanted to meet me because they were concerned at their son's lesson notes in class. Then, I must have a meeting with them partly because the parents had an interest to know why the son does not take notes in class. As a firstyear teacher, it has been like, what will I do, how could I approach it, and how could I demonstrate to the parents that I haven't messed up the child? It was fine because I ended up talking to the head of the department to sit in the meeting as well. So, I have real support from the academic staff here. (Interview data, 16/12/2018)

These comments produce evidence that distributive or shared leadership has a positive significance on students' learning. It indicates that such a leadership structure establishes the channels of communication through which various problems faced by students are addressed.

This example of the benefits of distributive leadership as a means to promote learning outcomes of students is in line with what ISSPP have previous established as one of the factors that enhance students learning (Day \& Sammons. 2013). Cultivating leadership in others within the school setup is a cardinal feature of effective school leaders (Hollander \& Won, 1978). The leader's role as a transformational agent is to influence and to transform individuals within the school to enhance the learning of students (Leithwood \& Jantzi, 2005) .

Such leaders are very much concerned with values, morals, standards, ethics of care, justice, trust, and critique, in order to drive colleagues to accomplish the school's vision 
which is ultimately focussed on students' learning (Sebastian et al., 2016; Starratt, 2004). Thus it can been seen that transformational leaders distribute leadership widely across their organisation (Sebastian et al., 2016).

Distributed leadership in a school is a shared enterprise where various roles and responsibilities are assigned to the departmental heads, teachers, students, and, if possible, parents (Heck \& Hallinger, 2009; Wallace, 2011). This model encourages and grants teachers the self-autonomy to carry out their duties as well as to learn from one another (Dou et al., 2016). In order for the leadership model to effectively improve learning in the school, teachers must also demonstrate leadership in guiding students to be accountable, responsible, and develop learning autonomy (Belcher, 2017; Dou et al., 2016). Leaders serve as role models for students by living an exemplary life in the classroom and beyond (Belcher, 2017). Teachers must be fair and firm in guiding the learning process as well as in supporting students of all abilities and backgrounds to learn (Sebastian et al., 2016). This may work more effectively where school leaders have quality training to execute their jobs (Leithwood \& Jantzi, 2005).

\section{Teaching qualification and principalship programmes}

The literature shows that conceptual learning, including quality teaching and learning, leadership preparation and development, a shared and a supportive leadership, and many other factors are aligned to professional learning communities (Olivier \& Huffman, 2016). The teachers in school $X$ in New Zealand emphasised the importance of highquality teacher education and qualifications in promoting schools' effectiveness in the following ways. For example, all the teachers acknowledged that they held bachelor's degrees in education, the basic qualification for teaching in their school (Interview data, $15 / 12 / 2018)$.

As one of the teachers explained: "You have to get a bachelor's degree in education or you get a diploma, or you can get a master's in teaching" (Interview data, 16/12/2018).

However, while the basic qualification in the school is a bachelor's degree, it emerged from my data that three out of seven teachers interviewed in this school also had their $\mathrm{PhD}$ 's within the field of education. They acknowledged that their long experience in education has had a tremendous impact on the way they guide the learning process and 
coordinate the school's activities to enhance students' outcomes (Interview data, $15 / 12 / 2018)$.

Recent developments in educational leadership have also heightened the need for special principalship training programmes for potential principals as means to improve quality human resources to enhance schools' effectiveness and development (Gurr, 2015; Hoerr, 2005). Such programmes include retraining, in-service and out-of-service service programmes on leadership and management (Taipale, 2012).

It emerged that school $\mathrm{X}$ had no mandatory official qualification for aspiring principals. This was explained by one of the teachers:

There are principal training courses that the principals can do, but not mandatory courses you should do beforehand. If you are a senior teacher, you could be appointed as a principal, or assistance principal through school. As part of being a teacher, you might do it as a parttime thing or full-time. But through that you do training to develop yourself as an educational leader. So, there are a number of courses that you could enrol in, but not mandatory courses. (Interview data, 26/10/2019)

This quotation provides evidence that there are no formal training programmes and requirements for aspiring principals in New Zealand schools. What an aspiring principal needs is to be a serving teacher with a range of working experience. He or she must be appointed and could take leadership courses and programmes after the appointment is offered.

The educational leaders of the school were of the view that making the principal preparation programme mandatory for aspiring principals might be good for the school's effectiveness and improvement. However, one of the teachers partially disagreed with this, saying:

My take on this official training thing is that it would be good if it was a good training thing. But what we don't want is, we don't want people to think that there is only one way to do this. I think it's good to have many ways to do it if you have this qualification. (Interview data, $16 / 12 / 2018)$

This comment suggests that at least some participants believe there must not be only one way to think about the path to principalship; rather there must be many and diverse ways. 
This finding is similar to what much international literature has established on successful leadership that promotes students' learning outcomes (Day \& Sammons, 2013; Gurr, 2015; Leithwood, Harris, \& Hopkins, 2008). Successful school leaders focus on developing people and are people-centred. They try to bring the best out in others (Gurr, 2015; Leithwood, Harris, \& Hopkins, 2008). Their ultimate satisfaction is to see how best their students can improve and be developed to contributeinto the wider society (Gurr, 2015). Also, they are concerned with how to develop personnel - including both teaching and non-teaching staff - to improve learning (Day \& Sammons, 2013). This is achieved through motivating and equipping personnel with adequate knowledge, skills and the resources needed to enhance their teaching and learning to improve students learning outcomes (Leithwood, Harris, \& Hopkins). Equipping personnel includes organising capacity building workshops, motivating their commitment levels, and fostering their resilience to apply their skills and knowledge in any given situation (Day \& Sammons, 2013). Furthermore, individual or group support has to be given to personnel to foster their intellectual stimulation to carry out their duties to enhance learning outcomes of their students (Hoerr, 2005). Such support includes modelling appropriate values and behaviours that foster this intellectual stimulation (Fullan, 2007). However, without proper working conditions for school leaders these and many others programmes may be negatively affected (Day \& Sammons, 2013).

\section{Teacher's conditions of service}

Recent evidence in education suggests that teachers' working conditions, including workload, salaries, class size, status, and recognition, have an effect on their work output in terms of enhancing teaching and learning (Langton \& Hall, 2006). It emerged from my data that teachers believe that successive governments of New Zealand have previously turned a blind eye to teachers' welfare, especially their working conditions (Interview data, 16/12/2018).

This was shared by one of the teachers:

One of the factors which makes the teaching profession unattractive is the money. The money is rubbish. My daughter earns more than me for working for five years. I started (teaching in) 1994. And the third factor is about the condition of service. The work that we are doing is increasing and will be fine if we are given more time to do it. But the time factor remains the same while the expectations increase. The 
status of a teacher goes down while the work load has increased. The whole system is of the national government is putting money in the hands of individuals. If you put money in the hands of individuals, they take up the system. Consequently, what is the position now? We have had nine years of poor funding. Why would I become a teacher? (Interview data, 16/12/2018)

The comment indicates that the conditions of service, including teachers' status, workload, and pay or salaries may very well put off many young people from becoming teachers. Also, participants feel that successive governments have not been doing enough to improve those conditions teachers face.

Fullan and colleagues (2017) have argued that external factors from the wider society influence school units and activities; this is evidenced in the New Zealand case. These external factors include formal governmental structures, systems, policies, and funding, official agencies, business, groups, foundations and advocacy groups, and international bodies (Fullan, Hill, \& Rincón-Gallardo, 2017).

\section{Teaching and learning constraints}

Another intriguing finding was challenges related to the provision of apprenticeship programmes. It emerged that the school lacked apprenticeship training programmes for their graduates. One of the teachers expressed her opinion on this, saying:

I think we need to strengthen our systems that they are going to be trained. I think probably this is one of the reasons. For example, in Germany, they have a very strong apprenticeship scheme. If you want to go into trade, you can go into apprenticeship schemes and you learn, and you get paid. The problem that we have here is that we have the apprenticeship schemes, but the employers have to pay little money to the apprentice. They lose the apprentice because sometimes they don't have money to pay them. The apprenticeship systems here need to be improved. There are two problem: One is: it is difficult for the students to get the apprenticeship because not all employers, for example a car mechanic, he doesn't want to employ the apprentices. He will rather employ a properly qualified mechanic. So, it is very difficult to get the apprenticeship. (Interview data, 18/12/2018)

This excerpt suggest that the New Zealand apprenticeship system needs to be strengthened to cover apprentices' pay. Again, the business owners do not feel comfortable to grant students with apprenticeship opportunities, instead choosing to hire more qualified staff. This reinforces that the impact of the community has a significant 
part to play in teaching and learning (Fullan, Hill, \& Rincón-Gallardo, 2017) as established in the New Zealand case above.

In order to improve schools, especially the learning environment, professional learning practices such as trust, love, ethics of care, students' autonomy, and research-based learning must be adhered to by educational leaders (Linder et al., 2012). This is because these professional practices influence students learning, performance, and ultimately success (Easton, 2011). Furthermore, international literature on education has identified practices that contribute to a school's professional learning community as including: a collaborative focus on learning; shared values and visions; collective responsibility on the part of the leadership and students; enquiry-based learning; mutual trust, autonomy, respect, love, and openness; networking, lifelong learning; and individual accountability (Stoll \& Louis, 2007).

In school $\mathrm{X}$ in New Zealand, almost all the teachers and the principal interviewees acknowledged that they have autonomy to carry out their day-to-day duties. This autonomy helps them to put in place proper mechanisms including an ethic of love, trust, care, respect, or Whanaungatanga, to support their students' learning outcomes. These values have significant impact on the school's effectiveness and development. For example, one of the teachers commented: "One of the things that we have is high teacher's autonomy" (Interview data, 15/12/2018). A colleague teacher also made a conection to an ethic of care:

I approach my teaching as a mother and very similar to how I parent my own two boys. I know as a woman I have the luxury of being able to parent the two boys and I find it natural that they are quite honest with me in terms of how they feel about things. and they have the luxury. I think this is something I make explicitly known to my students I do tell them like how I teach like how I care like a parent. (Interview data, 16/12/2018)

On the issue of love, a teacher shared her opinion on this as: "The question for me is how far we share the love; do we share the love with all our students. Some students are not getting enough love. But we must share the love equally for others to achieve" (Interview data, 16/12/2018).

Another teacher outlined a different perspective which highlighted the need to foster a sense of community: 
It's about a lot of respect and discipline. A strong sense of community. There is a lot of element and mechanisms of support not to let you fail but at the same time there is the tall poppy syndrome, don't show off too much" (Interview data, 16/12/2018).

The use of students' data to improve their learning outcomes was described by a teacher in this manner:

Sometimes, I go to colleague teachers and say, "You are entitled to some of my time and how would like to spend it?" They will come and say, "I don't know what to do, can you help me"? So, what I do is to call for particular students' data basically. My job is problem solving by getting people's data and reflecting on it and to help them to have a conversation around their own data. When a teacher experiences a little mess in relation to a student's learning outcomes, I collect data on that student to understand what is happening. We then collaborate to solve that students' challenge. Yeah, we then have a conversation about it, and they can solve their own problems. (Interview data, 16/12/2018)

These comments seemed to support the claims in the literature that there is a positive relationship between professional learning practices such as establishing a culture of respect, discipline, trust, autonomy, community, teamwork, and the use of students' data in addressing their challenges. This finding is similar to what was previously found by (Stoll \& Louis, 2007).

In conclusion, comparing the findings emerging from the data gathered from the school leaders in New Zealand with the claims made by the literature, it may be argued that school X may be considered as a professional learning one. This is based on the evidence from participants that the school's leaders use practices such as autonomy, academic freedoms, ethics of care, love, empathy, trust, teamwork, relationships, community, family, networking, and researched-based learning which are intended to meet students' needs and to provide support to enhance learning.

These findings are similar to what Leithwood and colleagues find and termed the "emotional path". It emphasis dispositions including, passion, feelings, and the affective nature of personnel in shaping their work to enhance the ultimate aim of the school, which is learning (Leithwood, Sun, \& Pollock, 2017). This can be seen in teachers' and students' commitment to learning, teachers and students trusting each other, and organisational practices that encourage a sense of belonging (Fullan \& Langworthy, 2014). These psychological and affective resources make significant contributions to school leadership 
(Leithwood, Sun, \& Pollock, 2017) to improve learning outcomes of students (Fullan \& Langworthy, 2014).

\subsubsection{New Zealand case: students' needs and support}

This final section of the New Zealand case provides an overview of the students' needs and the support available in school $\mathrm{X}$ to enhance teaching and learning. They include: ultramodern library, IT resources, music and art studios, guidance and counselling services, technical support, school-based nurse, free tuition, and cafeteria.

A number of studies have noted the importance of school-based guidance and counselling, a psychologist and other forms of support to act as catalysts to students' intrinsic and extrinsic motivation to improve learning outcomes (Brophy, 2004; Goldman et al., 2016).

In school $\mathrm{X}$ in New Zealand, each teacher interviewed agreed that the provision of the support services and resources listed above has positive impacts on the way they approached their job each day, as well as on students' learning, performance, and success. (Interview data, 17/12/2018)

This was expressed by one of the teachers as:

We have a counsellor here and I think her duty is to build relationships with students that are having some sort of challenges at home environment can access. We don't have a psychologist here. Perhaps that could be a reason why we have young people taking their lives in the country. Maybe, I don’t know. (Interview data, 16/12/2018)

This comment supports the notion that additional support for students, beyond that offered by classroom teachers, is of importance to their learning.

In conclusion, almost all those interviewed agreed on the importance of these support needs and services. They further recommended a school-based psychologist to offer additional support which may help to prevent young people from taking their lives, as reflected in the quotation above.

\subsubsection{Finland case: school culture and climate}

After almost three years of study, selected findings from the Finland case are presented. Readers of this thesis are reminded that the findings reported here cannot be generalised 
because the study selected only one school each from the sites. Therefore, the findings may not necessarily tell the entire story of all Finnish schools.

\section{Good politicians}

As explained in the literature the influence of power, politics, and ideology must not be underestimated as far as education and its development are concerned (Gibson, 1986; Giroux \& McLaren, 1989). It emerged from the interview data in Finland that participants believe that good politicians have a direct a relationship in influencing school-related issues and activities including students' learning, performance, and success. This was expressed by one of the Ministry's experts:

"We need to take care of our teachers and they are very good; our politicians are very good, and we have to make sure that we have a research, so we get all kind of information needed for decision-making and development" (Ministry expert, 28/04/2018).

The expert supported her claim with the following:

We revise the curriculum every four years. Whenever there is a new parliament and a new government, we write a new program for education, but it does not change much. It is not very different from the previous and the previous one before. That is because our politicians are to listen to the people who are working in the field of education. For example, the people here in the ministry, we always provide information for the political decision-making. That is my job and politicians listen to us. (Interview data, 24/04/2018)

This comment supports the idea that a good politician who respects expert advice may help improve educational-related matters.

\section{Respect for teachers and teaching profession}

Recent evidence suggests that failure of the teaching profession to attract young people may be attributed to the conditions within which teachers work (OECD, 2018a; Scott \& Norgrove, 2017). For this reason, there are massive shortages of good quality applicants to the teaching profession and teacher education in many countries around the globe (Paronen \& Lappi, 2018).

Reasons for this declining rate may be due to poor working conditions, such as contact hours, salaries, gender segregation, ageing population, and many other factors. These 
factors have an adverse effect on quality teaching and learning and, ultimately, students' success (OECD, 2018a; Paronen \& Lappi, 2018).

It emerged in the data that almost all the school leaders in school Y acknowledged that their work is valued, cared about, and respected in the community in which they operate. This prestige attached to their work makes a big difference in the way they carry out their duties to enhance students' learning. A teacher expressed her experience in this way:

In Finland, the teaching profession is much respected. I think that is one thing. I know in some countries the teaching profession is not very respected and low paid. Here in Finland, the teacher salary is not good, but quite good and our society respects teachers and their profession. So, many of our students have that zeal to work as teachers. The most motivation for teachers is that the interaction between the teachers and pupils motivates them. (Interview data, 24/04/2018)

The quotation indicates that the Finnish society values and respects the teaching profession. This recognition has been a catalyst for many young people in joining the profession. It also appears that teachers' working salaries play a part in this attraction.

This comment suggests that a culture of respect attached to the teaching the profession motivates the Finnish teachers as their job is valued in the society. This recognition likely has a ripple effects on students' learning, performance, and success as the profession attracts quality human resources who have the zeal to do the work. This finding is consistent with what Pasi Sahlberg found in his article "The Secret to Finland's Success" (Sahlberg, 2010).

\section{No school ranking system and private free tuition schools}

The ranking system which was an ideology or practice implemented to improve school quality during the neoliberal era in the 1980s is still present in many school systems in countries throughout the world, including in New Zealand (Cassell \& Nelson, 2013). It emerged, however, that school Y in Finland has no ranking system and parents prefer to send their children to any community school within their locality or catchment area (Interview data, 24/04/2018). This was expressed one of the teachers as: "The students choose to apply for any school, we do not have school ranking system. We don't have that; all the schools are good, so we do not rank them" (Interview data, 28/04/2018).

A colleague's statement expressed a similar sentiment: "We have very low difference 
between schools. You see Finland is unlike many other countries" (Interview data, 26,04/2018).

All the school leaders noted that private schools throughout Finland do not charge fees. For example, the Ministry of Education official said that there were:

Not too many differences because private schools cannot charge any fees. They are free of charge to all the children. They must use the same curriculum as everybody else is using. They must write the curricular and then must send it to the Ministry of Education and we approve it or not. They cannot have any profit; they get the money from the government. It is the same kind of money municipalities get for the schools in the municipality areas because it is not a good business in Finland to have a school. You cannot have a profit. Who wants to have a school without a profit on it? So, our private schools here in Helsinki area are very old historical schools founded somewhere around 1800 and they want to carry on those same kinds of traditions. We do have religious schools. Lutheran and some SIINA. They have their own pedagogies and issues they want to provide to their students (Ministry's expert, 27/04/2018)

This Finnish picture is distinctive in its rejection of elitism and in its determination to ensure equity across all schooling, inclusive of historical private schools and religious schools.

\section{Relationships, team work, collaboration, security, and environment}

It evident in the literature that teachers' capacity to lead the learning process through relationship-building, team-work, collaboration, and many others impacts students' learning outcomes and school's effectives (Sahlberg, 2010). In school Y in Finland, almost 90 percent of the school leaders interviewed agreed that a school environment that encourages support, relationships, team-work, "we-feeling”, empathy, care, and security makes a big difference to the way teachers approach their teaching to improve students' learning outcomes (Interview data, 24/04/2018).

This collaboration was explained by one of the teachers as:

We can share information about how we teach, what method we have found useful about the topics we teach. For example, we can have a course, which is taught by two teachers because the group is so big and has been divided into two. We talk with each other about "where we are", which topic each teacher is teaching and has reached to see if we 
are the same page. Also, we ask, "are you doing this" "how did you do that or this?" (Interview data, 24/04/2018)

Another teacher shared his experience as:

It quite easy to approach the principal. The door of the principal is usually open. Just walk in there. You do not need any appointment, but you just go there. Also, if the principal has something to tell, it is usually done at teachers' general meeting. So, the general role of a teacher like it is not different from communicating to other teachers. Our principals are easy to approach. (Interview data, 24/04/2018)

On the issue of autonomy and team-work, a teacher expressed this:

Even among Finnish students, there are some differences about their personalities and the way they do things. As I said earlier, we place much responsibilities on students and classroom learning. We allow the students to work together. We are not lecturing - that is old fashioned - but we place the students at the centre of learning. We try to involve them to the maximum. It is very important to work with various people who work at different pieces or in a different way. I think working in other schools or working later in life is important. (Interview data, 26/06/2018)

A variety of learning options were outlined by the following teacher:

Well, we have different kinds of classrooms and is not just like tables are in rows or anything. For example, our tables are in hexagons or whatever and it really supports learning. For example, we can do group or team learning so students are not just learning arbitrarily but learning a lot together and helping each other and so on. Our environment encourages learning. Also, we have many possibilities to use information technology. We have the smart board and phones in our schools. I think the environment is very supportive for different kinds of learning methods. (Interview data, 24/04/2018)

These comments provide evidence that a culture of students' learning autonomy, teamwork, collaboration between and among the school personnel, students and the wider community has a significant impact on students' learning outcomes including school leadership.

These findings are consistent with much of the literature within educational leadership management concerned with improving the learning outcomes of students; for example, in the rational path model which is associated with teaching and learning practices, that is, how teaching and learning are organised from the leadership perspective and context to enhance students learning outcomes (Leithwood, Sun, \& Pollock, 2017). The working 
knowledge and skills of staff members, including understanding of the curriculum and teaching and learning, are vital for effective teaching and learning (Gurr, 2015).

A conducive environment for conducting learning and teaching also includes technology usage, pedagogy used, and student participation in learning, including team work, collaboration, assessment, and feedback (Shankar, 2019).

These require intervention measures from school leaders for directing students' learning (Fullan \& Langworthy, 2014) such as ensuring that there are workable and guaranteed processes in developing quality teaching and learning, assessment of students, and learning autonomy (Gurr, 2015). Furthermore, participation of students to develop their learning, adequate know-how of the use of modern classroom technology to enhance learning by the school staff, and a conducive climate which is adequately inviting and attractive for learning (Day \& Sammons. 2013) are evident in the case of Finland.

\subsubsection{Finland case: school leadership and professional networking communities}

It clear from the literature that principals and teachers take the centre stage when the issue of quality and development arise in educational matters in Finland (Paronen \& Lappi, 2018). These competencies of a school's leaders are vital as they drive the developmental agenda of the school (Taipale, 2012). A large body of literature reports on distributive or shared leadership style as a means to strengthen organisational effectiveness and development, including schools (Northouse, 2004).

The teachers in school $\mathrm{Y}$ in Finland recounted the impact of distributive or shared leadership on their work. One of the teachers shared his experience on this as:

In our school, the development discussion is held by the home school teacher but not the subject teachers and we have our own class. For example, if I have a class that I see a few times in the year, we gather together for a few minutes and talk about general stuff. Basically, I should be on the same page with how the students are doing with the studies. If the subject teacher or, for example, a Biology teacher identifies a particular challenge of a student, I should know what kind of grade my own students are getting even I don't teach Biology. I will be the first person the Biology teacher should talk to. For example, "Oh, I have your student Alex here" and I worry about his grade and is not good. We discuss first what need to be done. Also, there is some sort of situation we have to contact home. I will contact the principal 
if the situation is serious, but I am the first person to be contacted and if the situation is out of hand, then, we contact students' parents. (Interview data, 26/04/2018)

This comment shows that school Y has a system of shared leadership where the duties of the school are shared among teams ranging from the principal to the students. Again, it appeared that each one of the groups has some sort of autonomy to carry out their duties and responsiblities and to be accountable for their actions and inactions within the school. This finding is consistent with what Sahlberg previously found in relation to autonomy for teachers (Sahlberg, 2013).

Furthermore, these findings support the existing literature on leadership and management that describes how distributive leadership has a significant impact on students' learning outcomes. For example, ISSPP reports that during interviews with some selected school successful leaders, they openly say that their success is due to a shared leadership model they used at school level (Day \& Sammons, 2013). Ultimately, this has a positive impact on the learning outcomes of their students (Hoerr, 2005).

Distributed leadership enhances academic improvement by ensuring accountability and responsibility to other sub units within the school level (Leithwood, Harris, \& Hopkins, 2008). It promotes democratic education to enhance learning which is the prime focus of a school (Moral, Martín-Romera, Martínez-Valdivia, \& Olmo-Extremera, 2018). For example, at the departmental levels of schools, teachers have a right to appoint or elect their Head of Departments, HODs, in order to facilitate the smooth running of their duties (Day \& Sammons, 2013). More so, at the teachers level, they have the privilege of appointing or electing their team leaders and many other positions (Hoerr, 2005). This aspect of decentralisation within various units of the school gives a say to every individual to contribute to the student's learning process. Again, it encourages the division of labor and specialisation in order to improve students learning outcomes (Gurr, 2015).

\section{Teaching qualification and leadership development}

International indicators suggest that that Finland is one of the most advanced societies with adequate knowledge and skills for her population and workforce (OECD, 2018b, 2018c). Quality education cannot be ruled out as being the backbone for this transformation (Sahlberg, 2010). This development would not have been achieved 
without taking into account how teachers and principals are trained and developed throughout Finland (Taipale, 2012). Almost all the participants expressed aspects about their job that they really enjoy, and all have master's degree as the basic qualification to teach (Interview data, 26/04/2018).

One of the teachers explained:

Everybody must hold a master's degree before he or she can teach in Finland. That gives confidence to the principal and governing body that the teachers know what they are doing and can be trusted for what they are doing. So, a master's degree is required for the classroom teachers who teach from grade 1 and 6 and the subject teachers who teach from grade 7 to 14 . (Interview data, 24/04/2018)

Clearly, the requirement that a master's degree within the field of education is the basic qualification for teaching in Finland gives some level of confidence to the principal and to the community at large to trust the competencies, including the professionalism, of the teachers to deliver. This finding is consisted with what is reported in "Finnish Education in a Nutshell" ( MOEC, 2017, p. 24).

Principal training and development programmes have an impact on schools' effectiveness (Hoerr, 2005). Such training and development varies from one country to another. For example, in Denmark, Germany, and France, potential principals are mandated to have a least a bachelor's degree within the field of education. Also, they must have served for not less than five years before being appointed to a principal's role (Taipale, 2012). In school Y in Finland, however, an aspiring principal must hold a master's degree with not less than five years teaching experience within the field of education. In addition, aspiring principals must hold a certificate in educational leadership and management or administration before the position can be offered (Interview data, 24/04/2018)

This was explained by the education expert thus:

There are different kinds of exams that potential principals must write if they think they aspire to a principal's position in the near future. Some take a year course and write an exam. Others take shorter courses. Like I said, the path is slightly different, and the courses might be slightly different. But the exams have to do with school administration and leadership. The leadership one takes a little bit longer and there is a face-to-face meeting. (Interview data, 24/04/2018)

The principal also commented on the variable preparation required for this role, saying: 
Because this is a big city, we often have good candidates, so that means that very often principals have many kinds of leadership education. But in rural areas, we cannot find too many candidates and maybe the principals don't have leadership training, maybe only administrative training. (Interview data, 24/04/2018)

This seems to indicate the importance the country, Finland, attaches to the principal training programmes for aspiring principals, especially administration and leadership. The latter quotation reveals the fact that, in the big cities like Helsinki, due to competition and numbers of qualified applicants, the potential principal must have additional qualifications compared with applicants in the smaller cities and rural areas.

\section{Local specific curriculum}

It is argued that in more democratic societies and communities what students learn is enriched to reflect the cultural aspirations of that society (Liston \& Zeichner, 1996). Teaching and learning are tailored to cater to the needs of all students irrespective of their gender, race, colour, sexual orientation, religion, and other factors (Gorski, 2012).

In Finland, each teacher interviewed considered that teachers have the autonomy to decide what to teach and what their students learn (Interview data 26/04/2018). This is empowered and backed by the national curriculum (FNBE, 2016). This was supported by one HOD, who said:

We have regular meetings with the whole subject groups, and we have meetings with colleague teachers. We sit down and prepare our localbased curriculum for example. We do them together, we just wash dishes together and put them in their right places and see everything is there. This is normal cooperation. (Interview data, 26/04/2018)

This comment reflects that the teachers in the school have autonomy to prepare their local-based curriculum through the departmental levels. This preparation involves the collective effort of all the teachers to meet the needs and aspirations of all the students. This finding is consistent to what has been found previously (Paronen \& Lappi, 2018).

In conclusion, it is evident that the leaders of school $\mathrm{Y}$ in Finland support the importance of the local-based curriculum as it provides them with some form of autonomy and flexibility. It makes a big difference in the way they approach their work, especially collaboration and teamwork among personnel. This finding is consistent with what I earlier found in the strategic policy document of Finland, the national curriculum. 
Extra-curricular activity, PLCs practices (autonomy, collaboration, ethics of care and more)

There is enough evidence in the international literature to suggest that no institution or leadership practices in the world are one hundred percent perfect in discharging duties and functions (Taipale, 2012). Therefore, there is the need for educational leaders including policy-makers, principals, teachers, and others to anticipate possible changes and innovations that will yield positive outcomes within their working environment (Northouse, 2004).

My data reveal that teachers and students in the school Y have little time to take extracurricular activities such as sports and athletics due to their workload.

This was expressed by one of the teachers as:

You see in Finland, their education system is purely academics, purely academics, and very academic. You know, studies, studies, studies. Even school days are short, especially at the high school is purely academic. So, anything concerned with wiping the law is all good for me in Finland, unlike North America. Sports is a big issue here. We don't have a sports team that after school we play. Is not like that here, but more of academic. (Interview data, 26/04/2018)

These comments are evidence that school Y concentrates more on academic activities and that the teachers have little time for extracurricular activity like sports.. Again, three out of six teachers interviewed admitted that they had less time to be collaborative due to the workload and individual autonomy enjoyed in the school. A teacher shared his experience on this as:

But I don't think I am as engaged as a typical teacher here. I work very hard independently and as a group which is quite unique; all in all, it is a great place to work and I have a nice colleague. Culturally speaking, it is on one hand laid back and, on the other hand, very hard working. (Interview data, 24/04/2016)

The above quotation suggests that this teacher was not as well engaged as he had expected. It is possible that the cause for this is that too much autonomy for teachers may make some teachers work in isolation.

It is evident in the literature that in professional learning communities the leaders resort to early interventional measures to deal with challenges related to students (Stoll \& Louis, 
2007). Ethics of care, respect, love, trust, and empathy are tools used for such engagements (Easton, 2011). Furthermore, leadership in the community exhibits a high level of collective responsibility, authentic leadership, problem-solving skills, and networking with other schools, both nationally and abroad (Stoll \& Louis, 2007).

The data from school Y in Finland revealed that almost all the teachers sought to employ an ethic of care, love, community, empathy, networking, collaboration respect, teamwork, early intervention, accountability, individual autonomy, and trust among others to improve pedagogy for achieving students' success (Interview data, 26/04/2018). This was expressed by one of the teachers: "We are dedicated, we care for the students, and we work hard to help our students to learn. I think it is quite enjoyable" (Interview data, 26/04/2018). Another teacher shared his experience on this:

So, the school is quite generous for giving the teachers the opportunity to network. Through that avenue, I get the opportunity to network outside of the school. I also meet colleagues from Finnish schools and international, especially the IB crews. We meet from Turku to South on a Ferry. (Interview data, 24/04/2018)

Furthermore, researched-based learning as a feature of the school was expressed as follows:

Yes, I think that the goal here is a research-based. It is not enough for us that methods, didactics, pedagogy just feel good. It is not enough. We always need to take care that our teaching is based on research. But at the same time, we need to help our teachers and students to find their own way to be teachers or good students. The way should be researchbased learning. We don't tell them you have to be that kind of teacher, but we tell them they could be many kinds of teachers. But what they do should be research-based. (Interview data, 24/04/2018)

These comments appear to show that professional learning practices such as networks, ethics of care, love, trust, autonomy, collaboration, and research-based learning have a positive impact on students' learning. The quotations above provide evidence that school Y can be considered to be a professional learning environment; one that considers students' needs and the support required for students learning, performance, and success. 


\subsubsection{Finland case: students' needs and support}

One IPAD and one Laptop policy, special education teachers, homegrown teachers, psychologist, guidance and counsellors, social workers, creators, school-based nurses and doctors, free tuition and food

It is evident in the literature that a strong focus of the school leadership on arousing and sustaining students' interests to learn involves supporting and encouraging them to be abreast with contemporary knowledge, skills, and aesthetic qualities in education (Brophy, 2004). These forms of support are part of several incentives students might need for good performance in the classroom and beyond (Anderman \& Weber, 2009).

In school $\mathrm{Y}$ in Finland, all the leaders interviewed emphasised the importance of a number of factors which include information technology, special education for those who are physically challenged, and the need for homegrown teachers to link up with student's parents. The "homegrown" teachers are those teachers that liaise with students' parents in solving a peculiar challenge of a particular student to enhance learning. Again, the school has a school-based psychologist, guidance and counsellors, social workers and creators. The creators are teachers assigned to each one of the classes in the school to see the academic progress and welfare of her given students. The school also has a schoolbased nurse, school-based doctor, free tuition, and free meals. The provision of these resources makes a big difference to the way teachers approach their teaching to improve learning. One of the teachers shared her thoughts on information technology:

Each student in the lower secondary schools has an IPAD and those at the upper secondary have personal computers. That is all they need. The books are there, the exercise books are there and many more. Even, maturation, the final years at the upper secondary school is now electronic. Calculators are there, test books are there, so what they need to do is to sign in for the test when the time is due. (Interview data, 26/04/2018)

These comments indicate that each student at the lower levels in the school has access to his or her personal iPad, and computers at the upper secondary level. These learning devices have software installed in them to allow pupils and students access to reading materials and calculators to enhance learning. Also, students are able to take their final maturation examinations online.

Another teacher spoke about further support resources: 
We take care of the wellbeing of our students. I can speak for the upper secondary school. We have various people in place for the students to approach if they have any challenges. We have a psychologist on site for students, so if they have some problems, they need to send him some messages by saying, "Can I make an appointment; can I come and talk to you?" We have a special education teacher in the upper secondary school. If it is the nurse, if it is a physical issue, they want to deal with it at the homegrown meetings. The homegrown teacher together with the nurse might talk about sleep, they might talk about importance of sleeping and the importance of nutrition. So, the homegrown teacher checks everything if it is okay. In the upper secondary school, we also have wellness tutors. We have students who want to promote wellness to other students, so they might organise events and might inform us a day, date, and time that they want to promote this. They educate their fellow students about the importance of good health including drinking enough water in the day, having a good sleep, and many others. All these tips are on their computers, especially the Wilmer platform as well. (Interview data, 24/04/2018)

This comment indicates that the school takes a serious interest in students' wellness and wellbeing by providing support services such as psychologist, special education teachers, nurses, homegrown teachers, wellness tutors, and the Wilmer computer platform to improve students' learning and development.

It emerged from the data that school provides students with free tuition and free food. For example, one of the teachers explained:

"You know education is free in Finland. It's free of charge so you don't pay anything before you go to school. So, we don't really have scholarships for students or people living in Finland, because they don't really need money for that" (Interview data, 26/04/2018).

Another colleague's comments supported this:

Oh, yes, the school feeding, and lunches are free for all students. This is very familiar for us in Finland because we think that all people in Finland need to have equal possibilities to develop themselves. At the same time, we want the best students, but not the richest students because they not the same thing. It's a bit different. You can be very smart and without money and maybe have a lot of money but not smart. The idea is to give equal opportunity to every student. (Interview data, 26/06/2018)

Students in this Finnish school enjoyed free tuition and meals. It is indicated that the free meals are intended to bridge the gap between the rich and poor, to give equal opportunity 
to all persons who are of school-going age. These findings are consistent with previous research (Paronen \& Lappi, 2018).

In summing up, these and other findings are what Fullan and friends describe as micro level factors which contribute to deep learning. These include: the ability of school leaders to build trust relationships with students and peer teachers and seek good mentors; helping students to find and build their interests and aspirations through deep learning tasks; changing learning goals, tasks, and success criteria for themselves and for students that require creation and the use of new knowledge; developing adequate repertoires for teaching strategies and using different strategies to activate learning; providing high quality feedback and encouragement, especially when students face challenges in learning; school leaders collaborating with other teachers and personnel in researching the impact of different learning strategies on students; and creating digital learning tools and resources to enhance teaching and learning (Fullan \& Langworthy, 2014).

\subsubsection{Ghana case: school culture and climate}

This section provides an overview of the selected findings from the school in Ghana. These findings have been given detailed interpretations for readers to understand what is going on in school Z. The first part of this section details examination of school culture and climate, followed by school leadership and professional networking communities, and concludes by identifying students' needs and support.

\section{Indigenous and minority quota}

Previous studies have reported that the culture includes the way of life of a particular people or group which has been held by them for generations and which new members are taught or learn (Burgess \& Hart, 2013). The contested purposes of education include knowledge and skill acquisition, promoting social and economic integration, preparing students, shaping national and regional identities, democratic engagements, emancipation and others (Eagan, 2010; Giroux \& McLaren, 1989).

These purposes depend on governments all over the world with their subsidiary agencies to draft policies and programmes to target educational needs of their citizens (Bray, 2015). It emerged from the data in Ghana that, in order to ensure equitable distribution of wealth including access to education, the government, through the Ministry of 
Education, has instituted a quota system for indigenous and minority groups including females and disabled students in relation to university and secondary admission entrances. This is to ensure fairness and ethnic balance in schools' admission processes (Fieldnote, 16/07/2018). This effects of this equity policy were referred to by one of the interviewees as follows:

For example, when I was doing my master's degree, I looked at how the university is helping to bridge that gap through the socio-economic development in Ghana. And it came to light that the university had a policy of allocating a certain place to the people of northern Ghana and that was about 40 percent or so of space meant purposely for those students from northern Ghana. It means that the university admits from all over the country, but a certain percentage of the total admission is given to such people. (Interview data, 16/07/2018)

Similarly, another participant also shared that:

If you go to the secondary schools, even though we may not have a clear-cut policy, there are informal ways, maybe through the directives from the ministry or the community, ensuring that once the school is established in the specific locality or community, the head or the principal should do everything possible to give them some protocol or privileges by admitting students from the community or giving them some quota of the admission intake. This system runs throughout the country. (Interview data, 16/07/2018)

The comments above provide evidence that the quota system is meant to encourage equal access, inclusion, and participation of females, disabled people, and the indigenous people within the catchment of the school. Recognition of the indigenous ethnic groupings are a matter of fairness as the country has as many as fifty major ethnic groups and languages (Lentz \& Nugent, 2000).

I crosschecked this indigenous quota admission intake from the Ghana Education Service. I was told that it is a policy that mandates that the headmasters, headmistresses, or principals throughout the country must adhere to the directive principle from the Ministry of Education to allocate 30 percent of all intakes to the communities in which the schools are situated. This is to ensure equal access, participation, and to recognise the chiefs and the people whose lands were used to build those schools (Fieldnote, 16/08/2018) 
This finding supports the work of MacBeath and collegues (2010) who note that Ghana almost has fifty tribal languages and dialects spoken in the country. As such, the cultural background of the people, especially the students, plays a major role in developing quality teaching and learning. That is the reason why the Education Ministry of the Ghana has instituted this quota system to encourage equal tribal access to education (MacBeath, Swaffield, Oduro, \& Bosu, 2010).

The macro factors identified by Fullan et. al encompass the cultural backgrounds of the people, formal governmental structures and systems, official agencies, groups, foundations, advocacy groups and international bodies outside the school, which influence teaching and learning (Fullan, Hill, \& Rincón-Gallardo, 2017). These factors directly link to the day-to-day activities within the school and any thus affect students' wellbeing, learning, performance and success (Fullan \& Langworthy, 2014). For example, in the case of Ghana, this quota system has been instituted by Ministry of Education for various cultural groups to promote tribal participation in schooling.

\section{Religious tolerance and boarding system}

Postcolonial theorists believe that some activities of the colonialists are still operating within the institutions of the annexed countries up to today (Le Grange, 2010). This may be seen in the ongoing perpetuation of the religious institutions of the colonisers and in ongoing inequities between different religious groups. This can be seen in that Muslim and Christian students attend the Christian Church service on certain days in school Z. A teacher explained:

As far as I am concerned, the Muslims on Fridays do not come to the assembly grounds. They have a place for them, they have a Muslim square behind the boys' dormitory. But Mondays and Wednesdays, they are supposed to attend because one of the rules of the school says that every school gathering is compulsory, so these Muslims do attend but they are not given the opportunity to preach their faith. I think though it is not stated in the school's rules and regulations, but it has become normal that the Bible is almost used so the Muslims are supposed to attend, but apart from the preaching that is where announcements are also said. So, the Muslims cannot also detach themselves from that culture, but they are not given the opportunity to preach anyway, but I am also not sure whether they have an association over here. I'm not sure whether they have gone there to ask to be given the opportunity to preach. But I can confirm that Muslims teachers at 
the staff meeting are given the opportunity to pray before we start the meeting. (Interview data, 17/07/2018)

These comments indicate that there is religious harmony and peaceful coexistence among the teachers and the students, Christian and Muslim. In regard to this, all the participants agreed that religious tolerance has a significance impact on students' learning, improving their performance and success in the school. On the other side of the coin, according to the comments, it appears that Muslims students are not given the opportunity to share their faith with non-Muslim students at the assembly grounds in the school.

Furthermore, the study established that the school $(\mathbf{Z})$ has boarding facilities to support students' accommodation. Most of the teachers agreed that there is some likelihood that this system impacts students' learning, performance, and success (Fieldnote, 16/07/2018). For example, one teacher explained that:

We have boarding system in the school. About 70 percent of the students, both boys and girls, (stay) in the boarding house and the day students are few. This boarding system has the boys' dormitories and we also have the girls' dormitories. We have about eight houses for both boys and girls. (Interview data, 17/07/2018)

The school provides boarding facilities for students who may have come from far off parts of the country. Also, the provision of the facility is intended to facilitate their stay and support their learning.

\section{Transgender issues}

It is evident from the literature that transgender, gay, and lesbian students around the globe experience abuses of all kinds including threats to their safety, exclusion, alienation, harassment, and violence (Bartholomaeus \& Riggs, 2017). My data shows that there is no policy to protect the minorities including transgender, gay, and lesbian students in Ghana including in school Z. This was expressed by the Ministry's official:

Our policies protect Ghanaians. We have not come across transgender among us. It has not become an issue in Ghana here. If it becomes an issue, and we must go back and look at our policy. We will go, but so far, we don't have clear policy on this. For instance, people were doing some studies on teenage mothers who are going back to school and they came to the Ministry and asked about our policies. And said we don't have an issue with anybody because if people are going to school you 
don't ask them if they have a child or not. So, until it becomes an issue, for now it's not an issue in Ghana. (Interview data, 26/08/2018)

The majority of my participants especially the teachers expressed otherwise on this same issue. They shared that there are transgender, gay, and lesbian students in the school, but the rules and regulations in the school make their voices unheard. This was expressed by one of the teachers as:

You mean those lesbians and gays. In fact, in our code of conduct and status, it is written strictly that gays and lesbians are not entertained in the school. If a student is caught, I can't recall it often, but I think your first punishment will be a dismissal. But there were cases where students who were lesbians were made to be day students. They were asked to be day students but were not dismissed. (Interview data, $17 / 07 / 2018)$

Based on the quotations above, then, it seems there is no policy protecting the transgender, gay, and lesbian students within institutions throughout of the country. There is also enough evidence in school $\mathrm{Z}$ that making one's sexual orientation known as transgender, gay, or lesbian may attract some form of sanctions including making them day students. That means removing them from the boarding house of the school and making them come from their homes to school. Again, it appears that they can be dismissed from the school outright. This finding is consistent with some previous research in South Africa (Thoreson, 2008).

Here macro level factors have negative consequences on students learning as seen in the Ghanaian case whereby some minority groupings such as transgender students have no voice in the school.

\section{Low respect for teachers and teaching profession}

Quality teachers are an important component in education and play a key role in students' learning outcomes (Scott \& Norgrove, 2017). For this reason, respect for the teaching profession has an impact on their daily activities (OECD, 2015, 2018b). However, this was not what the teachers in school $\mathrm{Z}$ were experiencing. One of the teachers expressed his views as:

The teaching profession is for those who are dropouts or individuals who come from a very poor background. I think that if we make teaching attractive that can attract high talented individuals to go into teaching because the quality of a school is determined by the quality of 
the teachers. If you have quality teachers, you have quality students and obviously this is not the first assessment suggesting that our student's performance is low. (Interview data, 16/07/2018)

Two of the school leaders affirmed this by expressing their opinions in the following ways: "One factor of these will be competencies of our teachers because over here the teaching profession is not respected" (Interview data, 15/07/2018). Another colleague also opined that, "There are some assessments that also give similar results, so we must look at the teaching force. That could be one of the factors contributing to our poor performance" (Interview data, 15/07/2018).

These comments indicate that low respect for teachers and the teaching profession in Ghana are due to two reasons. First, the society believes that students with low grades end up being in the teaching profession. Second, people from socio-culturally disadvantaged backgrounds who could not meet the university entrance requirements end up being teachers.

To throw more light on this, there is a higher entry requirement for universities than for the teacher training institutions. This has contributed to teaching gaining low respect from the society. Further to this, there is a higher cost for university education than for that of the teacher training institutions. As a result, students from financially challenged families are more likely to end up in the teaching profession.

This development has affected the psyche of people; so much so that almost all the teachers interviewed in school $\mathrm{Z}$ in Ghana said they got into the teaching profession because they could not get the required grades to enter the universities. One of the teachers emphasised that:

I got into the teaching profession by an accident. After completing my A levels, I was posted to do my national service. So, after the service, I was retained for some time because one of subjects was posing a problem to me to enter the university. ...I was teaching in primary school class five. So, my head teacher at that moment advised me if am interested in the job then it's better I go to teacher training college. So, I took his advice and then went to training college. Afterwards I became a professional teacher. (Interview data, 16/07/2018)

This story supports the perception that people end up as teachers or in the teaching profession due to the higher score required in the standardised examination to enter to 
various universities throughout the country than that of the teacher training colleges. For this reason, as the comment points out, some teachers end up as teachers accidentally.

\section{Relationships, team work, and collaboration}

Positive relationships including teamwork, collaboration, and interactions help the vision of the school to be carried out and achieved (Brown, 2015). Such relationships help build confidence among members of the school to communicate their ideas freely in order to benefit the school's ultimate goal; that is, students' learning, performance, and ultimately success (Lance, 2010). More so, trust is developed as a result of relationship-building among the principal, the teachers, the students, and students' parents, in order to enhance students' learning, (Brown, 2015; Lance, 2010).

In school $\mathrm{Z}$ in Ghana, almost all the teachers and the principal agreed that a supportive environment, team work, collaboration, and relationships where they are cared for, valued, and able to express their opinions can make a big difference in the way they approach their teaching and learning. The was expressed by one of the teachers as:

In fact, the relationship is very cordial. Sometimes when you enter the class you see some students may not be feeling comfortable, but so far as I am concerned, I always have a very cordial relationship with my students. Even if I fall sick, you will see that my students are not feeling comfortable at all. So, all the time they pray for me that I will be present in class regularly and punctually. I have never absented myself from class unless there is something beyond my control, especially if I fall sick. I will never miss my class, even at all if it is raining. I must make sure that I enter the class. I must make sure that I start my period at appropriate time and then close at the appropriate time and give the students the exercises. I mark and record the marks. I then come back to the students to discuss with them to see if they have problems. I explain what I encountered when I was marking their scripts to them. (Interview data, 15/07/2018)

This statement reflects the position that a strong relationship between the teachers and the students, especially cordiality, helps improve teaching and learning. As result of this intimacy, trust is built between the teacher and the students to enhance students' learning outcomes.

Another teacher supported the positive impact of collaboration in the school, especially collegiality, by sharing this: 
Is very true; for instance, if you are going to teach a topic and you don't know much about the content, you cannot just go there and just be doing things like that. Somebody that knows better than you can help. Normally for biology for instance, we are five teachers teaching biology, so if there is a topic that any of us don't understand much, we consult each other. Also, during examinations, we sit down and plan together as to what information to be given to the students. We cannot go and give false information or anything which is not true. So, we also collaborate well always. We sit down, and we do consult each other before we go inside. (Interview data, 16/17/2018)

This excerpt reflects the importance of team work, especially collegiality among teachers, in order to support teaching and learning. Also, the comment reveals that the teachers team up and develop a plan together. This teamwork appears to promote consistency and uniformity among the teachers in order win the confidence and trust of the students.

Conversely, the literature makes it evident that poor relationships among the principals, teachers, non-teaching staff, parents, and students is likely to have a negative impact (Brown, 2015; Goldring, 2002; Sapher \& King, 1985). Ineffective interactions among school actors may lead to tensions, antagonism, and misunderstandings within the school and beyond (Brown, 2015; Goldring, 2002; Sapher \& King, 1985).

On this matter, the educational leaders in school $\mathrm{Z}$ emphasised the importance of the school collaborating with the wider community in supporting students' learning. They all agreed that building positive relationships with the stakeholders' helps improve the school climate for learning and other developments (Interview data). A teacher of the school described this:

You know, right now each teacher has students' parents' phone numbers. In case there is a problem, we just call them. We call the parents sometimes to explain things to them about what they don't know about their kids. They [students] are good at home, but put up all sort of behaviours in the boarding house. We call to advise parents on children's behaviours, and they trust us. (Interview data, 16/07/2018)

It appears that the school-community partnership, especially teacher-parent relationships, helps all parties to know what a student is doing. Because of this, in situations of poor student behaviour in the school, correction measures or rewards can be put in place by both the teacher and the parents. 
The data revealed a strong relationship between the principal and teachers, teacher-toteacher, and teacher-to-students, as well as between the school and the wider community as a means to impact students' learning outcomes and development. On the other hand, it appeared that there was less relationship, collaboration, and team work among students. This may be due many factors including large class sizes, standardised examinations, and the curriculum which teachers must follow. These may not give room for activity learning, including team work.

These findings are consistent with some of the findings in the ISSPP report which discusses that successful school principals display a high level of ethics of care, collaboration, teamwork, and empathy for others at the work environment (Leithwood, Harris, \& Hopkins, 2008; Northouse, 2004). Such leaders value and appreciate the opinions of others (Leithwood, Harris, \& Hopkins, 2008) and exhibit democratic values such as freedom of speech and expression, responsibility and accountability, and collective care in order to build trust among members (Gurr, 2017).

Successful leaders view organisational hinderances as challenges to overcome (Day \& Sammons, 2013) and use a transformational leadership style as a tool to develop others (Thornton, 2011). In short, they are motivated to improve the learning environment at all times in the school (Moral, Martín-Romera, Martínez-Valdivia, \& Olmo-Extremera, 2018). And more importantly, they walk the talk and have the courage to do what is right to enhance their students total wellbeing and development (Day \& Sammons, 2013). These approaches can foster a conducive atmosphere for the engagement of students and personnel (Day \& Sammons, 2013).

\section{School environment}

Previous studies have reported that environmental safety measures within schools must be a priority of educational leaders who want to make positive impacts on students' learning outcomes and development (Koopman et al., 2010). All the participants in school $\mathrm{Z}$ expressed aspects about their job that reflected ways in which a positive school environment, including security, supports the way they approach their teaching to enhance learning. However, they really disliked having large class numbers.

This was reiterated by one of the leaders: 
As you can see the school is very large. It has a large compound surrounded with trees. We have this lazy chair around. All students need is a very quiet place to sit down and have their studies. Apart from that we have libraries, we have various infrastructure whereby students can sit there as a group and then learn. Talking about the environment supporting students learning, that one is not a problem here. Only if the student is serious and wants to learn, he or she will have a place to learn. So, either private or a group or whatever is not a problem here (Interview data, 16/07/2018)

On the other hand, in relation to the security and wellbeing of the personnel and students, an interviewee shared the following:

That is one good area that within the security, we have security personnel and they work 24 hours. They run on shift and even at the halls of the school, we have personnel and security posts in each hall. The halls are places of accommodation for the students or residences of faculty members, so security is something that is guaranteed in our institutions. If you go to the lower level, they too they have security personnel over there. (Interview data, 15/07/2018)

The comments provide evidence that good security and a serene environment benefit students' learning, performance, and success. This finding is consistent with what was previously identified (Cobb, 2014).

Effective leaders create a hospitable climate for the school's personnel, especially teachers, to promote students learning (Kearney et al., 2018; Wallace, 2011). This includes having good security, promoting good relationships and providing emotional, physical, psychological, and environmental safety for students within and outside the school to learn (Cobb, 2014). These aspects may motivate the students and personnel to learn, respect one another, and to care for the school property and environment (Sebastian et al., 2016; Wallace, 2011). These points link to the need for students and teachers to have their voices heard within the school.

\section{Teachers and students'voices}

It is evident in the literature that practicing and prospective teachers have to develop ways to deal with contextual issues by allowing their students to articulate their views, ideas, beliefs, and feelings about pertinent issues (Hopson \& Lawson, 2011). The teachers in school $\mathrm{Z}$ emphasised that expression of their views could impact the way they approach 
their teaching and improve students' learning. However, they experience this in a negative way. One participant shared her experience as:

This is what they told us if you insist on your right. At a point in time you even become a threat to administration. Sometimes, they say if you can't comply, you can leave the school to somewhere else. It has happened to a colleague teacher. You see some of the classes, we have the elective subjects. Say subject $\mathrm{X}$ is paired with the other subjects. So, the some of the students in class pursue subject $\mathrm{X}$ other pursue $\mathrm{Y}$. So, what happens is that sometimes the teachers will not have classrooms, so they will have to look for classroom. You go to administration and report this situation to give your own class, they see you as a threat of complaining too much. As a result, the teacher can be transferred from the school to another school. I have witnessed this in the school, and I didn't like it at all. So, it becomes like a threat, so the teacher was transferred, and it became you cannot do the work. (Interview data, 15/07/2018)

These comments provide clear evidence that teachers in school $\mathrm{Z}$ do not have enough voice or autonomy to initiate something new to support their teaching. Initiating something new without the approval of the principal amounts to gross disrespect of the school's authority. This may attract sanctions such as a transfer from the current school to another. Even when the teacher knows the importance of using iPads and Phones connected with the internet to support his teaching and learning, because he has no selfautonomy to initiate this, he must follow the status-quo without questioning and forego the use of such technological support.

On the issue of the students' voice, the school leaders expressed divergent opinions. For example, one of the interviewees remarked, "If you don't understand anything, you have to be bold enough to tell the teacher" (Interview data, 15/07/2018). A colleague also shared his experiences, saying "It's not in a negative way, but they will say something like, 'Oh Sir, for this one I don't understand', but this normally happens after the teaching hours when I am leaving the class" (Interview data, 16, 07, 2018).

Further to this, one of the teachers shared his experience on the same subject thus:

Sometimes some parents come and say, "My child called me or informed me that maybe the food in the school is not properly done and then is not well cooked or the quantity is small" and so forth. Maybe the school fees - something has been added to it and many others. They give misinformation to their parents and that brings problems to the teachers. (Interview data, 15/07/2018) 
The two quotations above suggest various platforms that students use to express themselves. Teachers are apparently willing to hear and support students upon their request. The latter comment, however, suggests that this teacher sees the student voice as complaints which always lead to trouble for the teachers.

This finding supports previous research which argued that sometimes the relationship between principals and teachers in Ghana is marked more by accusation and counter accusations and conflicts as to who is right or wrong or has the ultimate power in the school (MacBeath, Swaffield, Oduro, \& Bosu, 2010).

\subsubsection{Ghana case: school leadership and professional networking communities}

Recent evidence suggest that the schools' leaders must provide students with the needed tools to examine and re-examine their own experience in order to identity challenges confronting them (Hopson \& Lawson, 2011). Also they must act as role models for emulation by their students (Northouse, 2004). Leaders and managers must understand and appreciate the socio-cultural backgrounds of their students, and the curriculum and the pedagogy they use (Giroux \& McLaren, 1989; Rogoff, 1990).

The leaders in school Z in Ghana agreed that leadership qualities such as discipline, role modelling, punctuality, ethical and moral soundness, honesty, and trustworthiness which are attributes of a good teacher - have positive impacts on the way they approach their daily work and their students' development (Interview data). One of the teachers expressed his opinion on this:

You know every teacher is supposed to be a role model for the students. We use ourselves to set examples. I use myself as an example; the boys in the school are supposed to always dress well by tucking in their uniforms. It makes them look like students. This is a very simple rule now and because most of them cannot obey this, I use myself as an example by doing so. When they see me doing that automatically they will follow that. Apart from this, I also have the opportunity to punish any student who does not follow suit because I have done that already. (Interview data, 16/07/2018)

The comment supports the notion that school leaders should act as role models to students. Acting as a role model has a positive impact on their students' learning. It also 
supports the notion that the teachers are moral agents who shape and guide students' behaviours.

Studies on school leadership has shown importance of distributive leadership as one of the tools to address challenges faced by students, school's personnel including teaching and non-teaching staff, as well as parents, and the wider society towards students' learning (Hopson \& Lawson, 2011).

The school leaders in Ghana remarked upon the importance of leadership practices in the way they approach their daily work to promote work efficiency as:

The students too if they have problems, they have to see us first before they get to the headmaster or the principal. They must pass through us before the housemistress. The headmaster has appointed some of the teachers or delegated some of the duties to the teachers. Therefore, they are to follow this due process. The teachers must try to solve the students' problems first and if the problems are unresolved or too cumbersome, the house masters or the mistress, HOD must forward it to the headmaster or the principal. (Interview data, 15/07/2018)

These comments seem to suggest that there is a division of labour in relation to leadership which is shared or a distributed in the school. This leadership model sets out boundaries where students challenges must be addressed. It appeared that the ultimate authority and power is vested in the hands of the headmaster, mistress, or the principal of the school.

School leaders cultivation of leadership in others within the school is a cardinal feature to enhance students learning and development (Hollander \& Won, 1978). The leader's role as a transformational agent is to influence and transform individuals within the school (Leithwood \& Jantzi, 2005). They are very much concerned with values, morals, standards, ethics of care, justice, trust and critique, in order to drive members of the school community to accomplish the school's vision which is ultimately focussed on students' learning (Sebastian et al., 2016; Starratt, 2004). Transformational leaders distribute leadership (Sebastian et al., 2016). Such leaders make leadership within the school a shared enterprise by assigning various roles to the departmental heads, teachers, students, and, if possible, parents (Heck \& Hallinger, 2009; Wallace, 2011). They encourage and grant the teachers self-autonomy to carry out their duties as well as to learn from one another (Dou et al., 2016). For example, in order for the leadership to improve learning in the school, teachers must also demonstrate leadership in guiding 
students to be accountable, responsible, and develop learning autonomy (Belcher, 2017; Dou et al., 2016). Leaders must be positive role models for others (Belcher, 2017). Teachers must be fair and firm in guiding the learning process as well as supporting students of all abilities and backgrounds to learn (Sebastian et al., 2016).

\section{Communication structure and recruitment of leadership}

A number of researchers have reported that without effective school leaders their roles such as setting the vision, staffing, directing and evaluation and many others will fall short (Hopson \& Lawson, 2011; Wallace, 2011). In relation to this, teachers in school Z in Ghana emphasised the importance of a loose structure in service delivery. The teachers expressed top-down leadership structure in education in the country (Fieldnote). For example, one of the interviewees explained that:

What happens is that if you want to go outside, for example, for an excursion, you have to write through the HOD to the headmistress and the headmistress writes to the metro education office. The metro education also sends the letter to the regional office before an approval might be been given for us to go for the trip. (Interview data, $15 / 07 / 2018$ )

Another teacher also outlined some of the difficulties with hierarchical models of leadership:

In Ghana, the challenge we have is that the heads, headmasters, mistress or principals are bossy. Sometimes, when you go to them to seek some information, it becomes difficult. Sometimes, you may have a genuine concern and you go to them, they tell you that everything comes from Ghana Education Service, headquarters and we have no control. (Interview data, 15/07/2018)

These teachers' comments demonstrate that the school has a top-down structure of leadership. This structure sometimes delays resource allocation and service delivery to the school, so inhibiting the work of the teachers.

A centralised model of teachers' recruitment and posting emerged in the interview data from school Z (Interview data, 24/08/2018). A teacher shared his experience on this as follows:

Even at the secondary level, they don't have the power to initiate or recruit teachers or the posting process. They don't have the ultimate power to recruit. For the basic schools, they don't even have that 
influence to facilitate the process. It is at the district education level or the regional level through the national [level]. The national level gives the final say. (Interview data, 16/07/2018)

Teachers' recruitment and posting are done at the national level through the regional, districts and finally the schools. Schools have no power to recruit teachers, but follow orders from the national office.

\section{Shortages of professional teachers and teaching aids}

Factors found to be influencing students' learning include quality teaching and good working conditions for teachers (Sahlberg, 2010). In school Z in Ghana, almost all the leaders agreed that having adequate professional teachers, small class-size, teaching and learning aids including projectors, computers, in-service training, laboratories and many others have impacts on the way they approach their teaching (Interview data, 15/07/2018). This sentiment was expressed by one of the teachers in the following way:

Look at the teaching force, one of the factors contributing to the poor performance is inadequate teaching and learning materials. We have different class of schools even at the basic level, we have high classsize and less endeared schools. The majority of the schools in Ghana are not inadequately resourced in terms of infrastructure, in terms of everything so if you analysed, the schools that are performing in the country are the top schools and they are very few. If you go to other jurisdictions, it does not matter where your school is situated, resources are equitably distributed whether you are in a rural or urban area. Facilities in terms of staff, in terms of ICT are the same, but we don't have here. In our school, the students are overcrowded and large class size. All these contribute to a part of the poor performance in our schools. I talked about staff, I talked about infrastructure as of factors contributing to this poor performance. (Interview data, 15/07/2018)

It appeared that the school faced shortages of teaching and learning materials including information, communication and technology equipment, a large class-size, infrastructure such as building, overcrowding and many others.

Factors that impede quality teaching in Ghana that have previously been noted include: a shortage of teachers which sometimes results in a teacher teaching two or more subjects and classes; large class sizes which may often exceed eighty students; and a lack of professional development for teachers including ICT knowledge (MacBeath, Swaffield, Oduro, \& Bosu, 2010). These challenges affect quality teaching and learning as evident in the case of school $\mathrm{Z}$ above. 
It is evident in the literature that for a school to be an effective professional learning community, the following practices must be in place to support students' learning: collaboration focusing on learning; shared values and vision; collective and shared responsibility; reflective professional injury; operationalising values of respect and trust; teachers' and students' autonomy; openness; networking and partnership (Easton, 2011; Stoll \& Louis, 2007).

Given these attributes of a PLC, the data seems to suggest that school Z in Ghana cannot be classified as such. It appears that students, teachers, and minorities including the transgender, gay and lesbian students have low or moderate voices and autonomy. It also seems that there is less trust among personnel and students, and, finally, the capacity for school members to contribute to a culture of love, accountability, and individual responsibility in carrying out their daily duties is limited.

These above may work effectively when external forces such as the role of politics, governmental ministries and agencies, cultural values and traditions which have direct relationships with the school work hand-in-hand (Leithwood, Sun, \& Pollock, 2017). Therefore, there is the need for school leaders to respond to these direct and indirect influences of external factors in their teaching and learning process (Fullan \& Langworthy, 2014). Realising these will provide opportunities to produce an environment in the school that develops self and social empowerment for students, school personnel and the wider community (Roberts, 2004).

\subsubsection{Ghana case: students' needs and support}

Previous studies have established that supporting students' needs includes giving attention to the affective, cognitive, and psychomotor development of students (Brophy, 2004). The affective goal of students deals with the emotional wellbeing while the cognitive is with the mind (Cole, 1990). The psychomotor targets the development of skills acquisition which is crucial for the survival of an individual (Rogoff, 1990).

In school $\mathrm{Z}$ in Ghana, free school daily meals, free tuition, free textbooks, free uniforms for students, school nurses and clinics, counsellors, free boarding facilities, and membership in clubs and societies emerged as means to support students' learning and development. Correspondingly, all the teachers emphasised the importance of these services as having a positive influence (Interview data, 07/ 07/ 2018-24/08/2018). 
The Ministry official of Ghana shared his experience on this as: "Free tuition has been in Ghana since independence. Even at the university, the Government pays all the teachers exactly and that has been done from independence" (Ministry's official, 20/08/2019). Also, the teachers appreciated the provision of free meals in the school to motivate them towards their teaching and learning.

Furthermore, a teacher confirmed that the school has a guidance and counselling coordinator and that her role is of importance to students' learning, stating that: "In our case we use a guidance and counselling coordinator; for example, if I have a problem beyond my level, I then report the matter to the coordinator to deal with that particular student" (Interview data, 15/07/2018).

These comments provide evidence of the significance of the school feeding and lunches, free tuition, free textbooks, and many other services for students' learning, performance and success in the school.

In conclusion, school leaders' ability in helping to build motivational support and capacity for personnel facilitates students' learning outcomes (Leithwood, Sun, \& Pollock, 2017). Such leaders focus much of their energies and efforts in shaping the expertise and knowledge of others and giving out motivation of all forms to enhance learning (Pollock, Wang, \& Hauseman, 2017). For example, the principal's roles in improving school instruction, budgeting, school maintenance, occupational health, motivational needs and support, and safety compliance are conditions which in turn foster students' learning outcomes (Pollock, Wang, \& Hauseman, 2017). These motivations and support needs may also improve the cognitive and affective aspects of personnel and students (Gurr, 2015). 


\section{CHAPTER FIVE: Comparison of findings}

\subsection{Introduction}

This chapter is divided into four main sections and comprises a summary and comparison of the findings presented and discussed fully in Chapter Five. The first part presents the findings for New Zealand in response to the first and second research questions, the second part for Finland, and the third part for Ghana. The final part compares the three multiple cases to identify similarities and differences. Research question three is addressed in Chapter Six.

\subsection{Summary of findings: New Zealand}

Research question 1 asks:

- What is the relationship between school culture, climate, leadership, and students' success in New Zealand?

1) In New Zealand, there is a locally-based curriculum which is prepared within departments of school $\mathrm{X}$. This gives flexibility to teachers to decide what their students learn. In doing so, teachers are able to influence students' learning performance and success.

2) The study noted that school $X$ in New Zealand has three official languages, English, Māori, and New Zealand Sign Language as the media of instruction. The availability of these language options to students appears to satisfy individual language needs, especially for indigenous Māori students, to improve their learning outcomes.

3) Teaching colonial histories and treaties, especially the Treaty of Waitangi, appear to have significant impacts on students' learning, performance, and success in school X. These colonial legacies underpin the injustices which happened during colonialisation and teachers, so students must know about these in order to avoid reoccurring of these sad historical events.

4) A culture of sports, athletics, Marae-based activities, and Kapa Haka challenge dance appear to have a significance impact on students' learning, performance, 
and success. These activities often inspire, motivate, and psych the minds of students towards learning to improve their performance and success.

5) The mission statement, uniforms, logos, crest, wall paintings, designs, national flags, trophies, portraits of past students and symbols are of importance to school $\mathrm{X}$. These artefacts appear to give direction as to how the school must be run. Also, they serve identification purposes, especially in the wearing of uniforms, crest and flags. The trophies and the portraits of the past heroes displayed in the school are perceived to inspire and motivate students towards learning.

6) Spiritual beliefs and practices, especially of the Christian faith, appear to have positive impacts on students' learning performance and success in school X. The school has a Christian chaplain who offers counselling services relating to wellness, wellbeing, and spiritual growth for students' development.

7) The values of school inclusiveness, equity, respect, equal access, high quality and effective teaching have contributed to positive cultures that promote students' learning performance and success in school X. This points to the key role of teachers in promoting these values.

8) School, $\mathrm{X}$ is a decile ten ranked school. This high ranking is positively perceived by parents who then send their children to this school with the belief that such a ranking is associated with quality education that will improve students learning, performance, and success.

9) The study found that in 2015 the New Zealand Government spent $6.3 \%$ of its GDP on education, the second highest among all the OECD countries except Norway. This level of funding appears to have had a positivel effect on school $\mathrm{X}$ with the teachers acknowledging that the school has been renovated in recent years to include ultramodern buildings, libraries, music studios and an art studio to enhance teaching and learning.

10) The study found that a small-class size has positive impacts on students' learning, performance and success. The average class size of the school is 15 .

11) The study found that an effective security system, a good school environment, strong networking, team work, teacher autonomy, collaboration and relationships - including, teacher-teacher, teacher-student, teacher-principal, and schoolcommunity - have a positive impact on students' learning, performance, and success in school X. 
12) The study found that almost all the teachers in school $X$ ended up as teachers because of the love they have for the profession and their career choices. Also, it appears that the recognition the profession attracts from the wider society may have influenced this. However, teachers also expressed dissatisfaction about what they perceive as unfair salaries, heavy workloads, and poor recognition on the part of the successive governments, and that they would like to see changes. Teacher factors seem to have profound positive and negative effects on students' learning, performance and success.

13) The study found that teachers in the upper secondary school have more contact hours. They teach 760 hours a year as against OECD average of 662 in 2015. This appears to have negative impact on teaching and learning as teachers in the school $\mathrm{X}$ complained of about their too much workload in the school.

14) Upper secondary teachers salary ranked $7^{\mathrm{TH}}$ among the OECD countries in 2015. However, the teachers complained about their low salaries they receive when compare with their collegues in other professions. This sometimes gives them low motivation to do their work.

15) The study confirms the lack of or inadequate apprenticeship programs for students and graduates of school X. It appears that there is little or no job placement for these students and graduates because job owners do not want to open their doors to them. This factor seems to have a profound negative effects on students' learning, performance, and success in the school.

16) The study noted that school leaders follow national standards in guiding their students' learning especially, the New Zealand Education Act. The Act establishes the working relations, duties, and acceptable behaviours of education providers including, teachers, principals, and many others to avoid conflicts and duplication of functions to improve students' learning.

17) The study found that, in school $X$, there is a shared and distributive leadership approach which reduces teachers' workloads, encourages specialisation, improves job efficiency, and consequently positively affects students' learning.

18) The study found that a bachelor's degree within the field of education is a basic qualification for teaching in school X. Of the six teachers interviewed, three were PhDs holders within the field of education. Teachers agreed that higher qualifications and academic experiences, skills, and knowledge have an impact on their daily work to enhance their students' learning outputs. 
19) The study found that there is no official preparation program for an aspiring principal in school X. Currently, an aspiring principal must be a professional teacher with three to five years working experience, must have passed through a competitive interview, and thereafter, leadership and management programmes could be sought for after the appointment. Further to this, the principal of the school $\mathrm{X}$ expressed that making principalship training programs obligatory for aspiring principals may help improve administrative lapses, which have the potential to negatively affect students' learning, performance, and success.

20) New Zealand recognizes OECD's rankings as a valid indicator of students' learning outcomes.

The following are summaries of findings relating to the second research question:

- What is the relationship between the use of Professional Learning Communities, students' needs, motivation, and success in New Zealand?

1) The study found a positive relationship between the availibility of resources for meeting student' needs - for example, an ultramodern library stocked with books, a music studio, an art studio, a school-based guidance and counselling unit, a school-based clinic and nurses, a technical support unit, free tuition, a cafeteria, and a strong digital learning equipment - and the provision of cognitive, affective, and psychomotor support to enhance students' learning, performance, and success.

2) The study found that school $X$ is a professional learning community. This is supported by evidence of the use of researched-based learning, lifelong learning, academic freedom, students' autonomies and voices, trust and accountability, individual responsibility, wellbeing programmes, ethics of care, love, truthfulness, openness, sharing, community, empathy and the use of student's data to address his or her learning needs. These variables have a strong positive relationship with students learning, performance, and success. This finding is consistent with the values, aspirations, and directions of the New Zealand national based curriculum. 


\subsection{Summary of findings: Finland}

The following are summaries of findings that address the first research question for Finland:

- What is the relationship between school culture, climate, leadership, and students' success in Finland?

1) In Finland, the study found a locally-based curriculum prepared within departmental levels of school $\mathrm{Y}$ to guide teaching and learning. This flexible hand for schools and teachers to decide on what their students learn appears to have a positive effect on their students' learning performance and success.

2) The study found that school $Y$ has two official languages: Swedish and Finnish as media of instruction. However, there are other languages such as Sami, English and many more in which learning could be conducted within areas where those languages dominate. These options available to students in which learning may be conducted appeared to satisfy individual language needs, especially for minority groups in the school, to enhance quality teaching and learning.

3) Teaching colonial histories, especially Finnish independence from Russia in 1917 seems to have significant impact on students' learning, performance and success. Having such a curriculum highlights the injustices which happened during colonisation and what teachers and students must know to avoid reoccurring of such sad history and events.

4) Cultures of sports and athletics is seen to have a significance impact on students' learning, performance, and success. However, it appears that, for several reasons, teachers and the students have insufficient opportunities to engage in these extracurricular activities. The study noted that a reduced sports programme is likely to have a profound negative impact on students' extra curriculum activities which may support their cognitive, affective, and psychomotor development.

5) The mission statement, logos, crest, wall paintings, and designs, national flags, trophies, portraits of past students and heroes, symbols and other such items seem to be of much importance to school Y. These cultural artefacts give direction as to how the school must be run. The trophies, portraits of the past heroes and students displayed in the school seemed to inspire and 
motivate students positively towards learning. School Y does not have a uniform, but it does have a culture of jacket and shoes removal to make classroom conducive to enhance students' learning.

6) The study found that spiritual belief and practices have no place in school Y as the school has no Christian chaplain or Imam. It appears that the school gives minimal attention to matters of spirituality and how these support learning.

7) The culture of inclusiveness, equity, equality, respect, equal access, and high quality and effective teaching was perceived by the teachers as effective means to support their students' learning, performance, and ultimate success.

8) The study found that school $\mathrm{Y}$ does not operate under a ranking system. A non-ranking system is believed to have a positive effect on equal accessibility of students to their community school. This may or may not put pressure on specific targeted schools during admissions and other education-related matters to improve quality learning for their students.

9) Relating to school climate, the study found that the government of Finland spent a little below $6 \%$ of GDP on education in the year 2015. This finding indicates a trickledown effect on students' learning, performance, and success as the teachers acknowledged that the school has been renovated in recent times to include resources such as ultramodern buildings, libraries, and music studios to enhance students' learning by the municipal government.

10) The study found that small-class size has a positive impact on students' learning, performance, and success as the school has class size average of 15 .

11) The study found that school $Y$ has a strong security system, a good school environment, and strong networking, team work, autonomy, collaboration and relationships - including, teacher-teacher, teacher-student, teacher-principal, and school-community - factors which have a positive impact on students' learning, performance, and success.

12) The study noted that all the teachers in school Y ended up being teachers due to the love they have for the profession as well as representing their career choices. It is noted that the prestige and recognition the profession attracts from the society may have affected the teachers' career choices. These variables also have a profound impact on students' learning, performance, and success.

School culture, climate, leadership and success 
13) The study found that teachers in the upper secondary school have less contact hours. They teach 547 hours a year as against OECD average of 662 in 2015. This appears to have positve impact on teaching and learning as teachers in the school Y complained a little about their workload but satisfied overall.

14) Upper secondary teachers salary ranked $4^{\mathrm{TH}}$ among the OECD countries in 2015. This makes the teachers makes the teachers and serves as motivational tool to enhance their teaching and learning.

15) The study found that school Y teachers believe they have good politicians who listen to expert advice from teachers without influencing what they teach, how they teach, and whom they teach. This strong autonomy seems to have a positive impact on teachers' jobs and also their students' learning.

16) The study found that school $Y$ has a shared and distributive leadership style, thereby positively impacting students' learning outcomes as this style of leadership ultimately reduces the workload, encourages specialisation, and increases job efficiency.

17) The study found that a master's degree in Education is the basic qualification for teaching in school Y. Also, the study noted that two out of the six teachers interviewed held $\mathrm{PhDs}$ in Education. It is noted that higher degree awards and related experiences have a trickledown impact on teachers' daily work and on their students' learning outputs.

18) The study found that there is an official preparation program for an aspiring principal in school $\mathrm{Y}$. The requirement for an aspiring principal must also include: being a professional teacher with three to five years working experience within the field of education, holding a least a master's degree within the field of education as well as a certificate in educational leadership or administration and management, and successfully completing a competitive interview before an appointment is offered. The principal of school $\mathrm{Y}$ acknowledged that making principalship training programs obligatory for aspiring principals may help improve administrative lapses and improve students' learning, performance, and success.

19) Finland recognizes OECD's rankings as a valid indicator of students' learning outcomes.

The following are summaries of findings relating to the second research question: 
- What is the relationship between the use of Professional Learning Communities, students' needs, motivation, and success in Finland?

1) The study found that school $Y$ meets the criteria of a Professional Learning Community. This is supported by evidence of of the school's employment of, or commitment to, researched-based learning, lifelong learning, academic freedom, students' autonomies and voices, trust, individual responsibility and accountability, wellbeing programmes, ethics of care, love, sharing, community, empathy and the use of student's data to address his or her learning needs. These variables have a strong positive relationship with students learning, performance, and success. This finding is consistent with the values, aspirations and directions of the Finnish national curriculum.

2) The study found that the one iPad-one laptop policy for students at the upper secondary school, ultramodern libraries stocked with books, music studio, art studio, school-based guidance and counselling unit, school-based clinic and nurses and doctors, special education teachers, homegrown teachers, schoolbased psychologist, technical support officers, free tuition, free meals, cafeteria, school-based creators and social workers, as well as digital electronic learning equipment have a strong positive impact on students' learning, performance, and success in school $\mathrm{Y}$. These services and devices provide motivational and technical support required to address students' needs in relation to improving their cognitive, affective, and psychomotor development, and thereby enhancing their learning, performance, and success.

\subsection{Summary of findings: Ghana}

The following are summaries of findings from the Ghana case study for the first research question:

- What is the relationship between school culture, climate, leadership, and students' success in Ghana?

1) In Ghana, the study found that a national standard-based curriculum is the means through which teaching, and learning are delivered in school Z. The study noted that teachers have little freedom or flexibility to decide on the content of what they teach. This standard practice reflects a teacher-centred and examination- 
driven school culture that pays little attention to practices such as activity-based learning to enhance students' learning.

2) The study found that school $Z$ uses one official language, English, as the medium of instruction despite the make up of the school population including numerous students from different ethic and tribal backgrounds with several indigenous languages. Speaking those local languages at school sometimes attact some form of punishment from the school authorities. This rigidity appears to account for the poor performance of some students in the school as they struggle to learn a foreign language to write examinations and do daily classroom tasks.

3) The study found that teaching colonial histories, especially relating to Ghana's independence, seemed to have a significance role in students' learning, performance and success in school $Z$. The historical context seems to heighten the injustices during colonialisation and what teachers and students must know to avoid reoccurring those sad events.

4) The study noted that a culture of sports and athletics competitions appears to have a significance impact on students' learning, performance, and success in school Z. The school has many awards and displays these publicly in the school. These extra-curricular activities inspire and motivate students towards their learning to improve their performance and achieve success.

5) The study found that there is evidence of nepotism, favouritism, and tribalism in education delivery, especially relating to teacher posting, recruitment, appointments, and promotions. For many reasons, these practices have negative impacts on quality teaching and learning in the school. Also, the study revealed a strong sense of politics in education decision-making within school $\mathrm{Z}$ and the country at large. As such, expert advice is only considered relevant based on one's ethnic and political affiliations. This practice affects students' learning, performance, and success as the national curriculum is often changed by the government of the day to satisfy her manifesto pledges.

6) The study noted that the mission statement, uniforms, logos, crest, and displays of wall paintings, and designs, national flags, trophies, bust portraits of past students and royals, symbols, and a lot more seem to be of great importance to school Z. The mission statement gives direction as to how the school must be run. Wearing of the school uniforms, logos, crest, and more create a sense of identification. The displayed trophies and portraits of the past heroes inspire and 
motivate students towards learning, thereby improving their performance and success.

7) The study noted that the spiritual belief and practices - especially of Christian and Islamic faiths - take the centre stage of the school religious activities and that this variable seems to have a significance impact on students' learning performance and success in school Z. The study found evidence that school-based pastors and Imams offering counselling services on wellness, wellbeing, and spiritual growth to impact cognitive, affective, and psychomotor development of their member students.

8) The study found that teachers' promotion of inclusiveness, equity, equal access, and high quality and effective teaching are positive aspects of school culture as they promote students' learning performance and success in school Z. Evidence exists of the school using a quota system to encourage minority and indigenous tribes in which the school is situated to enrol, attend, and be retained in the school and to enhance students' learning.

9) The study noted that school $Z$ is a highly ranked one. Within the Ghanaian context, the ranking system has a negative profound effect on students' access to education and also puts pressure on the school admissions process. There is evidence that this ranking system may breed bribery and corruption, nepotism, and tribalism, factors which affect teaching and learning quality as well as disqualifying good and brilliant students who do not have those connections and networks.

10) The study found that in relation to the school climate the Government of Ghana spent a little below 5\% of her GDP on education in 2018. This finding reflects a trickledown effect on school $\mathrm{Z}$ as the teachers noted that the school has been renovated in recent times by the central government in a bid to enhance students' learning, performance, and success.

11) The study noted school $Z$ has an average class size of 70 students, with a maximum of 120 students per class. This large-class size has negative effects on the quality of teaching and learning, thereby affecting students' performance and success.

12) The study revealed that factors including strong security, good school environment, networking, team work, collaboration and relationships - including 
teacher-teacher, teacher-student, teacher-principal, and school-community - have a positive impact on students' learning, performance, and success in school Z.

13) The study found that teachers in the upper secondary school have more contact hours. They teach between 1056 to 1440 hours a year as against OECD average of 662 in 2015. This appears to have negative impact on teaching and learning as teachers in the school $\mathrm{Z}$ complained of about their too much workload coupled with inadequate teaching and learning aid.

14) Upper secondary teachers salary range between 300 to 500 US dollars a month depending on number of years in service. The teachers in the school $\mathrm{Z}$ were satisfied with the amounts as it appears, serves as a motivational tool for them to do their job.

15) The study also found that teachers and students, especially transgender, gays and lesbians, in the school have less autonomy and little or no voice. This is likely to have a negative effect on the teaching and learning of those groups.

16) The study found that almost all the teachers in school $Z$ ended up in the teaching profession accidentally and not as their career choice. This situation is explained by the low respect and recognition the teaching profession attracts from society. The absence of teacher choice seems to have a negative effect on teachers' daily practices and wellbeing, thereby affect students' learning, performance, and success.

17) While the study found that a shared and distributive leadership style are important for teachers and students' learning outcomes as they reduce teachers' workloads, encourage specialisation, and improve job efficiency, school $\mathrm{Z}$ has a top-down leadership structure and uses a national teacher-posting system and communication structures. These centralised structures create delays in service delivery, and increase red-tape and corruption which eventually affects students' learning, performance and success.

18) The study revealed that a bachelor's degree in education is the basic qualification for teaching in school Z. In addition, none of the six teachers interviewed held a $\mathrm{PhD}$ but agreed that their experiences, skills, and knowledge have a trickledown impact on their daily work to enhance their students' learning outputs.

19) The study found evidence of shortages of qualified teachers to lead teaching and learning in school $\mathrm{Z}$. This was perceived to be due to nepotism, tribalism, and ethnicity, as well as bribery on the part of some politicians, some ministry 
officials, and some principals and head teachers. Such a shortage of qualified teachers clearly affects the quality of both the teaching and learning, thereby impacting on students' learning outputs.

20) The study found that there is no official preparation program for an aspiring principal in school Z. However, an aspiring principal must be a professional teacher with not less than fifteen years of working experience in education, must hold a master's degree within the field of education, must have passed through the ranks to attain a director or an assistant director rank or position, and must have passed through a competitive interview before appointment. The principal of school $\mathrm{Z}$ expressed support for making principalship training programs obligatory for aspiring principals in order to help improve administrative lapses and improve effectiveness to enhance students' learning outcomes.

21) Ghana appears to recognize OECD's rankings as a valid indicator of students' learning outcomes.

The following summaries of findings relate to the second research question:

- What is the relationship between the use of Professional Learning Communities, students' needs, motivation, and success in Ghana?

1) The study found that school $Z$ does not meet the features of a Professional Learning Community. Evidence suggests little or no researched-based learning, lifelong learning, academic-freedom, students and teachers' autonomies and voices, trust and accountability, ethics of care, love, sharing, community, empathy and the use of student's data as variables to enhance students' learning, performance and success. This situation has occured because school $\mathrm{Z}$ heavily relies on the national standard-based curriculum which is more or less examination-driven and gives little attention to aesthetic aspects of education.

2) The study found that there is a library stocked with some old books, amusic studio, an art studio, a school-based guidance and counselling unit, a school-based clinic and nurses, free tuition, free feeding and lunches, free school uniforms and textbooks to students, free boarding facilities, clubs and societies. There are a few items of digital learning equipment, such as projectors, computers, and space in the school. 
3) The study found that the young teachers and students in school $X$ are technologically advanced as they have their personnel iPads, smartphones, and laptops to support their teaching and learning. However, within the hierarchical, top-down leadership command structure, the principal, headteachers, and headmistress do not allow the teachers and students to use these devices in support of their teaching and learning.

\subsection{Similarities and dissimilarities of the three multiple cases}

\subsubsection{Similarities in the three multiples cases}

1) All the three schools valued many aspects of their school culture such as language, history, traditions, rituals, and symbols and deemed these as important for their positive impacts on students' learning, performance, and success.

2) The teachers from all the three schools support the values of inclusiveness, equity, equal access, and high quality and effective teaching as means to improve student learning outcomes.

3) In the quest to improve quality teaching and learning, the governments of the three countries all spend above $4 \%$ of their GDPs on education and related matters in an effect to enhance students' learning outcomes.

4) All the three schools it appears that it is the role of the principal and HODs to lead teams to enhance learning.

5) The leaders and teachers in all three schools see school climate, such as adequate security and a good school environment including buildings, networking, teamwork, collaborations and relationships of all forms including, teacherteacher, teacher-students, teacher-principal or headmaster or mistress, and schoolcommunity as means to improve students learning outcomes.

6) The leaders and teachers in the three schools all perceived having good libraries, music and art studios, school-based guidance and counsellors, school-based clinics and nurses, free tuition and cafeteria and IT to support learning, and having a strong relationship to students' learning outcomes, including performance and success.

7) All the three schools, in New Zealand, Finland, and Ghana seem to recognize OECD's rankings as a valid indicator of students' learning outcomes. 


\subsubsection{Similarities present only in the two of the cases}

1) In New Zealand and Finland, schools have autonomy to design their local-based curricula to meet their students' needs, thereby improve learning outcomes at the classroom level.

2) Both participating schools in New Zealand and Ghana have school-based Christian chaplains to provide counselling and spiritual growth to enhance students learning and development.

3) In New Zealand and Finland the schools have comparatively small class sizes averaging around 15 students, promoting effective teaching to enhance students learning outcomes.

4) In New Zealand and Finland, schools have strong autonomy for teachers and students within broad curriculum guidelines.

5) The schools in New Zealand and Finland both had strong security check points to enhance security of their students.

6) The basic qualification for teachers in schools in both New Zealand and Ghana is a bachelor's degree within the field of education.

7) Almost $50 \%$ of the interviewees in New Zealand and Finland hold $\mathrm{PhDs}$ in education.

8) The principal, headmaster, or headmistress in both schools in New Zealand and Ghana agreed that they had no obligatory leadership preparatory programs for aspiring principals.

9) In New Zealand and Finland, the schools under study use research-based learning to improve their students' learning, performance, and success.

10) The teachers in New Zealand and Finland appeared to employ an ethic of care, love, sharing, empathy, and community as well as the use of student data to address students learning challenges to improve their performance and success.

11) In New Zealand and Ghana, both schools have school uniforms which provide a sense of belonging and collective identity, as well as acting as an equity strategy.

12) The schools in New Zealand and Ghana both use English as the medium of instruction.

13) Teachers and students in New Zealand and Finland respectively seemed to have a culture of academic freedom and a climate of encouragement to express their 
views including those who belong to minority groups such as transgender, gay, and lesbian students.

14) In Finland and Ghana the two schools provide free food to enhance their students' learning, improve their performance, and achieve success.

15) In New Zealand and Finland, both use an indigenous language as an official medium of instruction to enhance teaching and learning. For example, there is some use of the Māori language for New Zealand and Finnish language for people of Finland.

16) In the schools in both New Zealand and Finland, the dominant ethnic group seems to have the stronger school networking.

17) Teachers in the upper secondary schools in New Zealand and Ghana appear to have more contact hours than that of Finland. Teachers in New Zealand teach 760 hours a year while teachers from Ghana teach between 1056 to 1440 hours a year which is above OECD average of 662 in 2015. Comparatively, their counterparts from Finland on the same score teach 547 a year which below the OECD average of 662 in 2015.

18) Teachers in Finland and New Zealand receive more salaries than that from Ghana

\subsubsection{Dissimilarities present in the three multiple cases}

1) In New Zealand, the school attracts more international students than the two schools in Finland and Ghana.

2) Only in New Zealand is Sign Language recognised as an official language for medium of instruction to enhance learning.

3) While the teachers in the New Zealand school seem to become teachers due to the passion and love they have for the profession and the prestige and recognition the profession attracts from the society, they all seem to dislike the poor working conditions of service, including pay, workload and attitudes of successive governments towards their welfare.

4) In New Zealand and Ghana, there seems to be little or no apprenticeship training for in-school students and out-school graduates due to inability of job owners to open their doors for them. This case appears different in Finland.

5) In New Zealand and Finland, they adhere to the Education Act which sets the standards for education related matters in the country. However, their counterpart from Ghana has now passed a bill to introduce the act university act in 2021 . 
6) In Finland, they seem to have fewer extracurricular activities, especially for students as compared with New Zealand and Ghana.

7) In the school in Finland, there was no school-based Christian chaplain in support of students' spiritual growth and development, whereas in New Zealand and Ghana. The school in Ghana has school-based churches, chaplains, mosques and Imams to support student's spiritual growth and development

8) Finland and New Zealand appears to have a culture of shoes and jacket removal before students enter classrooms. This is partly because during the Winter season the weather becomes cold. This indicates respect for the cleanliness of the environment. This is not the case in Ghana.

9) In Finland parents prefer to send their children to any nearby community based schools, because of somehow uniformity of schools throughout the country unlike New Zealand and Ghana, in which, it appears there is a system of competitive ranking of schools in the country.

10) In the school in Finland, the presence of a school-based psychologist, provision of one iPhone and one laptop policy for upper secondary students, a school based doctor, school-based special education teachers, school based social workers are advocated in support of their students' wellbeing and learning. This is not in either New Zealand or Ghana.

11) The basic qualification to teach in Finland is a master's degree in the field of education but a bachelor's degree in New Zealand and Ghana.

12) Unique to Finland is that almost all the teachers considered that they became teachers due to the love they have for the profession, the recognition the profession attracts from the society, and their happiness with their conditions of service and careers. However, their counterparts from Ghana appeared to have become teachers accidentality. This seems they could not get the required entry marks to enter into the main universities and ended up in the teacher-training colleges as a second option.

13) Unlike New Zealand and Finland which officially emply indigenous languages as media of instruction, the school under study in Ghana uses only one official language, English (a coloniser language) despite her forty nine or so indigenous languages. 
14) In Ghana has a free boarding system, and provides free school uniforms and textbooks to support students' learning. This is not the case in either New Zealand or Finland.

15) Teachers in Ghana admitted that their current profession is not their dream one due to less respect, recognition, and poor conditions of service they received from the society including successive governments in the country unlike their counterparts from New Zealand and Finland.

16) In Ghana, there is a strong sense of nepotism, favouritism, and tribalism in education, especially in-service delivery, on teacher postings, appointments and promotions. These practices involve bureaucratic delays, bribery and corruption as well as discourage ethnic and tribal collaboration to enhance students' learning.

17) In Ghana, politics dominate all aspects of education matters and expert advice is only recognised if you belong to the party of the day unlike New Zealand and Finland.

18) Ghana has large class-sizes of 70 on average, with a maximum of 120 . This not the case in either New Zealand or Finland in which the maximum class size is about 20.

19) The study findings for Ghana did not reveal these words: accountability, responsibility, autonomy, trust, ethics of care, family, empathy, love from the teachers in guiding students' learning.

20) Ghana uses a top-down leadership, teacher posting and recruiting structure unlike those in New Zealand and Finland.

21) Teachers in the upper secondary schools in New Zealand have more contact hours. They teach 760 hours a year. While their colleagues from Ghana teach between 1056 to 1440 hours a year which both are above OECD average of 662 in 2015. Comparatively, their counterparts from Finland on the same score teach 547 a year which below the OECD average of 662 in 2015 .

22) Teachers in Finland receive more salaries than that of New Zealand and Ghana in that order.

While the findings outlined in this chapter have in some ways mirrored those of the global literature, they have also included additional insights. Therefore, I want to bring these to the attention of policy-makers, principals, teachers, students, and any other stakeholders who have transformational agendas for students' learning, performance, and success. 
Drawing on the data outlined, in the following chapter I propose to deepen understandings of school culture, climate, leadership, and other contributing factors that promote students' learning, performance, and success. Doing so will cover wider societal considerations including family, official institutions, politics, power, hegemony, curriculum, language, capital, history, custom, colonisation and global undercurrents which may or may not have direct influence on the subsystem. 


\section{CHAPTER SIX: Retheorizing school culture, climate, leadership, and success}

\subsection{Introduction}

The aim of this chapter is to delve deeply into the findings in order to understand more clearly the broader explanations for the relationships between school culture, climate, leadership, and success. The intention is to offer an answer to the third research question of the study:

- How can school culture, climate, leadership, and success be retheorized?

The next section covers the analytical framework that explains how global undercurrents, politics, power, policy, ideology, history, customs, rituals, environment, public opinion, and many others impact on schooling, especially on students' learning, performance, and success.

\subsection{Descriptive analysis from the three multiple cases}

The aim for this analytical and descriptive framework is to define the domain through which these multiple cases, the three schools in New Zealand, Finland and Ghana, can be further explained and give meaning to previously unearthed issues. Doing so allows me to delve deeper into asking "why" questions.

Merely identifying superficial school-based culture, climate, leadership, and success and commenting on their relationships in the school, and especially the classroom situation, is not adequate. This is because understanding and appreciating why these concepts operate and work in a more deep and practical manner is necessary for improving educational discourses which might improve teaching and learning. In the section which follows, five analytical levels through which school-based culture, climate, leadership, and success can be retheorised are presented.

\subsection{Five levels to give deep meaning to school culture, climate, leadership and success}

\subsubsection{Introduction}

As an introduction, this framework, which is informed by the findings of this study, has five analytical levels. The first and second levels of the framework, (A) and (B) represent 
activities, practices, experience, opinions, and rituals within the education subsystem which appear to support students' learning, performance, and success. These are termed as (A) organisational levels of culture, climate, leadership, and success, and (B) emergent organisational levels of culture, climate, leadership and success. The third and fourth levels, are termed as (C) contemporary educative, social, political, and cultural contexts and (D) historical educative, social, political , and cultural contexts representing opinions, activities, practices, and rituals outside schools that have a direct link to the school activities, including students' learning and performance. The final level, labelled as (E) represents the globalised educative, social, political, and cultural contexts, global undercurrents that appear to have a direct impact on schools in relation to students' learning, performance, and success.

\subsubsection{Level (A): Organisational levels of culture, climate, leadership, and success}

At level (A), school culture, climate, leadership, and other contributing factors which promote students' learning are intertwined with, and embedded within, the organisational framework of the sub-system of education.

In analysing the three multiples cases from New Zealand, Finland, and Ghana from the perspective of the school personnel, it appears that a functional and relational form of relationship to improve students' learning outcomes exists. The focus here is on organisational routines, practices, and responsibilities. See Figure 14: below for this first model of the framework. 
Figure 14: First Level of Analytical Framework

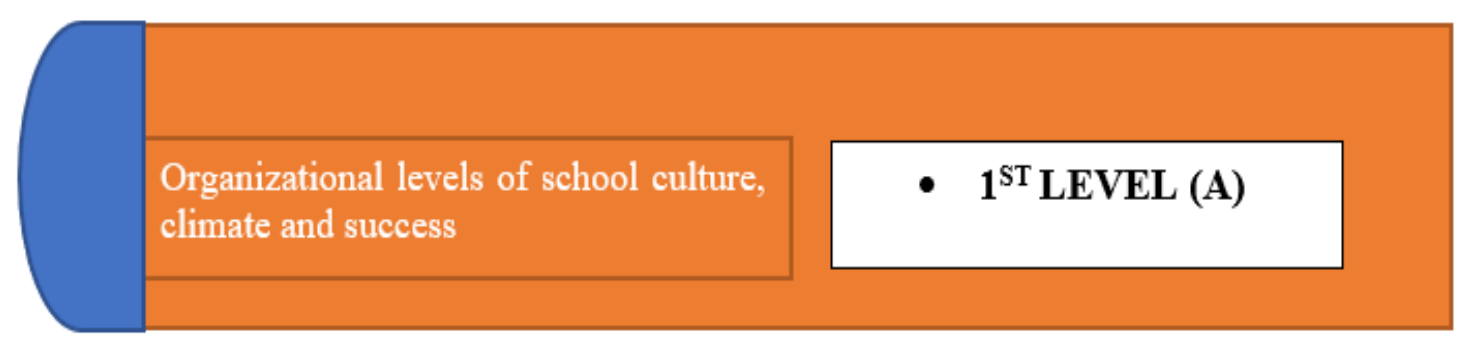

In all three schools in New Zealand, Finland, and Ghana, a shared and distributive leadership style is a means to improving learning outcomes. Also, teamwork and motivational and wellbeing support including free tuition and counselling, collaboration and quality core relationships (including, teacher-students, teacher-teacher, and teacherprincipal) are seen as tools that can have positive impacts on students' learning outcomes.

Some of these micro level changes in the Deep Learning concept (Fullan \& Langworthy, 2014) are evidenct in the three multiple cases, as means to improving students' learning, performance, and success but their applications vary from one case to another.

Furthermore, language is an important tool in supporting students' learning outcomes. The use of language, however, varies in each of the cases. Whereas New Zealand and Finland recognise one of their indigenous languages as an official language, Ghana does not. At the organisational level of education, this study shows that language, motivation, teachers and students' voices, and relationships through teamwork and collaboration appear to support students' learning outcomes. These findings align with the significance of the Vygotsky's sociocultural learning theory, thereby unearthing some ingrained issues in schooling (Gibson, 1986; Rogoff, 1990).

To understand this finding across these multiple cases, reference is made to Vygotsky's principles such as the need for understanding the interactive processes of learning (Cole, 1990) through the use of language, symbols, and gestures (Rogoff, 1990). The notion of the zone of proximal development whereby a learner learns with a competent teacher or a peer (Daniels \& Hedegaard, 2011) and a community of practice where a learner puts what he or she has learned into use or practice within a community of support (Rogoff, 1990) appear to be embedded in all the schools studied. 
As stated, New Zealand and Finland use one of their indigenous languages as a medium of instruction to purposely support students learning outcomes. However, despite having numerous ethnic and tribal languages, Ghana does not officially use any of these as a medium of instruction (Bemile, 2000). If Ghana realises the value of the vast cultural knowledges that are contained within the various languages, this may raise consciousness and potentially bring about transformative change in the lives of the teachers and students for societal development and improvement (Gutek, 2014).

As well, at level (A) students' and teachers' autonomy and voices, as well as high levels of trust, accountability, care, love, and respect highly impact on school effectiveness. While the extent of impact varies between the cases, these variables are important at the school organisational level. In New Zealand and Finland, teachers and students have more autonomy and voice than in Ghana. For example, evidence in the Ghana school indicated that a section of students such as gay, lesbian, and transgender students have no voice in the school, and since this will clearly affect their learning outcomes and their advancement of life, this is is an area for further teacher education and policy changes designed to support the rights of these students.

Previous research has suggested that in positive school cultures, there is a strong sense of community, positive relationships, empathy, we-feeling, trust, and collaboration held by personnel that is enacted beyond the symbolic mission statement hanging on the walls (Deal \& Peterson, 2016; Hargreaves, 1995; Schneider et al., 2013). However, in a toxic school culture, the purpose may instead be self-serving and focused on individual achievements rather than the collective interests (Peterson \& Deal, 2002; Prosser, 1999). As noted, the study found that strong teacher collaboration, team work, and good quality relationships have positive impacts on the way teachers carry out their duties, thereby enhancing their students' learning, performance, and success. However, also at level (A), formal decision-making and interactions between staff and among students appear to be more limited in the school in Ghana than in the other two schools where there was greater autonomy granted to schools and their personnel.

Furthermore, at level (A) in Finland some teachers find the appointment process of the principal to be a challenge. In their opinion, they see no reason why a principal is appointed from outside and brought into the school while there are equally competent teachers within and who may be considered. Similarly, in Ghana, the teachers complained 
and blamed the principal for everything, including for shortages of teaching and learning materials and for large class-sizes. A closer look at these organisational issues shows that the challenges can be explained partly by improved understanding by teachers of the workings of the school.

\subsubsection{Level (B): Emergent organisational levels of culture, climate leadership and success}

Level (B), Emergent organisational levels of culture, climate, leadership and success, is not mutually exclusive from the first level discussed above. However, in (B), an individual view is taken on the nature and extent of teams connected to their authority functions and their alignment of their practice to the ultimate aim, vision, and the mission statement of the school.

The study found that in the schools in all three countries, leaders and teachers commonly focused on improving their students' learning. However, this focus does not mean that all the leaders see this vision the same way or aligned themselves in the same way. The study reveals mixed configurations of school culture, climate, leadership, and success. See the figure below for levels (A) and (B).

Figure 15: The First and the Second Levels of the Analytical Framework

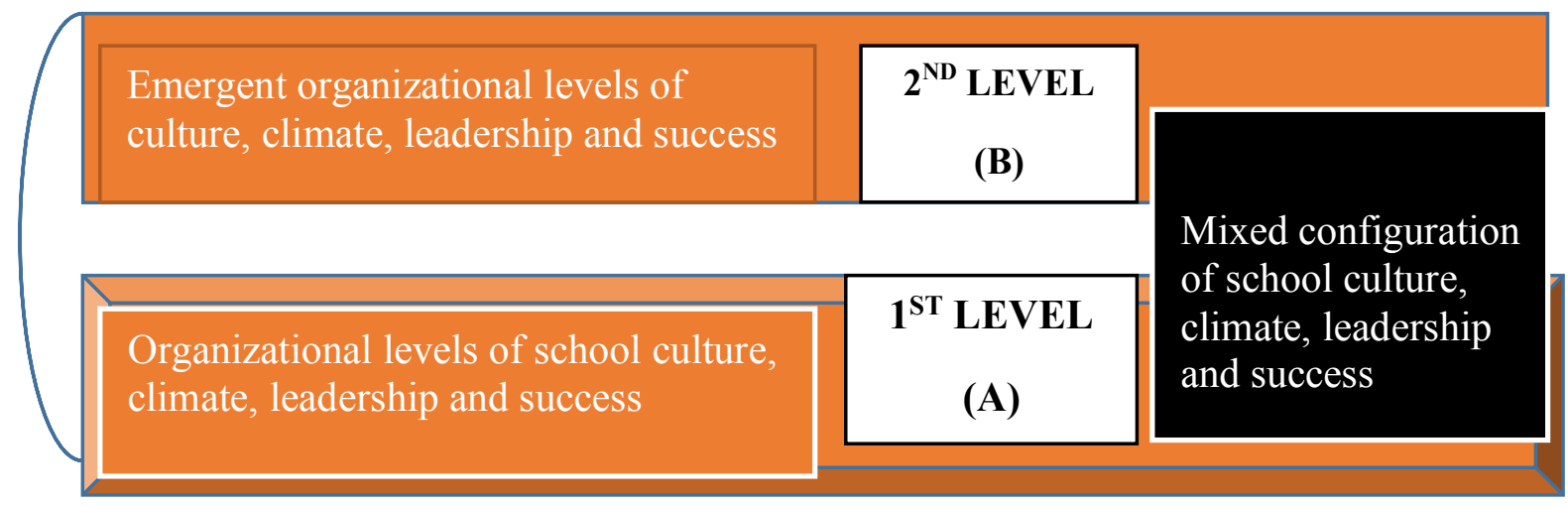

In all three schools in New Zealand, Finland, and Ghana, principals and the heads of departments, (HODs) lead the teaching teams as well as the wider school community. It is these two categories of school leaders who bear most of the responsibility and risks rather than their teachers. 
For New Zealand and Finland these responsibilities and risks have been approached with shared leadership, proactiveness, openness, network, care, community, accountability, autonomy, trust, early intervention, empathy, accessibility, freeness, ethical leadership, authentic leadership, and an ethic of care. These qualities appear to serve as intrinsic and extrinsic motivations to teachers and students to improve learning outcomes within the organisational level. In the case of the school in Ghana, however, the hierarchical and authoritarian leadership of both the external bureaucracy and internal school management structures appeared to inhibit the capacity to develop and display the above qualities.

In this analytical description of the framework, the emergent organisational levels of culture, climate, leaders, and success (B) always work in tandem with the first level (A). This is because the school principal, headmaster, or headmistress was once a teacher before he or she assumed an administrative role. Furthermore, while HODs might be operating at level (B) they also lead the teaching teams to enhance teachers and students' learning at the first level. So, while levels (A) and (B) are initial reference points of organisational culture, climate, and leadership, they do overlap in reality. Understanding these levels as both distinct and overlapping is essential for understanding students' learning, performance, and success within a school system.

Literature on educational leadership and management locates organisational level functions (A) and (B) of the school leaders as including the senior leaders, middle leaders, teacher leaders, and students leaders (Leithwood, Sun, \& Pollock, 2017).

Adequate expertise and effort are needed from the school principal to develop the competencies and expertise of the adults in the school (Murphy, 2017) in order to facilitate students' learning (Day \& Sammons. 2013). Key senior leadership responsibilities include improving school instructions, budgeting, school maintenance, and occupational health and safety compliance and conditions which, in turn, foster students' learning outcomes (Pollock, Wang, \& Hauseman, 2017). The middle leaders' roles involve the heads of departments working closely with teachers as mentors or coaches to plan curriculum (Gurr, 2015), review action plans, and support other teachers, especially the new-comers to familiarise themselves in the school to enhance learning (Murphy, 2017). 
Lastly, student leaders can also be supported to partner with the teachers and HODs to support the day-to-day activities of the school, such as including supporting the planning of the curriculum, leading student teams, as well as collaborating with other team leaders to address particular challenges of students (Day \& Sammons, 2013).

There are also conditions and expectations from the students' families, community, and the wider society (Day \& Sammons. 2013). Simply put, society orientation towards schools and education in general and these have much more influence on school activities (Leithwood, Sun, \& Pollock, 2017). This is what I have termed as the Contemporary Educative, Social, Cultural, and Political contexts.

\subsubsection{Level (C): Contemporary educative, social, cultural, and political contexts}

Schools are implicated in the contemporary dynamics of socio-cultural, socio-economic and socio-political complexities of the society (McLaren, 1994). Therefore, educators who are liberators and transformers must always aim to offer alternatives (Giroux \& McLaren, 1989). Consequently, an exercise in the analyses, inpretations, and descriptions must go beyond the subsystem of education that is level (A) and level (B) of my framework, above, to include scrutiny of the larger society including parents, community, politics, cultural dynamics, power, and various undercurrents from institutions outside the school (Leithwood, Sun, \& Pollock, 2017). See Figure 16, below for an an overview of the third level of the framework. 
Figure 16: The Third Level of Analytical Framework

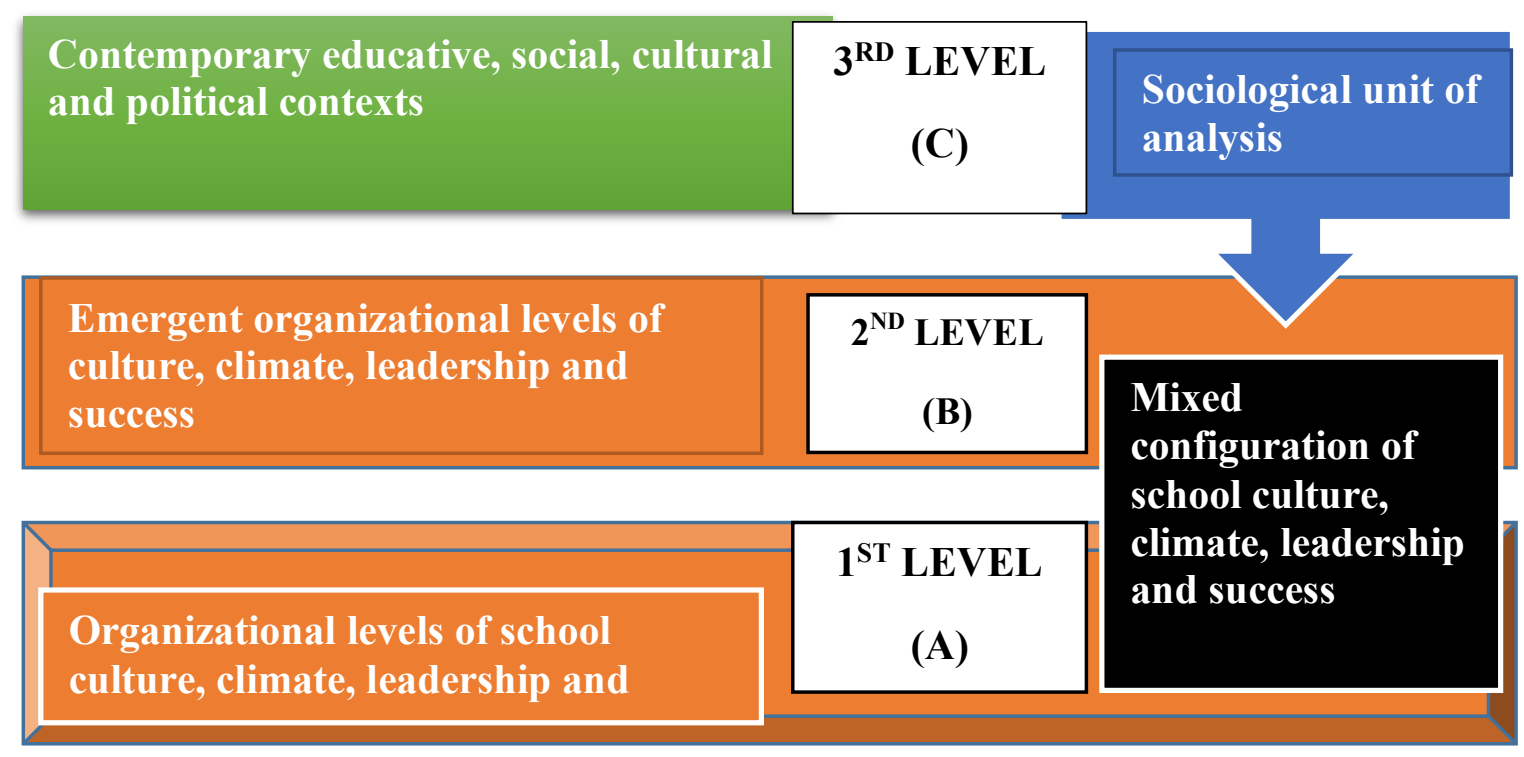

Level (C), the third level, refers the Contemporary Educative, Social, Cultural, and Political contexts. Unique to each case study, the third level includes the transferable functions of organisations including directions, expert advice, resource allocation, and policy credibility. Without these functions and their enabling environment, levels (B) and (A) will suffocate, thereby negatively affecting students' learning outcomes and development.

A comparative view of level (C) in New Zealand, Finland, and Ghana shows different paradoxical situations. For instance, in all three cases, strong school-community relationships, and especially teacher-parent relationships, are seen to support students' learning, performance, and success.

In New Zealand, the in-school and out-of-school graduate apprenticeships involving both school and the community were problematic as it was apparent that some business owners within the wider society were not able, or unwilling, to offer apprenticeships for students. This external force seemed to have impact on students' learning and development.

The study also noted that the degree of recognition and prestige of teachers from the wider community impacts their their sense of being a valued profession. Data in this study indicates that in Finland and New Zealand the teaching profession is respected, whilst this is less so for Ghana. 
Politics shapes policies and reforms within the education systems, as was evident in the New Zealand case study. For example, the Ministry of Education introduced the decile system. The intention was to give schools in poorer communities' adequate funds to function effectively. However, it was evident that this standardised practice has resulted in misconceptions, particularly in the minds of students, community members, and parents. Parents misconstrued this ranking system as being based on the quality of the education offered in the school instead of its economic equity motive. As a result of the perceived better quality of the higher ranked decile schools, parents preferred to send their children to more highly ranked decile schools than those which a lower decile ranking.

Similarly, in Ghana, the school ranking system, which seems to be a feature of the neoliberal system of the past for school improvement, has put pressure on highly ranked schools. As such, parents prefer to send their children to highly ranked schools with the motive to get quality tuition for their children. This contrasts with the situation in Finland where there is no ranking system of schooling. Parents prefer to, and are able to, send their children to any school within their locality.

Another feature of $(\mathbf{C})$ is that that the Ministries of Education set the standards by which schools and school leaders must operate within educational subsystems. In New Zealand and Finland, the Ministries of Education provide the national curricula from which schools derive their local specific curricula. In Ghana, the Ministry of Education prescribes the national standard-based curriculum for schools and educational providers throughout the country.

Knowing about students' and parents' backgrounds is important. Research has established that when the income of students' parents is low due to low levels of education and poorly paid jobs (Townsend, \& Bayetto, 2020) this may have negative impacts on students learning, performance, and success (Leithwood, Sun, \& Pollock, 2017). The awareness of students' circumstances, then, may help the school leadership to redistribute school resources according to the needs of individuals to enhance learning (Day \& Sammons. 2013).

It is obvious from the discussion above that the third level has a direct and indirect influence on the first and second levels within education subsystem. Without the third 
level (C), nothing can really work efficiently in the schools. This level is further connected to the fourth level (D) and the final level (E).

\subsubsection{Level (D): Historical educative, social, cultural, and political contexts}

There is clear evidence in the literature that the national culture and history of people, and their traditional norms and values, play a vital role in leading the learning process of students as well as what the students learn at school.

The New Zealand education system recognises the importance of history in relation to colonisation and, especially, the Treaty of Waitangi. This treaty is significant as it is recognised in the nation curriculum. A recent policy change now requires students to learn about New Zealand history and this treaty in schools. Furthermore, such education allows for policies, strategies, and measures to be put in place in order to support people perceived to be marginalised in the society to obtain a prosperous future (Gibson, 1986).

Another outcome of colonisation and the subsequent partnership between Māori, the indigenous people, and the settlers and their descendents, has been the place of languages in schools. In New Zealand, English, Māori, and New Zealand Sign Language are used, although English is the medium of instruction in the vast majority of schools (Education Review Office, New Zealand, 2020). In Finland, two official languages, Swedish from the Swedish colonisers and Finnish indigenous language, are used. In contrast to this, in Ghana, only English, a colonial language, is used in schools. Despite the country's fortynine or so numerous tribal and ethic languages, none of them is officially recognised in schools (Bemile, 2000).

Evidence in the literature suggests that, due to the nature of these complexities in the school unit, successful leaders must be culturally sensitive with regard to the context within which he or she works (Leithwood, Harris, \& Hopkins, 2008). For example, issues such as history, culture, customs, traditions, and norms must be given attention in order to improve the learning environment (Fullan, 2007). To make this a reality, the principal must demonstrates a high level of cultural competence in leading the school (Day \& Sammons, 2013). 
Demonstrating understanding of the context under which he or she operates optimises his or her chances of success, thereby improving the learning outcomes of students (Day \& Sammons, 2013). Such understanding includes improving working relations with different members and cultures within the school (Hoy, 1990). It may be necessary also to have the skills of mediation and moderation as tools to address mixed feelings among and between organisational members to in order to enhance the working climate (Fullan, 2007; Leithwood, Harris, \& Hopkins, 2008).

A further point of interest at this level of analysis relates to autonomy for teachers and students including transgender, gay, and lesbian students. Comparatively, in Ghana, transgender, gay, and lesbian students have no voice and are punished for their sexuality. They are judged and condemned based on religious grounds as most of the students and teachers are Christians and Muslims. These also, are part of the macro level impacts which have direct link on school activities (Fullan, Hill, \& Rincón-Gallardo, 2017).

Looking at these strong influences of the macro level, Fullan, Hill, and Rincón-Gallardo (2017) suggest that it is the role of the Ministry of Education and other interest groups to identify areas within the macro level that need change. Such change may include investing in digital infrastructure, policy credibility support, assessment systems, and strategies to help local schools to improve teaching and learning. See Figure 17, below, for this effect. 
Figure 17: The Fourth Level of Analytical Framework

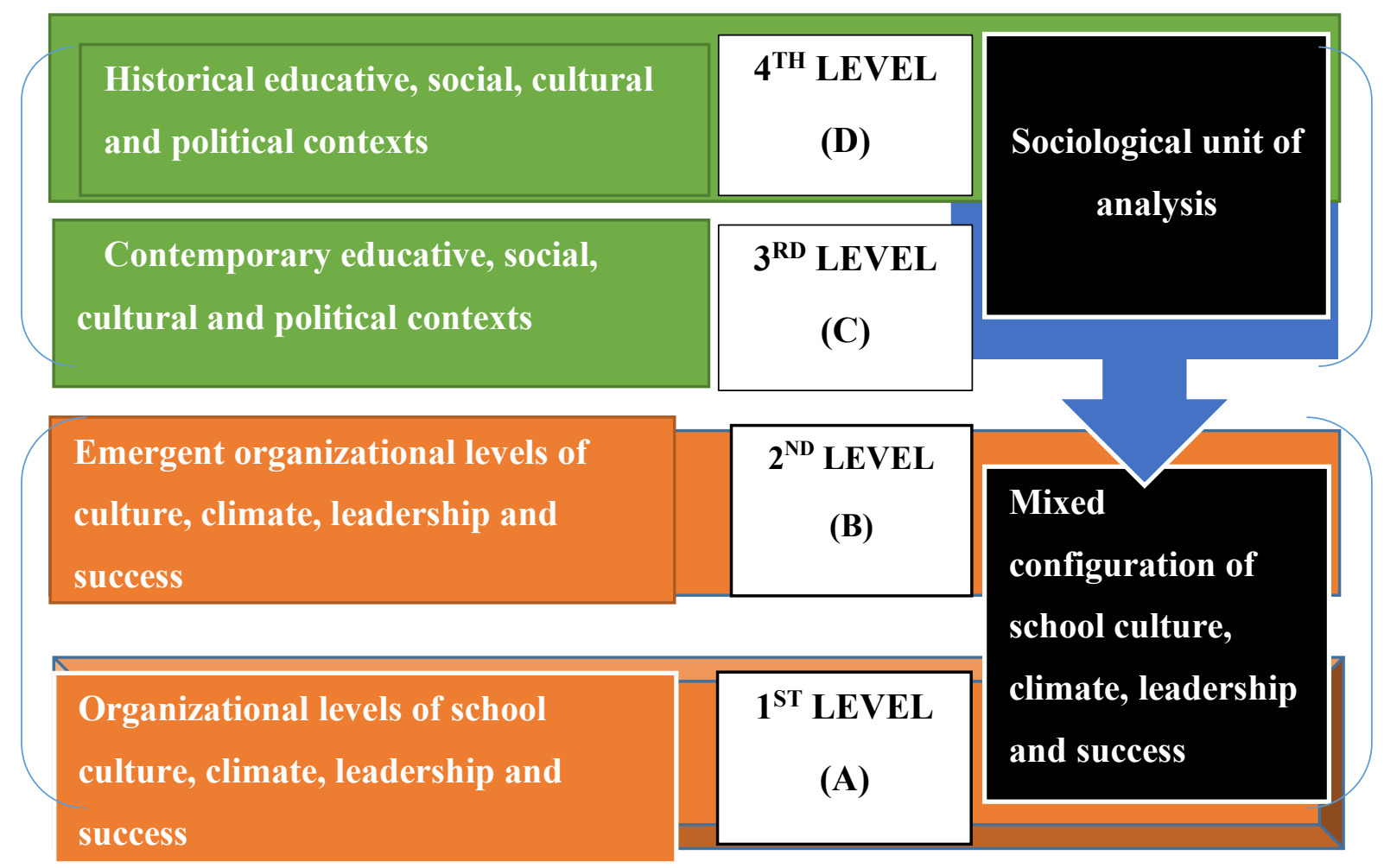

Furthermore, it is important that the ministries legitimise cross border partnership and learning, Such includes supporting the networking of schools across national, regional, and district boundaries, and establishing partnerships with the business community, nonprofit organisations, advocacy groups, and global bodies (Fullan, Hill, \& RincónGallardo, 2017).

Changes and values associated with engagements with globalised institutions such as UNICEF, UNESCO, OECD and others seeking children's welfare including in education (UN, 2019) have been found to have impacted students learning, performance, and success in the three multiple cases - New Zealand, Finland, and Ghana. This leads to level (E) on how the OECD impacts activities of the three multiple cases.

\subsubsection{Level (E): Globalised educative, social, cultural, and political contexts}

Global conventions relating to rights such as the right to education, right to own property, right to vote and be voted for, right for life, and many others are enshrined in the work of the United Nations and are morally and legally binding for members (UN, 2019). 
Termed as level (E), this refers to and includes global conventions and agendas from the Organisation for Economic Co-operation and Development (OECD), International Labour Organisation (ILO), International Monetary Fund (IMF), World Bank, and many others affecting education policies and the directions of countries (IMF, 1999; OECD, 2015; Rust \& Verran, 2018).

These global agendas are also affecting school leadership and students outcomes in New Zealand, Finland, and Ghana. For example, in 2018, PISA survey results showed New Zealand to be sliding backward. Finland, on the other hand, had improved from her previous performance. Ghana has yet to join the OECD PISA survey; this will possibly occur in the year 2020 .

See Figure 18, below, for a picture of the combined impact of these five levels on students' learning, performance, and success. 
Figure 18: The Combine Effect of the Fifth Level of the Framework

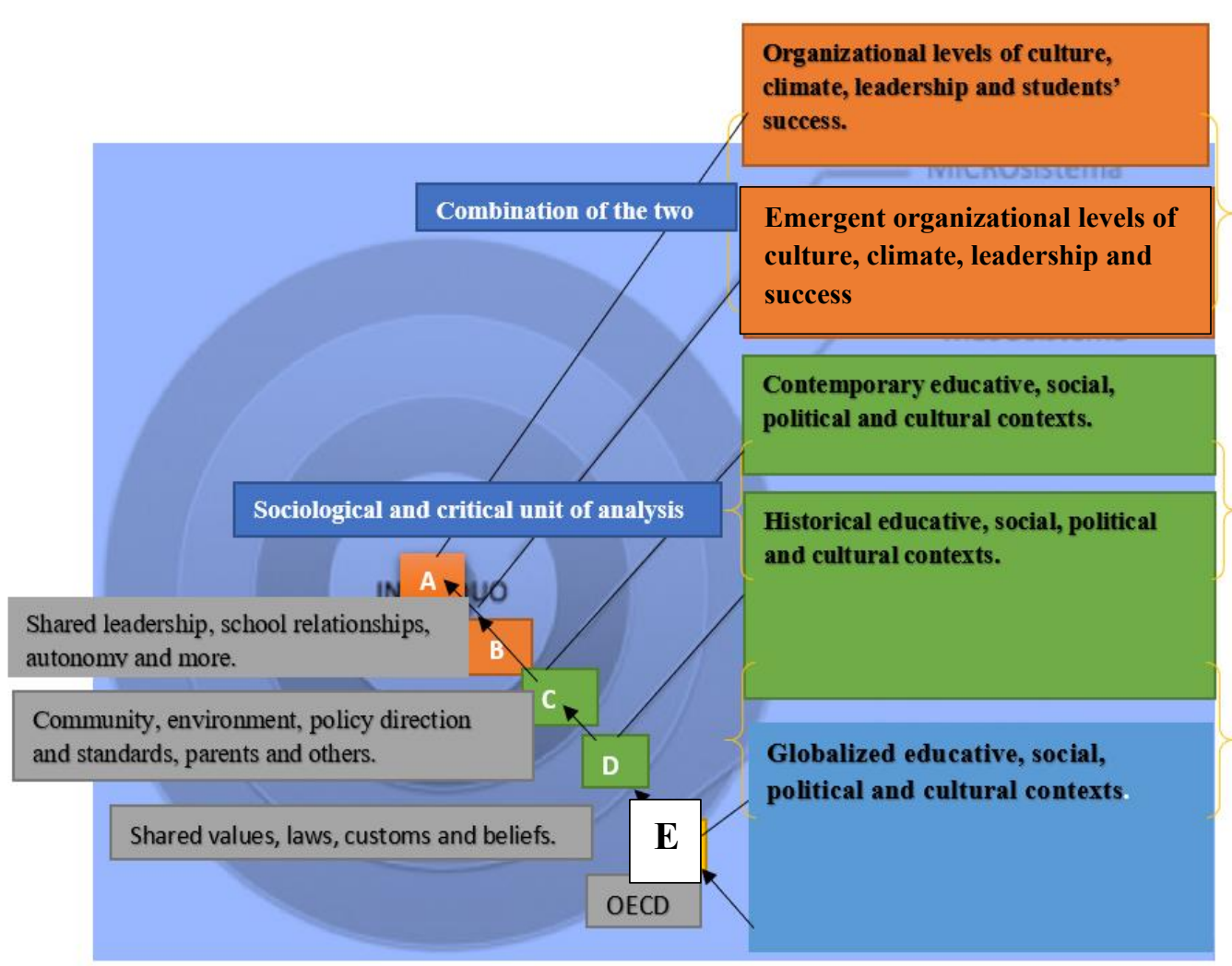

In conclusion, the five levels $-\mathbf{A}, \mathbf{B}, \mathbf{C}, \mathbf{D}$ and $\mathbf{E}-$ of the framework have demonstrated that factors that promote students' learning, performance, and success travel beyond what happens within the four walls of a school and classrooms. As such, there is the need for school leaders to take both micro and macro factors seriously because they have strong influence on school culture, climate, leadership, and success. This leads to sociological descriptions of the school based culture, climate, leadership, and success.

\subsection{Sociological descriptions for school culture, climate, leadership, and success}

As explained and presented above, this study which was conducted in New Zealand, Finland, and Ghana has generated five levels of sociological, descriptive framework which has partially deepened and supported the analysis of the global literature reviewed in the early part of the study. This framework of sociological descriptions of school-based culture, climate, and leadership and their relationship to students' success has shown a 
wide range of issues of complexities beyond those day-to-day practices of school leadership within education subsystems.

By injecting consideration of globalised undercurrents and trends, history, cultural values and norms, power, politics and authority, interest groups, and institutions into conceptualisations of school subsystems, the understanding of leadership of schools is enlarged to include influences from the third, fourth and the fifth of the levels thereby impacting hugely what happens within an education subsystem. This supports McLaren's (1994) description that knowledge of education, particularly of schooling, is intertwined fully with political, cultural, historical, and social interests. In effect, educators must factor in symbolic, social, and economic factors and political interactions and relationships of the wider society in an attempt to improve students' learning and education discourses Sociologcal factors to be considered include educating students through promoting cultural values, such as fairness, compassion, and love and integrating a disposition for lifelong learning (Moral, Martín-Romera, Martínez-Valdivia, \& OlmoExtremera, 2018).

The family has a direct or indirect relationship with schools (Leithwood, Sun, \& Pollock, 2017). This includes expectations from the students' families, community, and the wider society from schools (Day \& Sammons. 2013). As such, school leadership being able to positively impact the home contexts of students can enhance the teaching and learning process of students (Townsend, \& Bayetto, 2020). For this reason, successful school leaders tap the expertise of parents to address particular challenges faced by students (Day \& Sammons. 2013).

Understanding the external cultural norms, history, and traditions of the context under which school leaders operate optimises their chances of success in enhancing their students' learning, performance, and success (Day \& Sammons, 2013). This understanding includes improving working relations with different members and cultures within the school and beyond (Hoy, 1990).

The macro level of change encompasses the formal governmental structures and systems, official agencies, business, groups, interest groups, foundations and advocacy groups as well as international bodies like the OECD (Fullan, Hill, \& Rincón-Gallardo, 2017). 
These macro level bodies also affect students' learning, performance, and success (Fullan \& Langworthy 2014). 


\section{CHAPTER SEVEN: Conclusion and recommendations}

\subsection{Conclusion}

At the initial stage of the study, I set out to understand how school culture, climate, leadership, and other factors contribute to students learning and success in New Zealand, Finland, and Ghana. Having undertaken the study, I conclude with a partial rejection of some of the previous findings regarding school culture, climate, leadership, and other factors as the only means from which to examine students' learning outcomes and development.

I drew on the works of educational theorists such as Hoy (1990), Hargreaves (1995), Hopson and Lawson (2011), Cobb (2014), and the Wallace Foundation (2011) who have carried out research on principal leadership over twenty-five countries across the globe, focussing on school culture, climate, and leadership that promotes students' learning and improves their performance and success. These scholars have argued that school-based relationships, such as teacher-student, teacher-teacher, and teacher-parents' relationships have positive impacts on students' learning outcomes. Others have also argued that for a school to effectively enhance students learning outcomes, school leaders must develop measures to improve physical safety and the emotional, intellectual, and psychological wellbeing of their students (Hoerr, 2005). Moreover, school leaders should create leaders in others by sharing leadership, improving instruction practices, preventing abuses such as harassment, racial discrimination, name-calling, and bullying in all forms (Gurr, 2015). Further to this, leaders should shape the school vision for academic success and must act as ethical, moral, and transformational agents. These interventional measures and practices of the school leaders are deemed to create the conditions that will have a positive effect on their students' learning, performance, and success.

This study has addressed gaps in the previous literature by revealing complexities pertaining to the concepts within the educational subsystems under study in New Zealand, Finland, and Ghana. It has been long established by critical pedagogies such as McLaren (1994), Freire and Shor (1987), and many others that understanding the daily practices or day-to-day activities in a descriptive study within an education subsystem is more complex and sophisticated than what may previously have been suggested. Influences travel beyond the borders and the walls of the school to encompass the wider society. 
The key argument here is that merely describing the superficial school-based culture, climate, and leadership practices within an education subsystem is not adequate. We need to understand other forces such as global undercurrents, history, culture, ideology, power, politics, authority, and other factors that act as catalysts to happenings at the school level.

A sociological and critical analysis and descriptions of the day-to-day practices of the three cases outlined in this thesis have revealed additional influences and relationships with the happenings at school. These include the globalised undercurrents, the past and the current educative, social, cultural, and political contexts. Without taking into account these dimensions and their transferable functions such as enacting laws, practices, conventions and standards, giving expertise and policy advice, allocation of resources and many others, the activities of an education sub-unit may suffer.

\subsection{Recommendations and implications}

This study recommends the following to policy-makers, researchers, educational leaders, and managers who, as transformational agents, want to improve students' learning outcomes.

\subsubsection{For policy-makers in New Zealand}

This study recommends that New Zealand education policy-makers consider the following:

1) The provision of in-school and beyond school apprenticeship programmes for upper secondary students should be reviewed as this programme appears to support students' learning and success. A review would require a broader consultation involving stakeholders including policy-makers, business owners, and schools to agree on a holistic programme that will make an apprenticeship in upper secondary more widely available through the national curriculum.

2) A school-based psychologist policy be developed to enable having such professionals accessible and available in order to enhance students' psychological, emotional, and physical needs. This recommendation calls for collaboration between the Ministries of Education and the stakeholders including professional associations, teacher education institutions, parents, and schools with the aim that a long-term strategy be adopted. 
3) That consideration is given to make obligatory principalship qualifications and programmes for aspiring principals as such programmes appear to reduce administration lapses on the part of principals to enhance school effectiveness. This recommendation requires consultation with universities, teachers, unions, school principals, and others on all matters including content, approach, funding, and duration.

4) Consideration be given to developing a strategy to win back teachers' trust in politicians. It appears that some school leaders do not have trust in politicians when it comes to matters affecting their conditions of service. While public policy-makers may be able to do little to improve confidence in politicians, drawing the attention of education ministers through advice from officials and teacher professional bodies such as teacher unions is a first step in a political sensitive agenda.

5) A quota system is needed whereby specific educational slots are given to indigenous people in educational facilities in order to enhance enrolment, attendance, retention, success for minority groupings, and their development. Politically, a quota system as suggested is unlikely to be easily implemented thereby requiring considerable political courage to ensure that education policy is equitable and just.

6) The New Zealand decile ranking system be reviewed as it appears to create tension and competition at the school level for parents and students in relation to admission choices. Given the political nature of this recommendation, at the very least the Ministry of Education could mandate a number of research projects to investigate school level students and parents' issues relating to decile ranking. I understand the current government is doing away with the decile system and I make a note that this has happened since I conducted the research and drafted the thesis.

7) Research and policy-makers be directed towards the aim of fostering a range of forms of leadership models, strategies, styles, and schools which are likely to contribute to school improvement. The Ministry of Education in New Zealand may need to update its best evidence synthesis pertaining to school leadership so that officials, leaders, and teachers are kept abreast with latest ideas and leadership theories. 
8) Free school meals to be offered in all New Zealand schools across the range of socio-economic indicators as there are students in schools in wealthier areas who come from poor income families and backgrounds. Given the possibly contraversial nature of this recommendation, at the very least the Ministry of Education might consult with appropriate agencies and undertake needed research on this matter to inform policy considerations.

\subsubsection{For educational leaders and managers in New Zealand}

This study recommends that New Zealand educational leaders and managers give consideration to the following:

1) The ontology of school-based culture, climate, and leadership as the only means to improve learning outcomes must be revised to include consideration of globalised undercurrents, the past, the present histories, traditions, rituals, and customs. One possible way to approach this recommendation is to encourage school leaders to take regular professional development programmes especially ones which are relevant for understanding how to better support students' learning.

2) School leaders consider developing a complexly framed manual to improve schools and students' learning. Such a school-based manual might be developed as part of a whole-of-school initiative involving teachers, HODs, parents and even senior students.

3) School leaders consider the attributes of a wide range of leadership style to improve schools and students' learning outcomes. To counter potentially narrow perspectives, school leaders may need to participate in regular and relevant professional development programmes as well as be a part of mentoring programmes.

4) School leaders exercise sensitivity to socio-cultural backgrounds of students in designing the curriculum and the pedagogy. To improve and enhance understanding of diverse students and their socio-cultural backgrounds, school leaders will need to seek out help with meeting their needs for global mindset skills and capacities.

5) School leaders are advised to ensure they are well informed about the transferable functions of the Ministry of Education and its subsidiary agencies through in- 
service professional learning. School boards may need to build into the contracts of school leaders specific requirements for professional development programme participation.

6) Educational providers receive professional learning to deepen their understandings pertaining to the transferable and relational functions of the Ministries, globalised organisations such as OECD and UNESCO, and the relevance of such within curriculum and pedagogy for teachers, principals, and teacher trainees. While individual schools may find it hard to respond to this recommendation, it is one that a School Board may take up with a university or the Ministry of Education to offer such programmes to their leaders.

\subsubsection{For policy-makers in Finland}

The study recommends that:

1) Policy-makers to develop a policy intervention initiative that strengthens school leaders' participation, relationships, and collaborations. It seems that teachers' autonomy has encouraged a degree of isolation among teachers. A review would require a broader consultation involving stakeholders including policy-makers, teachers, principals, parents, and students to design a policy and programmes that will incorporate regular team-teaching to enhance students' learning among teachers.

2) Policy-makers to develop a policy initiative to encourage extra curriculum activities such as sports and athletics at national and municipal levels. It seems that there is imbalance in academic work for students with less extra curricula activities. This recommendation calls for collaboration between the Ministry of Education, municipalities, and other stakeholders including professional associations, teacher education institutions, parents, and schools, and a long-term strategy to be adopted.

3) Policy-makers to design programmes that seek to explain to teachers, principals, and teacher trainees the working functions of the Ministry of Education within curriculum and pedagogy. The Ministry may need to strengthen its capacity to offer outreach programmes and to keep abreast with the needs of schools. 


\subsubsection{For educational leadership and managers in Finland}

The study recommends that school leaders in Finland consider the following aspects:

1) School leaders to broaden their leadership styles in order to improve school and learning outcomes. One way to approach this recommendation might be to encourage school leaders to take regular professional development programmes so that officers are kept abreast of the latest ideas and leadership theories.

2) School leaders are to be sensitive about socio-cultural backgrounds of students in designing the curriculum and the pedagogy. To improve and enhance understanding of diverse students and their socio-cultural backgrounds, school leaders will need to seek out help with meeting their needs for global mindset skills and capacities.

3) Appropriate professional development programmes covering the implications of the globalised undercurrents with past and present histories, traditions, rituals, and customs affecting school leadership and students' learning included in the school in-service and mentoring training programmes. As such, a school-based manual might be developed to contain these as part of a school-based initiative involving teachers, HODs, parents, and even senior students.

4) School leaders to refrain from relying on simplistic strategies to improve schools and students' learning outcomes and instead understand this within a wider spectrum including politics, religion, customary background, students' background, and family history. Professional learning opportunities can support this process.

5) School Boards to consider recruiting potential principals within the qualified group of teachers in a particular school rather, than hiring a person from the outside as the only strategy. This is to reduce the time needed to adjust to the school's norms and traditions.

\subsubsection{For policy-makers in Ghana}

The study recommends that:

1) Policy-makers review the language policy to look into how some of the nation's indigenous languages may be recognised as official languages as well as used as the medium of instruction to cover large portions of students at the upper 
secondary level. This recommendation requires strong political will for its implementation.

2) A policy providing for school-based psychologists be developed. Having such professionals available seems to enhance students' psychological, emotional, and physical needs. This recommendation calls for collaboration between the Ministry of Education and the stakeholders including professional associations, teacher education institutions, parents, and schools and a long-term strategy to be adopted.

3) Policy-makers develop a policy to promote religious, tribal, and ethnic peaceful coexistence. The purpose of this is to address the undercurrent of tribal tension in terms of collaboration among students and service delivery including teacher postings and promotion. A policy relating to this undercurrent is not likely to be easily implemented. Therefore, considerable political and policy courage is required to ensure that education policy, especially the national curriculum, covers some core values such as ethics of care, fairness, oneness, trust, love, community, empathy, accountability and responsibility, and justice. It is anticipated that these values in the long run will contribute to Ghanaians seeing themselves as one. Furthermore, under such policy, service delivery pertaining to teacher's posting and promotion will be based on merit rather than inequitable appointments being made according to tribal and ethnic considerations.

4) A National Education Act be established in the country to set the rights, responsibilities, and boundaries of every educational provider, including principals, teachers, and students. This may reduce over-politicisation of education issues, particularly during changes of government.

5) Policy-makers develop a policy that protects minority rights for groups such as transgender, gay, and lesbian students. This long term recommendation requires strong political bipartisan discussion as there is currently no law protecting transgender people, gays, and lesbians in the country at the moment. In the short term, it is recommended that the national curriculum be reviewed to cover some core values such as ethics of care, acceptance, autonomy, fairness, oneness, trust, love, community, empathy, accountability, responsibility, and justice which are missing in the national secondary curriculum of Ghana.

6) Policy-makers consider reviewing the secondary school curriculum to include ethics of care, honesty, love, trust, responsibility, empathy, autonomy, 
accountability, community, and collaboration. Such a review would require broad consultation involving stakeholders including policy-makers, teachers, principals, parents, and students to design a policy and programmes that incorporate indigenous ethical values into the national secondary curriculum.

7) Policy-makers consider establishing a policy that encourages collaboration across various tribal groups. The purpose of this is to address the finding that, currently, teachers and students feel better collaborating within their own tribal groups but not with others. It is also expected that this will help reduce corruption in education and service delivery. The development of such a policy would require broad consultation involving policy-makers, teachers, principals, parents, and students to design a policy and programmes that will encourage oneness, one nation with one destiny. Such a policy needs a long term focus and to incorporate indigenous ethical values as honesty, love, acceptance, hospitality, care, empathy, respect, sincerity, oneness, and others as national core values to enhance students' learning outcomes.

8) An in-school and out-of-school graduate apprenticeship program for upper secondary students be introduced as such programs appear to support students' learning and success. At the moment, secondary schools throughout the country do not have these programs. The establishment of such a program would require broad consultation involving all stakeholders including policy-makers, job owners, and schools to agree on a holistic programme that will make an apprenticeship in upper secondary obligatory in the national curriculum.

9) Policy-makers review the national-based curriculum to give local-based autonomy to individual schools. Based on the findings of this study, it may be argued that this will encourage local participation and initiative on the part of teachers. This recommendation requires consultation with all political parties, universities, schools, teachers, unions, school principals, and others on all matters including content, approach, funding, and duration.

10) Policy-makers consider developing a policy reviewing the requirements for intakes into the teacher-training college. The study found that current requirements have lead to the perception that only weak and dull students end up as teachers. This recommendation requires consultations with universities, especially the teacher training colleges, teachers, unions, school principals, 
students, and others on all matters including entry requirements, content, approach, and duration.

11) Policy-makers consider developing IT programs for principals, teachers, and students to enhance teaching and learning. The purpose is to keep older teachers and principals abreast with technology as are the younger teachers and students. The development of these programmes would require broad consultation among policy-makers, teacher training institutions, principals, teachers, and students to agree on a holistic programme on IT that factors in the needs of the older teachers and principals.

12) Policy-makers consider developing principalship programs to provide specific training for aspiring principals as there is no official program to this effect at the moment. This recommendation requires consultation with universities, teachers, unions, school principals, and others on all matters including content, approach, funding, and duration.

13) Policy-makers consider developing policy to end the school ranking system which appears to have produced competition, corruption, nepotism, favouritism, ethnicity, and tribalism. Given the nature of this recommendation, the Ministry of Education could begin by mandating and funding research to investigate school level student and parents' issues relating to the school ranking system.

\subsubsection{For educational leaders and managers in Ghana}

This study recommends that:

1) School leaders take regular professional development programmes pertaining to school leadership collaboration with universities and other stakeholders in order to broaden the scope of their leadership strategies.

2) School leaders to be sensitive to the socio-cultural backgrounds of students in designing the curriculum and the pedagogy. To improve and enhance understanding of diverse students and their socio-cultural backgrounds, school leaders will professional learning opportunities.

3) The ontology of school-based culture, climate, and leadership as the only means to improve learning outcomes must be revised to include the globalised undercurrents, the past and present histories, traditions, rituals, and customs. One 
way to approach this recommendation might be to encourage school leaders to take regular and relevant professional development programmes.

4) School leaders refrain from developing a simplistic manual to improve schools and students' learning outcomes and instead look to a wider spectrum including politics, religion, custom, and students' background and family history, all of which have a great impact on what students learn. Such a school-based manual might be developed as part of a school-based initiative involving teachers, HODs, parents, and even senior students.

5) Educational service providers receive training programmes that involve the transferable and relational functions of Ministries and of global organisations such as the OECD and UNESCO within curriculum and pedagogy for teachers, principals, and teacher trainees. While individual schools may find it hard to respond to this recommendation, it is one that a School Board may take up with a university or the Ministry of Education.

6) Through in-service training, out-of-service training, and retraining, school leaders ensure that they are well informed about the transferable functions of the Ministry of Education and its subsidiary agencies. School boards may need to build into the contracts of school leaders, specific requirements for participation in professional development programmes.

7) School leaders and managers consider developing collaboration measures across tribal groups. This would require a broader consultation involving the school boards, principals, teachers, and students to agree on a manual within the school level that seeks to encourage teamwork and participation across students from different tribal groups. Further to this, it is recommended that school-based posters that speak against tribalism, corruption, nepotism, favouritism, and related issues be displayed on the notices of the school to create awareness.

\subsection{Overall conclusion}

The basic argument that education and its related development need to be changed to meet the learning needs of students and changing needs of the society remains uncertain (Hoerr, 2005). The uncertainty includes matters such as the kind of curriculum, pedagogy, and assessment to be adopted and used that will promote learning of students (Leithwood, Harris \& Hopkins, 2014). 
For this reason, this study set out to understand the ways and extent to which school cuture, climate, leadership, and other factors contribute to students' learning, performance and success in New Zealand, Finland, and Ghana.

The study sought to address the following research questions:

- What is the relationship between school culture, climate, leadership, and students' success in New Zealand, Finland, and Ghana?

- What is the relationship between the use of Professional Learning Communities (PLCs), students' needs, motivation, and success in New Zealand, Finland, and Ghana?

- How can school culture, climate, leadership and success be retheorized?

After four years of research, the study found that some leadership practices have tendencies to promote students' learning, performance, and success. These practices include leaders' ability to promote positive values, such as integrity, compassion, fairness; to develop relationships; to build team work; to improve interactions; to practice distributive leadership; to understand change processes; to foster knowledge building; and to strive for coherence with ethics of care, trust, love, empathy, energy, enthusiasm, and hopefulness in guiding the learning process of students. Furthermore, teacher autonomy; the provision for religion, school-based psychological services, free meals, and many others were also found to have a significant impact on the learning of students.

The next impact stresses the nature of school leaders' role in fostering and deepening the capacity development of teachers to enhance learning. Aspects include information sharing, in-service training, and the use of information technology tools to enhance teaching and learning. These above are impact factors associated with teaching and learning and practices at the school level of the three comparative contexts.

The study finally found that, beyond the boundaries of the school, external impact factors are also critical to determining the success of schools and the learning outcomes of students. These factors, include influences from the wider community, the society, and the world, ranging from the role of international bodies such as the UN, and the OECD; the history, culture, and traditions of the particular context; governmental policies and programmes; directives and controls from the ministries and agencies; and expectations 
from parents and community organisations such as factories and companies. Therefore, as well as internal factors such as school cuture, climate, and leadership, all of these external factors also need to be taken into account when considering impacts on schools' performance and students' learning and success.

\subsection{Epilogue}

Having undertaken this study, I end with my personal reflections on my $\mathrm{PhD}$ journey. On my first day at Victoria University of Wellington in early 2017, I was sceptical about whether I would complete the programme, particularly given my circumstance as an international student with no scholarship funding. On a positive note, during the first six months of my journey, my primary supervisor, Associate Professor Kabini Sanga socialised me and other doctoral students in a course, Advanced Qualitative Research, thereby helping to ground my understanding of key theories relating to research. In this programme, I learned about ideas and qualitative research tools which were useful. I was therefore able to complete my research proposal within a period of a one year.

Let me say this, when I began my programme, I never believed that the world would revolve around me. I thought that in undertaking doctoral studies, life would take a slow pace, but this was not what I experienced. For the entire period, I have had to cope with demands from my family, friends, students, supervisors, landlords, co-tenants, academic work and more. This period of my life has been most trying as I made sacrifices and adjustments and tried to balance all my life demands. For me, it has not been the fear of missing out which stressed me, but rather, the anxiety of not being able to meet all the demands on me. In looking back, I am grateful that I have been one of the students who was able to submit my thesis within the four years period. Saying this is not to boast but rather, that I sure enjoyed a good supportive system around me. Moreover, I am grateful for having two experienced supervisors, Associate Professor Kabini Sanga and Associate Professor Jenny Ritchie, both of whom understood teamwork and offered me wise counsel throughout my journey.

Despite the positive support, the doctoral journey has been a lonely one. Over the entire period of study, I had spent long days and nights in my office, reading and re-reading, thinking about ideas and writing and re-writing. I have also spent much time, unproductively, procrastinating and not meeting deadlines and scheduled targets. Through these challenges, I am grateful for three "graces", as follows: First, in my 
programme I had two friends with whom I shared materials, food, new useful techniques, especially the use of the NVIVO, and we often supported and encouraged each other. Having friends made my journey less lonely. Second, my status as a self-financing international student motivated me to work hard and to finish my programme quickly so as to avoid paying unnecessary additional fees. Thirdly and finally, my leadership philosophies and values including an ethic of care, trust, meeting deadlines, walking the talk, and having a can-do-spirit; acted as my daily platforms throughout the entire period of my doctoral journey. 


\section{REFERENCES}

Adamson, P. (2012). Two views of child poverty. Retrieved from: https://www.unicef-irc.org/publications/pdf/rc10 eng.pdf

Ahmad, K., Jasimuddin, S., \& Kee, W. (2018). Organizational climate and job satisfaction: Do employees' personalities matter? Management Decision, $56(2), 421-440$.

Aitken, P., \& Higgs, M. (2010). Developing change leaders: The principles and practices of change leadership development. Oxford, UK: ButterworthHeinemann.

Akrofi, C. A. (2018). Reminiscing the contribition of a pioneer of the development of the Twi language. Ghana Journal of Linguistics, 7(2), 244247.

Anderman, E. M., \& Weber, J. A. (2009). Continuing motivation revisited. In A. Kaplan, S. A. Karabenick, \& E. d. Groot (Eds.). Culture, self, and, motivation: Essays in honor of Martin L. Maehr, Charlotte NC: Information Age Pub.

Angelides, P., \& Ainscow, M. (2000). Making sense of the role of culture in school improvement. School Effectiveness and School Improvement, 11(2), 145-163.

Asif, F. (2011). Estimating the impact of denison's (1996). "What is the difference between organizational culture and organizational climate? A native's point of view on a decade of paradigm wars". Journal of Business Research, 64(5), 454-459.

Bartholomaeus, C., \& Riggs, D. W. (2017). Whole-of-school approaches to supporting transgender students, staff, and parents. International Journal of Transgenderism, 18(4), 361-366.

Barrett, A., Sajid, A., Clegg, J., Hinostroza, J., Lowe, J., Nikel, J., Novelli, M., Oduro, G.K., Pillay, M., Tikly, L., \& Guo-xing, Y. (2007). Initiatives to improve the quality of teaching and learning. A review of recent literature. Background paper prepared for the Global Monitoring Report 2008.

Bassey, M. (2012). Case Studies. In A. R. J. Briggs \& M. Coleman (Eds.), Research methods in educational leadership and management: London: SAGE Publications. 
Bear, G., Yang, C., Mantz, L., \& Harris, A. (2017). School-wide practices associated with school climate in elementary, middle, and high schools. Teaching and Teacher Education, 63, 372-383.

Behrens, P. (2013). Langauages in Aotearoa, New Zealand. Creative Commons, pp. 1-8. Retrieved from:

https://royalsociety.org.nz/assets/Uploads/Languages-in-Aotearoa-NewZealand.pdf

Belcher, D. (2017). Moral leadership in an age of school accountability. Journal of Leadership Studies, 11(2), 60-62.

Bemile, S. K. (2000). Promotion of Ghanaian languages and its impact on national unity: The Dagara language case. In C. Lentz \& P. Nugent (Eds.). Ethnicity in Ghana: A comparative perspective. United Kingdom: Macmillan Publishers Limited.

Berisha, A.-K., \& Seppänen, P. (2017). Pupil selection segments urban comprehensive schooling in Finland: Composition of school classes in pupils' school performance, gender, and ethnicity. Scandinavian Journal of Educational Research, 61(2), 240-254.

Bolman, L. G., \& Deal, T. E. (2013). Reframing organization: artistry, choice, and leadership (Third ed.). San Francisco, United States of America: Wiley.

Borish, D., King, N., \& Dewey, C. (2017). Enhanced community capital from primary school feeding and agroforestry program in Kenya. International Journal of Educational Development, 52, 10-18.

Bottiani, J., Bradshaw, C., \& Mendelson, T. (2014). Promoting an equitable and supportive school climate in high schools: The role of school organizational health and staff burnout. Journal of School Psychology, 52(6), 567-582.

Bray, M. (2015). International and comparative education: Boundaries, ambiguities and synergies. In M. Hayden, J. Levy, \& J. J. Thompson (Eds.): The SAGE handbook of research in international education.

Brennan, C., \& McGilloway, S. (2014). Suicide ideation, psychological adjustment and mental health service support: A screening study in an Irish secondary school sample. Irish Journal of Psychological Medicine, 29(1), 46-51.

Brion-Meisels, G. (2014). “Can I Trust You With This?” Investigating middle school students' use of learning supports. Urban Education, 50(6), 718749 . 
Brophy, J. (2004). Motivating students to learn (2nd ed.). New Jersey: LEA.

Brown, G. (2015). Strong one lasting one: An elementary school principal's ability to to establish a positive school culture by building trust. Journal of Cases in Educational Leadership, 18(4), 309-316.

Boyd, C. L. (2020). Transformed to authenticity: Where a leader's history meets destiny. In D. Peltz \& J. Wilson (Eds). Leadership: Leadership styles and the kenotic relationship: Switzerland, Palgrave Macmillan.

Bunniss, S., \& Kelly, D. R. (2010). Research paradigm in medical education and research. Medical Education, 44(4), 358-366.

Burgess, B., \& Hart, P. (2013). Climate and culture : Know your Iceberg. Principal Matters: (97), 44-46,48.

Caine, G., \& Caine, R. N. (2010). Strengthening and enriching your professional learning community: The art of learning together. Alexandria, US: Association for Supervision \& Curriculum Development.

Cardno, C. (1999). Appraisal policy and implementation issues for New Zealand schools. International Journal of Educational Management, 13(2), 87-98.

Cardno, C. (2018). Policy document analysis: A practical educational leadership tool and a qualitative research method. Educational Administration: Theory and Practice, 24(4), 623-640.

Cassell, J. A., \& Nelson, T. (2013). Exposing the effects of the "invisible hand" of the neoliberal agenda on institutionalized education and the process of sociocultural reproduction. Interchange, 43(3), 245-250.

Chazan, N. (1982). Ethnicity and politics in Ghana. Academy of Political Science, 97(3), 461-485.

Chen, J.-K., \& Wei, H.-S. (2013). School violence, social support and psychological health among Taiwanese junior high school students. Child Abuse \& Neglect, 37(4), 252-262.

Cobb, N. (2014). Climate, culture and collaboration : The key to creating safe and supportive schools. Techniques, 89(7), 14-18.

Cole, M. (1990). Cognitive development and formal schooling. In L. C. Moll (Ed.), Vygotsky and Education. New York: Cambridge University Press.

Collie, R. J., Shapka, J. D., \& Perry, N. E. (2012). School climate and socialemotional learning: Predicting teacher stress, job satisfaction, and teaching efficacy. Journal of Educational Psychology, 104(4), 1189-1204. 
Cooke, E., Hague, S., \& Mckay, A. (2016). Ghana poverty and inequality report: Using the 6th Ghana living standards survey. Retrieved from: https://www.unicef.org/ghana/Ghana_Poverty_and_Inequality_Analysis_F INAL_Match_2016(1).pdf

Cornell, D., Shukla, K., \& Konold, T. (2015). Peer victimization and authoritative school climate: A multilevel approach. Journal of Educational Psychology. 107(4), 1186.

Court, M., \& O'Neill, J. (2011). "Tomorrow's schools" in New Zealand: From social democracy to market managerialism. Journal of Educational Administration and History, 43(2), 119-140.

Cowie, M., \& Crawford, M. (2007). Principal preparation - still an act of faith? School Leadership \& Management, 27(2), 129-146.

Creswell, J. W. (2009). Research design: qualitative, quantitative, and mixed methods approaches (Third ed.). Thousand Oaks, California: SAGE Publications, Inc.

Creswell, J. W. (2013). Qualitative inquiry and research design: Choosing among five approaches. Thousand Oaks, California: SAGE Publications.

Day, C., \& Sammons, P. (2013). Successful leadership: A Review of the international literature. United Kingdom, CfBT Education Trust.

D'Ardenne, C., Barnes, D. G., Hightower, E. S., Lamason, P. R., Mason, M., Patterson, P. C., . . E Erickson, K. A. (2013). PLCs in action: Innovative teaching for struggling grade 3 readers. The Reading Teacher, 67(2), 143151.

Daniels, H., \& Hedegaard, M. (2011). Vygotsky and special needs education: Rethinking support for children and schools. London: Continuum.

Darling-Hammond, L., Wei, R. C., Andree, A., Richardson, N., \& Orphanos, S. (2009). Professional learning in the learning profession. Washington, DC: National Staff Development Council, 12.

Dawson, A., \& Wymbs, B. (2016). Validity and utility of the parent-teacher relationship scale-II. Journal of Psychoeducational Assessment, 34(8), 751-764.

Deal, T. E., \& Peterson, K. D. (2016). Shaping school culture (Third ed.). San Francisco, Ca: John Wiley \& Sons.

Denny, S., Grant, S., \& Galbreath, R. (2014). Health service in New Zealand secondary schools and the associated health outcomes for students. 
Retrieved from:

https://www.fmhs.auckland.ac.nz/assets/fmhs/faculty/ahrg/docs/Youth\%20 $\%$ E2\%80\%9912\%20Health\%20Services\%20and\%20Health\%20Outcomes. pdf

Denzin, N. K., \& Lincoln, Y. S. (2008). The landscape of qualitative research. The challenge to and from phenomenological paradigms. Retrieved from: https://books.google.co.nz/books?id=4StZvMUWJfOC

Dessel, A. (2010). Prejudice in schools: Promotion of an inclusive culture and climate. Education and Urban Society, 42(4), 407-429.

Dimitrov, K. (2013). Edgar Schein's model of organizational culture levels as a hologram. Economic Studies, 22(4), 3-36.

Dou, D., Devos, G., \& Valcke, M. (2016). The relationships between school autonomy gap, principal leadership, teachers' job satisfaction and organizational commitment. Educational Management Administration \& Leadership, 45(6), 959-977.

Dowson, M., Mclnerney, D. M., \& Van Etten, S. (2006). What we know about effective schools and effective schooling from a sociocultural perspective. In M. Dowson, D. M. Mclnerney, \& S. Van Etten (Eds.), Effective Schools. United States of America: IAP Information Age Publication.

DuFour, R. (2004). What Is a professional learning community? Educational Leadership, 61(8), 30-35.

DuFour, R., \& Fullan, M. (2013). Cultures built to last: Systemic PLCs at work TM. Bloomington, IN, USA: Solution Tree Press.

Eagan, J. (2010). Paulo Freire's pedagogy of the oppressed. Administrative Theory \& Praxis, 32(3), 429-430.

Earnest, A., \& Brady, S. (2014). Dating violence victimization among high school students in minnesota. Journal of Interpersonal Violence, 31(3), 383-406.

Easton, L. B. (2011). Professional learning communities by design: Putting the learning back into PLCs. Thousand Oaks, California: SAGE Publications.

EC. (2011). Cultural competencies for teachers of Maori learners. Retrieved from: https://teachingcouncil.nz/required/Tataiako.pdf

EC. (2017). The code of professional responsibility: Example in practice. Retrieved from: 
https://teachingcouncil.nz/sites/default/files/Code\%20Guidance\%20FINAL .pdf

Emory, L. B. \& Peltz, D. P. (2020). Leadership development: The role of learning in the authentic, transformational, servant, and kenotic leader. In D. Peltz \& J. Wilson (Eds). Leadership: Leadership styles and the kenotic relationship: Switzerland, Palgrave Macmillan.

Essuman, A., \& Bosumtwi-Sam, C. (2013). School feeding and educational access in rural Ghana: Is poor targeting and delivery limiting impact? International Journal of Educational Development, 33(3), 253-262.

Fitzgerald, T. (2007). Documents and documentary analysis: Reading between the lines. In A. R. J. briggs \& M. coleman (Eds.), Research Method in Educational Leadership and Management. London: SAGE Publication.

FNBE. (2016). Curriculum in Finland: Retrieved from:

https://dge.mec.pt/sites/default/files/Noticias_Imagens/1_curriculum_in fi nland.pdf

Freire, P. (1983). Pedagogy of the oppressed. New York: The Continuum Publishing Corporation.

Fuda, P. (2013). Leadership transformed. How ordinary managers become extraordinary leaders. London, Profile Books LTD.

Fullan, M. (2004). Leading in a culture of change. San Francisco, CA, USA: Wiley.

Fullan, M. (2018). Nuance: Why some leaders succeed and others fail. Ontario, Canada: Corwin Press.

Fullan, M., Hill, P., \& Rincón-Gallardo, S. (2017). Deep learning: Shaking the foundation. Ontario, Canada: Pearson.

Fullan, M. \& Langworthy, M. (2014) A Rich Seam: How new pedagogies find deep learning. London: Pearson.

Gaziel, H. H. (1997). Impact of school culture on effectiveness of secondary schools with disadvantaged students. Journal of Educational Research, 90(5), 310-318.

Gerring, J. (2007). Case study research: Principles and practices. New York, USA: Cambridge University Press.

GES. (2008). Teachers' code of conduct: Rules of professional conduct for teachers in Ghana. Retrieved from: 
http://etico.iiep.unesco.org/sites/default/files/ghana 2008 teachers code _o f_conduct.pdf

Ghavifekr, S., \& Pillai, N. (2016). The relationship between school's organizational climate and teacher's job satisfaction: Malaysian experience. Asia Pacific Education Review, 17 (1), 87-106.

Gibson, R. (1986). Critical theory and education. London: Hodder and Stougton.

Gilstad-Hayden, K., Carroll-Scott, A., Rosenthal, L., Peters, S., McCaslin, C., \& Ickovics, J. (2014). Positive school climate is associated with lower body mass index percentile among urban preadolescents. Journal of School Health, 84(8), 502-506.

Giroux, H. A., \& McLaren, P. (1989). Schooling, cultural politics, and the struggle for democracy. In H. A. Giroux \& P. McLaren (Eds.), Critical pedagogy, the State, and cultural struggle. New York: University of New York Press.

Goldman, Z., Goodboy, A., \& Weber, K. (2016). College students' psychological needs and intrinsic motivation to learn: An examination of selfdetermination. Theory Communication Quarterly, 65(2), 167-191.

Goldring, L. (2002). The power of school culture. Leadership, 32(2), 32-35.

Goleman, D., Boyatzis, R., \& McKee, A. (2001). Primal leadership: The hidden driver of great performance. Harvard business review, 79(11), 42-53.

Goleman, D., Boyatzis, R., \& McKee, A. (2002). Primal leadership: Realizing the power of emotional intelligence. Harvard Business School Press.

Gorski, P. C. (2012). Instructional, institutional, and sociopolitical challenges of teaching multicultural teacher education courses. The Teacher Educator, 47(3), 216-235.

Graham, C. K. (1971). The history of education in Ghana: From the earliest times to the declaration of independance. Oregon, United States: Frank Cass and Conpany Limited.

Guest, G., MacQueen, K. M., \& Namey, E. E. (2012). Applied thematic analysis. Thousand Oaks, California: SAGE Publication Inc.

Guest, G., MacQueen, K. M., \& Namey, E. E. (2014a). Planning and preparing the analysis. In G. Guest, K. M. MacQueen, \& E. E. Namey (Eds.), Applied Thematic Analysis. Thousand Oaks, California: SAGE Publication Inc. 
Guest, G., MacQueen, K. M., \& Namey, E. E. (2014b). Themes and codes. In G. Guest, K. M. MacQueen, \& E. E. Namey (Eds.), Applied Thematic Analysis. Thousand Oaks, California: SAGE Publication Inc.

Gurr, D. (2015). A model of successful school leadership from the international successful school principalship project: Societies: 5 (1), 36-150.

Gurr D. (2017) A model of successful school leadership from the international successful school principalship project. In K.Leithwood, J. Sun, \& K. Pollock (Eds). How School leaders contribute to student success. (Dordrecht: Springer), pp. 15-29.

Gutek, G. L. (2014). Philosophical, ideological, and theoretical perspectives on education: (Second ed.). Boston: Pearson.

Hakala, J. T., Uusikylä, K., \& Järvinen, E.-M. (2015). Neoliberalism, curriculum development and manifestations of 'creativity'. Improving schools, 18(3), 250-262.

Halawah, I. (2005). The relationship between effective communication of high school principal and school climate. Education, 126(2), 334-345.

Hargreaves, D. H. (1995). School culture, school effectiveness and school improvement. School Effectiveness and School Improvement, 6(1), 23-46.

Heck, R., \& Hallinger, P. (2009). Assessing the contribution of distributed leadership to school improvement and growth in math achievement. American Educational Research Journal, 46(3), 659-689.

Hoerr, T. R. (2005). The art of school leadership. Alexandria, Va. ProQuest Ebook Central https://ebookcentral-proquest-com.helicon.vuw.ac.nz

Hollander, E. P., \& Won, J. C. E. D. (1978). Leadership dynamics: A practical guide to effective relationships. New York: Macmillan Publishing Co. Inc.

Hopson, L., \& Lawson, H. (2011). Social workers' leadership for positive school climates via data-informed planning and decision making. Children \& Schools, 33(2), 106-118.

Horrocks, C., \& King, N. (2010). Interviews in qualitative research. London: SAGE Publication Ltd.

How, A. (2003). Critical theory. Great Britain: Palgrave MaCmillan.

Hoy, W. K. (1990). Organizational climate and culture: A conceptual analysis of the school workplace. Journal of Educational \& Psychological Consultation, 1(2), 149-168. 
Huff, A. (2013). Reforming the city: Neoliberal school reform and democratic contestation in New Orleans. Canadian Geographer, 57(3), 311-317.

ILO. (2019). National labour law profile for Ghana. Retrieved from: https://www.ilo.org/ifpdial/information-resources/national-labour-lawprofiles/WCMS 158898/lang--en/index.htm

IMF. (1999). Enhanced structural adjustment faculty for Ghana. Retrieved from: https://www.imf.org/external/np/pfp/1999/ghana/

Jenkins, R. (2002). Pierre Bourdieu: (Rev. ed.. ed.). London: Routledge.

Johnson, B., \& Christensen, L. (2008). Educational research: Quantitative, qualitative, and mixed approaches. Thousand Oaks, California: SAGE Publications.

Joseph, M. L. (2015). Organizational culture and climate for promoting innovativeness. JONA: The Journal of Nursing Administration, 45(3), 172178.

Kangaslahti, J. (2018). 100 years of Finland independence: A selection of facts and events in Finnish education. Euromentor, 9(1), 7-12.

Kaniņš, V., \& Golubeva, M. (2017). Ethics, Transparency and integrity in education. strasbourg: Council of Europe Publishing.

Kaplan, A., Karabenick, S. A., \& Groot, E. d. (2009). Culture, self, and, motivation: Essays in honor of Martin L. Maehr. Edited by Avi Kaplan, Stuart A. Karabenick, Elisabeth De Groot. Charlotte, NC: Charlotte, NC : Information Age Pub.

Kearney, W., Murakami, E., Bunch, K., Viamontes, C., \& Campbell, A. (2018). Leadership advocacy towards teacher and student success: Addressing inequities and opportunities in a rural district. Rural Society, 27(2), 143156.

Kim, H., \& Hopkins, K. (2017). The quest for rural child welfare workers: How different are they from their urban counterparts in demographics, organizational climate, and work attitudes? Children and Youth Services Review, 73, 291-297.

Kimball, S. (2011). Principals: Human capital managers at every school. Phi Delta Kappan, 92(7), 13-18.

King, N., Dewey, C., \& Borish, D. (2015). Determinants of primary school nonenrollment and absenteeism: Results from a retrospective, convergent mixed methods, cohort study in rural western Kenya. PLoS ONE, 10(9). 
Kirby, D. (2006). A concise history of Finland. London: Cambridge University Press.

Knox, C. (2002). Sound standard for schools is key to learning. Leadership, 32(2), 34-35.

Koopman, T. M., Patton, J. M., Ubbes, V. A., \& Zullig, K. J. (2010). School climate: historical review, instrument development, and school assessment. Vol. 28, 139-152.

Kraus, J. (1991). The struggle over structural adjustment in Ghana. Africa Today, 38(4), 19-27.

Krauss, S. E. (2005). Research paradigms and meaning making: A primer. Phi Delta Kappan, 10(4), 758-770.

Kubow, P. K., \& Blosser, A. H. (2014). Trends and issues in the teaching of comparative education. In A. W. Wiseman \& E. Anderson (Eds.), Annual review of comparative and international education. Bingley, UK: Emerald Publishing Limited.

Lance, A. (2010). A case study of two schools: identifying core values conducive to the building of a positive school culture. Management in Education, 24(3), 118-123.

Langton, B., \& Hall, D. (2006). Perceptions of the status of teachers. Retrieved from:

https://teachingcouncil.nz/sites/default/files/Perceptions $\% 20$ of $\% 20$ the $\% 20$ Status\%20of\%20Teachers\%20-\%202006.pdf

Lavery, J. E. (2006). The history of Finland. London: Greenwood Press.

Le Grange, L. (2010). African curriculum studies, continental overview. In C. Kridel (Ed.), Encyclopedia of Curriculum Studies.

Lee, A., \& Nie, Y. (2014). Understanding teacher empowerment: Teachers' perceptions of principal's and immediate supervisor's empowering behaviours, psychological empowerment and work-related outcomes. Teaching and Teacher Education, 41, 67-79.

Leithwood, K., Harris, A. \& Hopkins, D. (2008). Seven strong claims about successful school leadership, School Leadership and Management, 28:1, $27-42$.

Leithwood, K., \& Jantzi, D. (2005). A review of transformational school leadership research 1996-2005. Leadership and Policy in Schools, 4(3), 177-199. 
Leithwood, K. Sun, J. \& Pollock, K. (2017). How school leaders contribute to student success: The four paths framework. Springer International Publishing.

Lentz, C., \& Nugent, P. (2000). Ethnicity in Ghana: A comparative perspective. In C. Lentz \& P. Nugent (Eds.), Ethnicity in Ghana: The Limits of Invention (pp. 1-28). London: Palgrave Macmillan, UK.

Lin, H., Zhang, C.-X., Chen, P., \& Lee, C.-D. (2016). Factors that develop effective professional learning communities in Taiwan. Asia Pacific Journal of Education, 36(2), 248-265.

Linder, R. A., Post, G., \& Calabrese, K. (2012). Professional learning communities: practices for successful implementation. Delta Kappa Gamma Bulletin, 78(3), 13-22.

Liston, D. P., \& Zeichner, K. M. (1996). Culture and teaching. New Jersey: Lawrence Erlbaum Associates, Inc.

Lucas, P., Patterson, E., Sacks, G., Billich, N., \& Evans, C. (2017). Preschool and school meal policies: An overview of what we know about regulation, implementation, and impact on diet in the UK, Sweden, and Australia. Nutrients, 9(7), 736.

MacBeath, J., Swaffield, S., Oduro, G., \& Bosu, R. (2010). Developing leadership for learning in Ghana: Opportunities and challenges. In $23 r d$ annual congress for school effectiveness and improvement, Kuala Lumpur, Malaysia.

Macdonald, G. F. (1991). What Is Culture? Journal of Museum Education, 16(1), 9-12.

Macneil, A. J., Prater, D. L., \& Busch, S. (2009). The effects of school culture and climate on student achievement. International Journal of Leadership in Education, 12(1), 73-84.

Malloy, J. \& Leithwood, K. (2017). Effects of distributed leadership on school academic press and student achievement. In Leithwood et al. (eds.), How school leaders contribute to student success. Studies in Educational Leadership. 23, 24-50.

Mann, T. (2010). What is culture? Training Journal, 47-51.

Maxwell, T. W., \& Ross Thomas, A. (1991). School climate and school culture. Journal of Educational Administration, 29(2), 72-80. 
McEwan, P. (2013). The impact of Chile's school feeding program on education outcomes. Economics of Education Review, 32, 122-139.

McGregor, A., \& Medina, E. (2019). PISA 2018. Reading in New Zealand. Retrieved from: https://www.educationcounts.govt.nz/ data/assets/pdf file/0003/196626/ PISA-2018-Reading-in-New-Zealand.pdf

McLaren, P. (1994). Life in schools: An introduction to critical pedagogy in the foundation of education (Second ed.). New York: Longman Publishing Group.

McMaster, C. (2013). Working the 'shady spaces': Resisting Neoliberal Hegemony in New Zealand Education. Policy Futures in Education, 11(5), 523-531.

MOE. (2007). The New Zealand Curriculum. Wellington: Crown Publication.

MOE. (2013). Inclusive policy. Retrieved from: http://www.voiceghana.org/downloads/MoE_IE_Policy_Final_Draft1.pdf

MOE. (2017a). Medium term expenditure framework (MTEF) for Ghana: Retrieved from: https://www.mofep.gov.gh/sites/default/files/pbbestimates/2017/2017-PBB-MOE.pdf

MOE. (2017b). National teachers' standards for Ghana. Retrieved from: https://www.t-tel.org/notice.html

MOE. (2018). National pre-tertiary education curriculum framework for Ghana: Retrieved from: https://ghanaeducation.org/wpcontent/uploads/2021/01/National-Pre-Tertiary-Learning-AssessmentFramework_-24062020.pdf

MOFA. (2019). Finland remains among top nations in PISA education survey. Retrieved from: https://finland.fi/life-society/finland-remains-among-topnations-in-pisa-education-survey/

Moll, L. C. (1990). Vygotsky and education: Instructional implications and applications of sociohistorical psychology. New York: Cambridge University Press.

Moral, C., Martín-Romera, A., Martínez-Valdivia, E., \& Olmo-Extremera, M. (2018). Successful secondary school principalship in disadvantaged contexts from a leadership for learning perspective. School Leadership \& Management: 38:1, 32-52. 
Murphy, J. (2017). Creating communities of professionalism: Addressing cultural and structural barriers. In Leithwood et al. (eds.), How school leaders contribute to student success, Studies in Educational Leadership: 23, DOI 10.1007/978-3-319-50980-8_ 4

Murphy, M., \& Costa, C. (2016). Theory as method in research : On bourdieu, social theory and education. Abingdon, Oxon: Routledge.

Northouse, P. G. (2004). Leadership: Theory and practice. Thousand Oaks, California: SAGE Publications.

NZQA. (2018). Study in New Zealand: A guide for students considering secondary school study. Retrieved from ttps://www.nzqa.govt.nz/assets/About-us/Publications/Brochures/Study-inNew-Zealand-english.pdf

Oduro, G., Dachi, H., Fertig, M., \& Rarieya, J. (2007). Examining educational leadership and quality in developing countries. EdQual, 9(1), 1/27.

OECD. (2013). Education Policy outlook: New Zealand. Retrieved from: http://www.oecd.org/education/EDUCATION\%20POLICY\%20OUTLOO K\%20NEW\%20ZEALAND_EN.pdf

OECD. (2015). Education Policy outlook: Finland: Making reforms happen. Paris: OECD Publishing.

OECD. (2016). Table B2 - Results: Results for regions within countries in PISA 2015 Results (Volume II): Policies and practices for successful schools. Paris: OECD Publishing.

OECD. (2018a). Education at a glance 2018: OECD indicators. Retrieved from: www.oecd-ilibrary.org/education/education-at-a-glance-2018 eag-2018-en

OECD. (2018b). Education at a glance: Country note Finland. Paris, OECD Publishing.

OECD. (2018c). OECD Economic surveys: Finland 2018. Paris: OECD Publishing.

OECD. (2019). Education at a glance 2019: Country note Finland. Paris, OECD publishing.

Oginde, D. A. (2020). The character of a leader: Authenticity as a moral distinction. In D. Peltz \& J. Wilson (Eds). Leadership: Leadership styles and the kenotic relationship. Switzerland, Palgrave Macmillan. 
Olivier, D., \& Huffman, J. (2016). Professional learning community process in the United States: Conceptualization of the process and district support for schools. Asia Pacific Journal of Education, 36(2), 301-317.

Olson, K., Young, R. A., \& Schultz, I. Z. (2015). Handbook of qualitative health research for evidence-based practice. New York, US: Springer.

Ott, J. S. (2004). Understanding organizational culture. In J. M. Shafritz, A. C. Hyde, \& S. J. Parkes (Eds.), Classics of public administration. (Fifth ed.). Belmont, CA: Thomson Wadsworth.

Paronen, P., \& Lappi, O. (2018). Finnish teachers and principals in figures. Retrieved from: https://www.oph.fi/sites/default/files/documents/finnish teachers and prin cipals in figures.pdf.

Parsons, S. R. (2016). A PLC's realization. Educational Leadership, 73(7), 91-91.

Peltz, D. P. (2020). Distinguishing between servant leadership and authentic leadership: In D. Peltz \& J. Wilson (Eds). Leadership: Leadership styles and the kenotic relationship: Switzerland, Palgrave Macmillan.

Penner-Williams, J., Díaz, E., \& Gonzales Worthen, D. (2017). PLCs: Key PD component in learning transfer for teachers of english learners. Teaching and Teacher Education, 65, 215-229.

Pepperberg, I. M. (2006). Cognitive and communicative abilities of grey parrots. Applied Animal Behaviour Science, 100(1-2), 77-86.

Perlin, F. (1990). What is Culture? Bijdragen Tot de Taal-, Land-en Volkenkunde, 146, 147-168.

Peterson, K. D., \& Deal, T. E. (2002). The shaping school culture fieldbook. San Francisco, CA: Wiley \& Sons, Inc.

Phillips, D. (2011). Comparative education: An approach to educational inquiry. In C. F. Conrad \& R. C. Serlin (Eds.), The SAGE handbook for research in education: Pursuing ideas as the keystone of exemplary inquiry. Thousand Oaks, California: SAGE Publications, Inc.

Poghosyan, L., Nannini, A., Stone, P., \& Smaldone, A. (2013). Nurse practitioner organizational climate in primary care settings: Implications for professional practice. Journal of Professional Nursing, 29(6), 338-349.

Pollock, K., Wang, F. \& Hauseman, D. C. (2017). Complexity and volume: An inquiry into factors that drive principals' work. In Leithwood et al. (eds.), 
How school leaders contribute to student success. Studies in Educational Leadership 23, DOI 10.1007/978-3-319-50980-8_4

Power, S., \& Whitty, G. (1999). Market forces and school cultures. In J. Prosser (Ed.), school culture. London: SAGE Publications.

Prosser, J. (1999). School culture. London: SAGE Publications.

Rau, P. L. P. (2015). Cross-cultural design methods, practice and impact: 7th International Conference, CCD 2015. Held as part of HCI International 2015. Los Angeles, CA, USA. Proceedings: Springer International Publishing.

Reid, W. A (2020). The mind of the transformational leader. In D. Peltz \& J. Wilson (Eds). Leadership: Leadership styles and the kenotic relationship: Switzerland, Palgrave Macmillan.

Ribbins, P. (2007). Interviews in educational research: Conversations with a purpose. In A. R. J. Briggs \& M. Coleman (Eds.), Research Methods in Educational Leadership and Management (Second ed.). Thousand Oaks, California: SAGE Publication Inc.

Roberts, J. (2004). The dialectic of enlightenment. In F. Rush (Ed.), The cambridge companion to critical theory. United Kingdom: Cambridge University Press.

Robson, C. (1993). Real world research: A resource for social scientists and practitioner-researchers. Oxford, UK: Blackwell.

Roby, D. E. (2011). Teacher leaders impacting school culture. Education, 131(4), 782.

Rogoff, B. (1990). Apprenticeship in thinking: Cognitive development in social context. New York: Oxford University Press.

Rosa, A., \& Montero, I. (1990). The historical context of Vygotsky's work: A sociohistorical approach. In L. C. Moll (Ed.), Vygotsky and Education. New York: Cambridge University Press.

Rowley, W. J., Stroh, H. R., \& Sink, C. A. (2005). Comprehensive guidance and counseling programs: Use of guidance curricula materials. Professional School Counseling, 8(4), 296-304.

Rust, B., \& Verran, Z. (2018). How does New Zealand education system compare? OECD'S Education at a glance 2018. Wellington: Evidence, Data \& Knowledge 
Sahlberg, P. (2010). The secret to Finland's success: Educating Teachers. Retrieved from:

https://edpolicy.stanford.edu/sites/default/files/publications/secretfinland $\% \mathrm{E} 2 \% 80 \% 99$ s-success-educating-teachers.pdf

Sahlberg, P. (2013). Teachers as leaders in Finland. Educational Leadership, 71(2), 36-38.

Salleh, H. (2016). Facilitation for professional learning community conversations in Singapore. Asia Pacific Journal of Education, 36(2), 285-300.

Salmond, A. (2017). Tears of rangi: Experiments across worlds. Auckland, New Zealand Auckland University Press.

Sanga, K., \& Chu, C. (2009). Living and leaving a legacy of hope : Stories by new generation Pacific leaders Wellington: He Parekereke, Victoria University.

Sapher, J., \& King, M. (1985). Good seeds grow in strong cultures. Educational Leadership, 42(6), 67-73.

Sarlio-Lähteenkorva, S., \& Manninen, M. (2010). School meals and nutrition education in Finland. Nutrition Bulletin, 35(2), 172-174.

Schaufeli, W. B. (2016). Heavy work investment, personality and organizational climate. Journal of Managerial Psychology, 31(6), 1057-1073.

Schein, E. H. (2010). Organizational culture and leadership. Hoboken, US: Wiley.

Schneider, B., Ehrhart, M., \& Macey, W. (2013). Organizational climate and culture. Annual Review of Psychology, 64(1), 361-388.

Scott , D., \& Norgrove, A. (2017). How does New Zealand's education system compare? OECD's Education at a Glance 2017. Wellington, OECD Indicators of Knowledge

Seale, C., Gobo, G., Gubrium, J. F., \& Silverman, D. (2004). Qualitative research practice. London: SAGE Publication Ltd.

Sebastian, J., Allensworth, E., \& Huang, H. (2016). The Role of teacher leadership in how principals influence classroom instruction and student learning. American Journal of Education, 123(1), 69-108.

Shankar, B. S. (2019). How school leaders contribute to student success: The four paths framework, School Leadership \& Management, 39: 5, 561-564. 
Shanker, R., Bhanugopan, R., van der Heijden, B. J. M., \& Farrell, M. (2017).

Organizational climate for innovation and organizational performance: The mediating effect of innovative work behavior. Journal of Vocational Behavior, 100, 67-77.

Sheridan, S., Witte, A., Holmes, S., Coutts, M., Dent, A., Kunz, G., \& Wu, C. (2017). A randomized trial examining the effects of conjoint behavioral consultation in rural schools: Student outcomes and the mediating role of the teacher-parent relationship. Journal of School Psychology, 61, 33-53.

Shor, I., \& Freire, P. ( 1987). A pedagogy for liberation: Dialogues on transforming education. London: MaCmillan.

Silverman, D. (2004). Qualitative research (Second ed.). London: SAGE Publications.

Smith, P. B., \& Peterson, M. F. (1988). Leadership, organizations and culture: An event management model. London: Sage Publication Inc.

Soto, C., \& Deemer, E. (2018). Communal goals, campus racial climate perceptions, and cultural differences in perceived academic satisfaction. The Career Development Quarterly, 66(1), 35-48.

Spillane, J. (2017). Leadership and learning: Conceptualizing relations between school administrative practice and instructional practice. In Leithwood et al. (eds.), How school leaders contribute to student success, Studies in Educational Leadership: 23, DOI 10.1007/978-3-319-50980-8_4

Spoonley, P. (2015). New diversity, old anxieties in New Zealand: The complex identity politics and engagement of a settler society. Ethics and Racial Studies, 38(4), 650-661.

Stagwood, E. (2018). A decile snapshot: Socio-economic impact on legal education - University of Auckland case study. Auckland University Law Review, 24(1), 258-285.

Starratt, R. J. (2004). Cultivating an ethical school. San Francisco, USA: JosseyBass.

Stats. (2010). 2010, Population and housing census of Ghana: Summary report of final results. Retrieved from:

http://www.statsghana.gov.gh/docfiles/2010phc/Census2010_Summary_re port_of_fnal_results.pdf

Stats. (2014). 2013 Census quickstats about culture and identity of New Zealand: Retrieved from: http://archive.stats.govt.nz/Census/2013-census/profileand-summary-reports/quickstats-culture-identity/ethnic-groups-NZ.aspx 
Stats. (2016). Projected population by sex of Ghana: Data population unit. Retrieved from:

http://www.statsghana.gov.gh/docfiles/2010phc/Projected\%20population\% 20by\%20sex\%202010\%20-\%202016.pdf

Stats. (2019). Population of New Zealand. Retrieved from: https://www.stats.govt.nz/topics/population

Stewart, G., Benade, L., \& Devine, N. (2019). Freedom of academic speech in Aotearoa-New Zealand. New Zealand Journal of Educational Studies, 54(1), 1-4.

Stoll, L., \& Louis, K., S. (2007). Professional learning communities: Divergence, depth and dilemmas. UK: Open University Press.

Sun, J. \& Leithwood, K. (2017). Leadership effects on student learning mediated by teacher emotions. In Leithwood et al. (eds.), How school leaders contribute to student success, Studies in Educational Leadership: 23, DOI 10.1007/978-3-319-50980-8_4

Sun-Keung Pang, N., Wang, T., \& Lai-Mei Leung, Z. (2016). Educational reforms and the practices of professional learning community in Hong Kong primary schools. Asia Pacific Journal of Education, 36(2), 231-247.

Supovitz, J., Sirinides, P., \& May, H. (2009). How principals and peers influence teaching and learning. Educational Administration Quarterly, 46(1), 31-56.

Sutherland, K. A. (2018). Early career academics in New Zealand: Challenges and prospects in comparative perspective. Switzerland. Springer International Publishing AG.

Taipale, A. (2012). International survey on educational leadership. Retrieved from: https://www.slideshare.net/ghalebkandeel/143319-internationalsurveyoneducationalleadership

Thapa, A., Cohen, J., Guffey, S., \& Higgins-D'Alessandro, A. (2013). A review of school climate research. Review of Educational Research, 83(3), 357385 .

Tharp, R., \& Gallimore, R. (1990). Teaching mind in society: Teaching, schooling, and literate discourse. In L. C. Moll (Ed.), Vygotsky and Education. New York: Cambridge University Press.

Thomas, M. A. M. (2017). Teaching comparative education: Trends and issues informing practice. Comparative Education Review, 61(1), 217-220. 
Thoreson, R. R. (2008). Somewhere over the rainbow nation: Gay, lesbian and bisexual activism in South Africa. Journal of Southern African Studies, 34(3), 679-697.

Thornton, P. B. (2011). Why some leaders succeed, and others fail. Leader to Leader, 60 (2011), 17-21.

Thorpe, E. (2011). Winning at interviews. New Delhi, India: Dorling Kindersley (India).

Tian, L., Han, M., \& Huebner, E. S. (2014). Preliminary development of the adolescent students' basic psychological needs at school scale. Journal of Adolescence, 37(3), 257-267.

Townsend, T. (2009). Third millennium leaders: Thinking and acting both locally and globally. Leadership and Policy in Schools, 8:4, 355-379,

Townsend, T. \& Bayetto, A. (2020). Reaching out from Tasmanian schools:

Leadership for learning to support family and community engagement to improve reading. Leadership and Policy in Schools. DOI:

10.1080/15700763.2020.1777435

Tschannen-Moran, M. \& Gareis, C. R. (2017). Principals, trust, and cultivating vibrant schools. In Leithwood et al. (eds.), How school leaders contribute to student success, Studies in Educational Leadership: 23, DOI 10.1007/978-3-319-50980-8_4

UN. (2019). Youth for Human Rights. Retrieved from: https://www.ohchr.org/en/Issues/Youth/Pages/HROfYouth.aspx

UNESCO. (2019a). Student teacher ratio for primary schools in Ghana. Retrieved from:

https://www.theglobaleconomy.com/Ghana/Student teacher_ratio_primary school/

UNESCO. (2019b). Sustainable development goals. Retrieved from: http://uis.unesco.org/en/country/gh

UNICEF. (2017). What are facts in New Zealand. Retrieved from: https://www.unicef.org.nz/about

Vanblaere, B., \& Devos, G. (2016). Relating school leadership to perceived professional learning community characteristics: A multilevel analysis. Teaching and Teacher Education, 57, 26-38. 
Voight, A. (2015). Student voice for school-climate improvement: A case study of an urban middle school. Journal of Community \& Applied Social Psychology, 25(4), 310-326.

Walker, R. (1990). Ka Whawhai Tonu Matou. Auckland, New Zealand: Penguin Books.

Wallace, F. (2011). The school principal as a leader: Guiding schools to better teaching and learning. New York: Wallace Foundation.

Wang, L., Bruce, C., \& Hughes, H. (2011). Sociocultural theories and their application in information literacy research and education. Australian Academic \& Research Libraries, 42(4), 296-308.

Wennergren, A.-C., \& Blossing, U. (2015). Teachers and students together in a professional learning community. Scandinavian Journal of Educational Research, 61(1), 47-59.

Whitaker, M., \& Hoover-Dempsey, K. (2013). School influences on parents' role beliefs. The Elementary School Journal, 114(1), 73-99.

Witt, M., \& Barnett, P. (2012). Assessing the capacity of New Zealand health promoters to develop programs that meet the health literacy needs of both consumers and government. Health Promotion Journal of Australia, 23(2), 117-121.

Yin, R. K. (2010). Qualitative research from the start to finish. New York, United States of America: Guilford Publications.

Yukl, G. A. (2010). Leadership in organization. (Sixth, Edition ed.). New Jersey, United States of America: Pearson.

Zetterberg, S. (2017). Main outlines of Finnish history: Swedish, Russian and independent eras in Nutshell: Retrieved from: https://finland.fi/lifesociety/main-outlines-of-finnish-history/

Zhu, C., Devos, G., \& Li, Y. (2011). Teacher perceptions of school culture and their organizational commitment and well-being in a Chinese school. Asia Pacific Education Review, 12(2), 319-328.

Zhu, C., Devos, G., \& Tondeur, J. (2013). Examining school culture in Flemish and Chinese primary schools. Educational Management Administration \& Leadership, 42(4), 557-575. doi:

Zullig, K., Huebner, E. S., \& Patton, J. (2011). Relationships among school climate domains and school satisfaction. Psychology in the Schools, 48(2), 133-145. 


\section{APPENDICES}

Appendix 1: The Sample Copy: The Ethics Approval Letter

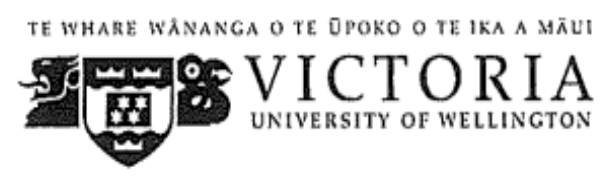

\section{MEMORANDUM}

\begin{tabular}{l|l}
\hline TO & Darko Baafi \\
\hline COPY TO & A/Prof Kabini Sanga \\
\hline FROM & AProf Susan Corbett, Convener, Human Ethics Committee \\
\hline
\end{tabular}

\begin{tabular}{l|l}
\hline DATE & 1 March 2018 \\
\hline PAGES & 1 \\
\hline
\end{tabular}

\begin{tabular}{l|l}
\hline SUBJECT & $\begin{array}{l}\text { Ethics Approval: } 25654 \\
\text { Educational leaders' views about school culture, climate, } \\
\text { leadership and success. A study of New Zealand, Finland and } \\
\text { Ghana }\end{array}$ \\
\hline
\end{tabular}

Thank you for your application for ethical approval, which has now been considered by the Standing Committee of the Human Ethics Committee.

Your application has been approved from the above date and this approval continues until 1 March 2021. If your data collection is not completed by this date you should apply to the Human Ethics Committee for an extension to this approval.

Best wishes with the research.

Kind regards

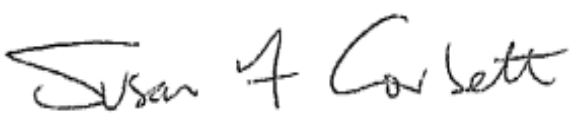

\section{Susan Corbett}

Convener, Victoria University Human Ethics Committee 
Appendix 2: The Sample Copy: The Letter of Invitation

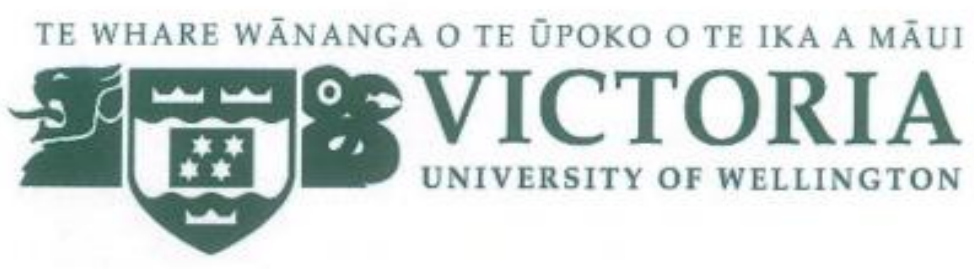

Baafi Darko

Dear Sir/Madam,

$\underline{\text { Letter of invitation: (University expert) }}$

Project title:

Educational leaders' views about school culture, climate, leadership and success: A study of New Zealand, Finland and Ghana

Thank you for your interest in this project. Please read this information before deciding whether or not to take part. If you decide to participate, thank you. If you decide not to take part, thank you for considering my request.

Who am I?

I am Darko Baafi and currently a Doctoral candidate in Education at Victoria University of Wellington. This research project is work towards my $\mathbf{P h D}$ thesis.

What is the aim of the project? 
This thesis aims to explore educational leaders' views, experience and practices in relation to school culture, climate, leadership and other factors contributing to students' learning, performance and success in three different countries: New Zealand, Finland and Ghana. And it is hoped that the study will lead to a greater understanding of the nature of school culture, climate and leadership and their influence on students' success in the three international contexts. This research has been approved by the Victoria University of Wellington Human Ethics Committee [provide approval number].

\section{How can you help?}

If you agree to take part, you will be involved in an individual interview. I am keen to:

- Invite you to take part in a face-to-face interview which investigates what you perceive school culture, climate, leadership and other factors contributing to students' success. The interview will take up to a one hour to a one hour to a one hour thirty minutes.

I will record the interview and write it up later. I will send you summary of the interviews for member checking on a request.

You can withdraw from the study by contacting me at any point before $30^{\text {th }}$ June 2019. If you withdraw, the information you provided during individual interviews will be destroyed or returned to you.

\section{What will happen to the information you give?}

Throughout the project, all attempts will be made to minimize the disruptive impact on your teaching and your students' learning activities. This research is confidential. This means that only my supervisors and I will be aware of your identity. The research data will be aggregated and your identity will not be disclosed in any reports, presentations, or public documentation. The observation field notes, video transcripts, interview transcripts, summaries and any recordings will be kept securely and destroyed five years after the data gathering ends.

\section{What will the project produce?}

The information from my research will be used in my $\mathrm{PhD}$ dissertation, written publications and oral presentations in national and international contexts.

If you accept this invitation, what are your rights as a research participant? 
You do not have to accept this invitation if you don't want to. If you do decide to participate, you have the right to:

- Ask any questions about the study at any time;

- Choose not to answer any question(s) in the interviews

- Ask for the audio recorder to be turned off at any time during the interview;

- Read over and comment on a written summary of your interview;

- Be able to read any reports of this research by emailing the researcher to request a copy. You will be given a consent form to complete before the data gathering begins.

If you have any questions or problems, who can you contact?

If you have any questions, either now or in the future, please feel free to contact either:

Student:

Name: Baafi Darko

University email address:

Darko.baafi@vuw.ac.nzl

baafidarko@yahoo.com

\author{
Supervisors: \\ Name: Assoc. Professor: Kabini Sanga \\ Role: Doctoral supervisor \\ School: Education \\ Phone: +6444636894 \\ Kabini.Sanga@vuw.ac.nz
}

\author{
Name: Assoc. Professor: Jenny Ritchie \\ Role: Doctoral supervisor \\ School: Education \\ Phone: +6444635716 \\ Jenny.Ritchie@vuw.ac.nz
}

\section{Human Ethics Committee information}

If you have any concerns about the ethical conduct of the research you may contact the Victoria

University HEC Convener: Associate Professor Susan Corbett. Email susan.corbett@vuw.ac.nz or telephone +64-4-4635480. 
Appendix 3: The Sample Copy: The Consent Form

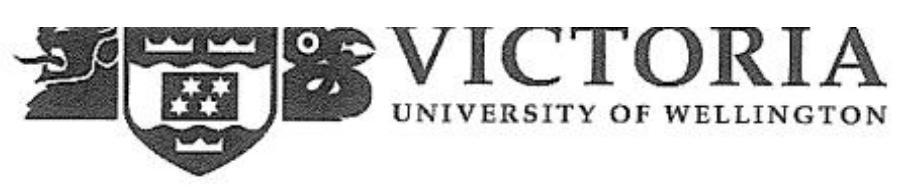

Consent form (Individual interviews)

Topic:

Educational leaders' views about school culture, climate, leadership and success: A study of New Zealand, Finland and Ghana

Darko Baafi

Kindly, underline one of the categories below to identify your professional role:

1. A university expert 2. A ministry official 3. A principal or 4. A teacher

This consent form will be held for five years.

Researcher: Darko Baafi, school of education, Victoria University of Wellington.

- I have read the Information Sheet and the project has been explained to me. My questions have been answered to my satisfaction. I understand that I can ask further questions at any time.

- I agree to take part an audio-recorded interview.

I understand that:

- I may withdraw from this study at any point before $30^{\text {th }}$ December, 2018, without giving any reason, and any information that I have provided will be destroyed.

- I can choose not to answer any question (s)

- I can ask for the audio recorder to be turned off at any time during the interview.

- Any information I provide will be de-identified so that I will not be identified

- I understand that the results will be used for a $\mathrm{PhD}$ thesis and a summary of the results may be used in academic reports and/or presented at conferences. 
The information I have provided will be destroyed five years after the data gathering is finished.

- My name will not be used in reports, nor will any information that would identify me.

- I would like a summary of the transcript of my interview.

- Yes No

- I would like to receive a summary of findings of the thesis and have

- Yes No added my contact details below.

Signature of participant:

Name of participant:

Date:

Contact details: 


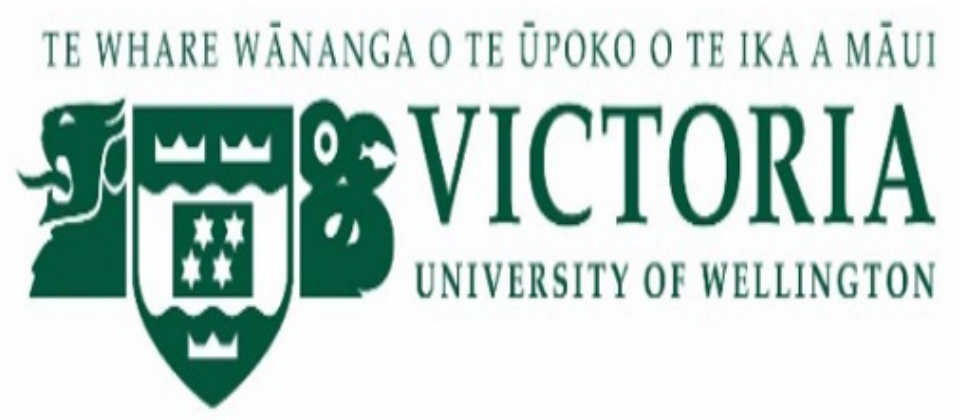

Interview protocol (Principals)

(Protocol questions for school-principals interviewees)

Project title:

Educational leaders' views about school culture, climate, leadership and success: A study of New Zealand, Finland and Ghana

1. Could you please tell me the basic history of the school?

2. What are the school values? What is your as a principal in fostering such values?

3. Can you give me some examples of how the school culture operates?

4. Can you please tell me how your school's vision helps to build the capacity of students and teachers in the school and thus supports students' learning, performance and success?

5. Can you give me some examples of some good practices models you put in place in developing the abilities of your teachers, non-teaching staff and students?

6. Can you tell me how you as the school's Principal impact the school climate and culture to promote students' learning, performance and success in this school?

7. Can you describe some ways the school collaborates with the wider society including students' parents?

8. As a principal, Can you explain to me how various tasks are shared among the school leadership groups?

9. Can you please tell me about the policies regarding discipline in the school?

(a) Can you tell me a bit about education achievements of this school?

(b) Can you tell me a bit about how you ensure an inclusion of students in the school?

10. Can you tell me some support services you have in the school for students' learning?

11. Can you describe how you ensure your students maintain good health?

12. Can mention some source of resources for the school's development? 
Appendix 5: The Sample Copy: The Interview Guide for Teachers
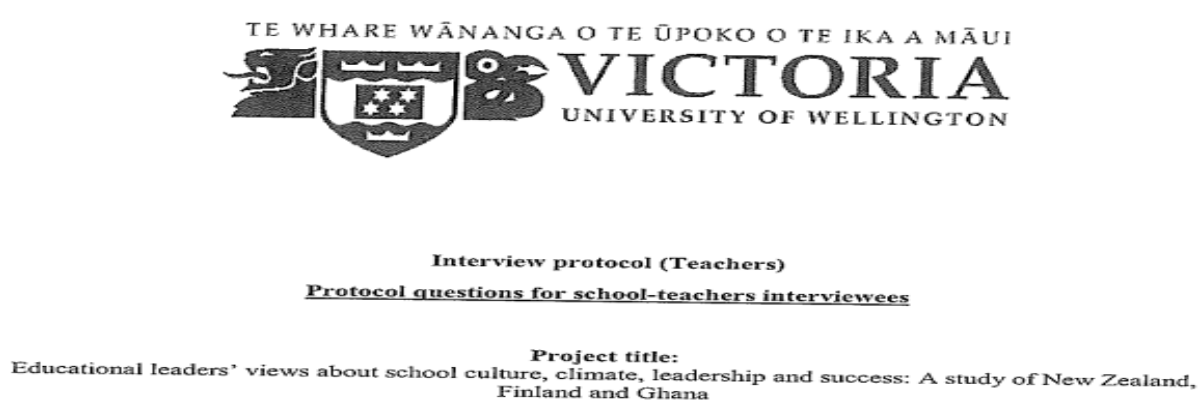

1. Could you please tell me the basic history of this school?

Can you please tell me a little bit about some examples of internal culture you have witnessed or participated in this school?

make you feel or perceive climate of this school? Could you please tell me a little bit about things that

Can you describe how you ensure an accountability, collaboration, and respect for diversity, equity and justice in the classroom and outside the classroom? What do you think or do to make your students learn, improve their performance and succeed in life? What personal qualities help you to do?

6. Can you please describe how you get feedback from students, principal and parents?

7. Can you give me some examples of support services you have in the school for students?

How do you collaborate with other teachers, the principal and non-teaching staffs to enhance students

Can you please tell me a little bit about how Professional Learning Community's practices you put in

place to support students' learning in the school?

high in the OECD's Pisa-surveys?
OEDe the reasons why New Zealand's education has been ranking 


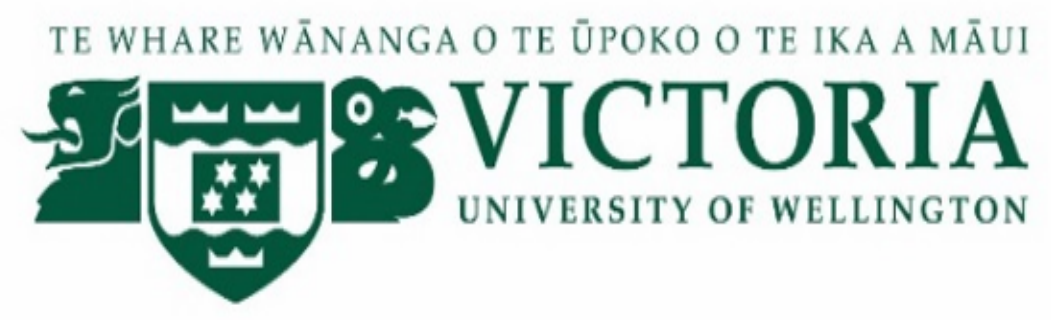

\section{Interview protocol (Lecturers)}

\section{Protocol questions for university-lecturers (interviewees)}

Project title:

Educational leaders' views about school culture, climate, leadership and success: A study of New Zealand, Finland and Ghana

1. Can you please tell me a bit about the history of this faculty?

2. Could you please tell me a bit about how your activities share the vision of this faculty?

3. Can you please tell me about the mission statement of the faculty and how it connects to your activities?

4. Can you tell me a bit about educational policy of this country?

(a) Could you please tell me how much the faculty receives from the government in a year? I meant the budgetary allocation?

5. Could you please educate me on the faculty's policy direction on the following priority areas?

(a) Developing quality teaching and learning for students?

(b) Developing principals and teachers to enhance teaching and learning?

(c) Boosting achievements of indigenous groups, developing refugees, protecting transgender students, disabled and others? What about inclusion of students?

(d) Are there any constraints?

6. Can you please tell me the faculty policy on the following areas: (a) scholarship (b) accommodation and housing (c) security and safety (d) health, food and wellbeing

7. Can you please tell me a bit about the faculty's direction on the following priority areas: creating modern learning environments, engagement of children, students' families and wider community participation and transition in education?

8. Can you please tell me a bit about how information is disseminated to various schools in the country? What about collaboration and networking?

9. Could you please tell me a little bit about what have accounted for your country's PISA success in recent years? 


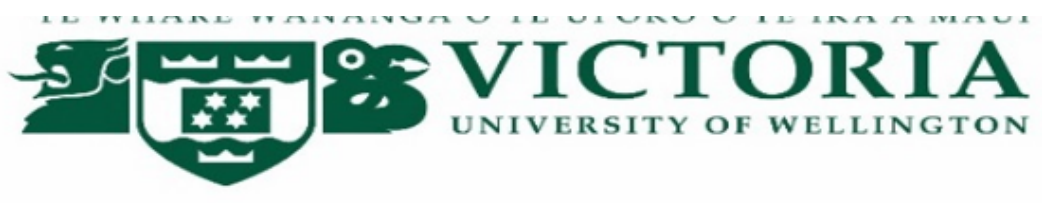

Interview protocol (Experts: education ministries)

Protocol questions for interviewees from education ministries

\section{Project title:}

Educational leaders' views about school culture, climate, leadership and success: A study of New Zealand, Finland and Ghana

1. Can you please tell me a bit about the history of the ministry?

2. Can you please tell me about the educational philosophy that currently guides your educational system?

3. Can you tell educational policy of this country and how your outfit is shaping it?

4. Could you please tell me how much the government spend on education in the country? I meant the budgetary allocation for education in a year?

5. Could you please educate me on how the government or the ministry policy direction on the following priority areas?

(a) Developing quality teaching and learning for students?

(b) Developing principals and teachers to enhance quality teaching and learning?

(c) Boosting achievements of indigenous groups, developing refugees, protecting transgender students and many others?

(d) Are there any constraints?

6. Can you please tell me a little bit about the following: Comment in line with the following themes: (a) scholarship (b) accommodation and housing (c) security and safety (d) health, food and wellbeing

7. Can you tell me a little bit about how the ministry?

Creates modern learning environments, engagement of children, students' families and wider community to participate and transition in education?

8. Can you tell me a bit about how information is disseminated to various schools in the country? What about collaboration and networking?

9. Can you please tell me a bit about your country's success in PISA rankings over the years? 


\section{Appendix 8: The Sample Copy: The Field Notes}

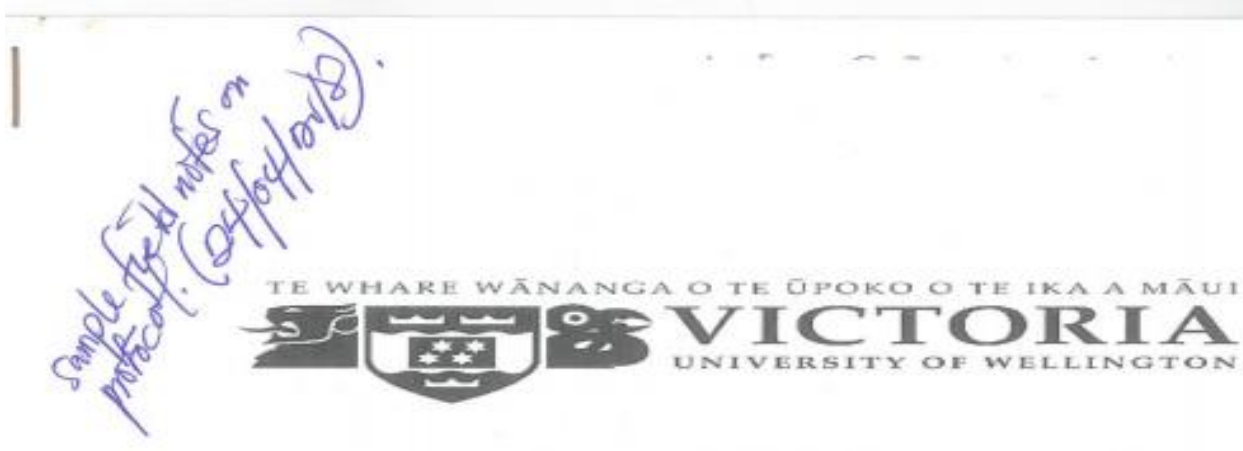

Interview protocol (A lecturer)

Protocol questions for university-lecturers (interviewees)

\section{Project title:}

Educational leaders' views about school culture, climate, leadership and success: A study of New Zealand, Finland and Ghana

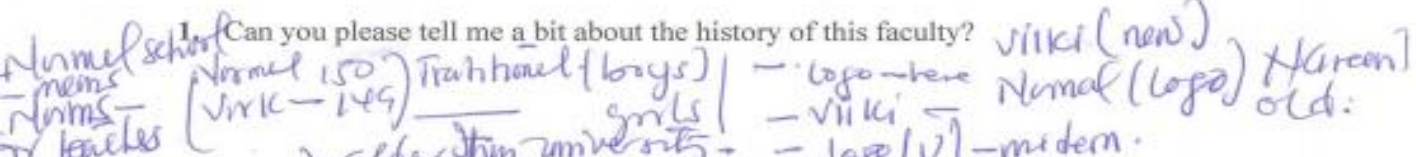

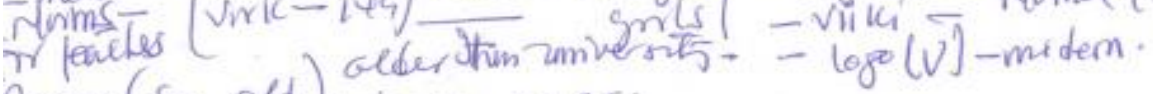

Reason (fo old). bays, cups.

2. Could you please tell me a bit about the vision staterpent of the faculty? .

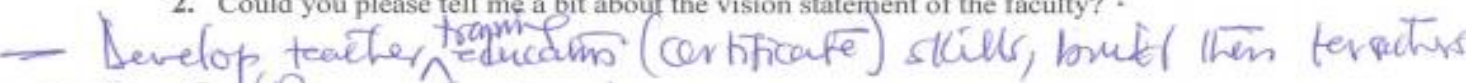

- Goal / Reoard based,

3. Can you please tell me about the mission statement of the faculty?

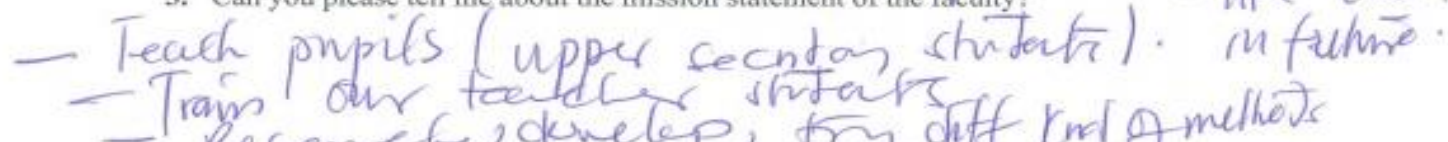

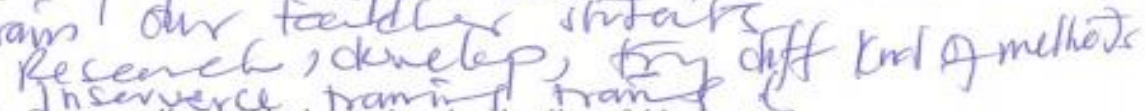

4. Can you tell me a bit about educational policy of this country?

(a) Could you please tell me how much the faculty receives from the government

- budjet Educum export.

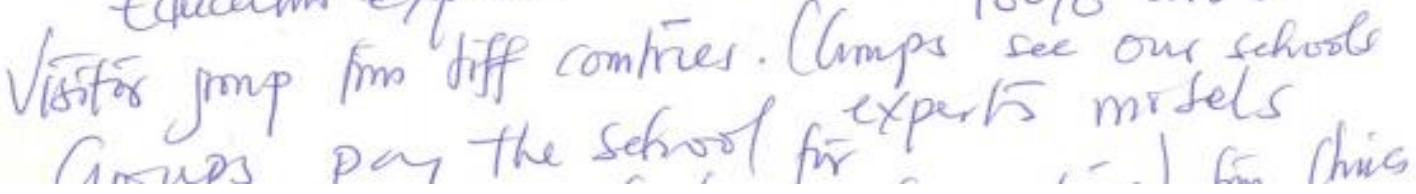


Appendix 9: The Sample Copy: The Information Sheet for Observed Practices

Summary of the observed support services, practices, symbols, behaviours, structures and environment of the three sites, New Zealand, Finland and Ghana

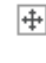

\begin{tabular}{|c|c|c|c|c|}
\hline $\begin{array}{l}\text { Observables/ } \\
\text { Availability }\end{array}$ & $\begin{array}{l}\text { Support } \\
\text { services }\end{array}$ & symbols & Behaviors & $\begin{array}{l}\text { Psychical } \\
\text { environment }\end{array}$ \\
\hline New Zealand & $\begin{array}{l}\text { School clinic- } \\
\text { based nurses, } \\
\text { counselling } \\
\text { services, free } \\
\text { tuition, } \\
\text { ultramodem } \\
\text { library, art and } \\
\text { music studio, } \\
\text { school-based } \\
\text { chaplain }\end{array}$ & $\begin{array}{l}\text { Flags, } \\
\text { uniforms, } \\
\text { mottoes and } \\
\text { trophies well } \\
\text { designs and } \\
\text { paintings, } \\
\text { displayed of } \\
\text { photos, mission } \\
\text { statements on } \\
\text { walls }\end{array}$ & $\begin{array}{l}\text { Relationships } \\
\text { were between } \\
\text { students and } \\
\text { among } \\
\text { personnel; } \\
\text { Teamwork, } \\
\text { network and } \\
\text { collaboration } \\
\text { were witnessed } \\
\text { within the } \\
\text { leaderships. }\end{array}$ & $\begin{array}{l}\text { Very strong } \\
\text { security check } \\
\text { post, } \\
\text { ultramodem } \\
\text { school } \\
\text { compound and } \\
\text { buildings, } \\
\text { cluster seating } \\
\text { arrangement } \\
\text { and less } \\
\text { bureaucracy at } \\
\text { the security } \\
\text { check points } \\
\text { and reception }\end{array}$ \\
\hline Finland & $\begin{array}{l}\text { School-based } \\
\text { clinic, nurses, } \\
\text { counselling } \\
\text { services, } \\
\text { psychologist, } \\
\text { social workers, } \\
\text { special } \\
\text { education } \\
\text { teachers, free } \\
\text { tuition and } \\
\text { lunches } \\
\text { ultramodem } \\
\text { library, art and } \\
\text { music studio }\end{array}$ & $\begin{array}{l}\text { Flags, mottoes } \\
\text { and trophies } \\
\text { well designs } \\
\text { and paintings, } \\
\text { displayed of } \\
\text { photos, mission } \\
\text { statements on } \\
\text { walls }\end{array}$ & $\begin{array}{l}\text { Relationships } \\
\text { were between } \\
\text { students and } \\
\text { among } \\
\text { personnel; } \\
\text { Teamwork, } \\
\text { network and } \\
\text { collaboration } \\
\text { were witnessed } \\
\text { within the } \\
\text { leaderships }\end{array}$ & $\begin{array}{l}\text { Very strong } \\
\text { security check } \\
\text { post, } \\
\text { ultramodem } \\
\text { school } \\
\text { compound and } \\
\text { buildings, } \\
\text { cluster seating } \\
\text { arrangement } \\
\text { and less } \\
\text { bureaucracy at } \\
\text { the security } \\
\text { check points } \\
\text { and reception }\end{array}$ \\
\hline Ghana & $\begin{array}{l}\text { School-based } \\
\text { clinic and } \\
\text { nurses, } \\
\text { counselling } \\
\text { services, free } \\
\text { tuition and } \\
\text { lunches, } \\
\text { boarding } \\
\text { systems, school } \\
\text { cadet less } \\
\text { ultramodem } \\
\text { library, art and } \\
\text { music studio, } \\
\text { school-based } \\
\text { chaplain and } \\
\text { Imams }\end{array}$ & $\begin{array}{l}\text { Flags, mottoes } \\
\text { and trophies } \\
\text { well designs } \\
\text { and paintings, } \\
\text { displayed of } \\
\text { photos, mission } \\
\text { statements on } \\
\text { walls }\end{array}$ & $\begin{array}{l}\text { Relationships } \\
\text { were between } \\
\text { students and } \\
\text { among } \\
\text { personnel; } \\
\text { Teamwork, } \\
\text { network and } \\
\text { collaboration } \\
\text { were witnessed } \\
\text { within the } \\
\text { leaderships; } \\
\text { some form of } \\
\text { tribal service } \\
\text { and } \\
\text { inducement. }\end{array}$ & $\begin{array}{l}\text { less } \\
\text { ultramodem } \\
\text { security post } \\
\text { and check } \\
\text { points; } \\
\text { ultramodem } \\
\text { school } \\
\text { compound and } \\
\text { buildings, } \\
\text { teacher in front } \\
\text { seating } \\
\text { arrangement, } \\
\text { some form of } \\
\text { bureaucracy at } \\
\text { the reception } \\
\text { and security } \\
\text { check points }\end{array}$ \\
\hline
\end{tabular}


Appendix 10: The Sample Copy: The Coding Process

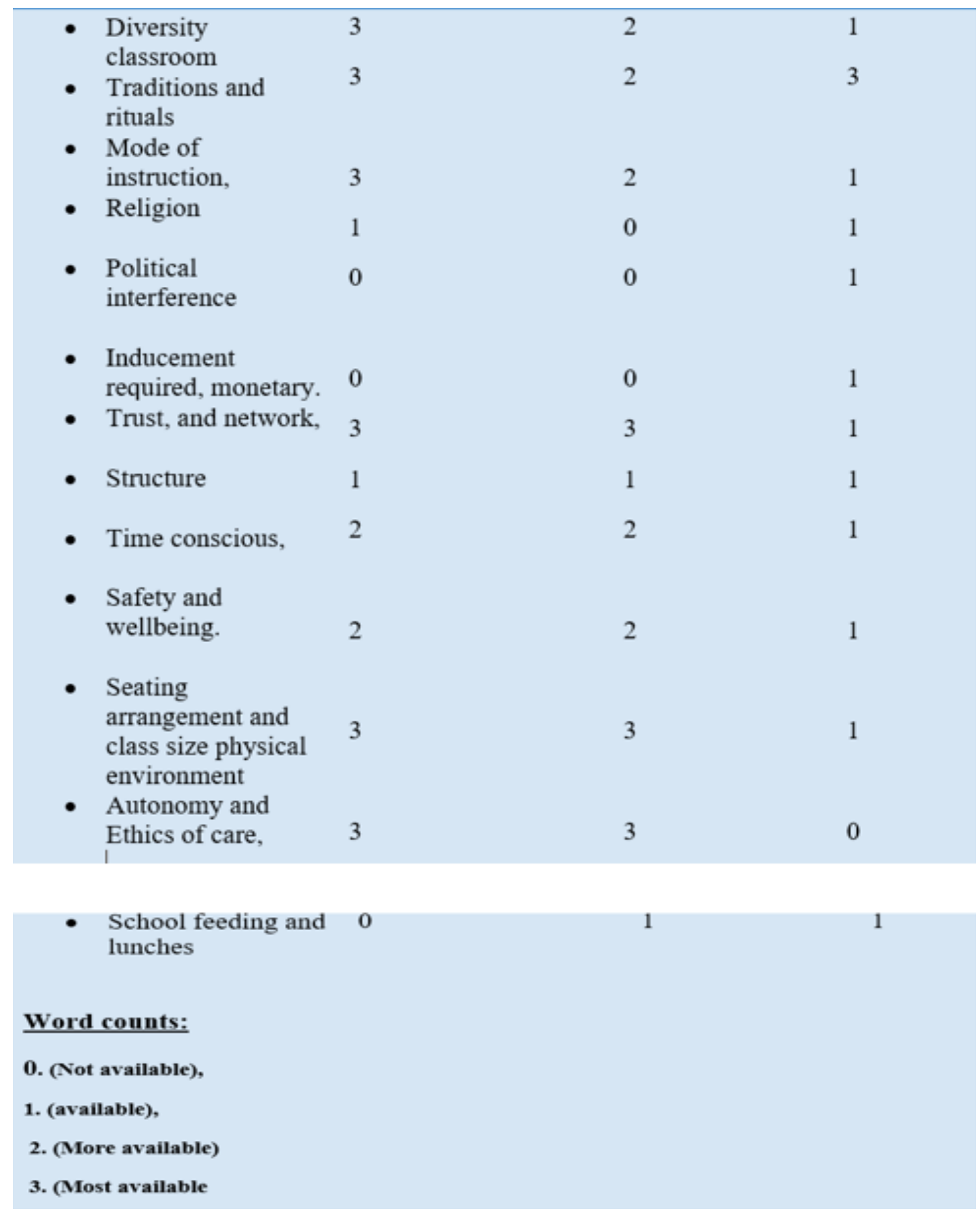


Appendix 11: The Sample Copy: The Word Frequency

\begin{tabular}{|c|c|}
\hline Word & Length \\
\hline come & 4 \\
\hline like & 4 \\
\hline safe & 4 \\
\hline sense & 5 \\
\hline world & 5 \\
\hline environment & 11 \\
\hline family & 6 \\
\hline teacher & 7 \\
\hline think & 5 \\
\hline around & 6 \\
\hline belongingness & 13 \\
\hline better & 6 \\
\hline community & 9 \\
\hline feel & 4 \\
\hline leave & 5 \\
\hline lot & 3 \\
\hline manage & 6 \\
\hline much & 4 \\
\hline people & 6 \\
\hline place & 5 \\
\hline principal & 9 \\
\hline school & 6 \\
\hline students & 8 \\
\hline tell & 4 \\
\hline tradition & 9 \\
\hline aggressive & 10 \\
\hline almost & 6 \\
\hline also & 4 \\
\hline back & 4 \\
\hline basketball & 10 \\
\hline belong & 6 \\
\hline brotherhood & 11 \\
\hline care & 4 \\
\hline changed & 7 \\
\hline classroom & 9 \\
\hline comfortable & 11 \\
\hline conversation & 12 \\
\hline
\end{tabular}


Appendix 12: The Sample Copy: The Coding Themes

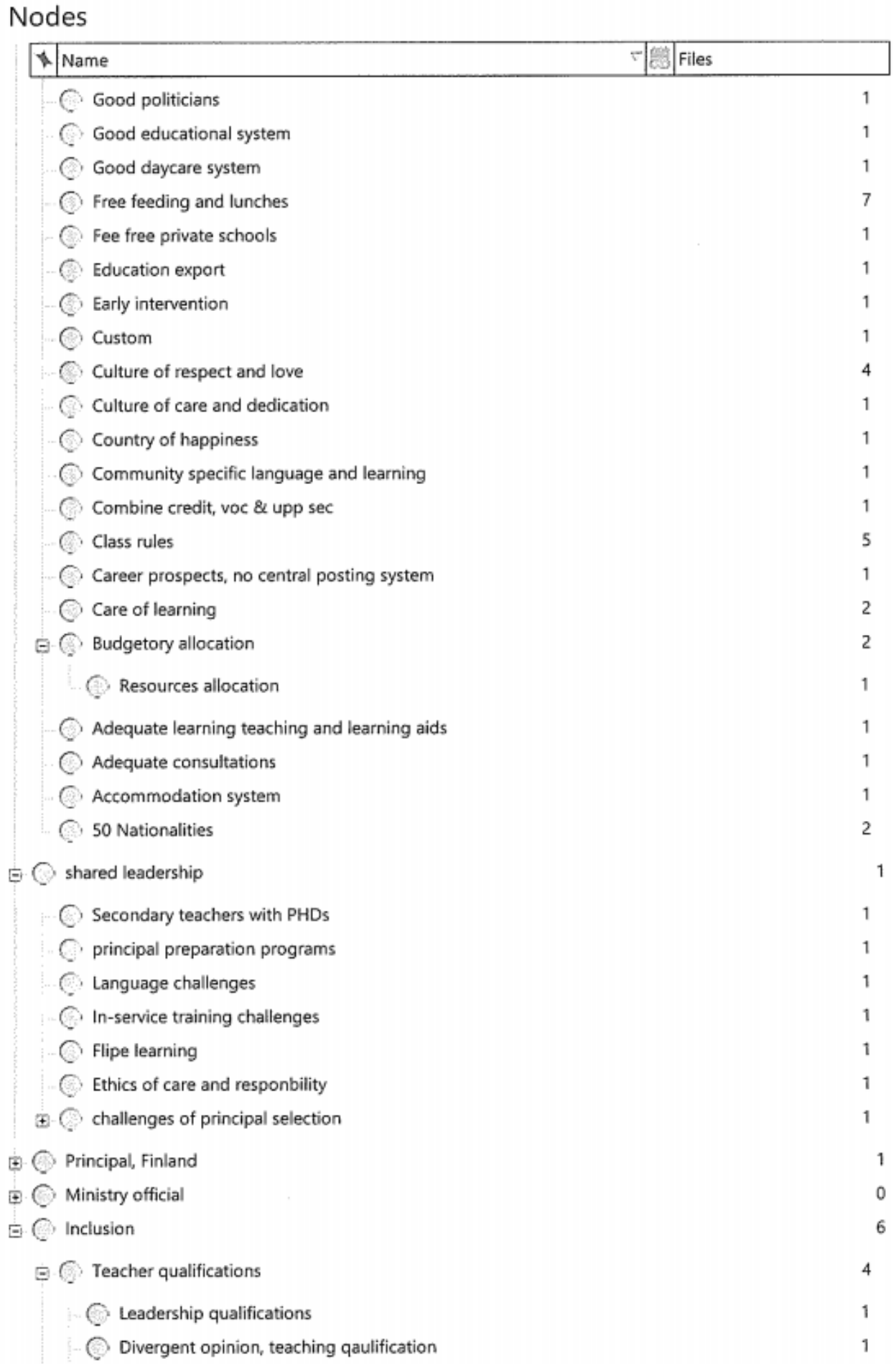

